\title{
Optimising Power System Frequency Stability using Virtual Inertia from Inverter-based Renewable Energy Generation
}

\author{
By \\ Warren James Farmer \\ Department of Electrical \& Electronic Engineering \\ University of Stellenbosch
}

Study leader: Dr. A. J. Rix

Report submitted in partial fulfilment of the requirements of...

M.Eng Electrical \&5 Electronic

April 2019 


\section{Declaration}

I have read and understand the Stellenbosch University Policy on Plagiarism and the definitions of plagiarism and self-plagiarism contained in the Policy [Plagiarism: The use of the ideas or material of others without acknowledgement, or the re-use of one's own previously evaluated or published material without acknowledgement or indication thereof (self-plagiarism or textrecycling)].

I also understand that direct translations are plagiarism, unless accompanied by an appropriate acknowledgement of the source. I also know that verbatim copy that has not been explicitly indicated as such, is plagiarism.

I know that plagiarism is a punishable offence and may be referred to the University's Central Disciplinary Committee (CDC) who has the authority to expel me for such an offence.

I know that plagiarism is harmful for the academic environment and that it has a negative impact on any profession.

Accordingly all quotations and contributions from any source whatsoever (including the internet) have been cited fully (acknowledged); further, all verbatim copies have been expressly indicated as such (e.g. through quotation marks) and the sources are cited fully.

I declare that, except where a source has been cited, the work contained in this assignment is my own work and that I have not previously (in its entirety or in part) submitted it for grading in this module/assignment or another module/assignment.

I, the undersigned, hereby declare that the work contained in this report is my own original work unless indicated otherwise.

Date: April 2019 


\section{Acknowledgements}

I would like to use this opportunity to thank,

God, my Heavenly Father for blessing me with the intellect and opportunity to make a success of this project. I would also like to thank Him for placing the following people on my path, who contributed to the success of this project:

Dr. A.J. Rix, my study-leader, for his patience and guidance during this period.

My parents, Amanda and James-Baron Farmer, for believing and supporting me.

The Center for Renewable and Sustainable Energy Studies (CRSES), without their work and funding this project would not have been a success.

Naniki Lukhele, my industrial mentor, for her advice, connecting me with the right people in Eskom and allowing me freedom to work in my own way.

Thabo Modisane, for his advice and time, which contributed significantly to the research project.

Wouter Sonnekus, for his advice, help and support writing the simulation interfacing scripts.

Matthew Groch, for his advice and referring me to the right people.

Lab colleagues and friends, without their presence, support and friendship the hours spent working everyday would have been unbearable. 


\section{Publications}

- 26th Southern African Universities Power Engineering Conference (SAUPEC 2018), Paper: Using Inverter-based Wind Turbine Generation to Provide Virtual Inertia for The South African Power System.

- 5th Southern African Solar Energy Conference (SASEC 2018), Paper: Current Methods for PV Generation to Provide Virtual Inertia for The Future South African Power System. 


\title{
Abstract
}

\section{Optimising Power System Frequency Stability using Virtual Inertia from Inverter-based Renewable Energy Generation}

\author{
W. J. Farmer \\ Department of Electrical and Electronic Engineering, \\ University of Stellenbosch, \\ Private Bag X1, Matieland 7602, South Africa.
}

Thesis: MEng (E\&E)

April 2019

Inverter-based renewable energy generation are integrated into power systems at an increasing rate. Governments continuously set higher goals for renewable energy generation considering only the impact on the environment, development time, financial and economical side, while ignoring the impact of high penetration of inverter-based renewable energy generation on the current power system's stability. This thesis investigates the impact of increased variable renewable energy generation integration into the power system, with a specific focus on inertial response for system frequency stability. The focus is on wind and solar power generation, which uses inverters to interface with the power system network. These generation sources have a detrimental effect on the generation/load power balance, which reduces the system frequency stability. The power system becomes more sensitive, with increased RoCoF, lower frequency nadir and increased difficulty to control system frequency with generation/load balancing. Current mitigation measures and regulations for the decreased frequency stability are reviewed, indicating that for high share of renewable generation not just long-term energy storage is required, but also short-term energy storage with fast power response capabilities. To evaluate the impact, power system components are examined and modeled to implement in a power system simulation. Power system operation and stability (rotor, voltage and frequency) are reviewed and discussed. The research then focuses on transient frequency dynamics and stability. For the mitigation of 
reduced frequency stability the concept of virtual inertia is introduced. Virtual inertia is then explained and simulated for wind and solar PV plants. Lastly the $H_{2}$-norm metric is used to evaluate power system frequency stability, rather than using the amount of inertia present in a power system. The metric follows from Lyapunov theory for analyzing non-linear system stability through energy functions. The distribution of virtual inertia in a network is then optimised using the Genetic Algorithm with the $H_{2}$-norm, which is used to analyze the system robustness against disturbances, as the cost-function. The results show significant performance improvement in transient stability for the Western Transmission network of the Eskom power system in South Africa. 


\title{
Opsomming
}

\section{Optimering van Kragstelsel Frekwensie Stabiliteit deur die gebruik van Virtuele Traagheid in Omsetter-gebaseerde Hernubare Energie Opwekking}

\author{
("Optimising Power System Frequency Stability using Virtual Inertia from \\ Inverter-based Renewable Energy Generation")
}

\author{
W. J. Farmer \\ Departement Eletriese en Elektroniese Ingenieurswese, \\ Universiteit van Stellenbosch, \\ Privaatsak X1, Matieland 7602, Suid Afrika.
}

Tesis: MIng (E\&E)

April 2019

\begin{abstract}
Omsetter-gebaseerde hernubare energie opwekking word in toenemende mate in kragstelsels geïntegreer. Regerings stel voortdurend hoër doelwitte vir hernubare energie opwekking waar slegs die impak op die omgewing, ontwikkelingstyd, finansiële en ekonomiese faktore in ag geneem word, terwyl die impak van hoë penetrasie omsetter-gebaseerde hernubare energie opwekking op die huidige kragstelsel se stabiliteit geïgnoreer word. Hierdie tesis ondersoek die impak van toenemende hernubare energie opwekking integrasie op die huidige kragstelsel. Die fokus is spesifiek op die traagheidsreaksie vir stelselfrekwensiestabiliteit, as ook op wind- en son-kragopwekking wat deur middel van omsetters aan die kragstelselnetwerk koppel. Hierdie hernubare bronne het 'n negatiewe effek op die generasie/las kragbalansering, wat die stelselfrekwensie se stabiliteit bedreig. Die kragstelsel word meer sensitief, met verhoogde RoCoF, laer frekwensie nadir en dit word moeiliker om die stelselfrekwensie te beheer met generasie/las balansering. Huidige regulasies en oplossings vir die agteruitgang van die frekwensie-stabiliteit word hersien. Om hoër aandele van hernubare energie opwekking te bewerkstellig, vereis dit langtermyn energiestoor sowel as korttermyn energiestoorkapasiteit met vinnige drywing
\end{abstract}


uittree reaksie vermoëns. Om die impak op die krag stelsel te evalueer, word die stelsel komponente ondersoek en gemodelleer vir die doel om dit in 'n kragstelsel simulasie te implementeer. Kragstelseloperasie en stabiliteit (rotor, spanning en frekwensie) word hersien en bespreek. Die navorsing fokus dan op oorgangs-frekwensie-dinamika en stabiliteit. Die konsep van virtuele traagheid word voorgestel as 'n oplossing vir die agteruitgang van frekwensiestabiliteit. Virtuele traagheid word dan verduidelik en gesimuleer vir winden son-kragopwekking. Laastens word die $\mathrm{H}_{2}$-norm gebruik om die stelsel se frekwensie-stabiliteit te evalueer, eerder as om die hoeveelheid traagheid in 'n kragstelsel te gebruik. Die metode volg uit die Lyapunov-teorie waar nie-lineêre stelsels se stabiliteit ge-analiseer word deur die opstel en gebruik van funksies wat die energie in die stelsel beskryf. Die verspreiding van virtuele traagheid in 'n netwerk word dan ge-optimeer met die gebruik van die Genetiese Algoritme. Die koste-funkise wat ge-minimeer word is die, $\mathrm{H}_{2}$ -norm. Die $H_{2}$-norm verteenwoordig die stelsel robuustheid teen versteurings en dus, word ge-mimimeer. Die resultate toon beduidende prestasie verbetering in oorgang-stabiliteit vir die Westelike transmissie netwerk van die Eskom krag-stelsel in Suid-Afrika. 


\section{Contents}

$\begin{array}{ll}\text { Publications } & \text { iii }\end{array}$

List of Abbreviations $\quad$ xi

List of Symbols $\quad$ xiii

Nomenclature $\quad$ Xv

1 Introduction 1

1.1 Problem Statement . . . . . . . . . . . . . . . . . . 5 5

1.2 Research Objectives . . . . . . . . . . . . . . . . . 5

1.3 Research Tasks . . . . . . . . . . . . . . . . . 6

1.4 Thesis Overview . . . . . . . . . . . . . . . . . 7

2 Renewable Energy Integration 9

2.1 Power System Stability . . . . . . . . . . . . . . . . . . . . 10

2.1 .1 Rotor Angle Stability . . . . . . . . . . . . . . . . . . 10

2.1.2 Voltage Stability . . . . . . . . . . . . . . . . . 11

2.1.3 Frequency Stability . . . . . . . . . . . . . . . . . . . 12

2.1 .4 Power-Flow . . . . . . . . . . . . . . . . . . 13

2.2 Renewable Energy Source (RES) integration plan . . . . . . . . . . . . . 14

2.3 Impact On Power System Operation . . . . . . . . . . . . . . . 17

2.3.1 Duck curve effect . . . . . . . . . . . . . . . . 18

2.3.2 Impact of VRE sources on balancing reserve . . . . . . . . . . . 20

2.3.3 Frequency response due to power imbalance . . . . . . . . . . . . 21

2.3.4 Grid code compliance for Renewable Power Plants . . . . . . . . . . 23

2.4 South Australia Blackout of 2016 . . . . . . . . . . . . . . . . . 25

2.5 Enabling higher renewable energy penetration . . . . . . . . . . . 26

2.5.1 Active Power Control . . . . . . . . . . . . . . . . 26

2.5.1.1 Wind turbines . . . . . . . . . . . . 27

2.5.1.2 Solar PV . . . . . . . . . . . . . . . . . . . . 28

2.5 .2 Storage systems . . . . . . . . . . . . . . . . 28 
2.5.2.1 flywheels . . . . . . . . . . . . . . . . . 29

2.5.2.2 hydrogen . . . . . . . . . . . . . . 30

2.5.2.3 compressed air energy storage (CAES) . . . . . . . . . 31

2.5.2.4 super-capacitors . . . . . . . . . . . . 33

2.5.2.5 battery storage . . . . . . . . . . . . . 34

2.5.2.6 pumped hydro-electric storage (PHS) . . . . . . . . . 35

2.6 Conclusion . . . . . . . . . . . . . . . . . . . . . 36

3 Virtual Inertia Implementation $\quad 38$

3.1 Inertia . . . . . . . . . . . . . . . . . . . 38

3.2 Synchronous machine inertia . . . . . . . . . . . . . . . 38

3.2.1 Kinetic energy . . . . . . . . . . . . . . . . . 40

3.2 .2 Inertia constant . . . . . . . . . . . . . . . . . . . 40

3.2.3 Different levels of inertia . . . . . . . . . . . . . . . . . 41

3.2.4 Variability of inertia . . . . . . . . . . . . . . . . . 42

3.2.5 Inertia placement . . . . . . . . . . . . . . . . 44

3.3 Virtual inertia . . . . . . . . . . . . . . . . . 45

3.3 .1 Control schemes . . . . . . . . . . . . . . . . 47

3.3.2 Wind Turbine Generator Virtual Inertia . . . . . . . . . . . . . . 47

3.3.2.1 Types of wind turbine generators . . . . . . . . . . . 47

3.3.2.2 Virtual inertia implementation . . . . . . . . . . . 50

3.3.2.3 Simulation models . . . . . . . . . . . . . . 52

3.3.2.4 Simulation results . . . . . . . . . . . . . 53

3.3.3 Solar PV Virtual Inertia . . . . . . . . . . . . . . . . 55

3.3.3.1 Solar PV setup . . . . . . . . . . . . . . . . . . . . . . . . . . 55

3.3.3.2 Implementation methods . . . . . . . . . . . . . . 56

3.3.3.3 Simulation models . . . . . . . . . . . . . 58

3.3.3.4 Simulation results . . . . . . . . . . . . 61

3.4 Wind virtual inertia vs solar PV virtual inertia . . . . . . . . . . . . 64

3.5 Virtual inertia vs synchronous machine inertia . . . . . . . . . . . . 64

4 Optimal Allocation Of Virtual Inertia $\quad 66$

4.1 Power system single-line diagram model . . . . . . . . . . . . . . 67

4.2 Linearising the power-flow equation . . . . . . . . . . . . . . 68

4.3 State-space model of the power system . . . . . . . . . . . . . . . 69

4.4 Cost-function . . . . . . . . . . . . . . . . . . 72

4.5 5-bus network simulation test . . . . . . . . . . . . . 74

4.5.1 Single-line diagram model . . . . . . . . . . . . . . . . 74

4.5.2 Graph theory and model construction . . . . . . . . . . . . 75

4.5.3 Verify graph model . . . . . . . . . . . . . . . 78 
4.5.4 Optimal virtual inertia allocation . . . . . . . . . . . . . . 79

4.5.5 Power system simulation results . . . . . . . . . . . . . 80

4.6 Western TX case study . . . . . . . . . . . . . . . . . . 81

4.6.1 Building the power system model and optimisation script . . . . . . 81

4.6.2 Case study sumulation results . . . . . . . . . . . . . . 86

5 Summary and Conclusions $\quad 88$

5.1 Conclusions. . . . . . . . . . . . . . . . . . . . 88

5.2 Recommended Future Work . . . . . . . . . . . . . . . . . 90

$\begin{array}{ll}\text { References } & 101\end{array}$

$\begin{array}{ll}\text { A The Swing Equation } & 102\end{array}$

$\begin{array}{ll}\text { B Power System Modeling } & 105\end{array}$

B.1 Synchronous machine . . . . . . . . . . . . . . . . . 105

B.2 Transmission line . . . . . . . . . . . . . . . . . 110

B.3 Transformer . . . . . . . . . . . . . . . . . . . 110

B.4 Load . . . . . . . . . . . . . . . . . . . . . . . . . 112

B.5 Wind Turbine Generator . . . . . . . . . . . . . . . . . . 114

B.6 Solar PV panel . . . . . . . . . . . . . . . . . . . . . 115

B.7 DigSilent PowerFactory . . . . . . . . . . . . . . . . . . . . 118

B.7.1 Single-line graphic . . . . . . . . . . . . . . . . . . 118

B.7.2 Composite frame . . . . . . . . . . . . . . . 119

B.7.3 Block diagram . . . . . . . . . . . . . . . . . . 119

B.7.4 Common model . . . . . . . . . . . . . . . . . . . . 120

B.7.5 Composite model . . . . . . . . . . . . . . . 121

$\begin{array}{lr}\text { C Bus vector } & 123\end{array}$

$\begin{array}{ll}\text { D Lyapunov Stability } & 125\end{array}$

$\begin{array}{lr}\text { E Simulation Scripts } & 128\end{array}$

E.1 Overview . . . . . . . . . . . . . . . . . . . . . . . 128

E.2 Extraction.py . . . . . . . . . . . . . . . . . . . . . . . 129

E.3 Graph.m . . . . . . . . . . . . . . . . . . . . . 130

E.4 Statesspace.m . . . . . . . . . . . . . . . . . . . . . . . 131

E.5 H2_construction.m . . . . . . . . . . . . . . . . . . . . 132

E.6 GArev1.m . . . . . . . . . . . . . . . . . . 133

E.7 Calc_inertia_settings.py . . . . . . . . . . . . . . . . . . . 134

E.8 Apply_VI_settings.py . . . . . . . . . . . . . . . . 135 


\section{List of Abbreviations}

\begin{tabular}{|c|c|}
\hline $\mathrm{AC}$ & Alternating Current \\
\hline AEMO & Australian Energy Market Operator \\
\hline AGC & Automatic Generation Control \\
\hline $\mathrm{APC}$ & Active Power Control \\
\hline AVR & Automatic Voltage Regulator \\
\hline BESS & Battery Energy Storage System \\
\hline CAES & Compressed Air Energy Storage \\
\hline CSP & Concentrated Solar Power \\
\hline $\mathrm{DC}$ & Direct Current \\
\hline DSL & DigSilent Simulation Language \\
\hline DSM & Demand Side Management \\
\hline EDLC & Electric Double Layer Capacitor \\
\hline Eskom & Electricity Supply Commission \\
\hline ESS & Energy Storage System \\
\hline $\mathrm{EU}$ & European Union \\
\hline FPR & Frequency-Power Response \\
\hline IPP & Independent Power Producer \\
\hline $\mathrm{KEC}$ & Kinetic Energy Control \\
\hline MMF & Magneto Motive Force \\
\hline $\mathrm{MPa}$ & Mega-pascal \\
\hline MPP & Maximum Power Point \\
\hline MPPT & Maximum Power Point Tracker \\
\hline NEM & National Electricity Market \\
\hline p.u. & Per-unit \\
\hline $\mathrm{PI}$ & Proportional plus Integral \\
\hline PV & Photo-Voltaic \\
\hline $\mathrm{P}-\mathrm{V}$ & Power versus Voltage \\
\hline PWM & Pulse Width Modulation \\
\hline $\mathrm{Q}-\mathrm{V}$ & Reactive power versus Voltage \\
\hline REDZ & Renewable Energy Development Zone \\
\hline RES & Renewable Energy Source \\
\hline
\end{tabular}




$\begin{array}{ll}\text { RLC } & \text { Resistor, Inductor, and Capacitor } \\ \text { RoCoF } & \text { Rate of Change of Frequency } \\ \text { RPP } & \text { Renewable Power Plant } \\ \text { SA } & \text { South Africa } \\ \text { SAGCC } & \text { South African Grid Compliance Code } \\ \text { SCADA } & \text { Supervisory Control And Data Acquisition } \\ \text { SE } & \text { Swing Equation } \\ \text { SFM } & \text { System Frequency Model } \\ \text { SGM } & \text { Synchronous Generator Model } \\ \text { SI } & \text { Systeme Internationale (French) or International System (English) } \\ \text { TSR } & \text { Tip-Speed Ratio } \\ \text { TX } & \text { Transmission } \\ \text { VI } & \text { Virtual Inertia } \\ \text { VRE } & \text { Variable Renewable Energy } \\ \text { WASA } & \text { Wind Atlas for South Africa } \\ \text { WTG } & \text { Wind Turbine Generator }\end{array}$




\section{List of Symbols}

\begin{tabular}{ll}
$E$ & Energy [joule] \\
$V$ & Voltage $[\mathrm{kV}]$ \\
$\omega$ & Rotating frequency $[\mathrm{rad} / \mathrm{s}]$ \\
$f$ & Frequency $[\mathrm{Hz}]$ \\
$t$ & Time $[\mathrm{s}]$ \\
$J$ & Moment of inertia $\left[\mathrm{kg} \cdot \mathrm{m}^{2}\right]$ \\
$H$ & Normalised inertia constant $[\mathrm{s}]$ \\
$M$ & Inertia constant $\left[\mathrm{MW} \cdot \mathrm{s}^{2}\right]$ \\
$D$ & Damping coefficient $[\mathrm{MW} / \mathrm{Hz}]$ \\
$P$ & Power $[\mathrm{MW}]$ \\
$S$ & Apparent power $[\mathrm{VA}]$ \\
$\delta$ & Rotor angle with respect to rotating reference frame $[\mathrm{rad}]$ \\
$p f$ & Power factor \\
$B$ & Susceptance $[$ siemens] \\
$G$ & Conductance $[$ siemens] \\
$\beta$ & Wind turbine rotor blade pitch angle $[\mathrm{rad}]$ \\
$\rho$ & Air density $\left[\mathrm{kg} / \mathrm{m}^{3}\right]$ \\
$A$ sweep & Wind turbine rotor sweep area $\left[\mathrm{m}^{2}\right]$ \\
$v_{w i n d}$ & Wind speed $[\mathrm{m} / \mathrm{s}]$ \\
$\lambda$ & Tip-speed ratio \\
$C p$ & Power coefficient \\
$\Delta$ & Change in quantity \\
& Laplace operator \\
\hline &
\end{tabular}




\section{List of Figures}

2.1 Power versus voltage $(\mathrm{P}-\mathrm{V})$ curve method. . . . . . . . . . . . . . . 11

2.2 2-bus power-flow. . . . . . . . . . . . . . . . . . . 13

2.3 Generation share mix of 2017 [GW] [19]. . . . . . . . . . . . . . . . 14

2.4 Generation share mix of the future $(2017)[\mathrm{GW}][19] \ldots \ldots \ldots$

2.5 Current Generation Footprint [19]. . . . . . . . . . . . . . 16

2.6 Future Generation Footprint [19]. . . . . . . . . . . . . . . . . 16

2.7 Residual load duck-curve shape [28]. . . . . . . . . . . . . . . . . . . . . 19

2.8 Inertial, primary, and secondary frequency control responses. . . . . . . . . 22

2.9 Power curtailment during over-frequency for RPPs (version 2.9) [16]. . . . 23

2.10 Frequency response requirement for RPPs of category C (version 2.9) [16]. 24

2.11 South Australia's generation mix prior to the disturbance [31] . . . . . . . 25

2.12 Example of inertial response emulation of a WTG [15] . . . . . . . . . . 27

2.13 Flywheel energy storage plant [36] . . . . . . . . . . . . . . . . . . 29

2.14 Hybrid wind and hydrogen plant [45] . . . . . . . . . . . . . . 31

2.15 Compressed Air Energy Storage plant [48]. . . . . . . . . . . . . . . . . . 32

2.16 Tesla battery in South Australia [58] . . . . . . . . . . . . . . 35

2.17 Pumped hydro-electric storage plant. . . . . . . . . . . . . 35

3.1 Frequency response for different system inertia levels. . . . . . . . . . . . . 41

3.2 Germany's inverter feed-in for 2012 [14] . . . . . . . . . . . . . . . . . . . . 42

3.3 The aggregated regional inertia $\left(H_{\text {agg }}\right)$ for Germany in 2012 [14] . . . . . . 43

3.4 Plot of frequency vs voltage angle difference, for a three-area network. . . . 45

3.5 Type 1 wind turbine generator. . . . . . . . . . . . . . . . . . 48

3.6 Type 2 wind turbine generator. . . . . . . . . . . . . . . . . . 48

3.7 Type 3 wind turbine generator. . . . . . . . . . . . . . . . . 49

3.8 Type 4 wind turbine generator. . . . . . . . . . . . . . . . . 49

3.9 Wind turbine power curve. . . . . . . . . . . . . . 51

3.10 Wind turbine with virtual inertia model. . . . . . . . . . . . . . . 52

3.11 Wind turbine generator step response. . . . . . . . . . . . . 53

3.12 Wind turbine rotation speed. . . . . . . . . . . . . . 54

3.13 Frequency responses for virtual inertia using different filter time constants. $\quad 55$ 


\section{LIST OF FIGURES}

3.14 Solar PV setup. . . . . . . . . . . . . . . . . . . . 56

3.15 Example of a solar PV panel's P-V characteristic curve with de-rated power reference. . . . . . . . . . . . . . . . . . . . 5 58

3.16 State-space simulation diagram. . . . . . . . . . . . . . . . . 60

3.17 PI-controller diagram. . . . . . . . . . . . . . . . . . 60

3.18 Virtual inertia and droop-controller diagram. . . . . . . . . . . . . . 61

3.19 Comparing the solar PV generation output for the scenarios: without virtual inertia, using virtual inertia, and virtual inertia with droop. . . . . . . 62

3.20 The impact of the solar PV power output response on the system's frequency. 63

3.21 Rate of Change of Frequency (RoCoF) comparison of the three scenarios. . 63

4.1 Energy imbalance in frequency excursion. . . . . . . . . . . . . 66

4.2 Single-line diagram model of the Eskom Western TX system. . . . . . . . . 68

4.3 5-bus network. . . . . . . . . . . . . . . . . 74

4.4 5-bus network graph model. . . . . . . . . . . . . . 76

4.5 Optimal allocation of virtual inertia for the 5-bus network. . . . . . . . . 79

4.6 Parallel buses in Gromis sub-station. . . . . . . . . . . . . . . . . . 82

4.7 Optimal allocation of virtual inertia for the South African western TX. . . 85

B.1 Basic structure of synchronous machine. . . . . . . . . . . . . . . 105

B.2 d-axis equivalent circuit. . . . . . . . . . . . . . . . 107

B.3 q-axis equivalent circuit - round rotor. . . . . . . . . . . . . 107

B.4 Synchronous generator control diagram. . . . . . . . . . . . . . 108

B.6 Equivalent $\pi$-circuit three-phase line model. . . . . . . . . . . . . . . . . 110

B.7 Equivalent circuit of a practical single-phase 2-winding transformer. . . . . 111

B.8 Simplified transformer model referred to primary side. . . . . . . . . . . . . 112

B.9 Per-unit equivalent circuit of a single-phase 2-winding transformer. . . . . . 112

B.10 RLC load. . . . . . . . . . . . . . . . . . . . . . . . . . . 113

B.11 3-phase Y-connected on the left, and $\Delta$-connected on the right. . . . . . . 114

B.12 Overview of the wind turbine generator (WTG) simulation model. . . . . . 115

B.13 Solar PV cell single diode model. . . . . . . . . . . . . . . . . . 116

B.14 Calculation of IV-curve. . . . . . . . . . . . . . . . . . . . 116

B.15 I-V and P-V curve of a solar PV cell. . . . . . . . . . . . . . . . . 117

B.16 Solar PV string per inverter. . . . . . . . . . . . . . . . . . 117

B.17 Single-line graphic. . . . . . . . . . . . . . . . . . . . . 118

B.18 Composite frame of hydro power plant. . . . . . . . . . . . . . . . . . . . . 119

B.19 Block diagram of Power System Stabiliser. . . . . . . . . . . . . . . . . 120

B.20 Common model of the Power System Stabiliser. . . . . . . . . . . . . . . 121

B.21 Composite model of a hydro power plant. . . . . . . . . . . . . . . . . . 121

B.22 PowerFactory model definition hierarchy. . . . . . . . . . . . . . . . 122 
E.1 Script overview. . . . . . . . . . . . . . . . . . . . . . . . . . . . . 128

E.2 extraction.py . . . . . . . . . . . . . . . . . . . . 129

E.3 Graph.m . . . . . . . . . . . . . . . . . . . 130

E.4 State_space.m . . . . . . . . . . . . . . . . . 131

E.5 H2_construction.m . . . . . . . . . . . . . . . . . . . . 132

E.6 GArev1.m . . . . . . . . . . . . . . . . . . 133

E.7 Calc_inertia_settings.py . . . . . . . . . . . . . . . . . . . 134

E.8 Apply_VI_settings.py . . . . . . . . . . . . . . . . 135 


\section{List of Tables}

2.1 Frequency Default Settings $[16] \ldots \ldots \ldots \ldots$. . . . . . . . . . 24

3.1 List of a few power stations and their total kinetic energy at normal operation. 40

3.2 Summary of real inertia vs virtual inertia . . . . . . . . . . . . . 65

4.15 -bus network buses (nodes) . . . . . . . . . . . 76

4.25 -bus network transmission lines. . . . . . . . . . . . . . . 77

4.3 5-bus network transformers. . . . . . . . . . . . . . . . . 77

4.4 Real power injection vector. . . . . . . . . . . . . . . . 78

4.5 Compare single-line with graph model using node voltage angles. . . . . . . 78

4.6 Optimal allocation of virtual inertia for 5-bus network simulation results. . 80

4.7 Simulation test results . . . . . . . . . . . . . . . . 86 


\section{Chapter 1}

\section{Introduction}

The power system is a large and complex machine consisting of generation sources, transformers, transmission lines, capacitors, reactors, loads, protection devices, and Supervisory Control and Data Acquisition (SCADA) systems [1] [2]. All the components within these categories work together to meet three objectives [1] [3]:

1. The first objective is to meet the electricity demand of the user/customer. Since the power system operates with no significant grid-size storage, thus no electrical energy buffer, the generation must match the load demand including network losses at all times. Keeping the power system balanced requires good load forecasting, dispatchable generation, and generation reserves for sufficient flexibility.

2. The second objective is to provide quality power. The power quality involves the voltage, frequency, and the waveform. The waveform must resemble a sine wave as close as possible. The frequency and voltage magnitude must remain within a narrow and pre-defined range. The power system components, protection devices, and loads depends on good power quality for proper operation and to avoid premature failure and damage.

3. The third operational objective of the power system is to be reliable. Although the power system is complex, it is very simple to use (plug and play). Power system reliability depends on component quality, backup systems, and stable operation. With a stable system the network components operate within their designed regions, meaning proper operation and predictable behavior and life-span.

Since the start of commercial electricity generation, the synchronous machine formed the "heart" of the power system [2]. Working as a generator, the rotor's rotation speed dictates the frequency of the electrical power output [4] [5]. When the synchronous machine is used as a motor the electrical frequency dictates the rotation speed of the rotor [5]. 
The power systems of the world are in the process of being "re-invented". The changes are driven mainly by climate change, environmental and resource sustainability concerns [6] [7] [8]. The old power system undergoes a rapid change of "heart", to transition towards the power system of the future. In other words, the traditional synchronous generator makes way for inverter-based generation [7] [8]. Variable RES generation interfaces with the power system through inverter systems, which converts the generation source's variable frequency to the power system's fixed frequency. This is true for wind and solar power, which are the fastest growing sources of renewable energy [9].

Maintaining the power system frequency within a narrow range, is a requirement for stable operation of power systems. An imbalance between generation and load results in frequency excursions away from nominal operating frequency (e.g $50 \mathrm{~Hz}$ in South Africa) [10]. To obtain sufficient control over the system frequency there must be adequate control over the generation output, in order for the generation to match the system load at all times [1] [2] [11]. When generation exceeds the net power consumed (including system losses), then the system frequency will increase. The opposite is true when the generation is insufficient for the system load [4] [11] [12]. Since the power system does not operate with any grid-size energy storage, there is no large-scale energy buffer to compensate for a generation/load imbalance [2]. This means that the total feed-in power minus the total load consumed must be kept close to zero, since an imbalance results in frequency deviation [10] [13]. It is important to keep deviations from the nominal frequency small, since damaging vibrations in machines occur for large deviations and may lead to load shedding. The frequency excursion can influence the whole power system, ending in fault cascades and blackouts in the worst-case scenario.

Traditionally, power systems are operated with dispatchable, i.e. controllable large synchronous generators that is reliably supplied with fuel (such as thermal or hydro power plants to generate electricity). The synchronous machine operates with strong coupling between mechanical and electrical dynamics. As a result, the stored kinetic energy in the rotor's rotating mass inherently provides inertia to the power system [4] [5] [8]. During a disturbance on the power system, which causes an imbalance between generation and load, the inertia slows down the frequency dynamics and thus, allow the governors and additional auxiliary services some time to activate and respond to the change in system frequency. Slower frequency dynamics is easier to control and thus, more desirable for system stability. This means that synchronous machines provide transient frequency stability to the power system, which is an important property for frequency stability and serves a vital role in reliable system operation [11] [12]. 
The world is in the middle of a transition in the power generation sector, which offers various opportunities while also introducing new and different operational issues and challenges [6]. The rate at which inverter-based renewable energy is being integrated into power systems is rapidly increasing, with wind and solar photo-voltaic (PV) being the front runners [9] [14] [15]. Integration of these variable renewable energy (VRE) sources increases the power injected into the power system without increasing the system's rotational inertia [12] [13]. This has implications for frequency dynamics and power system stability, reliability and operation. With inverter-based generation threatening to overtake the dominance of synchronous machine generation [11] [12] [14], the power system faces new challenges in stability, control, reliability, power quality, and ultimately in meeting load demand. The increasing share of inverter-based generation means that the power system inertia is not growing with increased generation capacity, and with decommissioning synchronous machine power plants the system inertia decreases [11] [12] [14]. The assumption that a power system has sufficiently high inertia for transient frequency stability, then becomes invalid for power systems with high shares of inverter-based RES generation [12] [14].

A low quantity of system inertia is detrimental to the power system's frequency stability, since low inertia means fast frequency dynamics and increased difficulty to control [8] [12]. The power system becomes much more sensitive to generation/load imbalance, causing higher rate of change of frequency ( $\mathrm{RoCoF}$ ). This leads to situations in which traditional frequency control methods become too slow compared to the disturbance dynamics timescales, thus unable to prevent large frequency deviations and the resulting consequences. Since renewable power plants (RPP) are allowed to disconnect from the power system network for high RoCoF and low frequency nadirs [16], means the sudden loss of generation can create a cascade effect of generation/load imbalance, and ultimately result in a system blackout if the power system is unable to stabilise and recover fast enough.

In the power system of the future, where inverters are the new workhorse of the power system, new problems arise in terms of operational objectives. The problems that are presented needs to be addressed in order to maintain the objectives of the power system. This thesis looks at virtual inertia as a way to combat the decline in system inertia and optimising the allocation of virtual inertia for maximum system robustness against generation/load imbalance disturbances. Sled-dogs as shown in figure 1.1a [17] can be used as an analogy for the power system. Each dog represents a synchronous machine generator, with the towlines representing the transmission lines connecting the generators to the loads, where the sled and musher represent the power system load in this analogy. What is interesting about the setup is that every dog plays a different role in pulling the 
sled according to their position. Figure 1.1b [18] illustrates the different positions for the dogs.

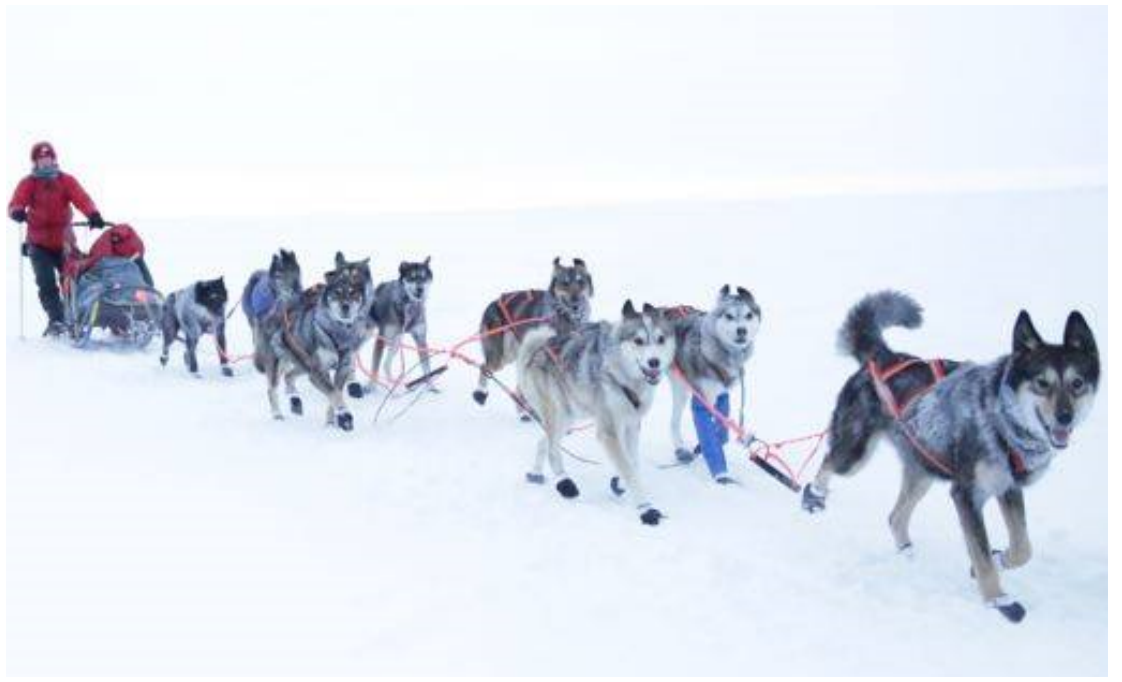

(a) Sled dogs with musher.

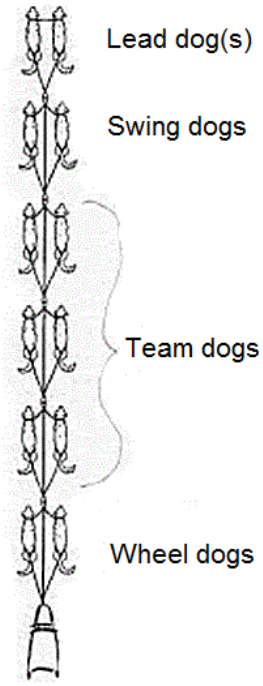

(b) Sled dog positions.

The Lead $\operatorname{dog}(\mathrm{s})$ leads the team, sets the pace and keeps the other dogs on the trail, by reacting to the musher's commands. The Swing dogs are responsible for keeping the team in formation when moving around corners. The Team dogs are the brawn of the team, pulling the sled and maintaining the speed. Lastly there are the Wheel dogs, these are the strongest and largest dogs since they are the first to take on the weight of the load being pulled, especially during starts and climbs. It is not uncommon for mushers to switch their dogs' positions during a race according to different weather and track conditions [18]. The lead dog in this analogy represents the reference synchronous machine, which sets the system frequency to which every other generator must conform to. The Swing dogs represents the ancillary generators used temporarily for compensating a generation/load imbalance after a disturbance on the system. The Team dogs represent all the other power stations which provides generation to match the load. Lastly the Wheel dogs represent the largest synchronous generators with large amounts of inertia.

Like the mushers, who switches dogs' positions for different conditions to achieve maximum results, so the power system can be optimally configured using virtual inertia for maximum robustness against generation/load imbalance disturbances. This concept of improving the power system's robustness based on optimal placement of virtual inertia will be simulated on the model of the Western Transmission network of the Eskom power system. The knowledge gained from this work will help understand the impact of increasing renewable energy penetration into the Eskom power system, which in turn will help with planning and control, to ensure reliable operation and maintain system stability during times of low system inertia. 


\subsection{Problem Statement}

\subsection{Problem Statement}

South Africa (SA) has the most favourable conditions for wind and solar power generation, yet SA is still strongly depended on its coal reserves for electricity. Due to climate change and environmental concerns, pressure is placed on governments to reduce their carbon footprint, to reduce their negative environmental impact and thus, focus on sustainable energy sources [19] [20].

Considering the amount of renewable energy resources of SA, it is well behind in the world with RES integration. The planned future RES generation share is the same as the European Union's current RES share. However, the SA power system faces additional challenges for large-scale RES integration, such as lack of support from neighbouring countries.

Large scale renewable energy (wind and solar PV) integration is very likely to be present in the near future. This technology is disrupting the way the power system operates. This transition comes with a number of technical challenges, which requires significant changes in a wide range of control and operational procedures.

The following main research questions that are set and of interest to be answered are:

- What is the impact of high share inverter-based generation on the power system's frequency stability?

- How can RES contribute to power system stability?

- What should be considered in network planning for large-scale integration of inverterbased RES considering power system frequency stability?

\section{$1.2 \quad$ Research Objectives}

The research focus is toward power system simulation, more specifically how large-scale penetration of inverter-based renewable energy sources effects the stability of the power system. Not only is RES generation intermittent, but they also don't contribute to system reserves and to the power system's inertia.

Since solar PV and wind power are injected through power electronic devices, called inverters, the power system does not gain rotational inertia with increased generation capacity, as in the case of synchronous generators. Synchronous machines naturally provide inertia to the power system, but with old generators being replaced by inverter-based 


\subsection{Research Tasks}

RES the system inertia will become endangered.

The list of research objectives are as follow:

1. The first objective is to find the impact of large-scale inverter-based RES on power system frequency stability. The implications of low rotational inertia on power system stability need to be identified and studied to understand the challenges that needs to be addressed to maintain system stability and meet the operational objectives.

2. The second objective is to investigate virtual inertia for inverter-based RES to help mitigate the decline in system inertia, due to the replacement and share decrease of synchronous machine generation in the generation mix. The research then focuses on the control of the power feed-in from renewable sources to provide virtual inertia to assist in stabilising the frequency. Using RES to emulate the inertial response of synchronous generators is important for large-scale integration of RES to help maintain system frequency stability. This study will entail creating dynamic models of the renewable energy sources. These models will then be integrated into the power system model, after which the control strategies will be simulated to obtain results for analysis.

3. From the perspective of the power system network, distributed generation such as, dispersed renewable energy generation operates differently from traditional centralised power generation plants. The objective is to see if distributed generation, which is intrinsic to RES generation, can be beneficial to the system frequency stability, by utilising distributed RES power plants to optimise the use and location of system inertia for improved frequency stability.

\subsection{Research Tasks}

With increasing renewable power integration, there is a rise in interest to investigate the impact of large-scale integration of RES on power system stability and control. Based on the main research objectives the following research tasks are set in order to find the answers.

1. Understand and clearly state the importance of power system stability.

2. Review and present the role of system inertia in power system stability.

3. Identify the drivers of the decline in system inertia.

4. Find the impact and control challenges of a low inertia power system. 


\subsection{Thesis Overview}

5. Create control strategies for wind and solar PV to emulate the inertial response for low inertia power systems.

6. Optimise the use of virtual inertia for the Western TX of Eskom considering a trip at Koeberg nuclear power plant as a case study.

In order to complete these tasks, dynamic power system models will be created to enable the investigation of system frequency stability, while new control strategies will be proposed for the use of inverter connected sources to assist with inertia in the power system. The optimisation of virtual inertia placement using cost-function minimisation requires translating the single-line diagram model of the power system to state-space domain. The state-space domain also allows for modeling governors and virtual inertia controllers. With the state-space models an augmented model can be created and used in the formulation of a cost-function.

\subsection{Thesis Overview}

The rest of the thesis is structured as follows:

- Chapter 2: The theme of this chapter is renewable energy integration. First an introduction is given on the current state of renewable energy integration is then presented. It introduces the renewable energy integration in the European Union and compares the European power system to the South African power system in terms of ability to safely integrate large-scale of renewable energy. From this comparison, important factors are highlighted, which should be taken into consideration for large-scale integration of renewable energy generation into the South African power system to maintain system stability. A review is then given on power system stability in terms of the three pillars: rotor-, voltage- and frequency stability. This background information introduces the different main categories in which large-scale renewable energy integration can affect the operation and stability of the power system. The focus is then placed on the South African power system. The renewable energy integration plan for South Africa is presented and the current and future generation mix for South Africa is discussed. The challenges of increased variable generation on power system operation is then presented. The grid code compliance for renewable power plants is reviewed to find the current requirements for mitigating some of the integration and operational challenges that come with renewable energy integration. The use of wind, solar PV power, and the current available energy storage systems are then discussed in terms of providing control, flexibility and stability support to large-scale power systems. 


\subsection{Thesis Overview}

- Chapter 3: This chapter looks at the implementation of virtual inertia using inverterbased renewable energy generation. An introduction to what inertia is and how it is utilised in power systems is given. The synchronous machine, which is the source of the inertia is then discussed with the focus on the rotor and frequency dynamics. The positive impact of inertia on frequency stability is then presented. The endangerment of inertia is then evaluated due to inverter-based generation replacing synchronous machine generation shares in the generation mix. With the emphasis on low amount of system inertia, the concept inertia location on stability performance is introduced. Virtual inertial is then introduced to as a method to mitigate the decline in system inertia and for the use of inertia placement. A review is given on inverter control schemes for emulating the inertial response of a synchronous generator. The section is split in two subsections, wind and solar PV generation. The different types of wind turbine generators are presented and discussed. Virtual inertia implementations for wind power generation is reviewed, virtual inertia control and simulation models are created, and the simulation results are presented. The second section focuses on solar PV plants. A basic PV setup is presented, followed by a review on virtual inertia implementations for PV plants. Lastly, virtual inertia control and simulation models are created, and the simulation results are presented.

- Chapter 4: In this chapter the method used for optimal allocation of virtual inertia is presented and discussed. The single-line diagram is converted to a state-space model with the use of linearisation and graph theory. The cost-function is derived and a 5-bus network was used to prototype the optimisation. After the 5-bus network's optimisation results were obtained, scripts in Python and Matlab were developed to perform a case-study on the western TX of Eskom. The results for optimal virtual inertia placement considering a trip at Koeberg power plant is then presented and discussed.

- Chapter 5: This chapter presents the conclusions drawn by the work done in this thesis. The impact of high RES share on power system stability is concluded, with the focus on transient stability due to the decline of rotational inertia and the optimal allocation of virtual inertia is discussed. 


\section{Chapter 2}

\section{Renewable Energy Integration}

The European Union (EU) power system is a world leader in large-scale RES integration. The EU-28 reached a 16\% share of RES into the generation mix in the year 2014 and is currently on track towards their goal of $20 \%$ in the year 2020. According to the European Commission's renewable energy progress report [9], large interest and focus is directed towards renewable energy innovation and is responsible for $30 \%$ of global patents.

The development of wind power has accelerated significantly in recent years. Over the period 2004 - 2015, the deployment of wind power generation has more than quadrupled, and currently accounts for one third of renewable electricity. Hydro power still contributes the largest share in RES generation, however since 2004 the share of hydro power has seen a decline from $74 \%$ to $38 \%$ by the year 2015 . This means that soon wind power generation will take the lead in renewable energy generation. The largest contributions with onshore wind power comes from Germany and Spain. Sweden, Germany, Denmark and the United Kingdom are the four largest contributers in regard to offshore wind generation [9].

A report on the German power system (which has significant interconnection capacity with neighboring EU members), states that in 2012, Germany had 21.3 GW of available interconnection capacity, a high level compared with an annual peak demand of 83.1 GW. In 2014, lignite and hard coal was responsible for about $44 \%$ of Germany's electricity generation. Germany wants to phase out nuclear power, which accounts for $16 \%$ of their power production, by the year 2022. This will leave a gap and make way for a RES share increase in their generation mix, which has already accounted for more than $25 \%$ of all generation in 2014. Germany shares connections with Austria, Switzerland, the Czech Republic, Denmark, France, Luxembourg, the Netherlands, Poland, and Sweden [21].

Comparing the South African (Eskom) power system to that of the EU. The European power system has significant interconnections between neighboring EU member states, meaning that member states have the luxury to depend on each other for system balancing, 


\subsection{Power System Stability}

reliability and system stability. South Africa does not have the luxury of neighboring countries to rely on for generation support, instead the neighboring countries depend on the South African power system for their energy security. For the ingratiation of RES, it is crucial for the South African power system to maintain and improve its system's stability.

\subsection{Power System Stability}

The authors of [22] define power system stability as the ability of the system, given an initial state, to regain a state of equilibrium after being subjected to a physical disturbance, with the state-variable being bounded and the system practically operational.

Power system stability is classified in three categories namely, angle, voltage, and frequency stability. The classification, however, does not mean that the instability events occur independently and in isolation. For example a large frequency deviation may cause large rotor angle excursions, which in return changes the power-flow and with it the voltage magnitudes.

\subsubsection{Rotor Angle Stability}

Rotor angle stability is the ability of all synchronous machines (generators and motors) in the network to maintain synchronism after a disturbance. When a disturbance causes an imbalance between the input and output torques, the rotors of the machines will accelerate in the direction of the net torque, meaning the rotation speed can increase or decrease. Angular swings occur due to instability resulting in the loss of synchronism. Stability therefore depends on the ability to maintain equilibrium between mechanical and electromagnetic torque of the synchronous machines. Rotor angle stability is divided into two categories according to the size of the disturbance rejection. The first category is termed, small-disturbance stability and the second is known as large-disturbance stability [4] [23].

Small-disturbance stability is the ability to maintain synchronism during a small disturbance. A disturbance is considered small when linearisation of the power system, which is non-linear, is permissible for analysis. Sudden changes like a step change in a small load, tripping of a small generator, or loss of a transmission line are examples of small disturbances. For this analysis the time-scale of this study is around 10 to 20 seconds.

Large-disturbance stability is the ability to maintain synchronism during large and severe disturbances. For large disturbances the synchronous machine rotor experiences large 


\subsection{Power System Stability}

angle excursions. Due to the large angle swings the linearisation of the power system (a non-linear system) is not permissible anymore for analysis. Examples of large disturbances include, sudden change in a large load, loss of a transmission line, or the trip of a large generation plant. The time-scale of interest for this study range from 0.1 to 10 seconds.

\subsubsection{Voltage Stability}

Voltage stability is the ability of the power system to maintain steady voltages at every bus, following a disturbance on the network [23]. The main factors responsible for placing voltage stability at risk are heavy loading, network faults or lack of reactive power[4]. Voltage instability results in continuous increase or decrease in voltage at the local buses. Large scale voltage instability leads to voltage collapse and ultimately to a system wide blackout.

The most commonly used method for voltage stability analysis is the power versus voltage (P-V) curve method, see figure (2.1), also known as the nose curve.

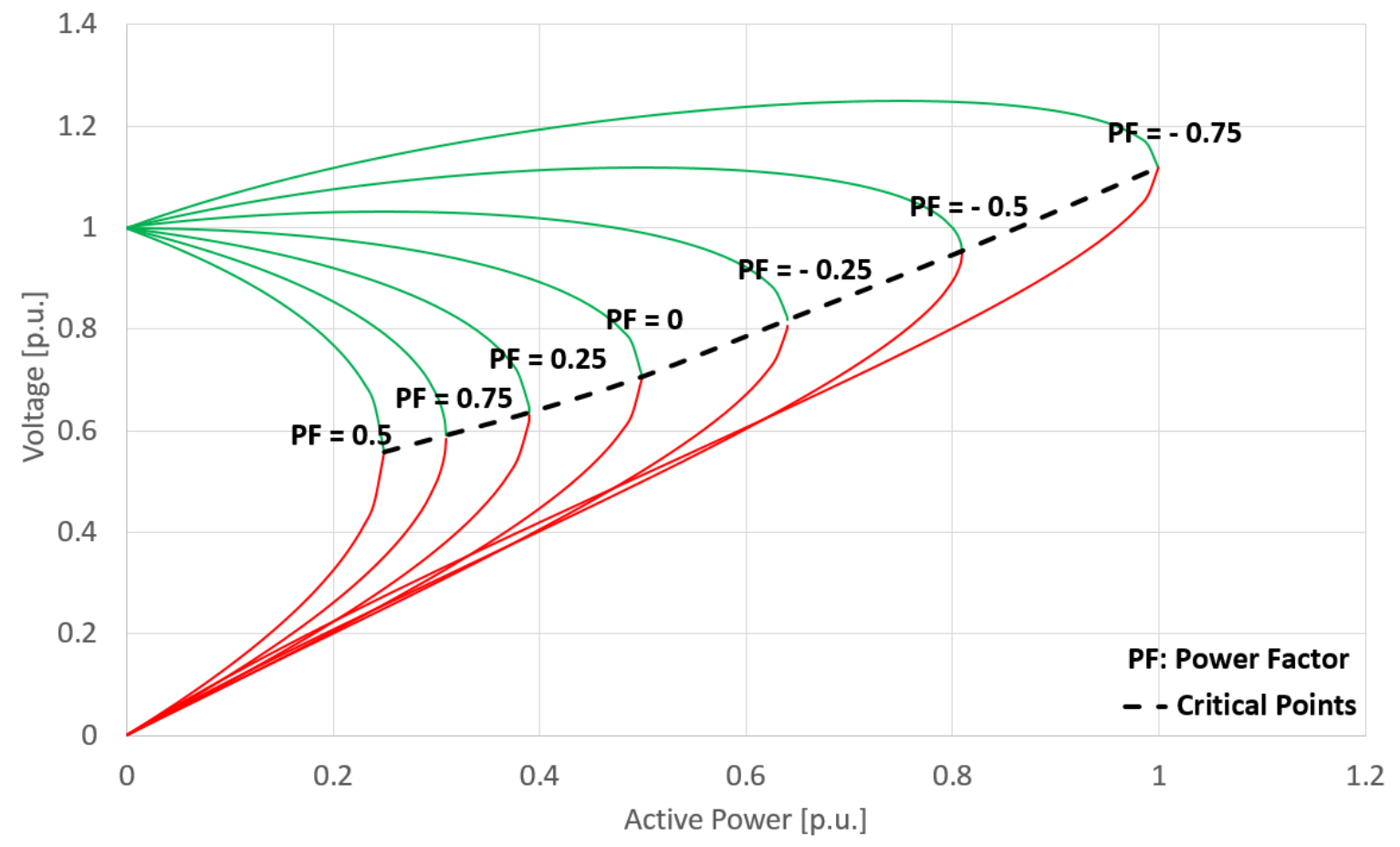

Figure 2.1: Power versus voltage (P-V) curve method.

The P-V curve in figure (2.1) shows two voltage operating regions for a given active load, except at the nose of the curve, which is known as the critical point or maximum loading point. Exceeding the critical point means that there is no intersection between the load and the P-V characteristics, and thus, indicates voltage instability. Disturbances such as loss of a transmission line causes an increase in the equivalent reactance, or the trip 


\subsection{Power System Stability}

of a generator reduces the maximum loading point. If the post-disturbance P-V curve's maximum loading point is less than the load (assuming the load is relatively unchanged), the bus will enter voltage instability. Thus, it is important not to operate close to the maximum loading point and leave margin for a disturbance event [23] [24].

The red line indicates operating points with low voltage and high current. The green line represents operating points with high voltage and low current, which is more energy efficient. When operating in the green region, with a change in active power the voltage remains relatively steady compared to the red region. Analyzing the red region, it is seen that as the load increases the voltage increases as well, this however, is not possible. Therefore, power systems operate in the upper stable region of the P-V curve [24].

A shortage of reactive power is typically associated with voltage collapse, in other words, voltage instability occur when the injected reactive power does not match the load requirement. A system is said to be voltage stable if the voltage increases with an increase in reactive power injection (positive $\mathrm{Q}-\mathrm{V}$ sensitive) for each bus in the power system. A power system is voltage unstable when the voltage decreases for an increase in reactive power injection for at least one bus, thus negative Q-V sensitive. By injecting more reactive power, the nose of the $\mathrm{P}-\mathrm{V}$ curve extends and thus, makes it possible to operate at higher power without losing voltage stability or to improve the stability margin. The opposite is true for a lagging power factor which decreases the active power limit. Reactive power is thus, useful for voltage control and stability [24].

\subsubsection{Frequency Stability}

Frequency stability is the ability of the power system to maintain nominal frequency after a disturbance on the system results in a generation/load imbalance [23]. The synchronous generator is the heart of the power system. The power system is designed around the synchronous machine operation. Since the power system does not operate with significant energy storage, and due to the strong coupling between the mechanical dynamics and the electrical dynamics of the synchronous machine, the electrical frequency serves as primary indicator of the generation and load balance. If the generation exceeds load demand the synchronous generator will speed up and in turn increase the power systems frequency. The opposite is true when the load demand exceeds the amount generated, which results in a decline in the system's frequency. The network components (e.g. generators, transformers, transmission lines, loads, etc.) are designed for the network frequency of $50 \mathrm{~Hz}$. Circuit breakers activate when the frequency deviate outside a predefined range in order to protect the network components. This can lead to restricted power flow and generation resulting in further generation and load imbalance, and thus, increased frequency 


\subsection{Power System Stability}

deviation and ultimately to a system blackout. It is of high importance that the power system is frequency stable to ensure reliable operation.

\subsubsection{Power-Flow}

The power-flow between two sources connected by an inductive reactance and neglecting resistance is as follow [4]:

Bus 1

Bus 2

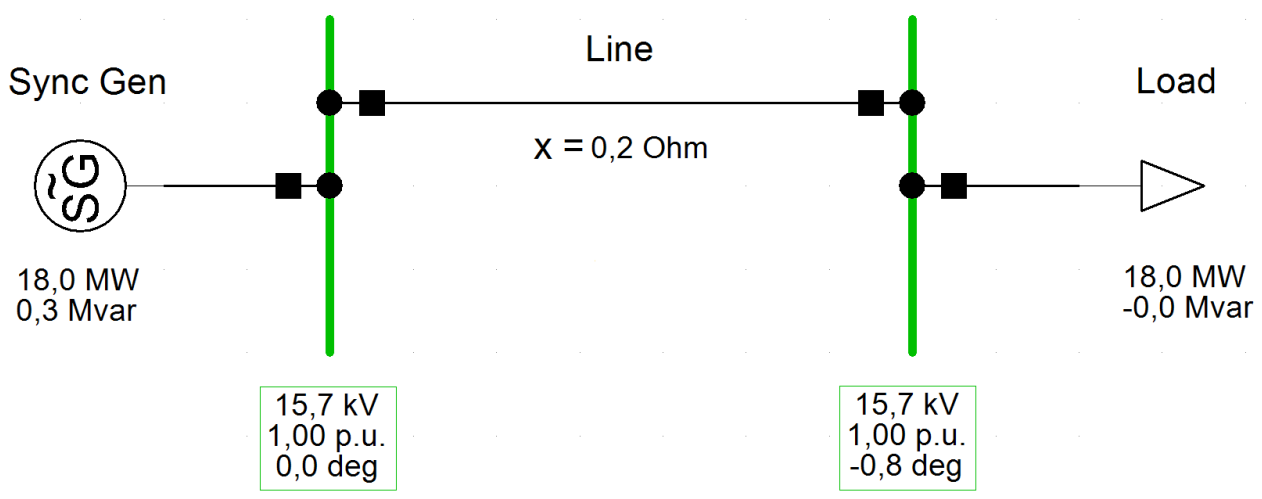

Figure 2.2: 2-bus power-flow.

$$
\begin{gathered}
P_{1,2}=\frac{V_{1} V_{2}}{X_{1,2}} \sin \left(\delta_{1}-\delta_{2}\right) \\
Q_{1,2}=\frac{V_{1}^{2}-V_{1} V_{2} \cos \left(\delta_{1}-\delta_{2}\right)}{X_{1,2}}
\end{gathered}
$$

The real or active power transfer is denoted by $P_{1,2}$, where the power is transfered from bus 1 to bus 2 . The reactive power flow between the two buses is denoted by $Q_{1,2}$. The voltages at the two buses are denoted by $V_{1}$ and $V_{2}$ with their respective angles $\delta_{1}$ and $\delta_{2}$, respectively. The voltage at each bus in the power system must operate significantly close to the nominal value i.e. at 1 per-unit. This means, from equation (2.1) the active power transfer is controlled by the angle difference between the two buses. There is thus, a link between rotor angle stability and active/real power flow.

Voltage stability and control is linked mainly with reactive power flow. Reactive power flow is mainly determined by voltage difference between connected buses, where the flow is from the bus with higher voltage to the bus with the lower voltage. The amount of power is mainly depended on the voltage magnitudes, as seen in equation (2.2). Reactive power does not travel far as this would require a large voltage gradient, thus reactive power is produced and consumed locally. 


\subsection{Renewable Energy Source (RES) integration plan}

\subsection{Renewable Energy Source (RES) integration plan}

The power system stability as discussed in the previous section is placed in danger with an increase in RES integration, which has a negative effect on the basic operation, network infrastructure and stability of the power system. This is due to the wide-spread distribution and the change in the type of generation in the new power plants. The following section looks at the generation mix for South Africa in the year 2017. The planned RES integration capacity for the future (the year 2027) is presented, and the effect RES will have on the generation mix and footprint, i.e. moving from central to distributed generation, is discussed, for the South African power system.

The installed generation capacity in South Africa for the year 2017 summed to 48.3 GW. From the total generation capacity $7.3 \%$ is variable generation (see figure 2.3). Wind has a $2.9 \%$ share in the total generation mix and constitutes $42.2 \%$ towards the variable generation. Solar PV is the other major source of variable generation, which is responsible for $3.2 \%$ of the total generation mix, and has a $47.7 \%$ share in the variable generation mix. Concentrated Solar Power (CSP) forms the third largest source $(19.17 \%$ ) of variable RES generation [19].

\section{GENERATION SHARE MIX OF 2017}

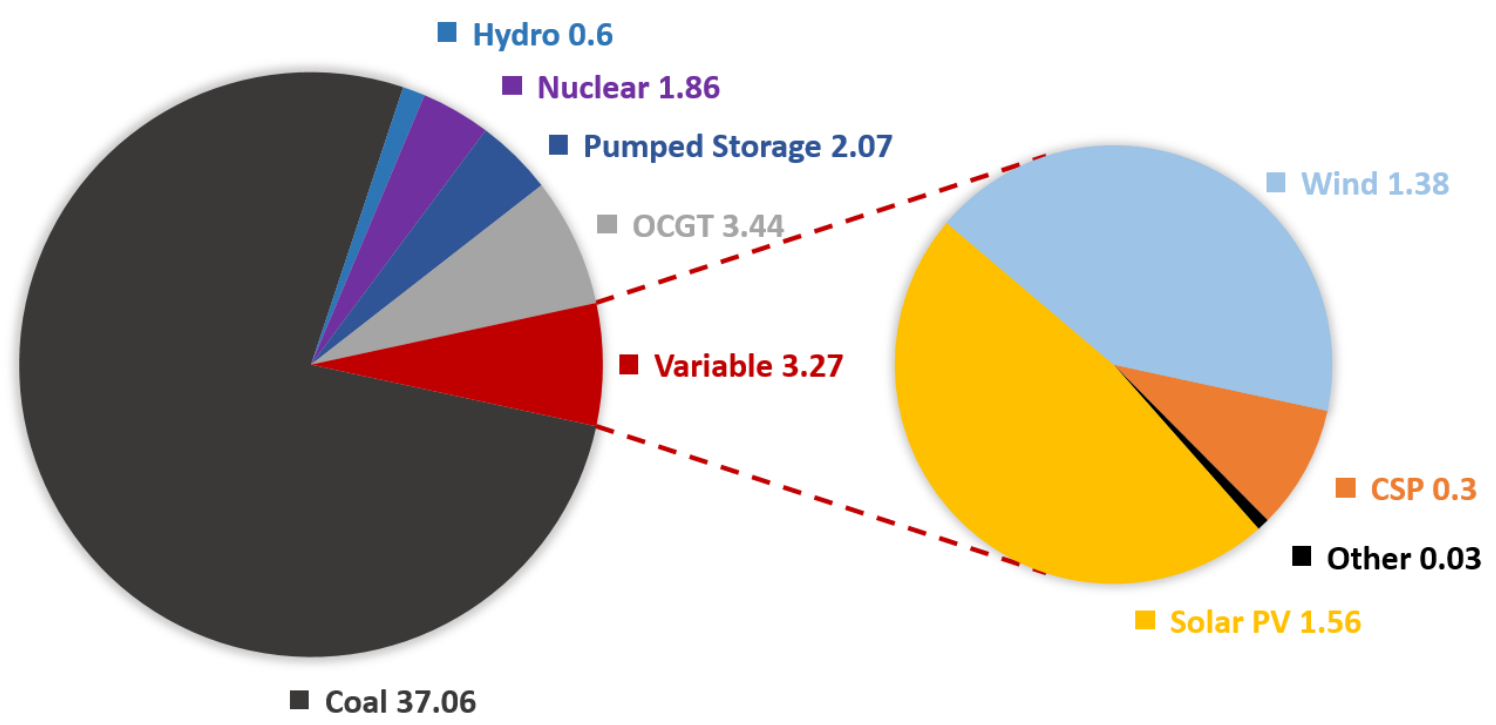

Figure 2.3: Generation share mix of 2017 [GW] [19].

For the year 2017 the total approved capacity of Independent Power Producer (IPP) projects was $8269 \mathrm{MW}$. A total of 36 wind projects were approved with a total capacity of 3382.6 MW. Solar PV has 53 approved projects with a combined capacity of about 2435.5 MW. Together with the approved 500 MW CSP distributed over 6 projects, the 


\subsection{Renewable Energy Source (RES) integration plan}

variable generation mix has a $76.4 \%$ share in the approved IPP projects [19]. To enable this integration will require extensive network development and upgrades.

\section{GENERATION MIX OF THE FUTURE (2027)}

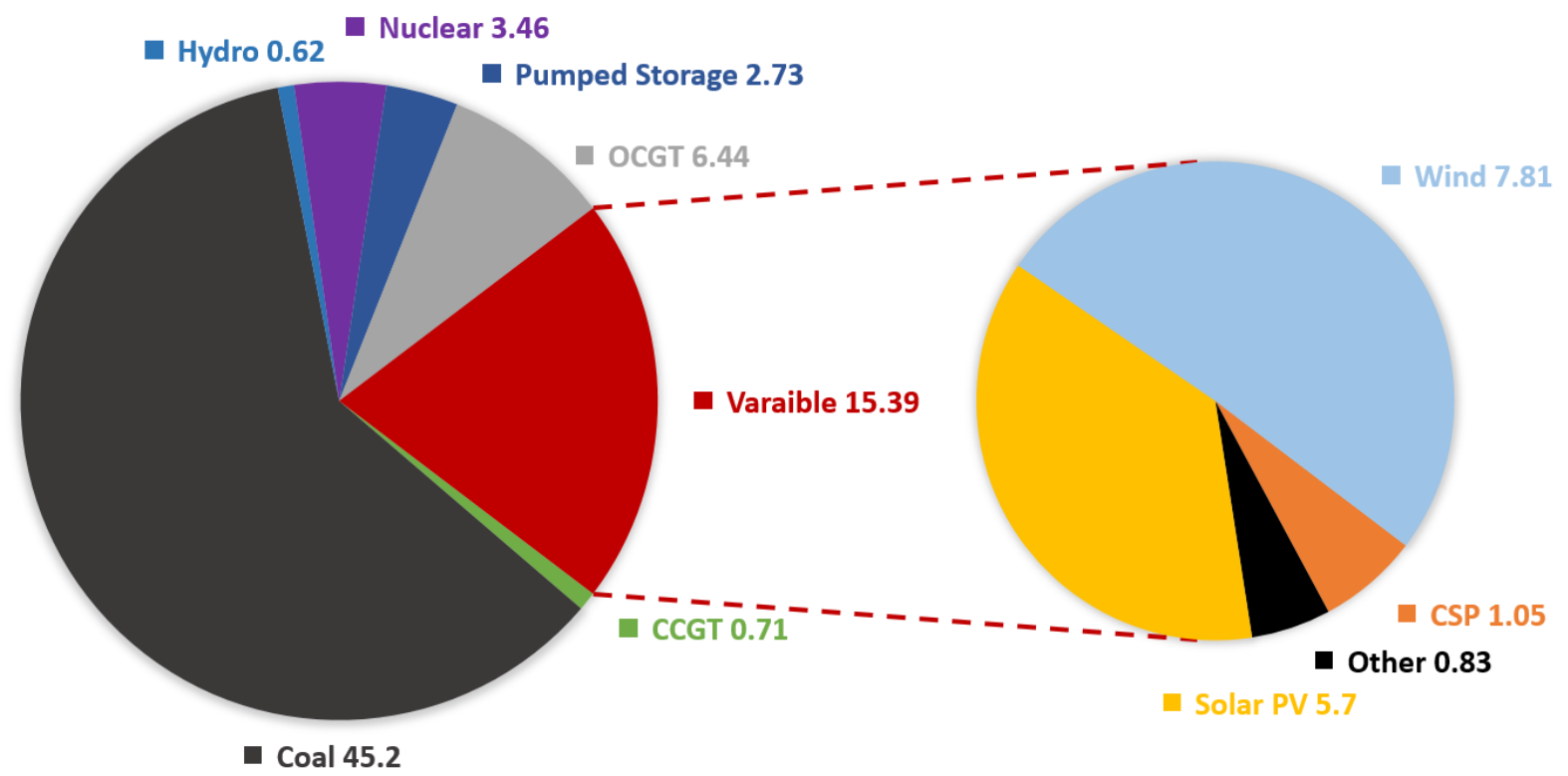

Figure 2.4: Generation share mix of the future (2017) [GW] [19].

The future (2027) generation mix is shown in figure 2.4. The expected installed generation capacity is estimated to be $74 \mathrm{GW}$. The share of variable generation would increase from $7.3 \%$ to $20.8 \%$. Wind contributes $10.6 \%$ to the total generation mix and is responsible for $50.8 \%$ of the variable generation. The presence of solar PV would also increase from $3.2 \%$ to $7.7 \%$ of the total generation and contribute $37 \%$ to the variable generation mix. The remaining shares of variable generation consists of CSP (6.8\%) and other RES sources $(5.4 \%)[19]$.

Since coal has an overwhelming majority $(76.7 \%)$ share in the generation mix, the dominant generation pool is located in the north-eastern part of South Africa, as shown in figure 2.5 [19], where the coal is mined. In order to accommodate the future power system's high share of RES generation mix, the transmission infrastructure planning requires spatial information about the new generation footprint. This information includes the type and size of the generation plant, and specifically the location. Figure 2.6 [19] illustrates the change in the generation footprint for the future power system. 


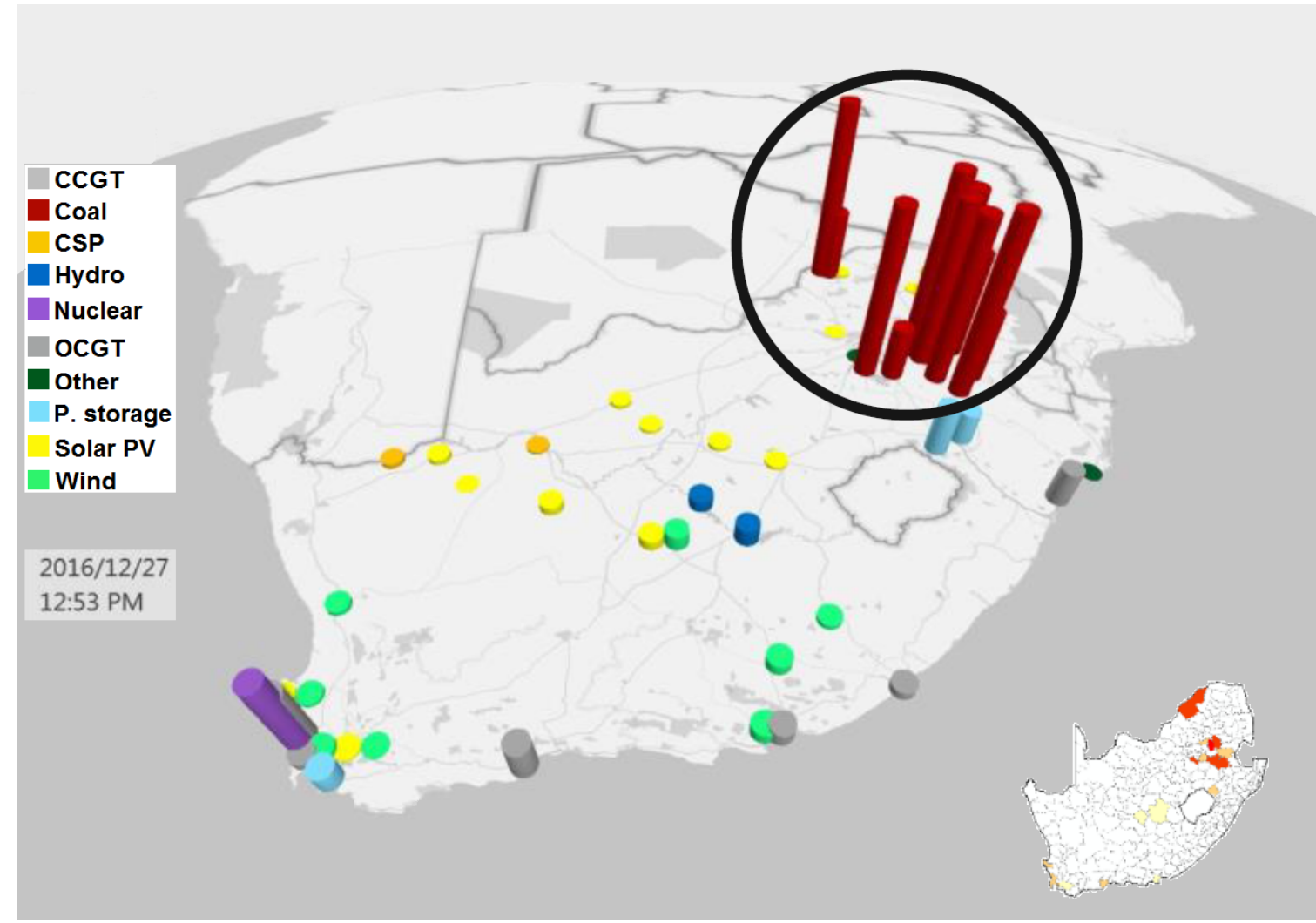

Figure 2.5: Current Generation Footprint [19].

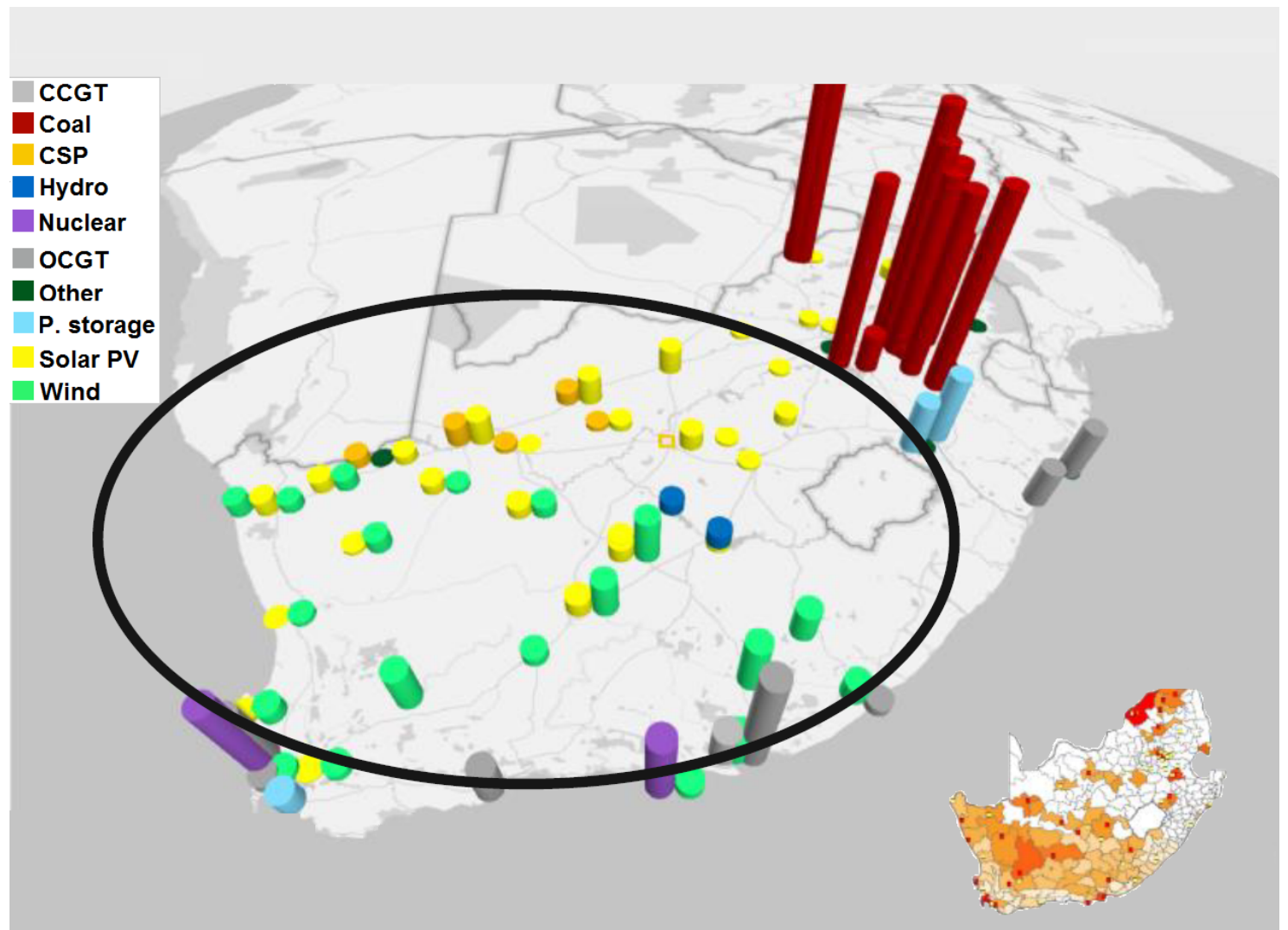

Figure 2.6: Future Generation Footprint [19]. 


\subsection{Impact On Power System Operation}

A report on wind and solar PV aggregation for South Africa [20] founded that South Africa is so rich with solar and wind energy sources that it is possible to generate more electricity than what is needed using the designated zones for RES development. The benefit of wide distributed wind turbines has a strong aggregation effect, meaning reduced feed-in fluctuations and significant reduced forecast errors. According to [20], around 20 to $30 \%$ RES share does not significantly increase the short-term (15 min) ramps in the presence of a balanced combination of solar PV and wind, which creates a strong complementary effect in terms of generation time, i.e. when solar PV generation is at its lowest the wind generation is high, and vice-versa. This is beneficial for the enabling and integration of these sources of generation.

The annual power system electricity demand for South Africa (domestic and export) was between 250.2 TWh and 234.6 TWh in the period 2014 to 2017. With the maximum power consumption at around $34 \mathrm{GW}$ [25]. A grid-focused wind turbine distribution scenario is proposed by [20], where the objective is to determine locations close to the sub-stations, which will operate with high load factors (0.4 minimum). The maximum distance from the sub-stations is $13 \mathrm{~km}$. Wind Atlas for South Africa (WASA) data was used to generate time series of the electricity generation and is aggregated for the distribution scenario [20]. By using the assumption of $0.1 \mathrm{~km}^{2} / \mathrm{MW}$, the grid-focused distribution requires $6796 \mathrm{~km}^{2}$ to generate 250 TWh using 67.7 GW installed capacity, where South Africa needs about 250.2 TWh a year. The total area of the Renewable Energy Development Zones (REDZ) is $80530 \mathrm{~km}^{2}$, the grid-focused distribution only requires $8.44 \%$ of the available space. This means only $0.6 \%$ of South Africa's land area needs to be utilised to supply the electricity demand of South Africa [26].

\subsection{Impact On Power System Operation}

The power system load varies during the day and across the year. It is the responsibility of the system operator to dispatch power plants accordingly to match the varying load. Power plants have operational constraints, which includes: minimum start-up time, ramprate limit, and minimum generation level for stable operation. These constraints are also tied to financial costs. Due to the constraints, conventional power plants must be setup well in advance. This involves predicting the system load and dispatch the power plants through an optimisation process to minimise costs, while matching the load demand.

Predicting the load, a day-ahead is important for planning power plant dispatch. However, there are intrinsic errors in any prediction due to uncertainty, thus a power reserve is required to compensate for the error between the predicted and the actual load. This power reserve is known as the balance reserve, since it compensates for the error between 


\subsection{Impact On Power System Operation}

the predicted and the actual load [27].

Balancing reserve comes from conventional and dispatchable generation plants, such as thermal power plants. Balancing/operating reserve is categorised based on the response time. The operating reserve is categorised as follow [27]:

1. Instantaneous Reserve: This is automatically activated and controlled by the governors, which takes between 2 - 10 seconds to activate.

2. Regulating Reserve: This is activated by Automatic Generation Control (AGC). This takes about 10 seconds to activate and 10 minutes to completely deploy.

3. 10-Minute Reserve: The System Operator manually activates this reserve and it takes up to 10 minutes to become available.

4. Emergency Reserve: This is the same as for the 10-Minute-Reserve, however, this is utilised less frequently.

The integration of variable renewable energy (VRE) sources (e.g. wind and solar PV) introduces additional variability to the power system. VRE and load is similar in that both change over time and cannot be scheduled but only predicted. In terms of generation and load balancing the difference between VRE and load is the sign, VRE can be seen as negative load. Residual load is the system load minus the power generated by VRE [27]:

$$
P_{\text {res }}=P_{\text {load }}-P_{\text {vre }}
$$

Where $P_{\text {res }}, P_{\text {load }}$, and $P_{\text {vre }}$ are the residual load, total system load, and the VRE generation respectively. By incorporating the predicted VRE with the predicted load, means that the conventional generation is dispatched on the basis of the predicted residual load and not the actual load. Flexibility is thus, required due to the fact that generation and load demand varies independently over time. This means that power plants must adapt their power output to the demand, in order to keep the generation/load balanced. A power system with significant share of VRE generation needs conventional dispatchable power plants to provide flexibility to the system. This is evident in the duck curve effect.

\subsubsection{Duck curve effect}

An negative impact of variable RES on the power system is over generation. Over generation leads to an excess of energy in the system, which are absorbed by synchronous generators, speeding them up and thus, increases the system's frequency. Generation/load balance is accomplished with conventional and dispatchable generation plants. Conventional generation is dispatched according to the residual load. 


\subsection{Impact On Power System Operation}

Figure 2.7, modified from [28], presents a graph of the total system load of the state of California, the wind and solar PV power feed-in, and the residual load. The shape of the residual load resembles the silhouette of a duck, where the early morning demand represents the "tail", the middle of the day forms the "belly", and the evening peak is the "head" of the duck. The duck's "belly" is shaped due to the generation pattern of solar PV during the day. With the increase in solar PV installations and power system feed-in the belly of the duck grows, meaning more conventional generation is displaced by VRE sources and less dispatchable generation is online.

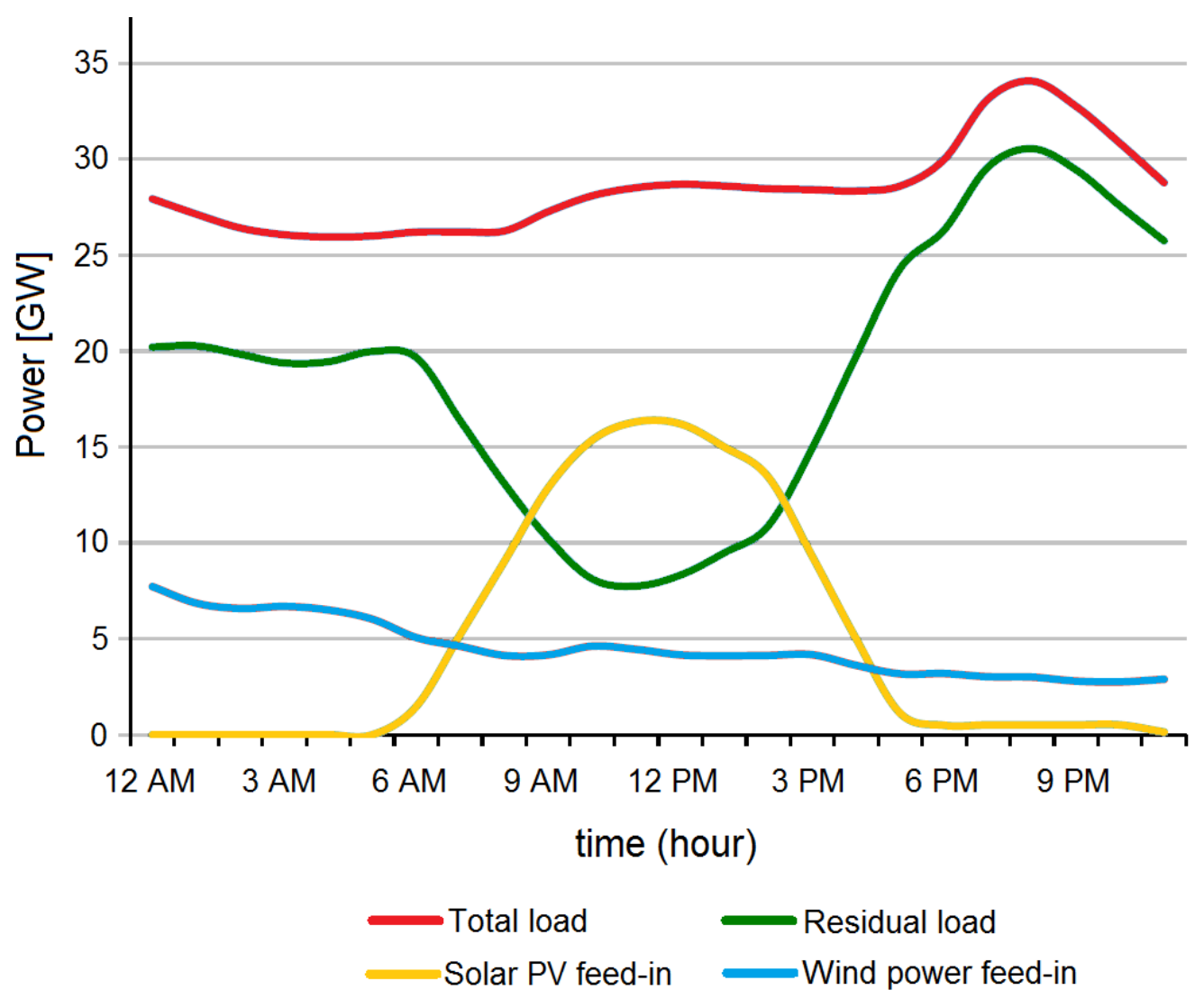

Figure 2.7: Residual load duck-curve shape [28].

Over generation occurs when the amount of dispatchable power cannot be reduced any further for the accommodation of VRE feed-in. The growth of the belly is accompanied by increased ramp rates of conventional generation plants, since peak demands occurs right before and after solar PV generation. The system operators is paying significant attention to this dark curve signal, since new operational techniques and strategies are required to operate with the change in dispatch profile while maintaining system stability at all times.

With the previously mentioned constraints of dispatchable power in mind, the solution is to use curtailment on the VRE plants. Wind power generation is curtailed by changing 


\subsection{Impact On Power System Operation}

the blade pitch angle to decrease the energy captured from the wind. Solar PV is curtailed be reducing the inverter power output, or disconnecting from the power system. Curtailment is a relative simple to implement solution, however it is economically and environmentally undesirable. With every energy unit not fed in to the power system the RES plant does not make money. The increase in RES integration will lead to increased curtailment and thus making it non-viable to integrate more VRE plants.

Power system flexibility is the limiting factor for large-scale integration of VRE. To accommodate more VRE, increase in flexibility is required. To flatten the duck requires all approaches that increases the flexibility of the power system. This includes designing units for more frequent cycling, shorter times for startup and shutdown, and improve VRE forecasts. VRE should also provide operating reserves and system frequency stabilisation ancillary services. These applications reduce the total minimum generation requirement, and thus increased the margin for VRE feed-in and growth in the belly shape.

To accommodate for large-scale increase of VRE RES will require understanding the change in residual load shape. System planners must adjust operations which was historically driven by dispatchable thermal and hydro power plants. Non-conventional generation sources will need to provide operational reserves and frequency stability. In the future system operators will need visibility and control of distributed PV, storage, and load for continuous stable operation [28].

\subsubsection{Impact of VRE sources on balancing reserve}

A study on the South African power system flexibility [27] investigated the impact of VRE on the error in day-ahead prediction and the actual generation. The predicted installed capacity for the year 2020 is estimated to be $4.2 \mathrm{GW}$ of wind and $2.8 \mathrm{GW}$ of utility-scale $\mathrm{PV}$ integration. These VRE sources increases the day-ahead prediction errors with about $9 \%$. With the addition of $10 \mathrm{GW}$ of rooftop PV the error increases by $13 \%$. The reserve power required for balancing the variability of residual load ranges from $1541 \mathrm{MW}$ to 1730MW, which is less than for the worst-case contingency event (2166 MW). Thus, the increase in VRE has no impact on the Operating Reserve, since the worst-case contingency dominates over the variability.

The impact of VRE on the error between the day-ahead prediction and the actual generation for the year 2030 was also investigated [27]. The integration of wind accumulates to $11.1 \mathrm{GW}$, and a total of $7.4 \mathrm{GW}$ of utility-scale PV capacity. This increase in VRE, increases the prediction error with $25 \%$, and with the addition of $20 \mathrm{GW}$ of rooftop PV the predicted error increases with a further $10 \%$, thus a total increase of $35 \%$ in error. 


\subsection{Impact On Power System Operation}

The integration of $11.1 \mathrm{GW}$ wind and $7.4 \mathrm{GW}$ solar PV does not impact the required operating reserve, since the worst-case contingency criteria still dominates the variability component of the operating reserve. The variability component of the operating reserve starts to dominate the worst-case contingency criteria with the addition of $10 \mathrm{GW}$ or more of rooftop PV. The added $10 \mathrm{GW}$ rooftop PV would require a 10\% increase in operating reserve, and $32 \%$ for $20 \mathrm{GW}$ rooftop PV [27]. In both cases wind is contributing more to the prediction error and thus, to the variability reserve required.

\subsubsection{Frequency response due to power imbalance}

Traditionally the power system network depends on heavy synchronous generators fueled with fossil fuel to generate power. The generator's rotating frequency is directly coupled with the power system's electrical frequency and thus, a disturbance on the power system network will have an influence on the synchronous generator's rotor [4] [5].

The system frequency serves as primary indicator for the power balance between the total generation and the total load in the power system [29]. When a generation/load imbalance disturbance event occurs, the synchronous generator will inject or absorb kinetic energy into or from the power system to counteract the imbalance and thus, the frequency change [30]. Consider the steady-state system frequency at the reference value (50 $\mathrm{Hz}$ for South Africa). When an excess of power is generated compared to the total load demand, then all the synchronous generators will start to accelerate in the direction of the mechanical input torque, since the electrical torque on the generator decreases. This leads to an increase in the system frequency, thus the frequency becomes higher than the reference frequency. The opposite is true for when the system frequency decreases or drops below the reference frequency, meaning the load demand exceeds the generation. Figure (2.8) modified from [15], presents a typical network frequency response to a disturbance such as loss of a generator, or load step increase.

The initial declining slope, as seen from figure (2.8), is determined by the system inertia and the power imbalance disturbance magnitude. This frequency response period is known as the transient response or the inertial response of the power system. When the system is in a state of low inertia the slope is steeper, thus the rate of change in frequency (RoCoF) is higher. The opposite is true for a system with high inertia, resulting in a more gradual slope and thus, will have a smaller RoCoF.

The lowest point is called the frequency nadir, which is the largest deviation point. Deviations from nominal value should be kept as small as possible, since synchronous machines 


\subsection{Impact On Power System Operation}

experience damaging vibrations, protection devices become activated, and islanding occur for larger deviations. This can influence the whole power system, and in the worst scenario ending in fault cascades resulting in a system wide blackout [14].

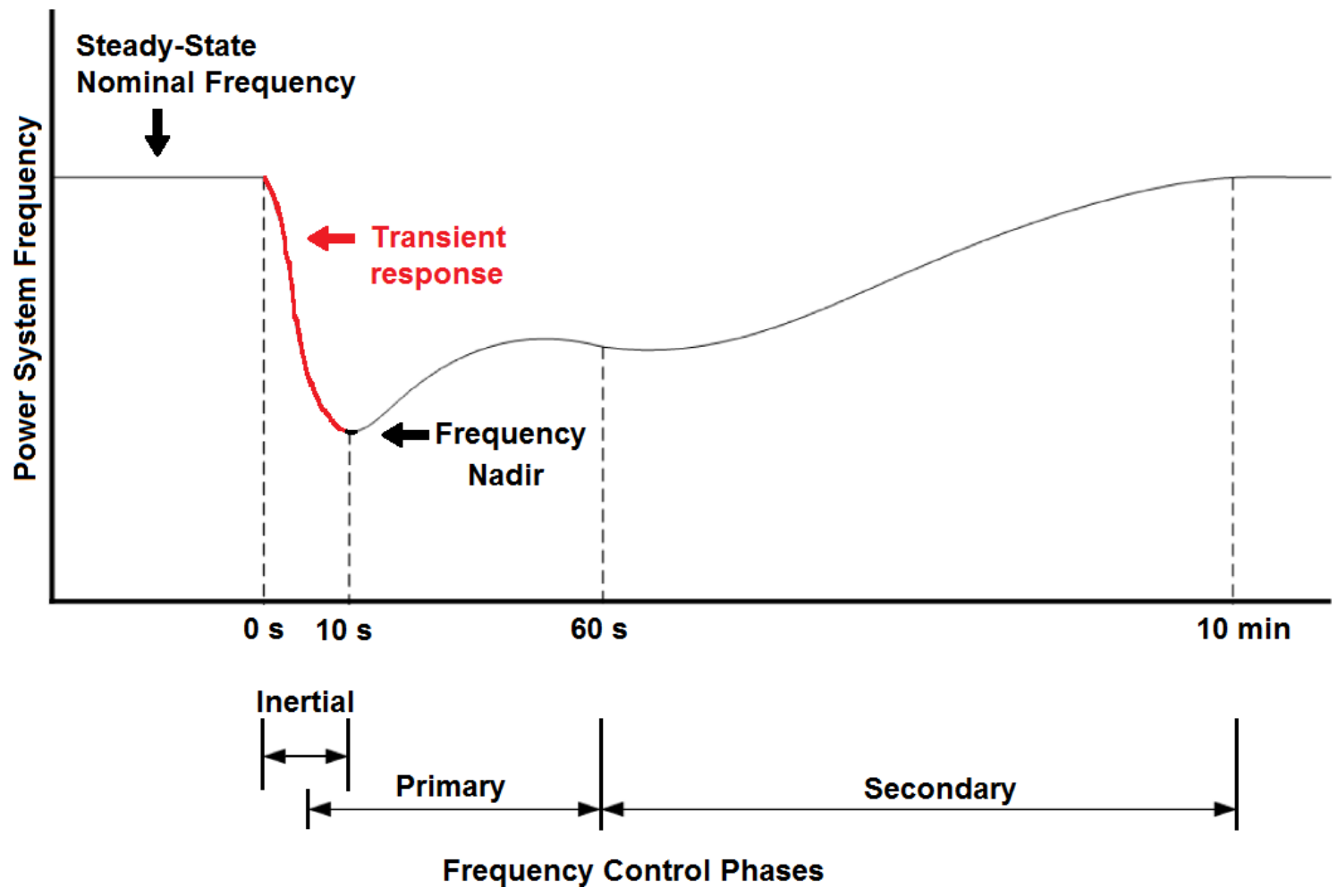

Figure 2.8: Inertial, primary, and secondary frequency control responses.

During the inertial response phase, the primary frequency control activates, which responds in a few seconds after the disturbance. The primary frequency control stabilises the frequency at a new equilibrium point, preferably within a desired range of the nominal frequency. The primary control consists of speed controllers known as governors, and frequency dependent loads. Governors regulate the speed of the synchronous generators by adjusting the energy input into the prime mover, which turns the generator. The response is automatic and not connected to a central system controller, meaning that the governor reacts on local frequency changes only. Frequency dependent loads such as motors without variable speed drives contribute a significant share to primary frequency response, however the response is unpredictable as well as uncontrollable.

Secondary frequency control takes over after the primary control has stabilised the frequency. Secondary control adjusts the power output set points of the power stations, with the aim to correct the imbalance that is responsible for the original frequency deviation, and restore the frequency back to nominal value as well as restoring the primary frequency response capability. The secondary frequency control can be manual or automated from a central control dispatch system, known as Automatic Generation Control (AGC). 


\subsection{Impact On Power System Operation}

\subsubsection{Grid code compliance for Renewable Power Plants}

The South African Grid Code Compliance for Renewable Power Plants version 2.9 (July 2016)[16] makes provision for frequency response control for RPPs. The grid code states that RPPs should be designed such that it will provide mandatory active power reduction during high power system frequency, in order to stabilise the system.

According to the grid code, when the system frequency exceeds $50.5 \mathrm{~Hz}$, the RPP shall reduce the active power as a function of the frequency as illustrated in figure (2.9) [16].

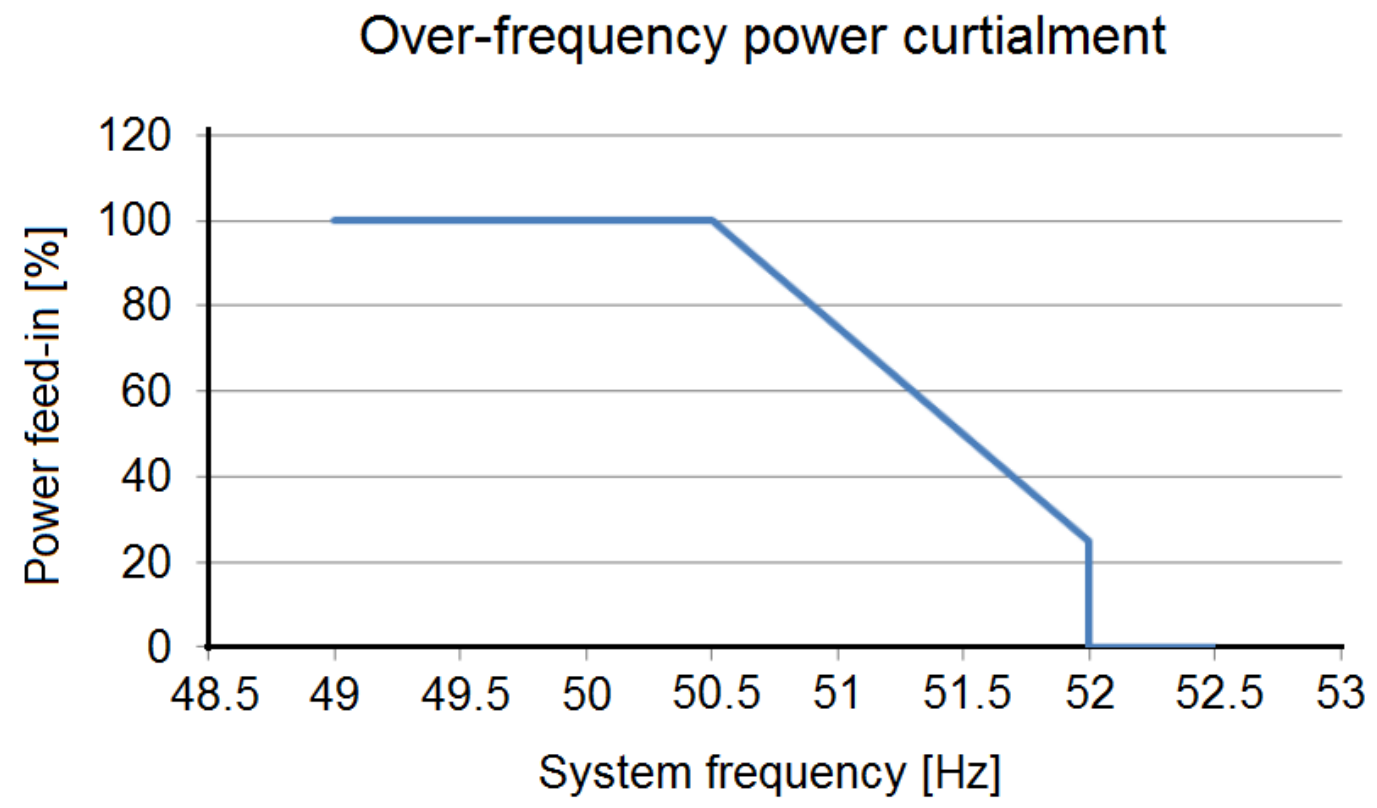

Figure 2.9: Power curtailment during over-frequency for RPPs (version 2.9) [16].

When the power system frequency surpasses $51.5 \mathrm{~Hz}$ for more than 4 seconds the RPP shall be disconnected from the power system. From figure (2.9) it is clear that during low system frequency $(f<50 \mathrm{~Hz})$ the RPPs are required to produce $100 \%$ of their available power. There is thus, no reserve power left to stabilise the drop in frequency during low frequency events. Synchronous generators provide inertial response to combat the drop in frequency, thus providing additional power from the stored kinetic energy in the rotating masses. With RES replacing synchronous generators, it is then required of RES to participate in the inertial response for low frequency events, in order to combat the decline in online synchronous generators

Since RPPs don't contribute to the inertial response, the grid code for RPPs specifies a power-frequency response curve for RPPs, excluding solar PV plants, of category C (20 MVA or higher) as illustrated in figure (2.10) [16]. The grid code specifies that the RPP 


\subsection{Impact On Power System Operation}

must be designed with the capability of providing a power reserve, $P_{\text {Delta }}$, of not less than $3 \%$ of the available power, $P_{\text {available }}$,

\section{Power-frequency response requirement}

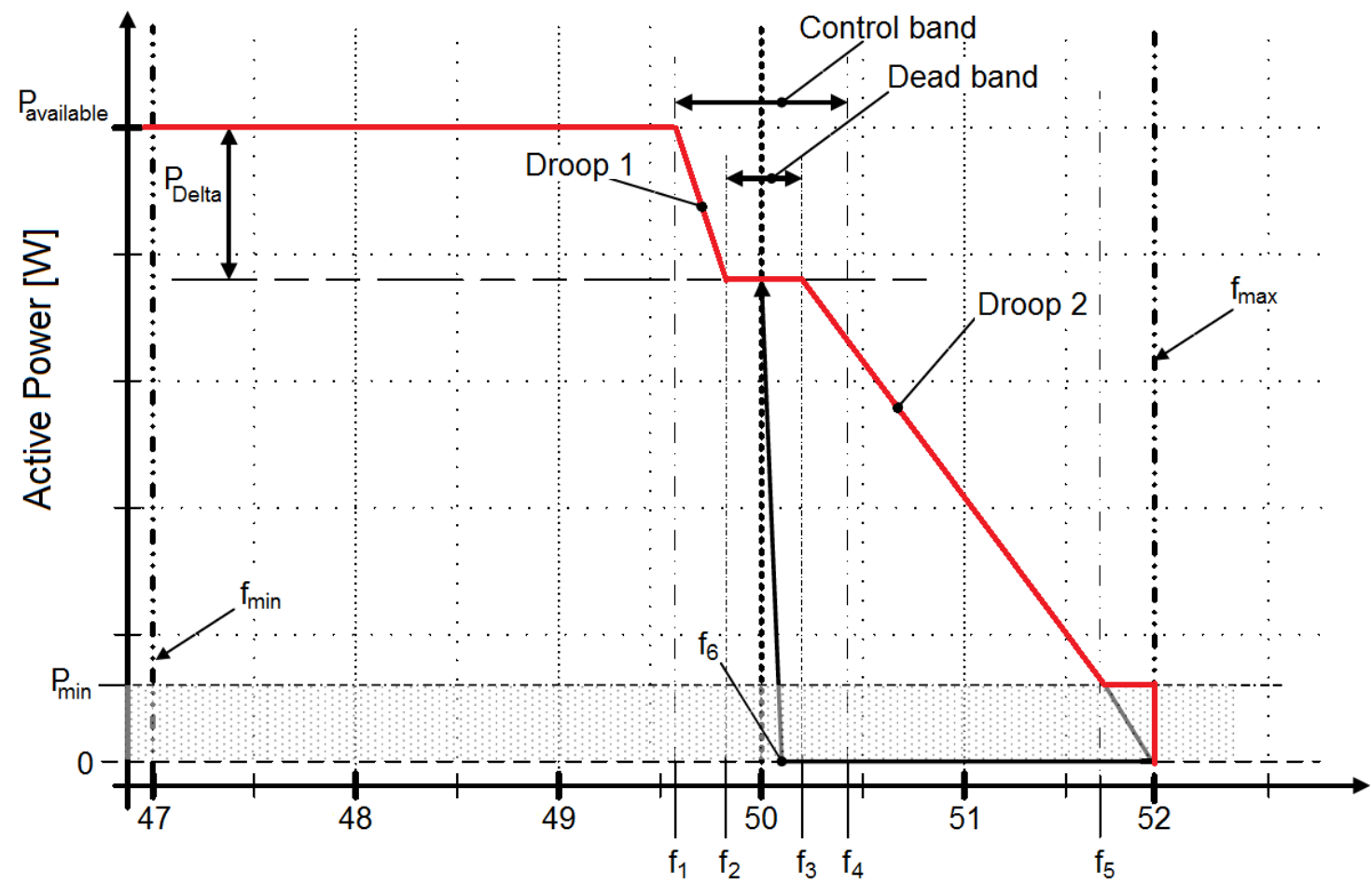

System frequency $[\mathrm{Hz}]$

Figure 2.10: Frequency response requirement for RPPs of category C (version 2.9) [16].

Table 2.1: Frequency Default Settings [16]

\begin{tabular}{|l|l|}
\hline Parameter & Magnitude $(\mathrm{Hz})$ \\
\hline$f_{\min }$ & 47 \\
\hline$f_{\max }$ & 52 \\
\hline$f_{1}$ & As agreed with system operator \\
\hline$f_{2}$ & As agreed with system operator \\
\hline$f_{3}$ & As agreed with system operator \\
\hline$f_{4}$ & 50.5 \\
\hline$f_{5}$ & 51.5 \\
\hline$f_{6}$ & 50.2 \\
\hline
\end{tabular}

where $P_{\text {Delta }}$ is the amount of reduced active power output, in order to provide reserves for the purpose of frequency stabilisation. This reserve power can function as the inertial 


\subsection{South Australia Blackout of 2016}

response (similar to a synchronous generator) during a low frequency event. The curtailed output means that the RPPs are not injecting their maximum available power into the power system network, which is financially undesirable for the RPP, since their income is linked to there generation output.

The provisions made by the grid code only addresses the primary frequency control, and leaves the inertial response from RPPs untouched. The problem of declining inertia still needs to be addressed to ensure the system is sufficiently stable for transient dynamics.

\subsection{South Australia Blackout of 2016}

On Wednesday 28 September 2016, South Australia experienced a blackout across the state, leaving 850000 customers without electricity, according to the Australian Energy Market Operator (AEMO) [31]. On the day of the blackout two tornadoes, with wind speeds ranging from $190-260 \mathrm{~km} / \mathrm{h}$, damaged two $275 \mathrm{kV}$ transmission lines. The damage caused the transmission lines to trip, resulting in a sequence of faults over a period of two minutes around the time 16:16 [31]. The fault disturbances on the power system networked activated the protection features of the wind farms. According to AEMO [31], nine wind farms in South Australia reduced their output as a result, with a total of 456 MW in reduced generation, which is a $25 \%$ of the load demand, lost in generation, in less than seven seconds. The generation mix of South Australia prior to the disturbance is presented in a pie-chart graph in figure 2.11 [31].

\section{Wind $\quad$ Thermal $\quad$ Import}

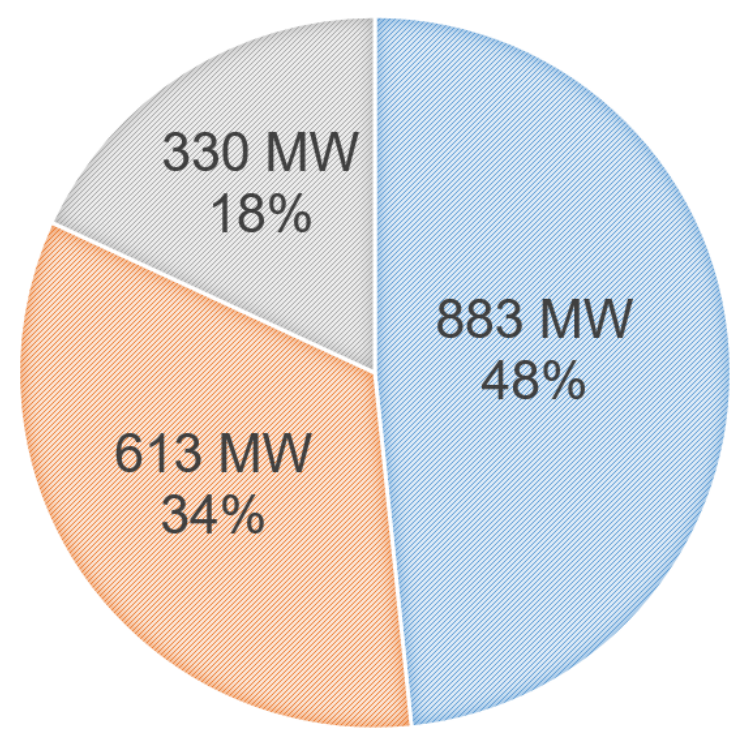

Figure 2.11: South Australia's generation mix prior to the disturbance [31]. 


\subsection{Enabling higher renewable energy penetration}

The total load demand for South Australia summed up to 1826 MW. The demand is met with $34 \%$ thermal generation, which uses conventional synchronous generators, $48 \%$ of the load demand is met with wind power, and the Heywood interconnection with neighboring state, Victoria, supplementing the remaining $18 \%$ of the load demand requirement.

The reduced wind power feed-in resulted in significant power-flow through the VictoriaSouth Australia Heywood interconnection. The interconnection experienced such a large and sudden increase in power-flow that a special protection scheme was automatically deployed, which tripped the interconnection offline. This happened all within 700 milliseconds after the power reduction of the wind farms.

With South Australia separated ("islanded") from the National Electricity Market (NEM), the remaining generation was insufficient for the load, thus the frequency of the islanded power system could not be maintained. As a result the system frequency experienced a high rate of decrease, leading to the loss of all the remaining regional generation by the time 16:18.

The investigation report (final) from AEMO [31] concludes that the disturbance caused by the damage and tripping of the transmission lines, combined with the high share of inverter-based RES generation in the generation mix, which decreased the system inertia and making it more vulnerable to a system blackout event, resulted in large power and frequency excursions. The problem was then aggravated by over protective protection settings, which lead to the shutdown and sudden loss in generation from the connected wind farms. The report further stated that if the generation deficit and the large frequency excursions did not occur, South Australia would have remained connected to Victoria via the Heywood interconnection, based on AEMO's modeling and simulation.

\subsection{Enabling higher renewable energy penetration}

To increase the share of RES in the generation mix, while contributing to generation/load balance and frequency stability support, it requires the inverter-based RES to provide the system operator with control over the active power output and energy storage to accommodate for the generation variability.

\subsubsection{Active Power Control}

With VRE generation replacing dispatchable generation, system operators need new methods to control the generation and system frequency. These new RES generation 


\subsection{Enabling higher renewable energy penetration}

plants (wind and solar PV) have to provide active power control (APC) in order to accommodate further increase in RES generation and system operators a means to balance generation with varying load.

\subsubsection{Wind turbines}

Wind power generation can be used to balance generation with load demand through active power control (APC). APC is the control of the real power output of a wind turbine by adjusting the rotor blade pitch angle of attack [15].

As the share of wind generated power increases on the power system, more interest is placed on wind turbines to actively control their power output in order to meet power set-points and to participate in frequency regulation. This can be beneficial to power system operators since wind turbine APC can react faster than traditional thermal power plants to generation and load changes. The interest in wind turbines to potentially provide frequency regulation support has motivated and led to new opportunities in wind turbine control research and development [15].

There are two goals in the development of APC on wind turbines. The first goal is to emulate the inertial response of conventional synchronous generators during a low frequency event. The second goal is to track the power reference from the network operator as secondary or Automatic Generation Control (AGC) response [15].

Figure (2.12) [15] illustrates the inertial response emulation power output and rotor speed of a wind turbine generator (WTG).

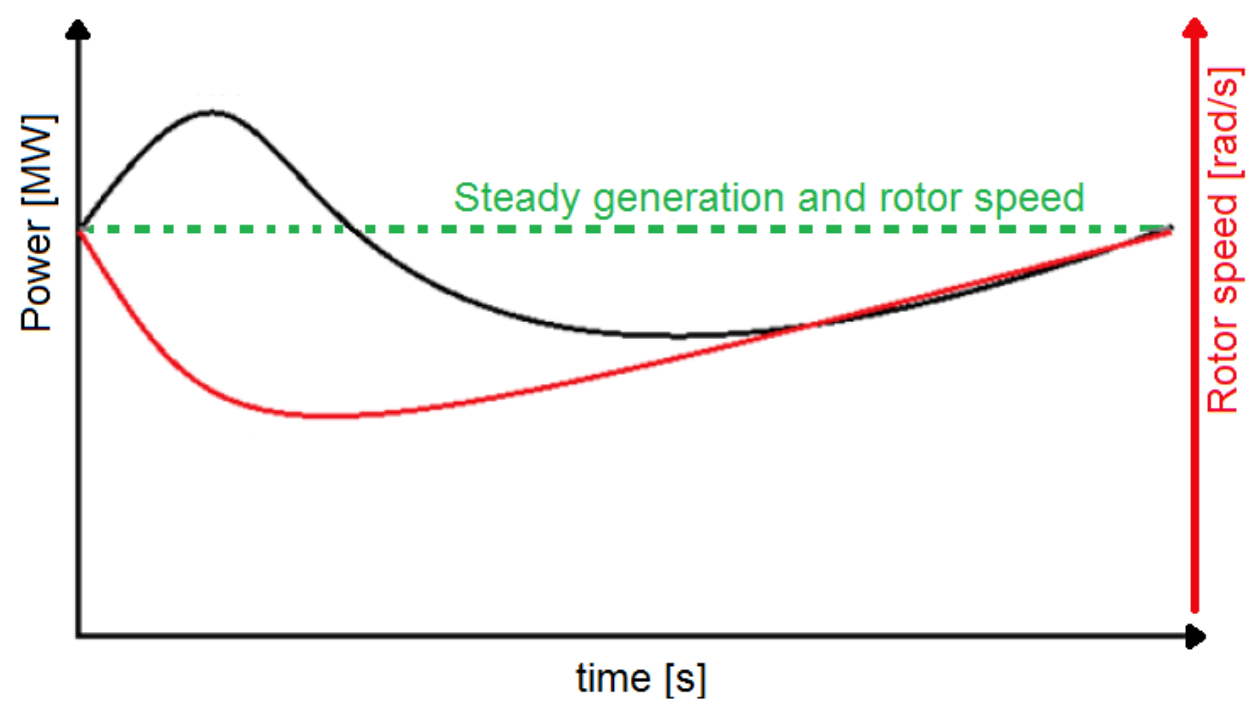

Figure 2.12: Example of inertial response emulation of a WTG [15]. 


\subsection{Enabling higher renewable energy penetration}

With the sudden increase in generator torque, the kinetic energy extraction causes the turbine rotor speed to decrease, while the power momentarily rises above the reference point. The disadvantage is that the WTG might stall and that during the recovery period the WTG will produce less power, which will impact the frequency again. Thus, the objective is to find a control strategy that minimises the recovery period, while maintaining fast response.

\subsubsection{Solar PV}

The research of solar PV APC is in the early stages, whereas wind APC has been implemented commercially [32]. As the amount of solar PV integration increases it becomes more important for PV to assist in frequency regulation, which is currently only provided by conventional synchronous generators, which are being replaced by the intermittent sources.

Wind and solar PV share similar characteristics for APC such as, subjected to weather conditions and lost opportunity of not delivering their maximum available power output. The difference for solar PV APC is that it is not available during night time, and is not subjected to mechanical dynamics and the constraints of it. This is beneficial for solar PV APC, since the inverter can adjust the output power much faster than mechanical governors.

$\mathrm{APC}$ and frequency regulation can be implemented without storage device, through the use of curtailment. This requires operating below the maximum power point (MPP) to create a sufficient power reserve margin to meet the needs for frequency regulation. The drawbacks of curtailment is the lost financial revenue due to reduced active power feed-in, and the difficulty in operating below a varying MPP while maintaining a set power reserve margin.

Solar PV APC can be implemented with energy storage components, such as batteries or super capacitors. Batteries can extend the hours of the day which the plant feedsin power to the power system network and also be used to balance generation with the change in load. Supercapasitors are used for very quick bi-directional ramp-rates, which is necessary for frequency stability. However, these storage components increases the setup and maintenance cost of a solar PV plant.

\subsubsection{Storage systems}

Energy storage would drastically reduce the difficulty of large-scale RES integration, while minimising the risk of generation/load imbalance. Storage systems can improve the qual- 


\subsection{Enabling higher renewable energy penetration}

ity of generated power and support loads during disturbances on the system. This section looks at the available grid-size storage schemes, which could be used for either long-term or short-term energy storage for the purpose of balancing the generation side with the load demand.

\subsubsection{1 flywheels}

A flywheel is simply a rotating mass, which stores kinetic energy due to its inertia and induced rotation speed. The advantages of flywheels are, they have high power density, no toxic material, fast charge and discharge responses, long cycle life and they provide rotating inertia to the power system. The disadvantages include, high speed moving parts that could be a danger to any surrounding objects and that the storage efficiency is strongly dependent on the stand-by losses [33] [34].

A basic operation summary of the flywheel is as follow, when generation exceeds demand, the access power is used to drive an electrical machine (operating as a motor) connected to the flywheel. In contrast, when the demand exceeds the generation, the electrical machine operates as a generator, where the flywheel serves as prime-mover and thus, feeds additional power into the system.

Flywheels are also used at RES plants to improve the quality of generated power, acting as a low-pass filter smoothing out fluctuations in power output. The authors of [34] proposes a deployment of flywheel matrices across the power system network to regulate the local frequency, by compensating the local generation/load imbalance [35]. Figure 2.13 [36] illustrates the basic setup of a flywheel plant for power system frequency regulation.

\section{Flywheel energy storage plant}

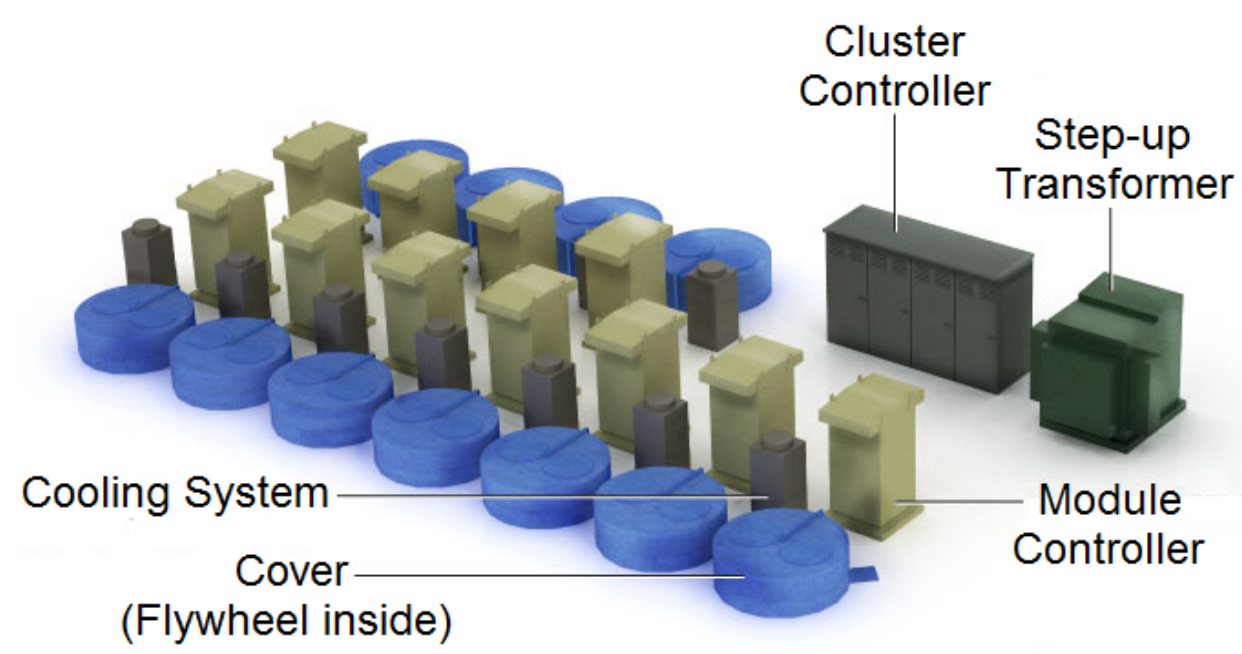

Figure 2.13: Flywheel energy storage plant [36]. 


\subsection{Enabling higher renewable energy penetration}

In January 2011, Beacon Power commenced commercial operation of a $20 \mathrm{MW}$ flywheel plant in Stephentown, New York, USA. The plant consists of 200 flywheels, which provides a frequency regulation service to the New York Independent System Operator (NYISO). A similar plant is situated in Hazle Township, Pennsylvania, USA. The Hazle plant is also rated for $20 \mathrm{MW}$ and reached full commercial operation in 2014 [36].

\subsubsection{2 hydrogen}

Hydrogen is the most abundant element in the universe and on earth majority of it is bonded with oxygen to form water $\left(\mathrm{H}_{2} \mathrm{O}\right)$ [37]. To extract the hydrogen from water a process called electrolysis is used. This process involves two electrodes (anode and cathode) and a DC power supply to separate the hydrogen from the oxygen [38] [39]. Hydrogen fuel can be stored in one of three ways, compressed gas, liquid, or using metal hydrates [40] [41] [42]. The choice of technology depends on the application.

Electrical power is produced in a fuel cell using an electrochemical process, which is 2 to 3 times more efficient than combustion [40] [43]. A fuel cell is an electrochemical device in which electricity is produced from a chemical reaction. A fuel cell is different from batteries, since a fuel cell consume fuel and requires an external fuel supply to keep operating. On the other hand batteries store electrical energy chemically in a closed system [40]. In the case of a hydrogen fuel cell the hydrogen fuel is combined with oxygen to produce electricity, heat and water, with the latter two being the only emissions [40] [39].

The advantages of using hydrogen storage include, long duration (months) energy storage, negligible self-discharge, high energy density, highly versatile, portable and clean emissions [40]. However, the disadvantages of hydrogen storage include, storing the hydrogen in a safe manner, and the low round trip conversion efficiency (35\% to 45\%) makes it an energy intense consumption and not cost-effective technology [44]. Hydrogen storage can improve power quality by smoothening large and rapid fluctuations from wind power generation [35].

In 2014 the worlds first wind and hydrogen hybrid plant was completed in Utsira Island, Norway. The pilot project was sued to supply 10 households with wind energy. During times of excess generation, the wind power is used to power an electrolysis process to produce hydrogen from water. The hydrogen is then compressed and stored to be used when wind power is insufficient to match the load [45]. Figure 2.14 [45] present a picture of the Utsira wind and hydrogen plant. 


\subsection{Enabling higher renewable energy penetration}

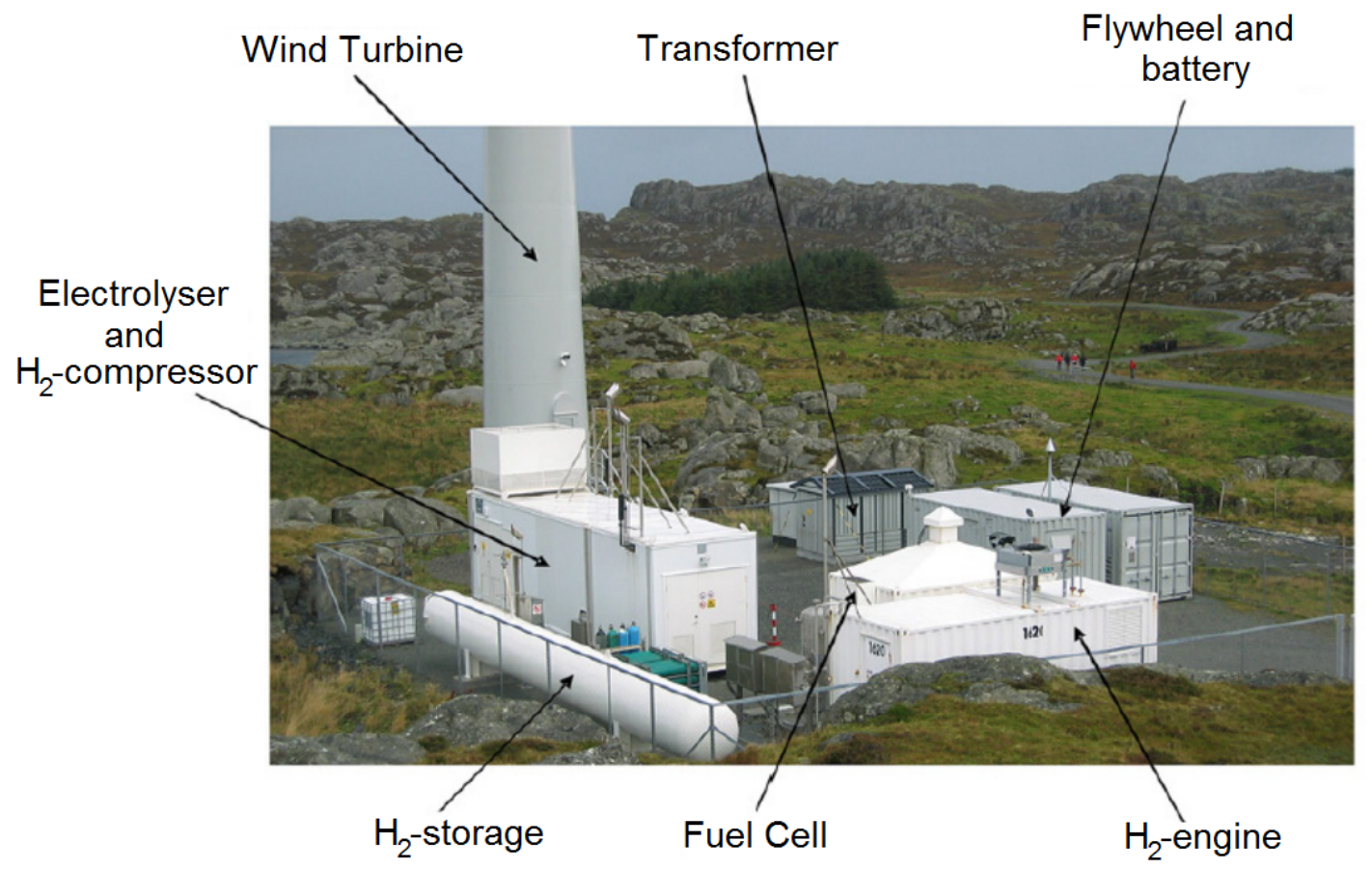

Figure 2.14: Hybrid wind and hydrogen plant [45].

The plant consists of two Enercon E40 wind turbines (600 kW each). To stabilise the intermittent generation of the wind power, a flywheel with a $5 \mathrm{kWh}$ capacity is installed to smoothen the generation output. The hydrogen is produced with an electrolyser, whose peak power consumption is $48 \mathrm{~kW}$. The hydrogen gas is then compressed with a $5 \mathrm{~kW}$ Hofer compressor and stores the hydrogen in a $2400 \mathrm{Nm}^{3}$ (normal cubic metres) at 200 bar pressure [45].

In 2007 a similar pilot project was started in Ramea, Newfoundland, Canada, for the storing access wind generation using hydrogen technology. The project costs the Canadian Federal Government about 4.7 million Canadian dollars [46].

\subsubsection{3 compressed air energy storage (CAES)}

Energy is stored in the form of compressed air. The compressed air can be stored in underground caverns or above ground in high pressure vessels. Natural gas found in underground aquifers have been stored for millions of years. These aquifers are highly recommended as they have a proven record of storing large amount of gas for many years [47]. Figure 2.15 [48] illustrates the basic setup of a CAES plant. 


\subsection{Enabling higher renewable energy penetration}

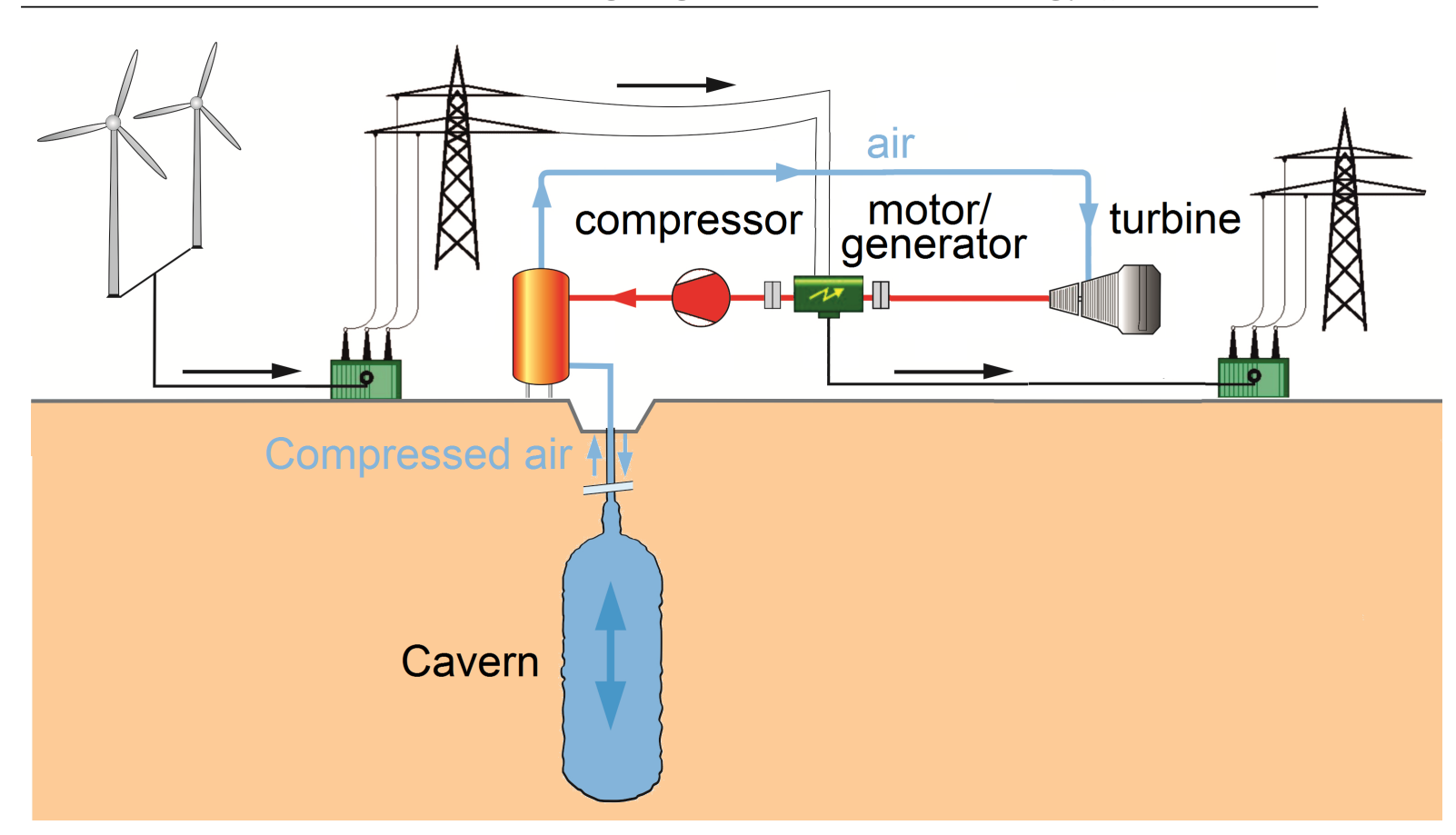

Figure 2.15: Compressed Air Energy Storage plant [48].

A compressor compresses air and stores it in an air reservoir. When additional power is needed in the power system, the compressed air is released in a combustion chamber, mixed with fuel and ignited to produce a rapid expansion of hot air to drive a turbine that turns a generator [35].

CAES consists of a motor which drives a compressor, during off-peak periods. The compressor compresses and stores the compressed air at high pressure (up to $10 \mathrm{MPa}$ ) in an underground cavern. When additional generation is needed in the power system the compressed air from the underground cavern is extracted, heated and mixed with fuel to combust and drive a turbine, which turns the rotor shaft of a generator [49].

There are only two commercial CAES plants operating in the world. The first CAES plant is in Huntorf, Germany and is operational since 1978. The cavern for storing the compressed air has a volume of about $310000 \mathrm{~m}^{3}$ and is about $600 \mathrm{~m}$ underground. The maximum rated pressure that can be provided by the $60 \mathrm{MW}$ compressors is $10 \mathrm{MPa}$ or a 100 bar, which is 98.69 times the pressure of the atmosphere at sea-level. The CAES plant normally operates between $50 \mathrm{MPa}$ and $70 \mathrm{MPa}$, and can output $290 \mathrm{MW}$ of power for 2 to 3 hours [40] [50].

The second CAES plant is in McIntosh, Alabama, USA and is commissioned since 1991. The cavern at this plant a has a volume of about $500000 \mathrm{~m}^{3}$ and is located about $450 \mathrm{~m}$ underground. The compressors can compress the air up to $7.5 \mathrm{MPa}$ or 75 bar, which is 


\subsection{Enabling higher renewable energy penetration}

74.02 Atm. The CAES plant is able to output $110 \mathrm{MW}$ for up to 26 hours [51] [52] [40].

The extensive shaft mining operations in South Africa results in plenty of abandoned large underground excavations, which could be a possibility for CAES. However, these man-made underground caverns where not constructed with high pressure air storage in mind and to utilise these unproven caverns is high risk. Therefore extensive research, planning testing needs to be done to consider CAES in the mines' after-life [47] [53].

CAES have the ability to store energy for long periods (over a year) of time. They have significant large power outputs, which can range around 50 to $300 \mathrm{MW}$. The CAES plants operate with high efficiency, which is in the typical range of $70-89 \%$ and the plants are designed for frequent cycles and high cycle tolerance [40].

\subsubsection{4 super-capacitors}

Conventional capacitors have very low energy storage capacity, thus very few research work exists on their application for power system scale energy storage is done. However, with the introduction of super-capacitors a new type of storage element opens the road to new research. Super-capacitors, which are also known as ultra-capacitors or electric double layer capacitors (EDLC), have long life cycle and due to its high power density is suitable for short discharge applications [35].

Super-capacitors are in many ways like conventional capacitors, such as the capacitance is still determined by the effective area of the parallel plates, the distance between the plates and the dielectric medium between the plates. The differences for the super-capacitor is firstly the use of porous electrodes, which significantly increases the surface area of the plates compared to the conventional plate structure. The second key difference is that the electrolyte between the plates creates an electrical double layer of separated charges. These differences greatly enhance the capacitance compared to conventional capacitors [54] [40] [55]. The downside of super-capacitors is it can only provide high power output for very short durations like flywheels.

Super-capacitors have higher energy density than conventional capacitors, and they have higher power density than batteries. Super-capacitors are currently used in un interruptible power supply (UPS) systems, motor drives and smoothing of intermittent renewable generation feed-in [54]. 


\subsection{Enabling higher renewable energy penetration}

\subsubsection{5 battery storage}

Batteries can be considered to complement the power generation considering the integration of variable RES. There are several types of batteries, lead acid, nickel-based, lithium-ion, sodium-sulphur and metal air. They provide rapid charge and discharge responses, however, the discharge rate is limited by the chemical response rate [35].

Lead-acid (Pb-A) batteries are commercially mature and they are re-chargeable. Leadacid batteries consists of lead metal and lead dioxide electrodes sub-merged in a sulphuric acid electrolyte. Over $100 \mathrm{MW}$ of battery capacity is installed in the United Kingdom (UK) power system [56]. The largest lead-acid battery is located in Chino, California, which has a $40 \mathrm{MWh}$ storage capacity and is rated for $10 \mathrm{MW}$ power output for 4 hours. The disadvantages of using lead-acid batteries includes, low cycling capacity, long charging time and careful maintenance.

Nickel Cadmium (Ni-Cd) is an old standard battery technology. These batteries are heavy and struggles with the memory effect. The memory effect is when a battery, which hasn't been completely discharged, remembers the old charge state when the battery is recharged. This means the full capacity of the battery is not utilised.

Nickel Metal Hydride (Ni-MH) is the cadmium free replacement for Ni-Cd. Ni-MH is less prone to the memory effect, requires less maintenance and has approximately twice the energy capacity than Ni-Cd. This means also that Ni-MH weighs less than Ni-Cd. However, Ni-MH has a reduced temperature operating range compared to Ni-Cd.

Lithium Ion (Li-ion) is the new standard battery technology for portable devices. Li-ion has about the same amount of energy storage capacity as Ni-MH, however, Li-ion weighs about $20 \%$ to $30 \%$ less. Another advantage of using Li-ion is the it does not suffer from the memory effect. The drawback from using Li-ion is the fact that is very easily ignites, which can make it very dangerous.

In December 2017, a year after the South Australia blackout, the electric car company, Tesla, completed the installation of the world's largest lithium ion battery in South Australia [57]. Figure 2.16 [58] shows a photo of the battery. The battery has a power rating of $100 \mathrm{MW}$ and $129 \mathrm{MWh}$ storage capacity. The battery is charged at Hornsdale Wind Farm near Jamestown, South Australia [59]. 


\subsection{Enabling higher renewable energy penetration}

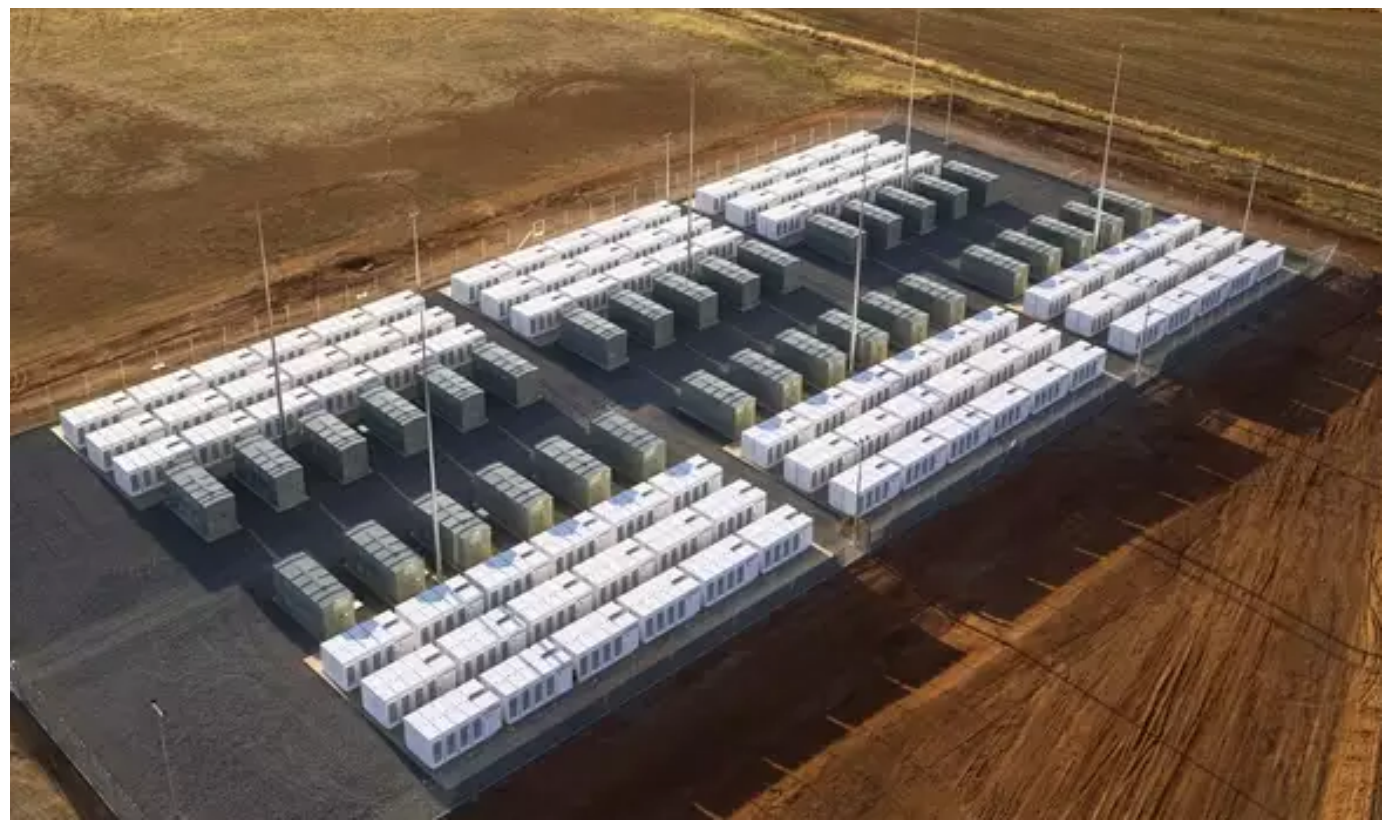

Figure 2.16: Tesla battery in South Australia [58].

Comparing $\mathrm{Pb}-\mathrm{A}, \mathrm{Ni}-\mathrm{Cd}, \mathrm{Ni}-\mathrm{MH}$ and Li-ion battery technologies, Li-ion is on top in terms of efficiency, which is in the range of $75 \%$ to $90 \%$. Li-ion also has the highest charge/discharge cycling ability (approx. 3000) with $80 \%$ depth of discharge (D.O.D), and has an high energy density in the range of $90-190 \mathrm{Wh} / \mathrm{kg}$.

\subsubsection{6 pumped hydro-electric storage (PHS)}

Pumped Hydro-electric Storage (PHS) is currently the most available form of bulk energy storage. The main elements of a PHS system consists of two reservoirs, pump, governor valve, turbine and generator. Figure 2.17 illustrates the basic setup of a PHS plant.

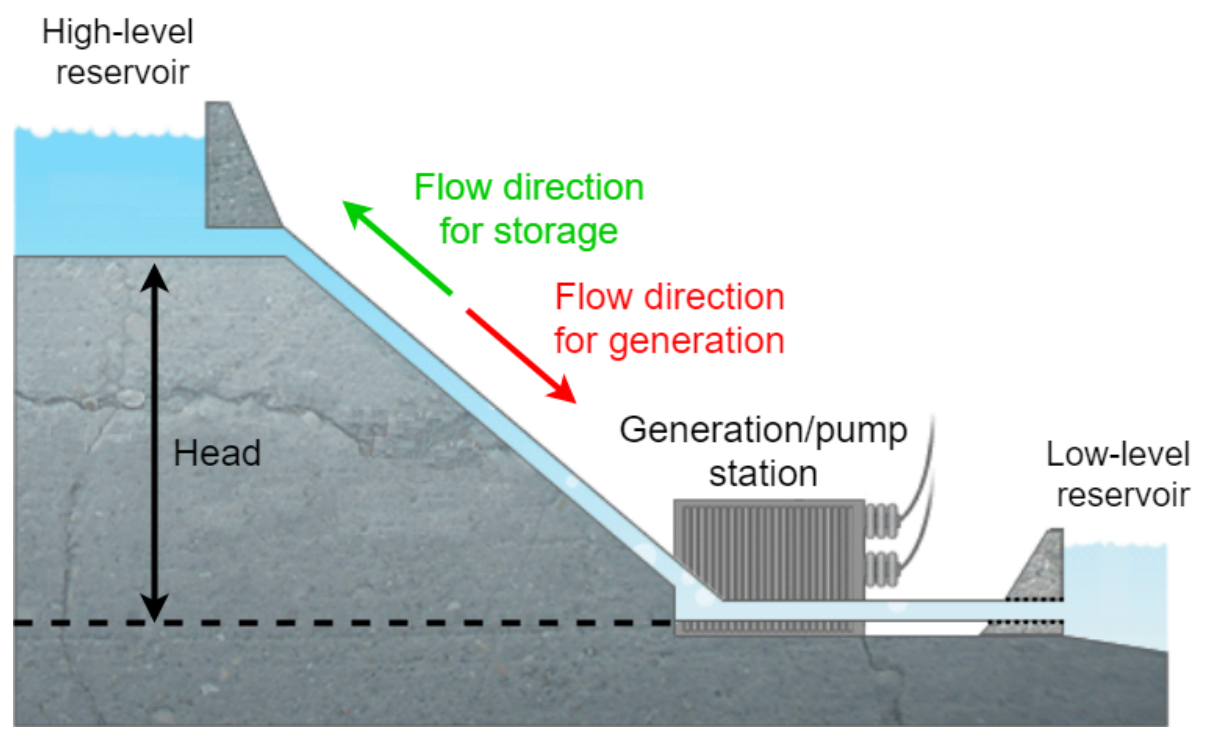

Figure 2.17: Pumped hydro-electric storage plant. 


\subsection{Conclusion}

The two reservoirs consist of an upper and a lower reservoir. The pump transfers water from the lower to the higher reservoir during times of surplus generation in the power system or during load off-peak periods, thus store electricity in the form of gravitational potential energy [60] [61].

When generation is needed from the PHS system it operates the same as an hydro-electric power plant, i.e. flowing water turns a turbine which drives the rotor of a generator and thus, produces electricity. The round trip conversion starts with electrical energy converted to kinetic energy, and then stored as gravitational potential energy. When the PHS generates electricity the opposite is true, with the gravitational potential energy changing to kinetic energy, which is then used to generate electrical energy. The available power that can be harvested with the turbine depends on the water flow-rate and head, where head is the elevation between the upper and lower reservoirs. By increasing the head the flow-rate can be reduced for the same amount of power, and vice versa [40] [44].

The advantages of using PHS is that it has high energy and power capacity. The round trip efficiency is between $70 \%$ and $85 \%$. The disadvantages include, favorable geography is required for the two reservoirs and the local environment is impacted due to the removal of trees and natural habitats for the reservoir build and fill-up. Depending on the size of the project the project may have high construction costs and long construction times.

\subsection{Conclusion}

Variable RES integration is increasing with an accelerating rate. Most of the arising technical challenges are related in one way or another to the intermittent nature of RES generation. The variability inherent in renewable energy generation challenges the existing control structures. This places increased pressure on the current power system infrastructure, operating on the limit of the power system's flexibility, and introduces increased variability into the system. The grid code compliance for RES does not require RES plants to participate in system flexibility and stability, however, to accommodate the increase in RES integration it is important for RES to provide the services, which were traditionally and currently provided by conventional synchronous generator power plants.

The possibilities for safe RES integration includes, wide-spread distribution of RES power plants in order to benefit from the aggregation effect, which reduces variability in generation, APC and energy storage implementation for system control and flexibility. It must be noted that for the successful integration of variable RES it is not only necessary 


\subsection{Conclusion}

for long-term energy storage, but also fast acting short-term energy storage to maintain system stability. The benefits of using energy storage in the power system includes:

- Assists the integration of RES.

- Allows existing generation to operate at their optimal level, by providing or absorbing the deficit or excess generation.

- Decreases the dependency on inefficient and "dirty" energy generation.

- Energy storage creates a buffer for generation/load imbalance, thus increases the power system's flexibility and stability.

Power systems have to focus for the first time on sources which must provide artificial or virtual inertia, which requires fast acting energy storage. However, there is a lack of knowledge about virtual inertia operation and optimal deployment. The work in this study attempts to find control methods in which renewable energy sources provide their share in stabilising the power system frequency by contributing to the system inertia, as will be discussed in the next chapter. 


\section{Chapter 3}

\section{Virtual Inertia Implementation}

\subsection{Inertia}

The moment of inertia $(\mathrm{J})$ is a measure of resistance of a body to angular acceleration. The moment of inertia of a body, in this case the rotor mass of the synchronous machine, is defined as the integral of all the elements of mass about an axis [62]:

$$
J=\int_{m} r^{2} d m
$$

With the radius from the axis to the incremental mass denoted by, $r$ in metre $[\mathrm{m}]$, and $m$ denoting mass. Due to the square of $r$ the moment of inertia is always positive with SI units $\left[\mathrm{kg} \cdot \mathrm{m}^{2}\right]$.

Inertia is the property of the power system, which lets the system resist change in frequency. The inertia is provided freely from the synchronous machines connected to the power system due to the strong coupling between mechanical and electrical dynamics. The amount of system inertia was always assumed to be constant and sufficient, but as discussed in this chapter it will be shown that this assumption is no longer valid [14] [2].

\subsection{Synchronous machine inertia}

Large and heavy synchronous generators intrinsically provide inertial response due to their heavy rotating mass. The dynamics of the synchronous generator during the inertial response is mathematically described by the swing equation (3.2), see appendix A for the derivation [63]:

$$
\frac{2 H}{\omega_{\text {syn }}} \omega_{p . u .}(t) \frac{d^{2} \delta}{d t^{2}}+\frac{D}{\omega_{\text {syn }}} \frac{d \delta}{d t}=P_{m[p . u .]}(t)-P_{e[p . u .]}(t)
$$

Where, 


\subsection{Synchronous machine inertia}

- $H$ : inertia constant $[\mathrm{s}]$, which is a measure of how long (in seconds) the generator can provide nominal power using only the angular momentum or inertia.

- $\omega_{\text {syn }}:$ synchronous rotating frequency $[\mathrm{rad} / \mathrm{s}]$.

- $\delta$ : angular position relative to the synchronously rotating reference frame [rad].

- $D$ : damping coefficient.

- $P_{m[p . u .]}(t)$ : mechanical power [per unit].

- $P_{e[p . u .]}(t)$ : electrical power [per unit].

Modeling the inertia constant $H$, starts with calculating the kinetic energy stored in the rotating mass.

$$
E_{K . E .}=\frac{1}{2} \cdot J \cdot \omega_{m}^{2}
$$

Where,

- $E_{K . E .}:$ kinetic energy in the rotating mass of the generator rotor in $[\mathrm{J}]$ (Joule).

- $J$ : moment of inertia of generator rotor, measured in $\left[\mathrm{kg} \cdot \mathrm{m}^{2}\right]$.

- $\omega_{m}$ : rotating frequency of the rotor in radians per second $[\mathrm{rad} / \mathrm{s}]$.

The inertia constant $H$ is defined as follow:

$$
H=\frac{E_{K . E .}}{S_{\text {rated }}}=\frac{J \cdot \omega_{m}^{2}}{2 \cdot S_{\text {rated }}}
$$

Where $S_{\text {rated }}$ is the rated power [VA] of the generator.

The swing equation can also be written in standard form:

$$
M \frac{d}{d t} \omega(t)+D \cdot \omega(t)=P_{m}(t)-P_{e}(t) \quad ; \omega(t)=\frac{d}{d t} \delta(t)
$$

Where,

- $M$ : inertia constant with units megawatt-seconds-squared $\left[\mathrm{MW} \cdot \mathrm{s}^{2}\right]$.

- $D$ : damping coefficient with units megawatt per Hertz $[\mathrm{MW} / \mathrm{Hz}]$ or $[\mathrm{MW} \cdot \mathrm{s}]$.

- $\delta$ : angular position relative to the synchronously rotating reference frame measured in radians $[\mathrm{rad}]$.

- $\omega(t)$ : the synchronous machine's rotor speed in radians per second [rad/s].

- $P_{m}(t)$ : mechanical input power from the prime mover measured in megawatt [MW].

- $P_{e}(t)$ : electrical power output measured in megawatt [MW]. 


\subsection{Synchronous machine inertia}

\subsubsection{Kinetic energy}

From equation (3.5) it can be seen that when generation and load are in balance the right side of the equation equals zero. This means that the frequency deviation, $\omega(t)$, and the rate of frequency deviation, $\frac{d}{d t} \omega(t)$ must equal zero for the equation to be true. When the right side of the equation is not equal to zero, then the generation and load is in imbalance. As the frequency changes and deviates accordingly, the inertia and damping must temporarily provide the power to minimise the power imbalance and thereby also the frequency excursion.

The kinetic energy available from a rotating mass at any given time is described by equation (3.3). The kinetic energy from a synchronous generator can alternatively also be calculated as follow:

$$
E_{K . E .}=H \cdot S_{\text {rated }} \cdot p f
$$

where pf is the power factor. Table 3.1 lists a few power stations in the South African power system with their individual total kinetic energy available for inertial response at normal steady-state operation.

Table 3.1: List of a few power stations and their total kinetic energy at normal operation.

\begin{tabular}{|l|ccccc|}
\hline Power Station & $\begin{array}{c}\text { Generator } \\
{[\mathrm{MVA}]}\end{array}$ & $\begin{array}{c}\text { Generator H } \\
{[\mathrm{s}]}\end{array}$ & $\begin{array}{c}\text { Power } \\
\text { Factor }\end{array}$ & $\begin{array}{c}\text { Number of } \\
\text { Generators }\end{array}$ & $\begin{array}{c}\text { Total Kinetic } \\
\text { Energy [GJ] }\end{array}$ \\
\hline Koeberg & 1072 & 5.61 & 0.9 & 2 & $\mathbf{1 0 . 8 2 5}$ \\
Duvha & 666 & 3.96 & 0.9 & 6 & $\mathbf{1 4 . 2 4 2}$ \\
Kendal & 810 & 3.02 & 0.9 & 6 & $\mathbf{1 3 . 2 0 9}$ \\
Hendrina & 222 & 4.06 & 0.85 & 10 & $\mathbf{7 . 6 6 1}$ \\
Kriel & 555 & 4 & 0.9 & 6 & $\mathbf{1 1 . 9 8 8}$ \\
\hline
\end{tabular}

When the system frequency changes due to a power imbalance, and the system frequency increases, then the rotating mass will speed up and gain more kinetic energy. When the system frequency decreases, the generator will convert its kinetic energy for additional electrical power in order to reduce the imbalance of the generation and load, as well as minimising the frequency dynamics.

\subsubsection{Inertia constant}

The inertial response that can be harvested from the rotor's kinetic energy is obtained by taking the time derivative of equation (3.3) as follow:

$$
P_{\text {inertial }}=\frac{d}{d t} E_{K . E .}=J \omega_{m} \frac{d \omega_{m}}{d t}
$$




\subsection{Synchronous machine inertia}

The term $J \omega_{m}$ is in literature also called the inertia constant but is not normalised to the generators rated power and is denoted by $M$. The power obtained from the inertia is denoted by $P_{\text {inertial }}$. The relationship between the two inertia constants $H$ and $M$ are as follow:

$$
H=\frac{M \cdot \omega_{m}}{2 \cdot S_{\text {rated }}}
$$

The units of $H$ and $M$ are, seconds [s] and Watt-seconds-squared [W. $\left.\mathrm{s}^{2}\right]$ respectively.

\subsubsection{Different levels of inertia}

Figure 3.1 demonstrates the effect of different levels of inertia on the frequency dynamics during a low-frequency event.

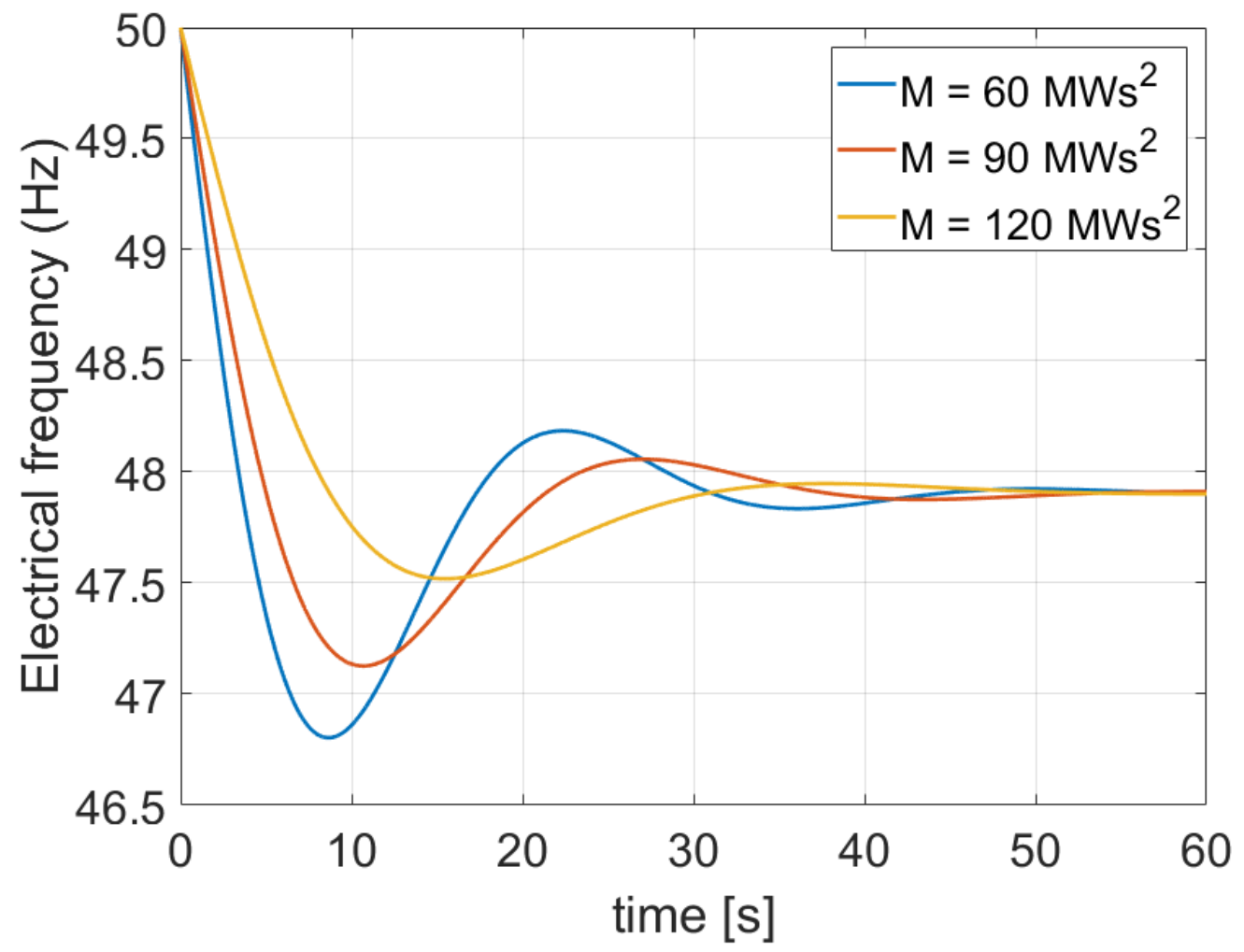

Figure 3.1: Frequency response for different system inertia levels.

Figure 3.1 shows that frequency response generally improves with increase in system inertia. The initial RoCoF magnitude increases for a decrease in inertia, and the RoCoF magnitude decreases with an increase in inertia. The frequency nadir shifts back in time, with an increase in inertia, thus delaying the point when the frequency deviation is at its maximum from the nominal value. Delaying the frequency nadir is beneficial as this provides more time for primary frequency control and other auxiliary services to activate 


\subsection{Synchronous machine inertia}

and reach full deployment, which increases the frequency nadir point, and stabilises the frequency closer to the nominal value.

\subsubsection{Variability of inertia}

Inverter-based RES generation, i.e. wind turbine and solar PV, do not provide any rotational inertia for the power system. High share penetration of these sources result in a power system with low levels of rotational inertia as these sources replaces synchronous generators, which has negative implications for frequency stability.

In the time from 1998 to 2012, the total German load demand, which was supplied with RES generation increased from $4.7 \%$ to $20 \%$. The majority share of RES generation comes from wind (8.3\%), PV (5\%), and hydro (3.9\%). Figure 3.2 presents a histogram of inverter-based power injection in the German power system, as a share percentage of the generation mix, for the year 2012 [14].

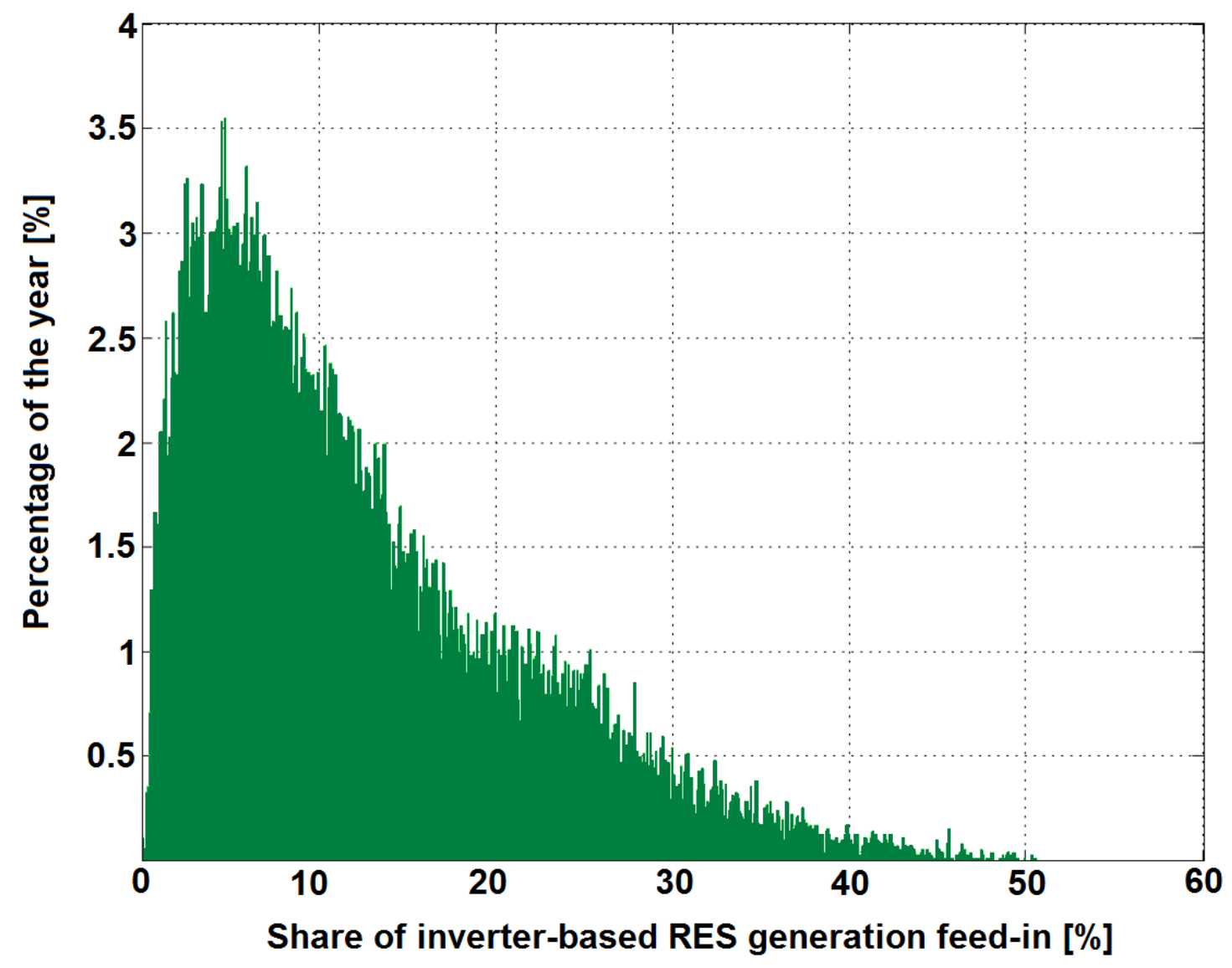

Figure 3.2: Germany's inverter feed-in for 2012 [14].

The histogram in figure 3.2 shows that inverter-based power generation reached a maximum of $50 \%$ of the load in Germany, during 2012. The data from [14] shows that the inverter feed-in contributed $30 \%$ and more to the consumed generation for 495 hours in 


\subsection{Synchronous machine inertia}

that year (5.6\% of the time), $40 \%$ and more of the consumed generation for 221 hours (2.5\% of the time), and $50 \%$ for 45 minutes in the year. With an increase in RES generation capacity, the amount of time which inverter-based generation contributes a large share or dominates the generation mix feed-in also increases.

The inertia in Germany plummeted to significant low levels due to wind and PV displacing conventional generation, which uses synchronous machines generators. With an increase in RES penetration, the amount of time per year in which RES contributes significant or majority to the generation mix will also increase. This is problematic for frequency stability as the inverter-based generation feed-in is variable over time. The assumption of constant and sufficient system inertia across a multi-area network becomes invalid due to the variability in power feed-in and conventional generation dispatch. Equation (3.9) [14] shows how the aggregated inertia is calculated, and by taking into account the variability of synchronous generation dispatch, due to high penetration of inverter-based feed-in, the variability of the German power system's inertia is shown in figure 3.3 [14].

$$
H_{\text {agg }}=\frac{\sum_{i=1}^{n} H_{i} \cdot S_{\text {rated }, i}}{\sum_{i=1}^{n} S_{\text {rated }, i}}
$$

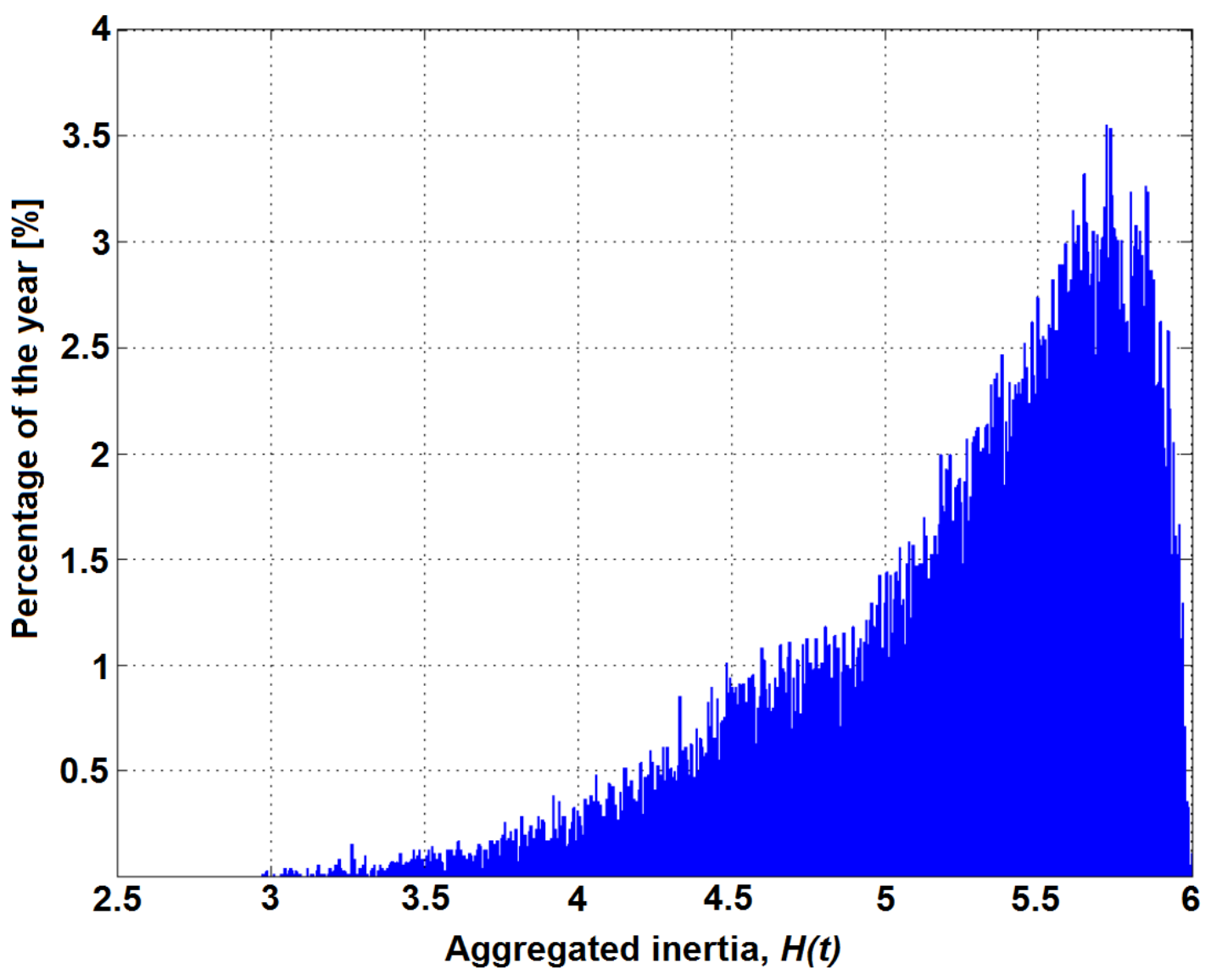

Figure 3.3: The aggregated regional inertia $\left(H_{\text {agg }}\right)$ for Germany in 2012 [14]. 


\subsection{Synchronous machine inertia}

The histogram in figure 3.3 shows how the German power systems inertia fluctuates from $\mathrm{H}=6$ seconds, when majority of the feed-in is from conventional generation, to $\mathrm{H}=3$ seconds when a significant share of inverter-based generation is utilised. The results from [14] shows that the aggregated inertia, $H_{\text {agg }}$, dropped below 4 seconds for $3.3 \%$ (293 hours) of the year. For 57 hours of the year $(0.65 \%)$ the system inertia was below 3.5 seconds. It can therefore be concluded that the variability of inverter-based generation introduces additional challenges for power system frequency stability. The increase in inverter-based generation capacity replaces large scale dispatchable and inertia providing generation. This significantly diminishes system stability control, and results in time-variant system inertia.

\subsubsection{Inertia placement}

Further investigation shows that not only is the amount of inertia important, but the location of the inertia sources has a significant effect on the frequency response. A threearea network system was simulated using a fixed amount of total system inertia, i.e. $M_{\text {total }}=90 \mathrm{MW} \cdot \mathrm{s}^{2}$, but with different distributions of inertia sources. The system was disturbed with a load step increase, to trigger a generation/load imbalance. Figure 3.4 shows a plot of the frequency deviation versus voltage angle differences. Equations (3.10 $\&$ 3.11) describes the voltage angle and frequency dynamics [14].

$$
\begin{gathered}
\dot{\delta}_{i}=\omega_{i} \\
\dot{\omega}_{i}=\frac{1}{M_{i}}\left[\Delta P_{i}-D_{i} \omega_{i}-\sum_{j=1 ; j \neq i}^{n} V_{i} V_{j} B_{i j} \sin \left(\delta_{i}-\delta_{j}\right)\right]
\end{gathered}
$$

Equation (3.10) describes the dynamics of the voltage angle $\left(\delta_{i}\right)$ at bus $i$. Equation (3.11) describes the frequency $\left(\omega_{i}\right)$ dynamics at bus $i$, with $M_{i}, \Delta P_{i}, D_{i}$, and $V_{i}$ representing the bus inertia, power imbalance, damping, and voltage at each bus respectively. The line susceptance between buses $i$ and $j$ is denoted by $B_{i j}$.

All trajectories in figure 3.4 start at the same coordinates $(0,0)$. The origin $(0,0)$ refers to the desired steady-state of the frequency and voltage differences between the areas during normal operation. For three different inertia allocation scenarios, identical disturbance inputs were used. The results show different voltage angle and frequency dynamics. Each trajectory ends with different new equilibrium points. To maintain power system stability, it is important that the trajectory is stable along the vertical axis. This means the frequency between areas should not experience significant deviation [14]. Swings in 
voltage angles will result in fluctuating power transfers, which is detrimental for power balance.

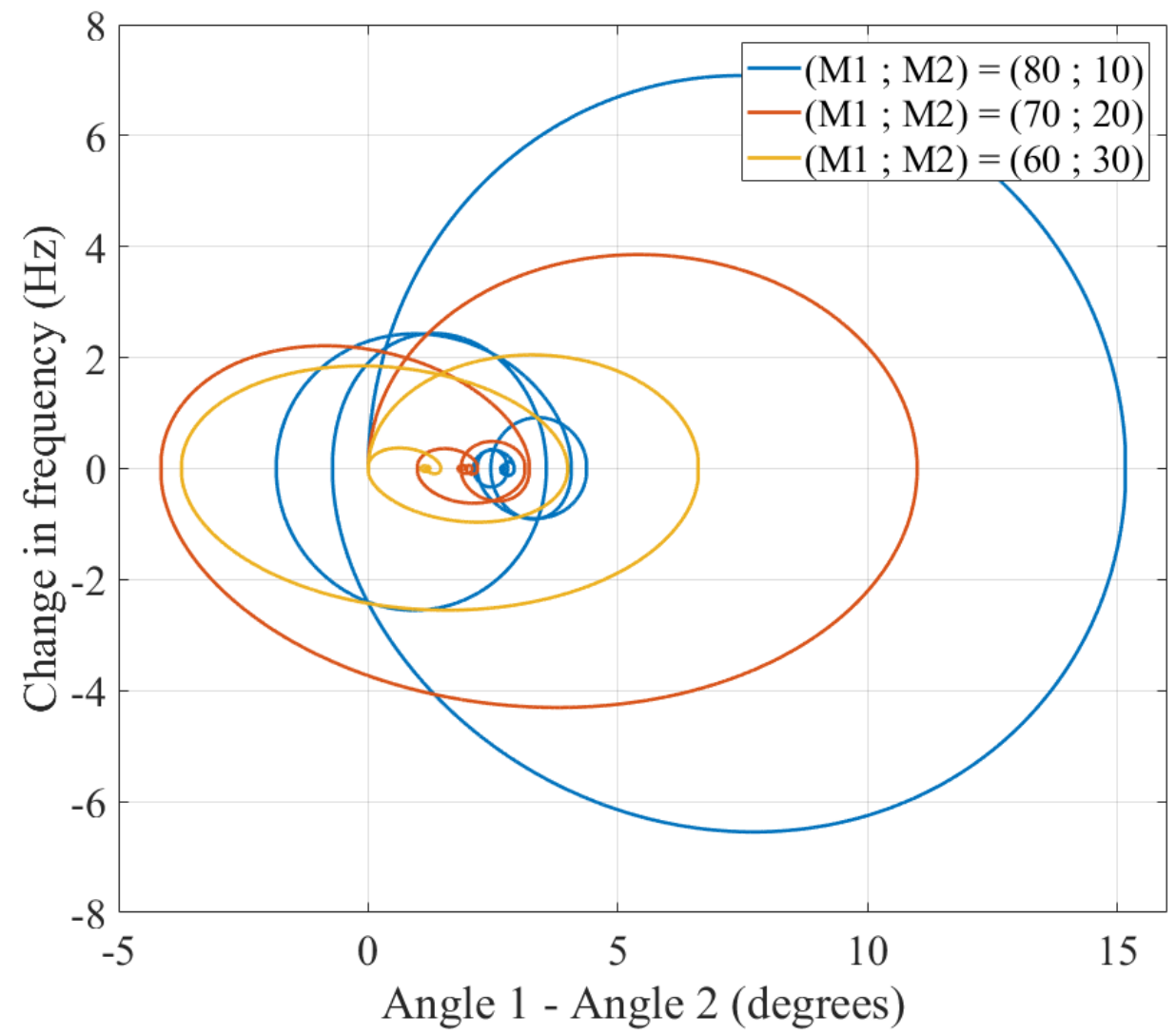

Figure 3.4: Plot of frequency vs voltage angle difference, for a three-area network.

The South African Grid Connection Code [16] requires RPP(s) to remain connected for a RoCoF up to $1.5 \mathrm{~Hz}$ per second. When the power system frequency is less than $47 \mathrm{~Hz}$ for longer than 200 milliseconds, the RPP is allowed to disconnect. This results in increased generation/load imbalance and thus, further driving the power system towards instability and ultimately to a system blackout.

In a network where inertia is in low quantity, there exists an optimal allocation for a multi-area network that results in maximum stability. It is therefore extremely important to practice inertia management and using it in an optimal manner to preserve system stability.

\subsection{Virtual inertia}

Inertia can be seen as the system's ability to resist change from its current state. Inertia prevents the power system frequency from suddenly changing by converting kinetic energy from the synchronous generator's rotating mass to electrical energy. This keeps the frequency stable when there is a sudden generation/load imbalance due to a system fault 


\subsection{Virtual inertia}

disturbance. The inertial response gives more time to for fast acting auxiliary services and generators to react and minimise the generation/load imbalance.

Historically wind and solar power generation have not been required to participate in frequency support and thus, were not considered in the design process. Solar PV and wind (types $3 \& 4$ ) are inverter-based generation, in other words, they interface with the power system through inverters. The inverters decouple the operational dynamics of the generating units from the rest of the power system and thus, does not naturally provide inertial response. This means that these sources does not contribute to the resistance to the change in frequency [8].

From the swing equation (3.2) it can be seen that during a frequency drop, the inertial response can be emulated by increasing the active power feed-in. The aim is to reduce the generation/load imbalance and thus, minimise the frequency dynamics, i.e. slowdown the response. Virtual inertia implementation can be divided into four methods to provide frequency support [30]:

1. Energy Storage System (ESS): Batteries are added together with a PV plant or wind farm. These batteries and/or capacitors can assist in quickly increasing the plant's power output and thus, contribute to slowing down the RoCoF and minimising the divination in frequency.

2. De-loading or curtailment of generating units: By de-loading a PV or wind farm, the generating units operate at a sub-optimal generation point. A power reserve is created, which is then used for frequency regulation and control.

3. Demand Side Management (DSM): By actively changing the load according to the generation output in order to mimic the response of frequency and voltage dependent loads, improves the frequency behavior after a generation/load imbalance disturbance. This does not emulate system inertia directly, but contributes to the positive effect of system inertia.

4. Utilising kinetic energy reserve: Extracting the kinetic energy from wind turbines by interchanging the kinetic energy of the turbine with the grid, for temporarily frequency support. This emulates the inertia response of synchronous generators.

Since virtual inertia is not real it does not have to represent the power plant's true inertia, but can be selected to be any value within reasonable means of the power plant. This means the RPP's inertia (artificial) can change by command and is not static like conventional power plant's inertia. With RPP's forming distributed generation, the system operator has the ability to control the inertia in different regions by adjusting the artificial or virtual inertia of each RPP. 


\subsection{Virtual inertia}

\subsubsection{Control schemes}

The authors of [64] presents three main topologies in which inverters can emulate the response of a synchronous generator to low frequency events. These topologies are: Synchronous Generator Model (SGM) based, Swing Equation (SE) based, and FrequencyPower Response (FPR) based topologies.

The SGM makes use of detailed model equations, of the synchronous machine, to operate the inverter and emulate the same dynamics of the synchronous generator. This topology can emulate the synchronous generator with very high fidelity, but this is at the expense of longer calculation time.

The SE topology approximates the control dynamics of the SGM by solving the swing equation every control cycle. Thus, the SE emulates the synchronous generator with less fidelity than the SGM, but is simpler to implement.

The FPR topology is the most intuitive approach. It provides dynamic inertial response based on the derivative of the measured system frequency. This method does not require detailed model equations describing the dynamics of a synchronous machine. The downside of FPR is that, because the control depends on the derivative of the frequency signal, the response is highly susceptible to system and measurement noise. Extensive signal filtering needs to smooth out the signal, but this can lead to extra delay in inertial response time.

\subsubsection{Wind Turbine Generator Virtual Inertia}

Although wind turbines possess large rotating masses (such as rotor blades and gears) the inertia from these wind turbines are decoupled due to the inverter interface. As the amount of wind power generation increases and contributes more to the generation mix, the power systems of the near future will require wind turbine generators to participate in frequency support and regulation. Before virtual inertia can be implanted WTG it is first necessary to understand the types of WTG interfaces.

\subsubsection{Types of wind turbine generators}

Wind turbine generation is divided into four types, which are categorised according to how they operate and interface with the power system network. The four types include, types $1,2,3$, and 4 [65]: 
- Type 1 consists of an induction generator with fixed rotor resistance, see figure 3.5.

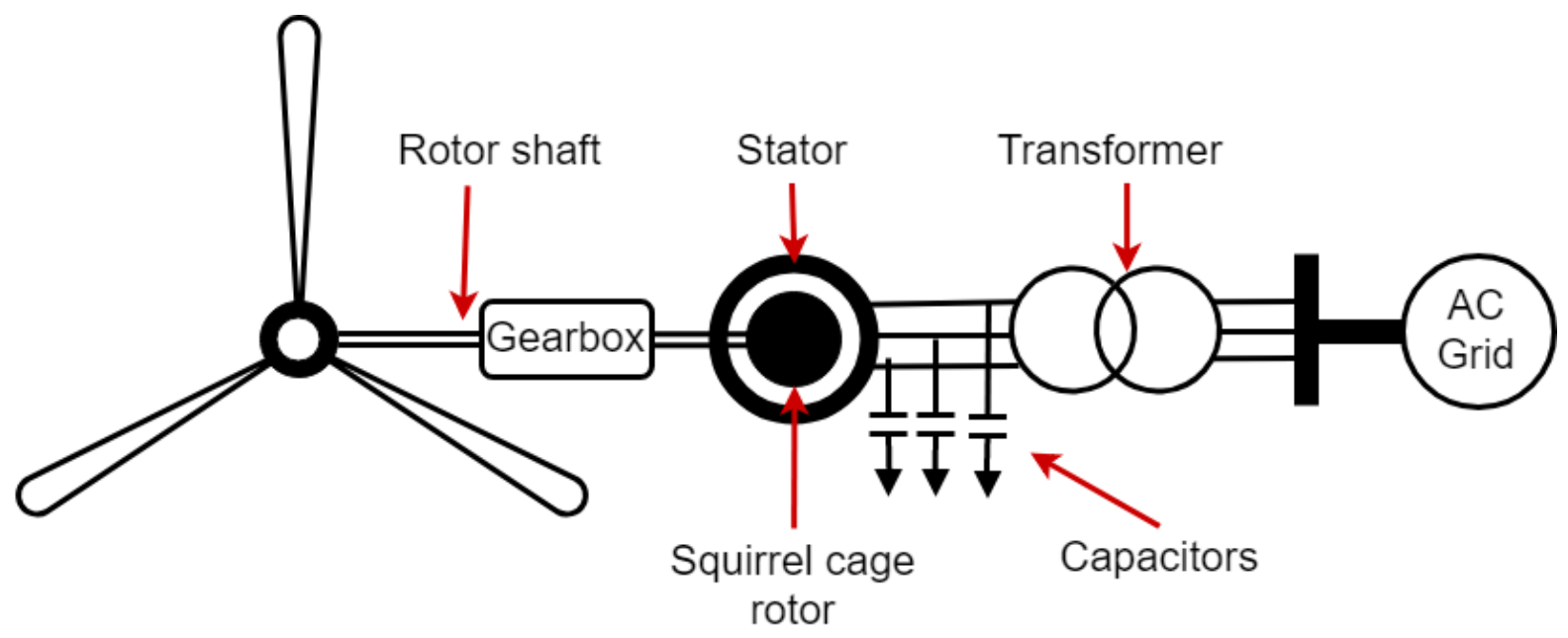

Figure 3.5: Type 1 wind turbine generator.

The stator windings are connected to the AC grid through a transformer. The rotor current is induced by relative motion between the resultant rotating magnetic field of the stator, and the rotor. This means that the rotor speed is determined by the AC grid. A gearbox matches the slow turbine rotor to the higher speed generator input shaft. The induction generator consumes reactive power for its operation and thus, a capacitor bank is connected to the stator terminals to provide the required reactive power.

- Type 2 is an extension of type 1, with variable rotor resistance as shown below in figure 3.6.

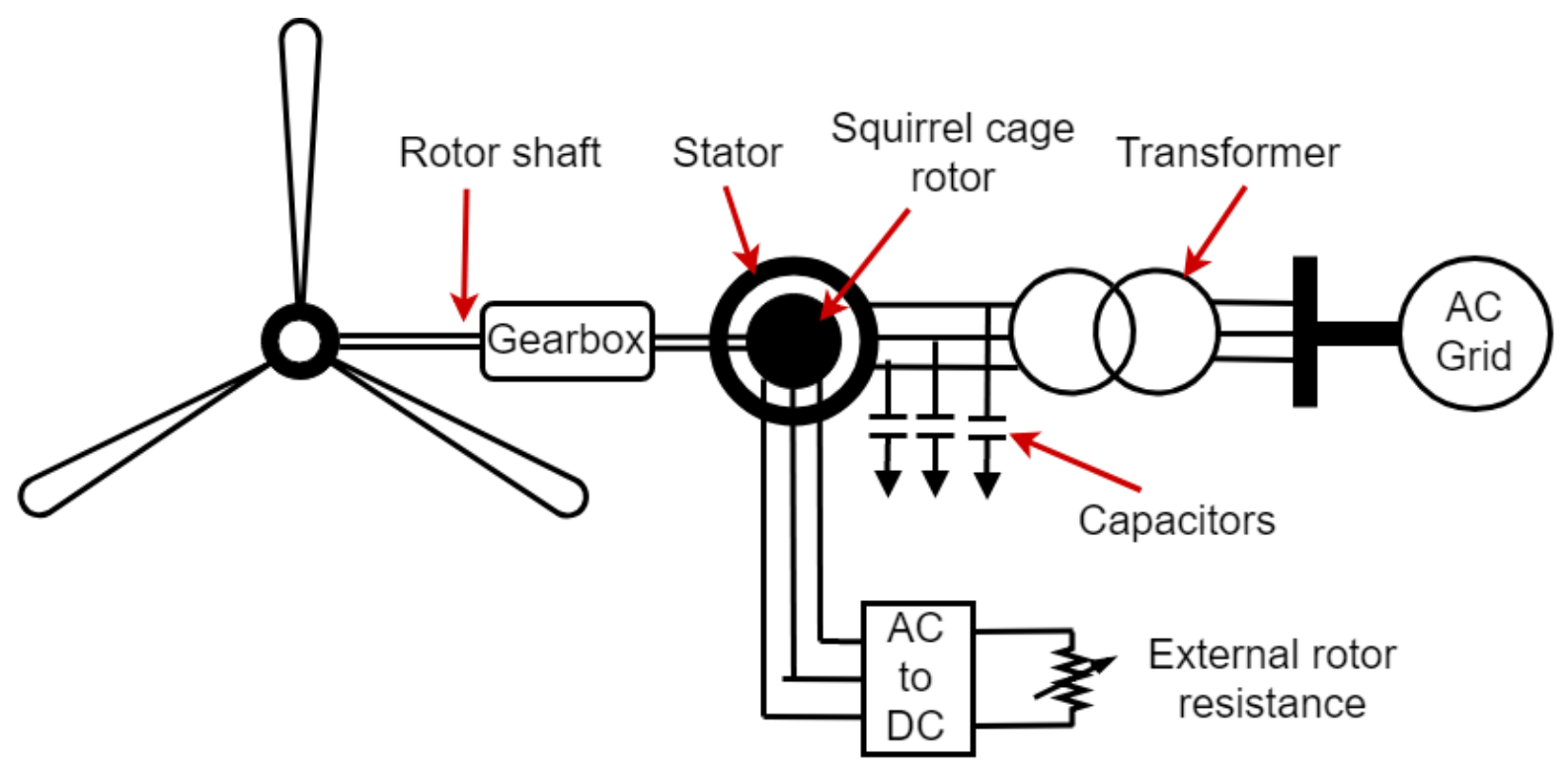

Figure 3.6: Type 2 wind turbine generator. 
This configuration makes it possible to control the rotor speed by varying the rotor resistance. Typical speed control is around 10\%, but results in energy loss in the form of heat in the external rotor resistor.

- Type 3 is a doubly-fed induction generator as shown below in figure 3.7.

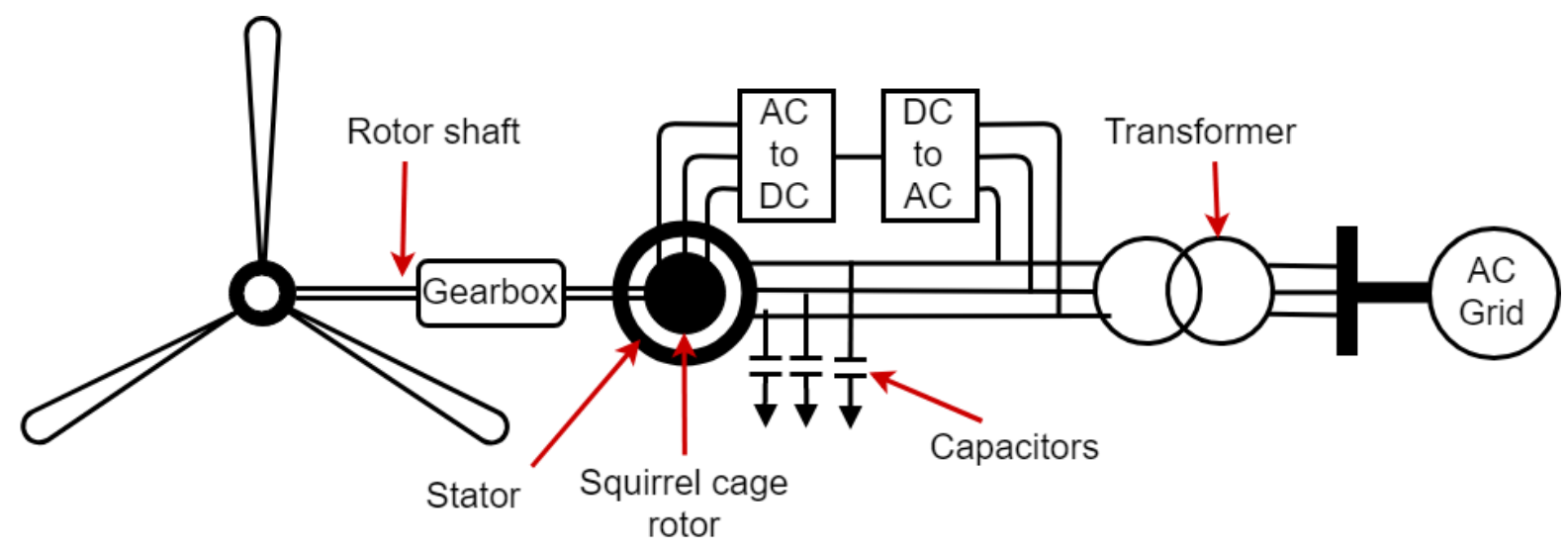

Figure 3.7: Type 3 wind turbine generator.

The type 3 wind turbine utilises the energy, which are lost in type 2. About $30 \%$ of of the power flows through the back-to-back converter. The back-to-back AC-DC-AC converter allows for wider range of rotor speed control, and is also used for reactive power control. This means that the capacitor bank is not essential.

- Type 4 is known as a full converter generator, see figure 3.8.

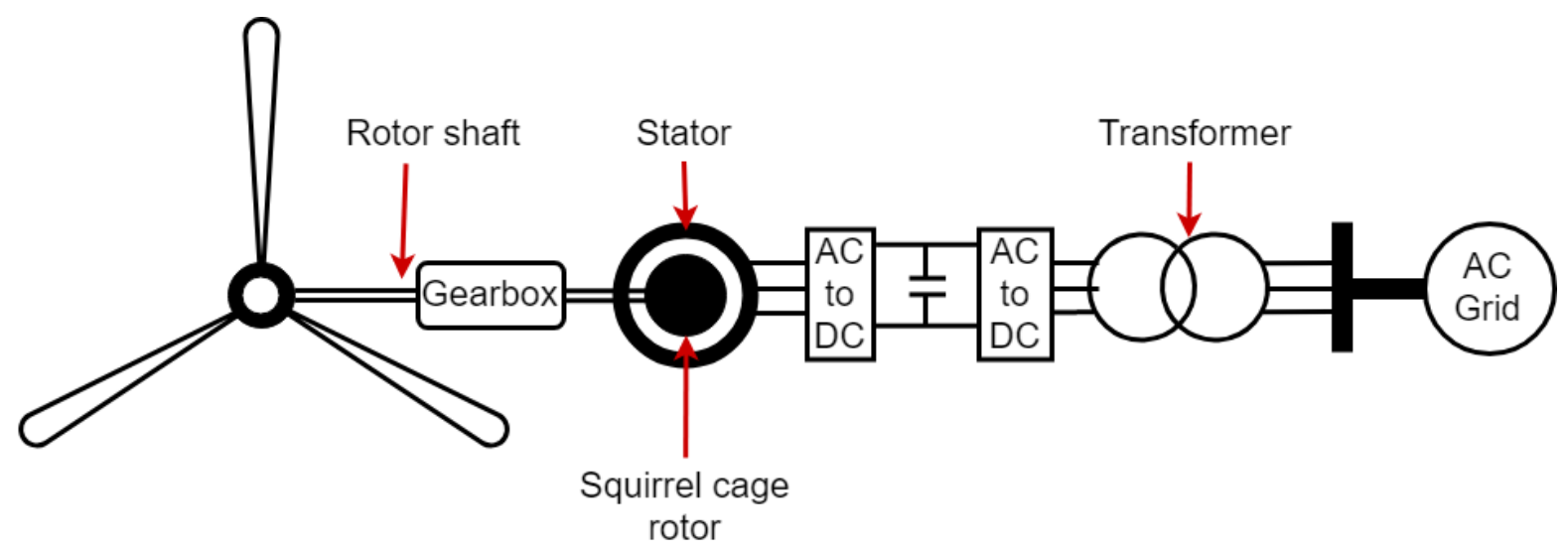

Figure 3.8: Type 4 wind turbine generator.

Type 4 is completely asynchronous. All the power flows through the AC-DC-AC converters, and thus, has to handle more power than the type 3 converters. The wind turbine's 
dynamics is completely decoupled from the power system network. The decoupling allows for considerable freedom in choice of generator type (e.g. synchronous or induction generator), and a wide speed range. Of the four types of WTG, types 3 and 4 lends themselves to possibly supply virtual inertia.

\subsubsection{Virtual inertia implementation}

To implement virtual inertia on wind turbine generators, it is first necessary to understand how the wind energy is harvested. The available power in the wind is calculated as follow [66]:

$$
P_{\text {wind }}=\frac{1}{2} \cdot \rho \cdot A_{\text {sweep }} \cdot v_{\text {wind }}^{3}
$$

Where the parameters, $\rho, A_{\text {sweep }}$, and $v_{\text {wind }}$ represents the, air density $\left[\mathrm{kg} / \mathrm{m}^{3}\right]$, rotor sweep area $\left[\mathrm{m}^{2}\right]$, and the wind speed $[\mathrm{m} / \mathrm{s}]$ respectively. However, only a fraction of the available wind energy can by extracted by the wind turbine, since $100 \%$ energy extraction would require the downwind side to be stationary, which is not practically possible. The fraction of wind energy being converted to kinetic energy is called the power coefficient, $C p(\beta, \lambda)$. The power coefficient has a theoretical upper limit equal to 0.593 , which is called the Betz limit. The power coefficient is dependent on the rotor blade pitch angle, $\beta$, and the tip-speed ratio (TSR), $\lambda$. The TSR is simply the ratio between the speed of the rotor tip and the incoming wind speed. The equation for calculating the TSR is as follow [66]:

$$
\lambda=\frac{\omega_{\text {rotor }} \cdot R_{\text {rotor }}}{v_{\text {wind }}}
$$

With, $\omega_{\text {rotor }}$, denoting the rotation speed of the rotor in $[\mathrm{rad} / \mathrm{s}]$, and the rotor length is denoted by, $R_{\text {rotor }}$, in [m]. The maximum power point tracker must vary the rotor speed in proportion to the wind speed, together with the blade pitch angle to find the maximum power coefficient. Incorporating the power coefficient into equation (3.12) the mechanical power driving the generator is calculated as follow [66]:

$$
P_{\text {mechanical }}=\frac{1}{2} \cdot C p(\beta, \lambda) \cdot \rho \cdot A_{\text {sweep }} \cdot v_{\text {wind }}^{3}
$$

To find the optimal blade pitch angle, the relationship between mechanical power, wind speed, and rotor speed, the optimal trajectory is depicted in the example of a power versus turbine speed, characteristic curve in figure 3.9 below:

Figure 3.9 shows that for a given wind speed there exists a rotor turbine speed which will produce the maximum mechanical power for the generator input. The rotor speed can be 
controlled from two separate actuation inputs. The first input is the adjustment of the rotor blade's pitch angle. This method control input is relative slow due to the mechanical time constants. The second actuation input comes from adjusting the generator's electrical torque applied on the mechanical input side. It is important to note that the generator's electrical dynamics are much faster than the mechanical dynamics i.e. time constant of blade pitch angle change. Refer to appendix B for further detail on WTG model and control.

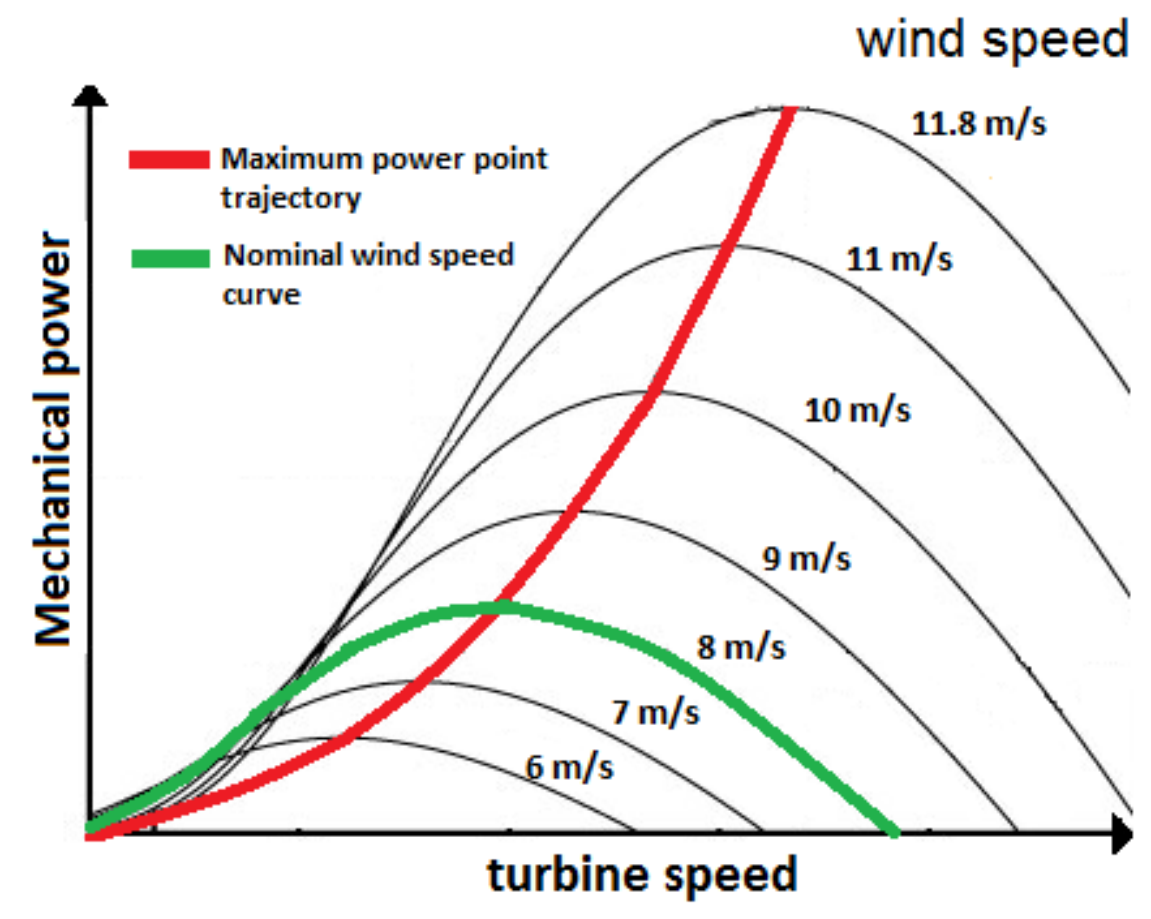

Figure 3.9: Wind turbine power curve.

Now that the basic operation of a wind turbine generator is understood, the methods for implementing virtual inertia are discussed. The most intuitive method to emulate the inertial response, is called "Kinetic Energy Control" (KEC). The KEC I method is the closest to emulating the inertial response of the synchronous generator, by quickly increasing the generator torque in response to negative RoCoF, resulting in the decline of the rotor speed. The decline in rotor speed is a result of the kinetic energy in the rotor being transfered to electrical energy. The downside to KEC I is that after the inertial response, a recovery period follows in which the wind turbine generator produces less power in order for the rotor to accelerate back to optimal speed. There is also a danger that the rotor speed drops to far (e.g. below cut-in speed), resulting in a shutdown of the wind turbine.

An alternative approach to KEC I is presented by [67] named, KEC II. The KEC II method works by first increasing the speed of the rotor before the generator applies extra 
torque to the turbine rotor. The benefit of KEC II over KEC I is that KEC II minimises the recovery period, since the rotor does not decelerate below normal operation for the course of kinetic energy extraction and thus, preventing turbine stall. However, the concern with KEC II is the delay in response. Due to the time it takes to accelerate the rotor to a higher speed, the magnitude of the RoCoF becomes more severe than with KEC I.

Another method for providing inertial response is to operate the wind turbine at a higher than optimal rotor speed to maintain a power reserve, thus the wind turbine generator operates in de-rated mode. During a low frequency event the controller increases the generator torque, which slows down the rotor to optimal rotational speed. The wind turbine can maintain the higher power point and so also provide primary frequency response, which is the same as for the governor of a synchronous generator.

\subsubsection{Simulation models}

The DigSilent PowerFactory (2017) simulation software was used for simulating the power systems and virtual inertia implementations. Within PowerFactory the DigSilent Simulation Language (DSL) was used to create the virtual inertia controllers, which were implemented on the type 3 and type 4 wind turbine generators. Figure 3.10 presents a top-layer view of the wind turbine generator with virtual inertia simulation model. Refer to appendix B for further detail on the WTG model setup and control.

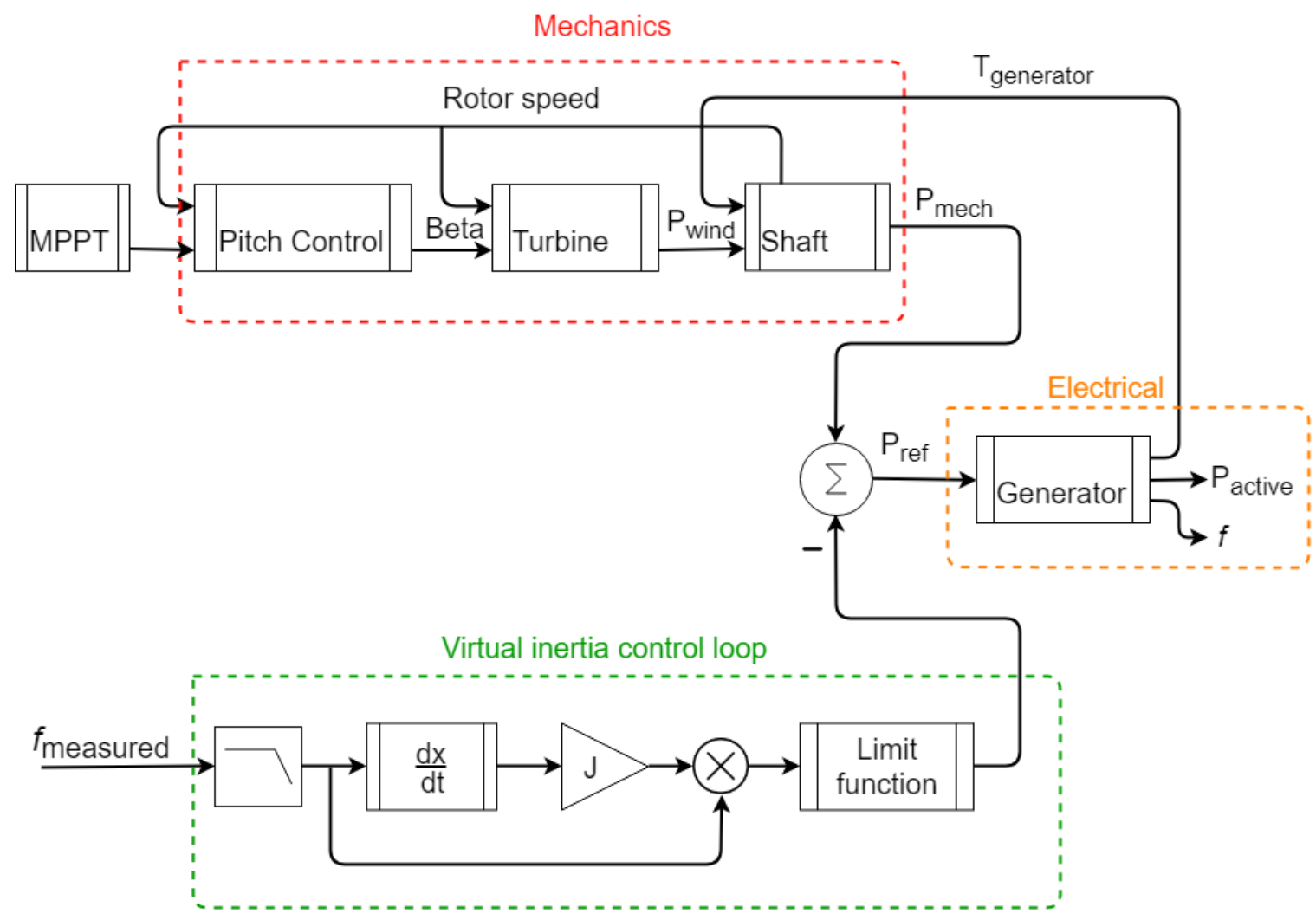

Figure 3.10: Wind turbine with virtual inertia model. 


\subsection{Virtual inertia}

The mechanics section of the model contains the blade angle pitch controller, turbine kinetic energy extraction model, and the shaft dynamics model. The pitch controller uses proportional plus integral control (PI-control) to regulate the turbine speed, by varying the rotor-blade's angel of attack to the varying wind speed, with the reference signal produced by the maximum power point tracker (MPPT). The speed of the pitch angle change is limited to $10 \mathrm{~m} / \mathrm{s}$, and operates between $0^{\circ}$ and $27^{\circ}$.

The turbine model uses equation (3.14) to calculate the mechanical power harvested from the wind, assuming constant wind speed. The shaft model simulates the drive-train by using the two-mass model. The shaft model block then outputs the mechanical power reference, which feeds into the generator input. The generator forms the electrical section. The generator model used, is the standard, Powerfactory 2017 DFIG model.

The virtual inertia control loop starts with the frequency measurement as input (note: convert $\mathrm{Hz}$ to $\mathrm{rad} / \mathrm{s}$ ). The measured signal is then passed through a low-pass filter. The derivative block calculates the RoCoF and multiplies it with the virtual inertia parameter, $J$. The product of the inertia and the frequency, $\omega$, is equal to the inertia constant, $M$. The limit block ensures that the virtual inertia applied is within reasonable values, since the derivative function can result in large output spikes.

\subsubsection{Simulation results}

Figure 3.11 presents the simulation result of the virtual inertia control when a WTG experiences a load step increase. The load step increase creates a negative generation/load imbalance, which causes a low frequency event, and thus, triggers the inertial response.

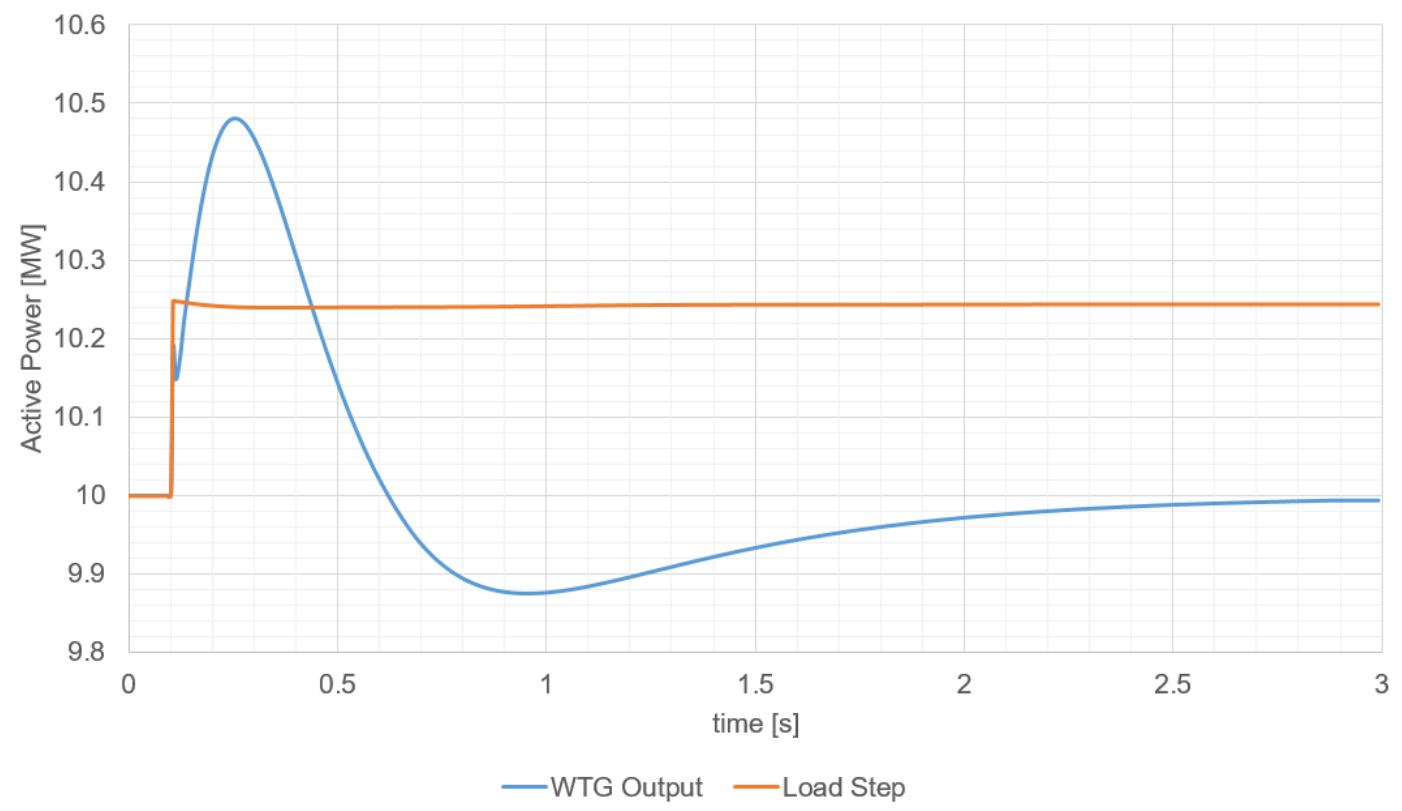

Figure 3.11: Wind turbine generator step response. 


\subsection{Virtual inertia}

The load step introduces an imbalance between generation and load demand. This results in a negative RoCoF, meaning that the frequency is decreasing, as described by the swing equation. The virtual inertia controller increases the active power reference at the rotorside inverter. This results in increased rotor current, thus increased active power output. The increase in current means increased counter torque on the rotor, which leads to the de-acceleration of the turbine rotor, as the simulation results indicate in figure 3.12.

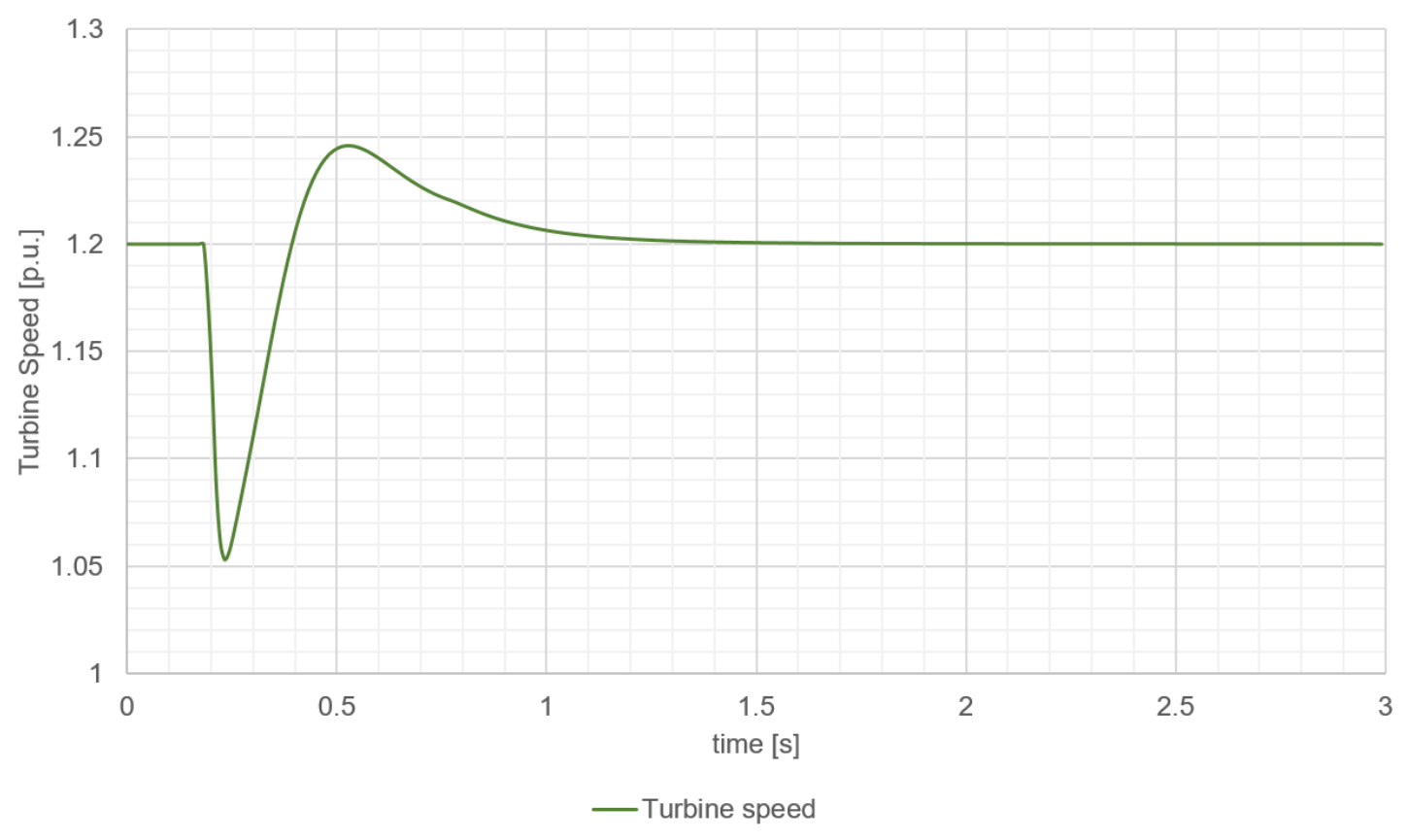

Figure 3.12: Wind turbine rotation speed.

Figure 3.12 shows how the turbine rotor speed changes as kinetic energy is being extracted, from the turbine rotor, for additional electric power generation. The decline in rotor speed corresponds with kinetic energy being converted to electrical energy, while the recovery period in figure 3.11 links with the increase in rotor speed. Thus, the additional power is provided by the rotor turbine's inertia.

Since the virtual inertia controller responds to the RoCoF, which is a derivative operation, signal filtering (low-pass) is required to smooth out the frequency signal. However, there is a trade-off between extensive filtering and the delay that is caused by the signal processing. Figure 3.13 compares different filter time constants by the frequency responses obtained by each. Analysing the results it is clear to see that, the larger the time-constant of the low-pass filter is, the slower the virtual inertia response time is. This highlight the fact that larger response delays leads to weaker inertial response, which ultimately results in worse frequency responses. 


\subsection{Virtual inertia}

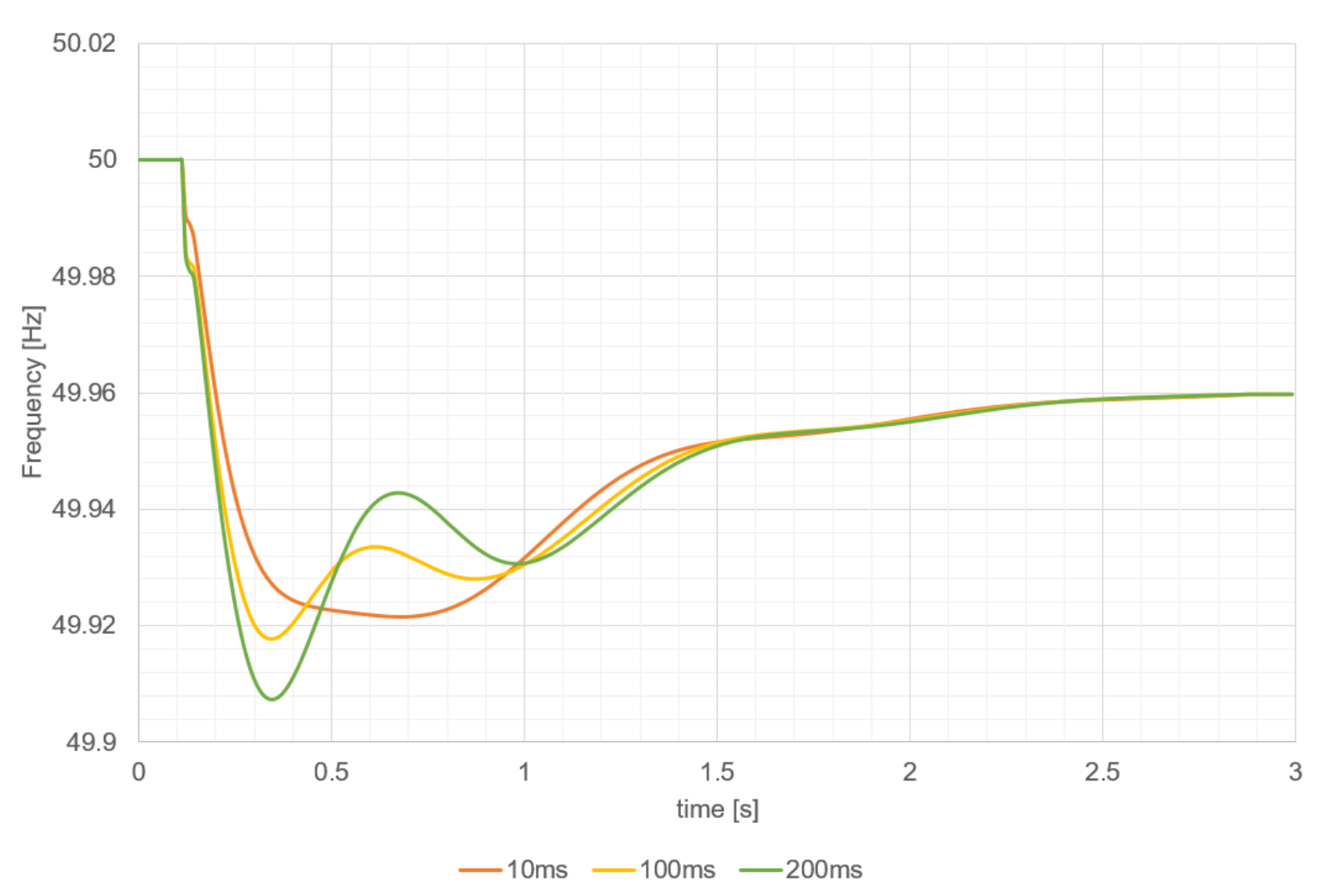

Figure 3.13: Frequency responses for virtual inertia using different filter time constants.

\subsubsection{Solar PV Virtual Inertia}

Historically solar PV generation were not required to participate in frequency regulation due to their small share in the generation mix [16]. However, with a future increase in $\mathrm{RPP}(\mathrm{s})$ in South Africa, which is especially favorable for solar PV installation, the need arises to place additional attention on frequency stability.

The South African Grid Connection Code (SAGCC) [16] does not require RPP(s) to participate in inertial response. However, the SAGCC requires renewable power plants of category C (20 MVA or higher), with the exception to solar PV plants, to maintain a 3\% power reserve for frequency regulation.

\subsubsection{Solar PV setup}

Figure 3.14 illustrates a typical solar PV setup. The PV modules are grouped together in strings. A Maximum Power Point Tracker (MPPT) controls the strings operating point (i.e. voltage and current), and uses an algorithm to find the point, which yields the maximum power that can be delivered, known as Maximum Power Point (MPP). This ensures that the solar panels operates at maximum efficiency. 
3.3 Virtual inertia

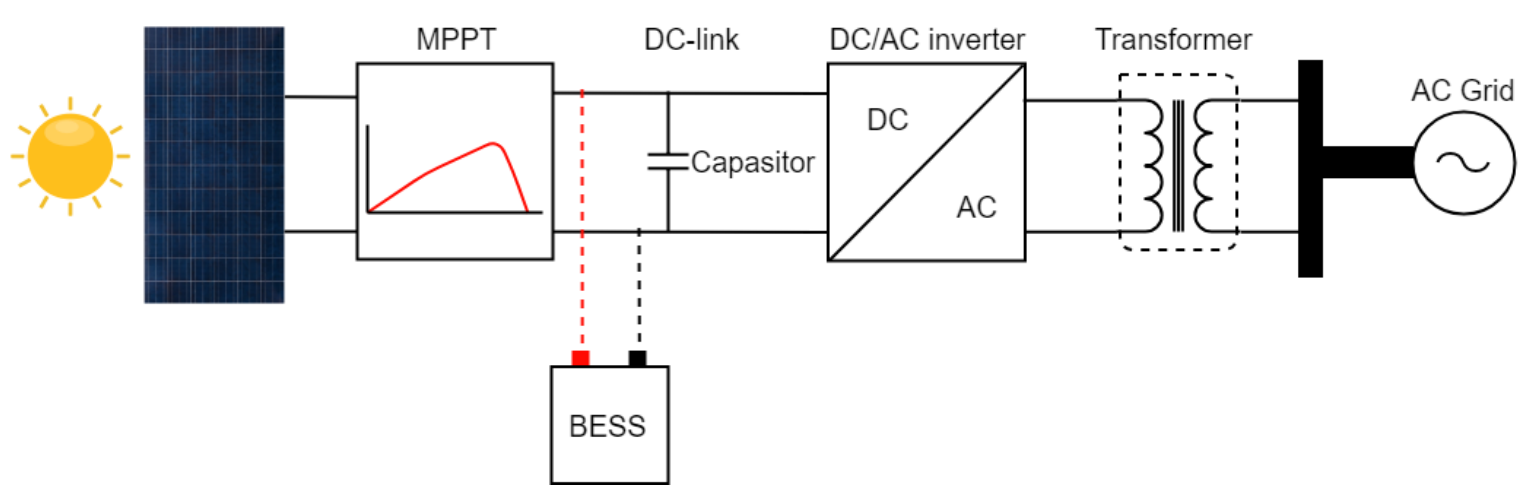

Figure 3.14: Solar PV setup.

The MPPT, a DC-DC converter, outputs to the DC-link where a DC-to-AC converter interfaces with the AC grid. The DC-link makes use of a capacitor to keep the DC-link voltage stable.

A battery energy storage system is optional to the setup and is not essential for operation. The BESS interfaces with the DC-link and takes a major share of the installation cost, but provides improved generation reliability.

Refer to appendix B for further detail on the solar PV model and control.

\subsubsection{Implementation methods}

Since there are no sources of kinetic energy in solar PV generation, alternative methods are required to provide inertial response. A method proposed by the authors of [68], combines a battery energy storage system (BESS) with the solar PV plant using a bidirectional DC-DC converter. The purpose of the BESS is to regulate the DC-link voltage. By keeping the DC-link voltage constant ensures a sufficient energy buffer to provide the additional active power output. The BESS can temporarily and quickly, release or absorb electrical energy. Thus, the BESS emulates the kinetic energy reserve of the synchronous generator's rotating mass. This means that the temporary mismatch between generation and load demand is compensated for by the BESS. The benefit from this method is that the PV system is able to operate continuously at the instantaneous maximum power point (MPP). However, due to the expensive cost, relative low cycle life and low power density of batteries, means that the down-side of this implementation may outweigh the positive contribution.

Inverters are designed with little to no built-in capacity for energy storage, but unlike controlling mechanical components, power electronic devices such as inverters can be actuated at much shorter time scales. The authors of [69] uses the DC-link voltage as feedback signal, due to the fact that the DC-link voltage reflects the generation and load 


\subsection{Virtual inertia}

balance, similar to the system frequency. When generation exceeds load demand, the DC-link voltage increases. Conversely, when generation is insufficient for load demand, the voltage level of the DC-link decreases. For the inverter to maintain a constant ACvoltage amplitude output, the inverters modulation index must be controlled and updated as follow [69]:

$$
m=\frac{2 \cdot V_{o u t}^{*}}{V_{D C}}
$$

With $V_{\text {out }}^{*}$ as the reference signal, $V_{D C}$ is the measured DC-link voltage, and $m$ is the modulation index. Virtual inertia controllers using frequency as a feed-back signal, needs to perform extensive signal processing on the AC measurements to calculate and obtain the system frequency used to adapt the inverter's current output. For practical implementation of these controllers, the time delay due to sampling, signal processing, and, control loops can render the virtual inertia ineffective [70].

Due to the time consuming process of obtaining the system frequency through AC measurements, where immediate response is of high importance, and realising that the DC-link voltage is an indicator of power imbalance, inspired the authors of [71] to control the inverter with a virtual oscillator whose frequency is linked to the DC-link voltage. The DC-link voltage signal is much easier and faster to obtain for use as feedback to generate the Pulse Width Modulation (PWM) signal:

$$
\omega_{v}=\eta \cdot V_{D C}
$$

Where, $\omega_{v}$ is the frequency of the virtual oscillator. The constant, $\eta=\omega_{\text {ref }} / V_{D C, r e f}$ relates the reference DC-link voltage to the power system's reference frequency. Exact matching between inverter in closed-loop and synchronous machine dynamics are achieved through the use of equation (3.16). The inertia constant, $M$, of the equivalent synchronous machine is found to be [71]:

$$
M=\frac{C_{D C}}{\eta^{2}}
$$

Where, $C_{D C}$ is the capacitance of the DC-link bus capacitor. The total energy storage is calculated using the energy equation of a capacitor:

$$
E_{\text {cap }}=\frac{1}{2} \cdot C_{D C} \cdot V_{D C}^{2}
$$




\subsection{Virtual inertia}

Comparing equation (3.18) with that of the kinetic energy stored in the synchronous machine rotor:

$$
E_{\text {rotor }}=\frac{1}{2} \cdot J \cdot \omega_{m}^{2}
$$

It is seen that the capacitance (in Farad) of the capacitor plays the role of the rotor inertia $J$ in $\left[\mathrm{kg} \cdot \mathrm{m}^{2}\right]$, and the DC-link voltage $[V]$ stands in the place of the rotor speed $[\mathrm{rad} / \mathrm{s}]$.

\subsubsection{Simulation models}

In the case of synchronous generators, the significance of the inertia is essentially the ability to source additional energy immediately (e.g. kinetic energy converted to electrical energy). In the case of solar PV, there are mainly two options to source additional energy immediately. These options include, de-rated operation, and energy storage (e.g. batteries, large or super-capacitors). These methods emulate the kinetic energy of the synchronous generator, which solar PV lacks.

With the aim to minimise cost and making it possible for current solar PV plants to participate in virtual inertial response, the method of de-rated/curtailing operation is discussed further. Before curtailing a solar PV plant for frequency regulation, the first question coming to mind is, how much reserve power is needed? This question has an inherent trade-off aspect between generation (capital income for the PV plant) and power system stability (improved reliability of the power system). Figure 3.15 presents an example of a solar PV panel's P-V characteristic curve. The de-rated power reference is shown as a reserve margin, $\Delta P$, held from the maximum power point (MPP). The objective is to find a better suited reserve margin, rather than using a generic arbitrary value of $3 \%$ as stated in the SAGCC.

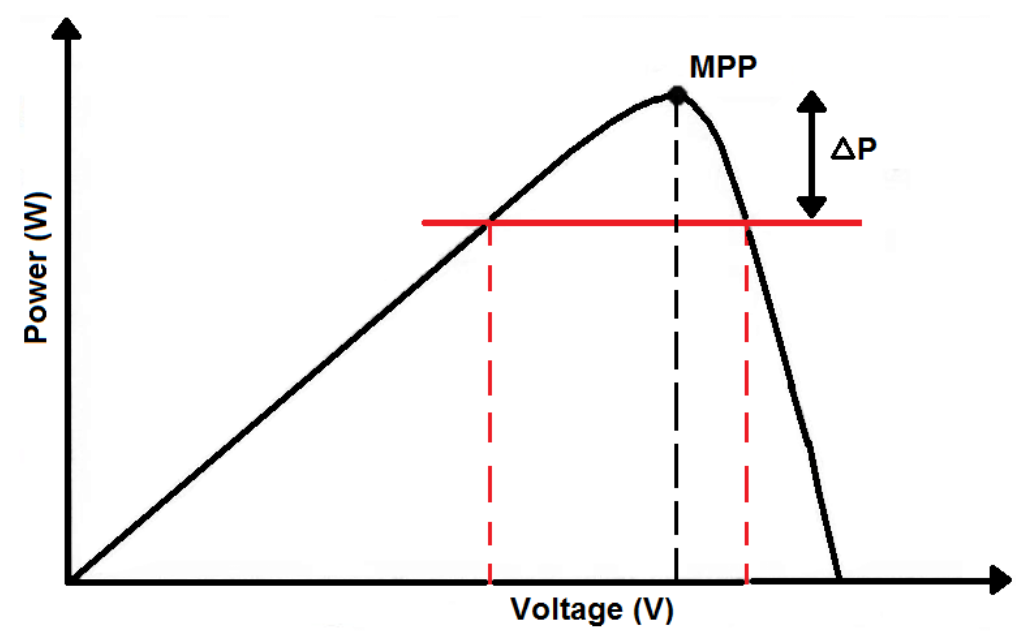

Figure 3.15: Example of a solar PV panel's P-V characteristic curve with de-rated power reference. 
To calculate an appropriate reserve margin, the swing equation in standard units (3.5) is used, and re-written here for convenience:

$$
M \frac{d}{d t} \omega(t)+D \cdot \omega(t)=P_{m}(t)-P_{e}(t)
$$

When the damping term is neglected, $D=0$, the left term of equation (3.20) must be able to match the imbalance on the right side of the equation. Assuming the PV plant should contribute to the inertial response up to the point where the PV plant is allowed to disconnect, then the following is stated:

$$
\left.\Delta P\right|_{\text {imbalance }}=\left.2 \pi \cdot M \frac{d f(t)}{d t}\right|_{\max }
$$

Where,

$$
\left.\frac{d f(t)}{d t}\right|_{\max }=1.5 \mathrm{~Hz} / \mathrm{s}
$$

The maximum RoCoF before the plant is allowed to disconnect is $1.5 \mathrm{~Hz}$ per second as stated by the SAGCC [16]. The reserve margin is chosen as such, that the PV plant is able to deliver the desired inertial response.

The virtual inertia controller must maintain the required reserve margin, $\Delta P$, which is accomplished with a PI-controller. The controller's reference power point is calculated as follow:

$$
P_{\text {ref }}=P_{m p p}-\Delta P
$$

During a low frequency event the virtual inertia controller adjusts the power reference point, $P_{r e f}$, to provide the inertial response:

$$
\begin{aligned}
P_{\text {ref }+V I} & =P_{\text {ref }}+M \frac{d}{d t} \omega(t) \\
& =P_{m p p}-\Delta P+M \frac{d}{d t} \omega(t)
\end{aligned}
$$

With the selected reserve margin, the virtual inertia controller is able to move the reference point all the way to MPP, for a RoCoF up to $1.5 \mathrm{~Hz}$ per second, after which, no more reserve is available and the PV plants are then allowed to disconnect from the power system.

To test the virtual inertial response of the solar PV system, a System Frequency Model (SFM) was constructed to simulate a low inertia power system. To create the SFM, equation (3.20) was used and re-arranged into standard state-space form, as follow:

$$
\frac{d \omega(t)}{d t}=-\frac{D}{M} \cdot \omega(t)+\frac{1}{M} \cdot\left[P_{m}(t)-P_{e}(t)\right]
$$




\subsection{Virtual inertia}

Selecting the state-variable $x=\omega(t)$, thus $\dot{x}=d \omega(t) / d t$. The frequency dynamics is now captured in standard state-space vector form:

$$
\underline{\dot{x}}=A \underline{x}+B \underline{u}
$$

Where,

$$
\begin{array}{ll}
A= & -\frac{D}{M} \\
B= & \frac{1}{M} \\
\underline{u} & =P_{m}(t)-P_{e}(t)
\end{array}
$$

The frequency dynamics are simulated and solved by integrating $\dot{x}$ in small time steps, using the Runge-Kutta method and an ODE23 solver, as depicted by figure 3.16:

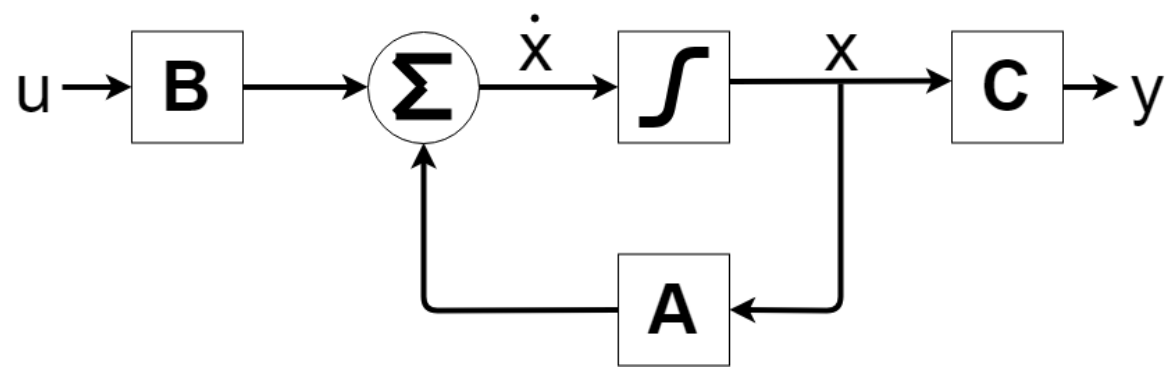

Figure 3.16: State-space simulation diagram.

After the inertia is allocated to the PV plant, the virtual inertia controller commands the maximum power point tracker (MPPT) to regulate the PV generation such that a constant reserve margin is available. This is performed using a PI-controller, see figure 3.17 .

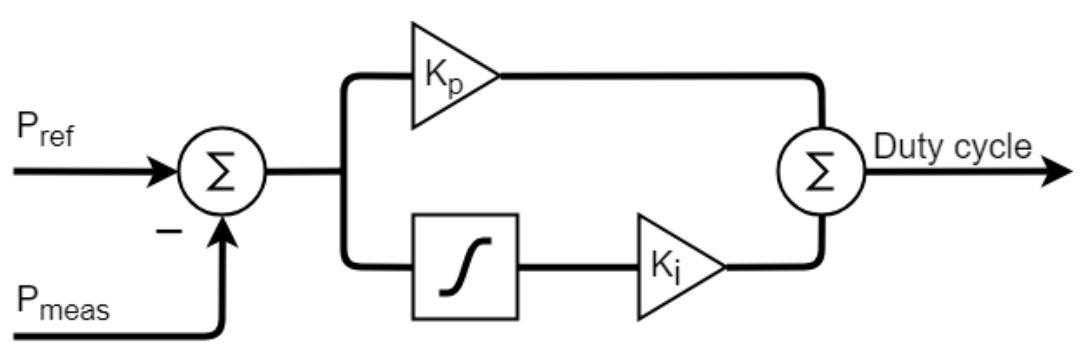

Figure 3.17: PI-controller diagram.

The PI-controller receives the measured PV output power, $P_{\text {meas }}$, and the calculated reference power, $P_{r e f}$, as input signals. The output is a duty cycle reference for a PMW signal, which regulates the power being generated and maintaining the reserve margin. 
The controller in figure 3.18 consists of two controllers combined as one. The first controller is a droop controller, which provides the primary frequency response. The controller is responsible for increasing or decreasing the PV output power in response to the position of the system frequency in relative to the desired scheduled frequency, thus it reacts on the frequency deviation.

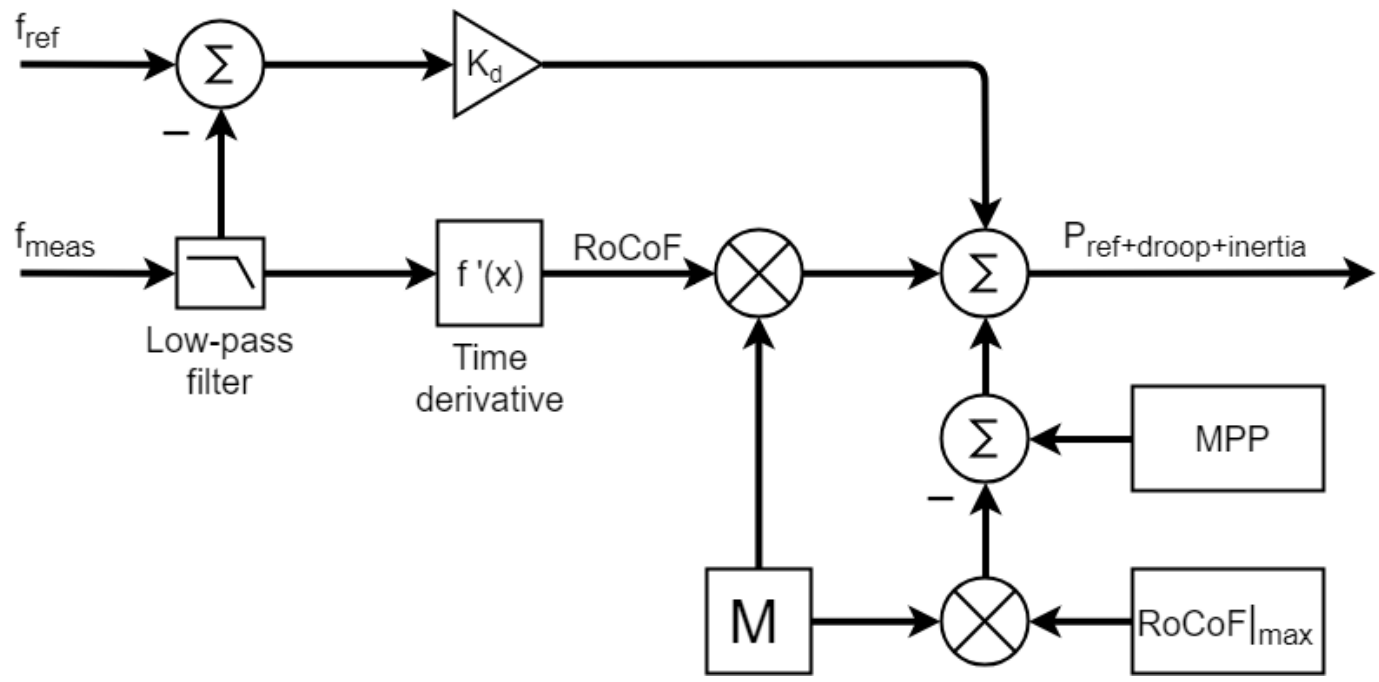

Figure 3.18: Virtual inertia and droop-controller diagram.

The second controller is responsible for the inertial response. The inertia constant, $M$, which is assigned to the PV plant is multiplied with the maximum RoCoF $(1.5 \mathrm{~Hz}$ per second) to find the reserve margin $\Delta P$. The reserve margin is then subtracted from the last updated MPP, to find the new de-rated/curtailed reference point. The inertia constant is also multiplied with the systems calculated RoCoF and, is added to the output reference. The virtual inertia controller outputs a new reference to the PI-controller in figure 3.17. This results in the power reference changing, in response to a generation/load imbalance disturbances, and there by adjusting the PV power feed-in as required for frequency stabilisation.

\subsubsection{Simulation results}

The simulation scenario consists of an input disturbance in the form of a $10 \%$ step increase in load. The step disturbance, scheduled for time $=1$ second, creates a generation/load imbalance, which triggers a low frequency event, and thereby activates the virtual inertial response of the solar PV plant. Figures 3.19, 3.20 and 3.21 compares three control scenarios. The control scenarios include: with and without virtual inertia, and virtual inertia with droop or primary control. The results shows the power output response, frequency response, and the system's RoCoF, respectively. 
Figure 3.19 present the normalised power response of the solar PV for the cases: without virtual inertia, using virtual inertia, and virtual inertia combined with droop control.

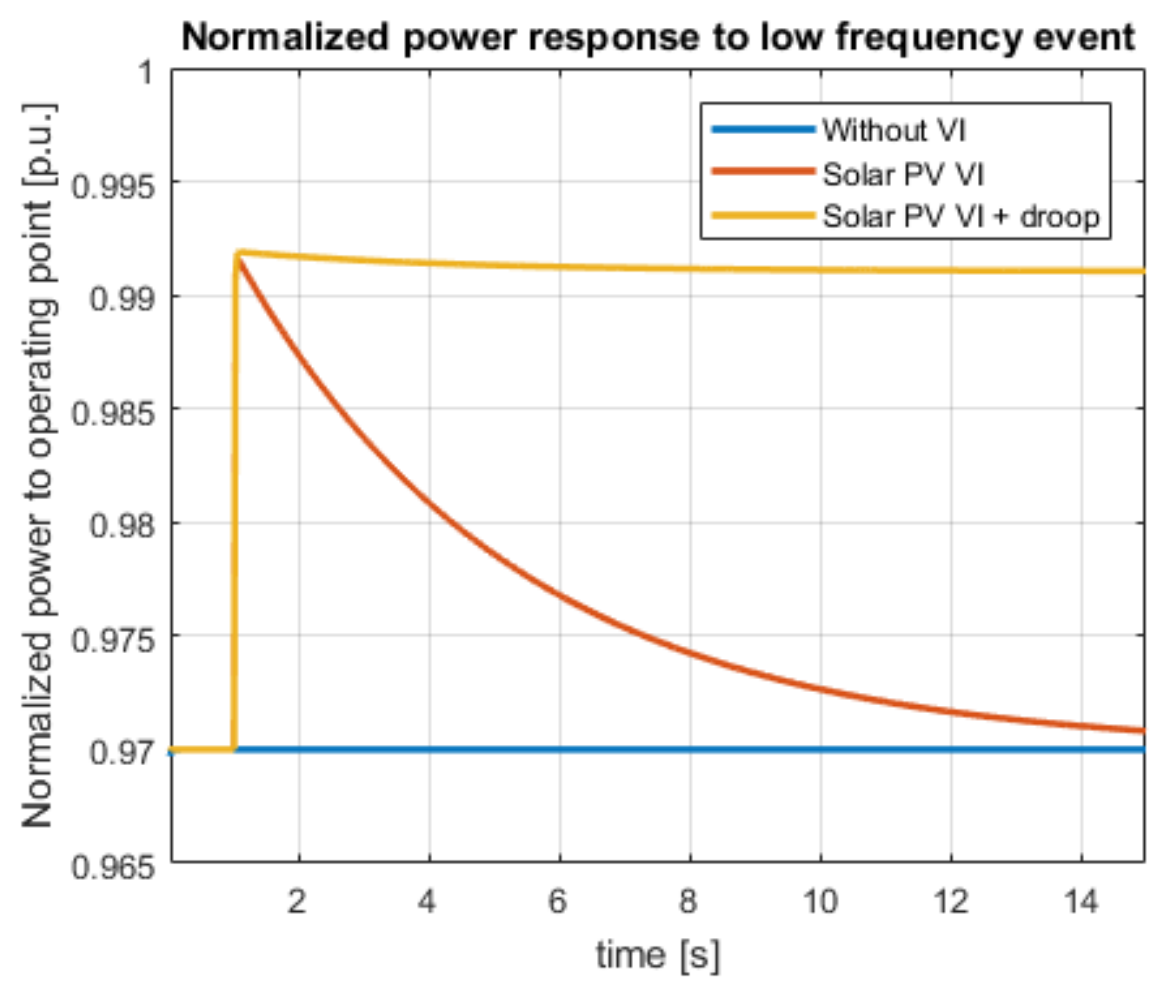

Figure 3.19: Comparing the solar PV generation output for the scenarios: without virtual inertia, using virtual inertia, and virtual inertia with droop.

Analyzing the responses, it is seen that the virtual inertia response is near instantaneous. The virtual inertia reacts only to the RoCoF, thus the response dies out as the system frequency stabilises and approaches a new steady-state. However, the droop controller maintains the additional power response since this controller reacts to the error between scheduled and current measured frequency.

The fast responses are contributed to the fact that the power electronics have fast update cycles together with PV generations ability to change the operation point very fast, unlike a mechanical prime mover, which has longer time constants.

The impact of the solar PV's output power response on the system frequency is shown in figure 3.20. Comparing the frequency responses in figure 3.20, it is seen that the virtual inertia increases the frequency stability, by slowing down the frequency dynamics i.e. reducing the RoCoF magnitude, and thus, improving the frequency response. The droop controller does not improve the initial frequency response of the virtual inertia controller, however, from time $=4$ seconds the frequency response starts to improve on top of the virtual inertia, resulting in a higher frequency nadir, which is more desirable. 
These responses are due to the fact that the virtual inertia controller reacts only to the RoCoF, while the droop reacts to the frequency deviation.

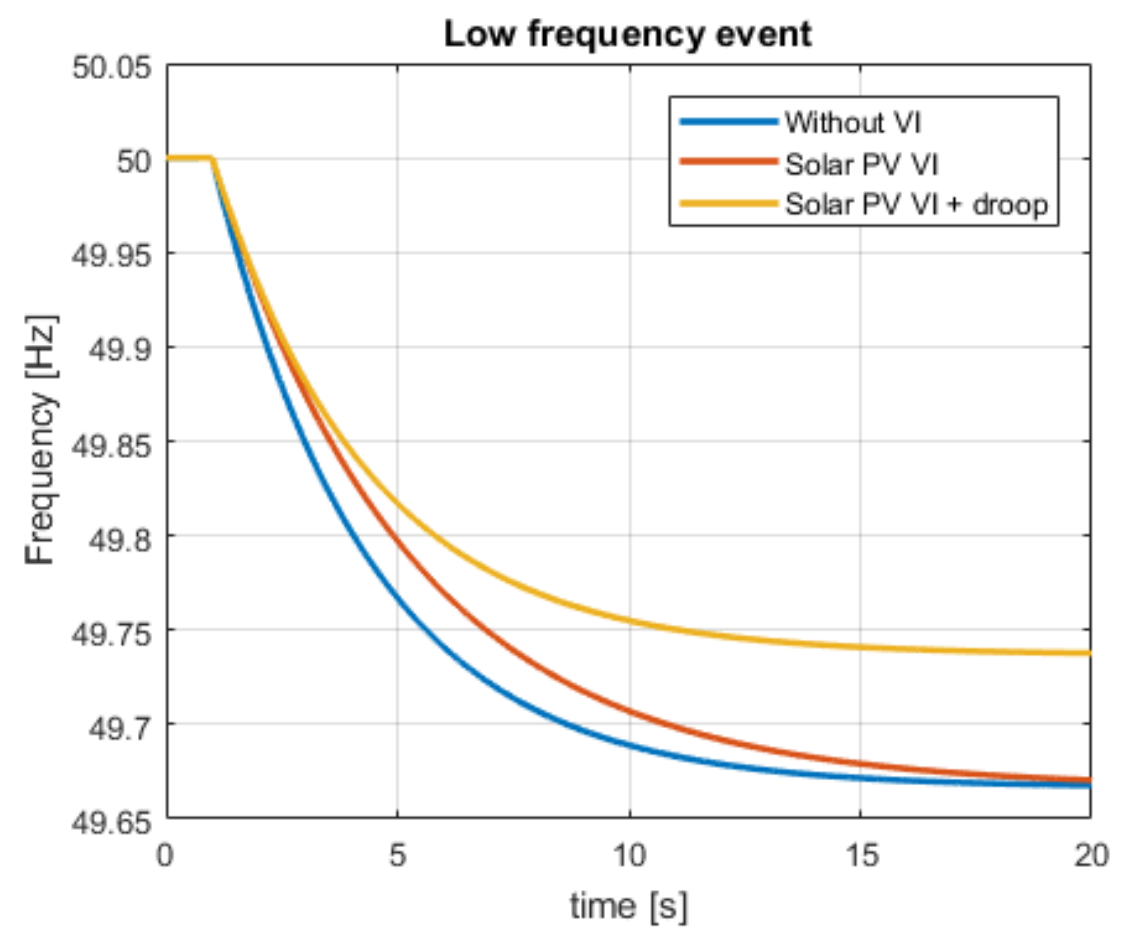

Figure 3.20: The impact of the solar PV power output response on the system's frequency.

Figure 3.21 compares the RoCoF of the three cases and supports the results from figure 3.20 .

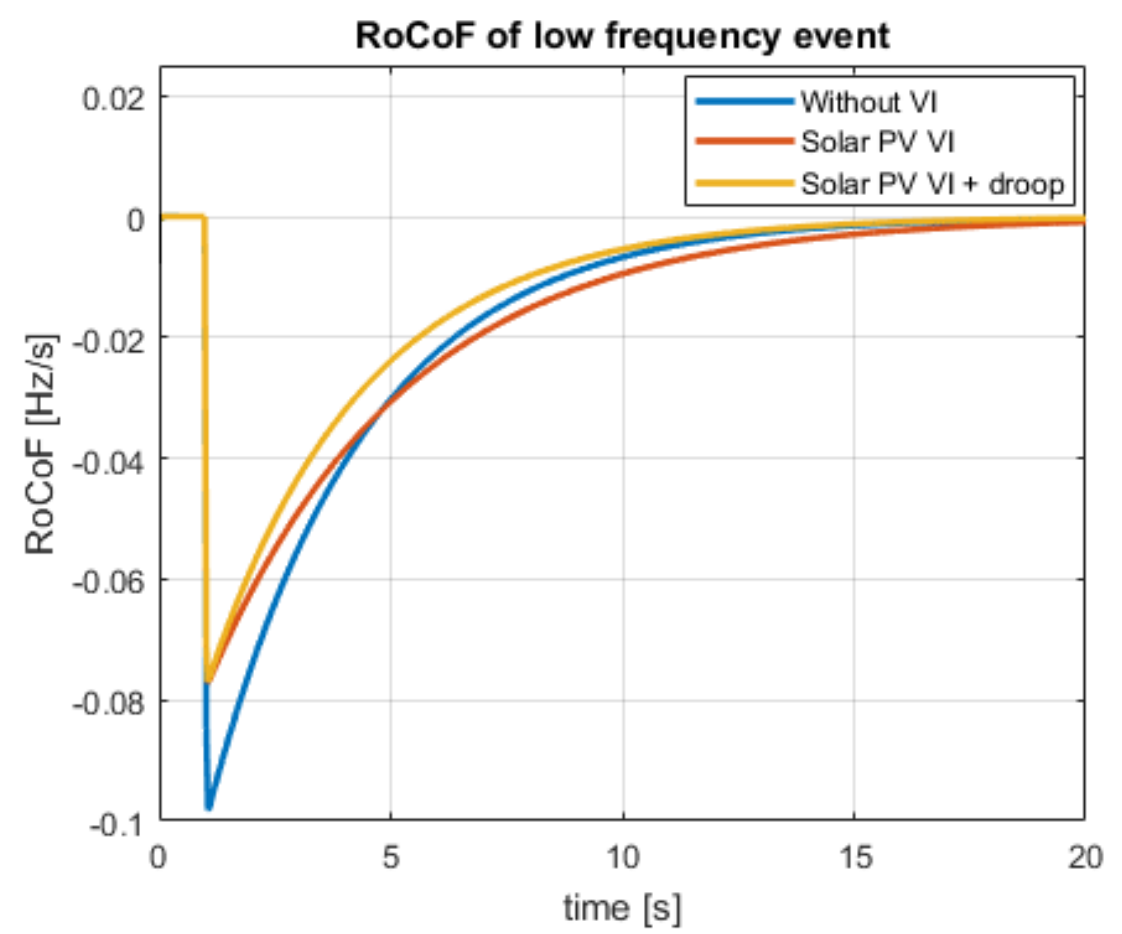

Figure 3.21: Rate of Change of Frequency (RoCoF) comparison of the three scenarios. 


\subsection{Wind virtual inertia vs solar PV virtual inertia}

Analysing figure 3.21, it is seen that the initial and maximum RoCoF improves with virtual inertia, compared to the scenario using no virtual inertia. Due to the frequency dynamics settling as it reaches a new equilibrium point, the response of the virtual inertia also reduces after the point of maximum RoCoF. The droop does not improve the initial RoCoF, since it reacts to the frequency deviation, which is still small when the RoCoF is at its maximum. As the frequency deviation increases over time, the droop action becomes more significant and starts to complement the diminishing response of the virtual inertia, by maintaining a higher power output.

\subsection{Wind virtual inertia vs solar PV virtual inertia}

Comparing the virtual inertial responses of wind and solar PV power generation the following is noted:

Wind: WTG does have real inertia in the turbine, however, it is not utilised for frequency stability. The power output response ramp-up rate is slower compared to the PV response ramp-up, due to the inertia in the rotor and turbine. Since WTG inertia emulation makes use of KEC (kinetic energy control), the inertial response is followed by a recovery period where generation output is below normal operating point. There is also a risk of the turbine speed dropping too low causing a shutdown.

Solar PV: Since there is no inertia in the generation of power, a additional reserve is needed, which has fast power response capability. The inertial response compared to that of a WTG has a faster power ramp-up output rate. The solar PV can also maintain higher power output for longer periods depending of the power reserve method.

\subsection{Virtual inertia vs synchronous machine inertia}

Table 3.2 compares real inertia from a synchronous machine with virtual inertia and presents a summary: 
3.5 Virtual inertia vs synchronous machine inertia

Table 3.2: Summary of real inertia vs virtual inertia

\begin{tabular}{|l|l|}
\hline \multicolumn{1}{|c|}{ Real inertia } & \multicolumn{1}{c|}{ Virtual inertia } \\
\hline $\begin{array}{l}\text { Real inertia is a parameter of the } \\
\text { synchronous machine rotor mass } \\
\text { thus, real inertia is fixed and not } \\
\text { configurable. }\end{array}$ & $\begin{array}{l}\text { Since virtual inertia is not real it does } \\
\text { not have to correlate to the generation } \\
\text { size of the plant. Virtual inertia is con- } \\
\text { figurable and thus, can be controlled } \\
\text { to best suite the network and disturb- } \\
\text { ance location. }\end{array}$ \\
\hline $\begin{array}{l}\text { The inertia response is autonomous } \\
\text { thus, requires no input to be } \\
\text { evaluated for triggering a response. }\end{array}$ & $\begin{array}{l}\text { Virtual inertia is implemented using } \\
\text { a control-loop thus, signal measuring } \\
\text { is required and a controller. Therefore } \\
\text { virtual inertia is not autonomous and } \\
\text { has to be implemented. }\end{array}$ \\
\hline $\begin{array}{l}\text { The inertial response is immediate, } \\
\text { since it is autonomous and has no } \\
\text { signal processing delays. This is } \\
\text { highly advantageous for frequency } \\
\text { stability. }\end{array}$ & $\begin{array}{l}\text { The inertial response is not instant- } \\
\text { aneous, but has a time delay. This delay } \\
\text { in response is due to signal sampling, } \\
\text { processing and since virtual inertia } \\
\text { changes the power generation point of } \\
\text { power system and thus, does } \\
\text { there is no need for a frequency } \\
\text { stability and regulation market. } \\
\text { eacherating unit, of which the res- } \\
\text { ponse has a time constant, means that } \\
\text { virtual inertia has an inherent response } \\
\text { delay. }\end{array}$ \\
\hline $\begin{array}{l}\text { Inertia is an inherent property } \\
\text { virtual inertia is not freely provided, } \\
\text { it requires additional development } \\
\text { and in some cases reduce the feed-in } \\
\text { power from the generation plant. } \\
\text { Therefore an incentive has to be intro- } \\
\text { duced to the generating plants to } \\
\text { provide this auxiliary service. }\end{array}$ \\
\hline
\end{tabular}




\section{Chapter 4}

\section{Optimal Allocation Of Virtual Inertia}

In chapter 3 virtual inertia using wind and solar PV power were investigated. The limitations and benefits of virtual inertia were found, and considering section 3.2.5, the questions arise of how much virtual inertia must a RRP provide and where future RRPs would be beneficial for frequency stability. The increase in inverter-based RES generation and decline in rotational inertia means that inertia will be seen as a valuable property and thus, should be used in an intelligent manner for maximum results. This chapter will utilise a method introduced by [72], which aim to find the optimal placement of virtual inertia within a power system network. The authors of [72] proposes the use of energy metrics, rather than the quantity of inertia, which could be misleading, and can deliver different stability results as mentioned in section 3.2.5. The first energy metric used for the cost-function is the energy imbalance due to the frequency excursion (see figure 4.1 for illustration) or the fluctuation in frequency due to variable RES generation feed-in.

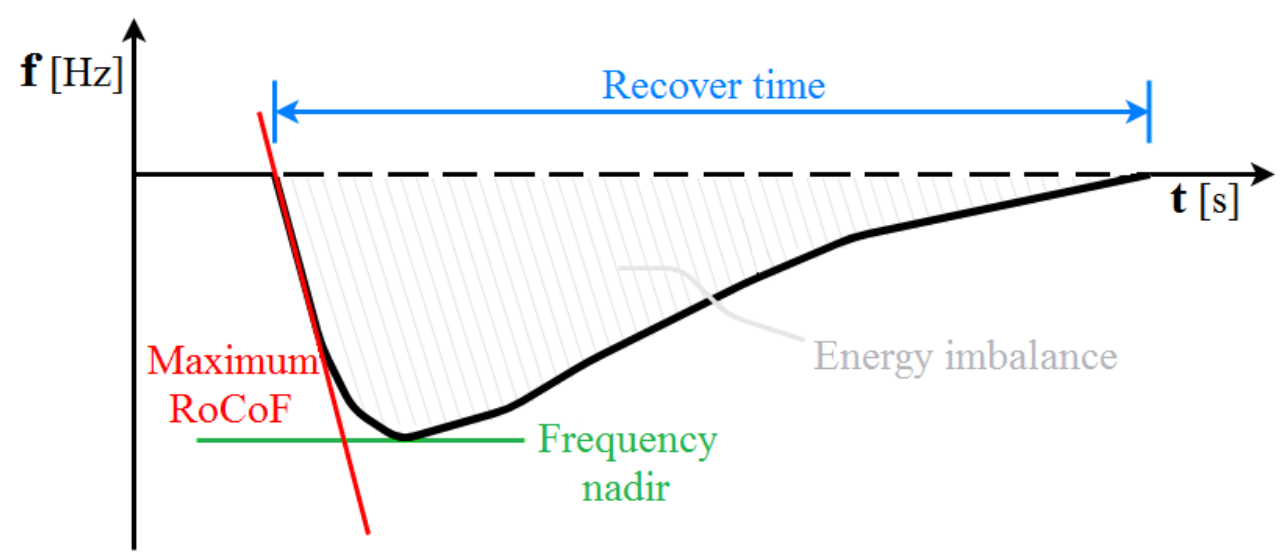

Figure 4.1: Energy imbalance in frequency excursion.

$$
E_{\omega}=\int_{0}^{\tau} \omega^{T} Q \omega d t
$$




\subsection{Power system single-line diagram model}

Equation (4.1) states the energy metric of the frequency excursion. The variable $\omega$ is a vector of the frequencies at each sub-station (node) in the network. The matrix $Q$ is a diagonal matrix containing positive weights on the different frequency excursions, which might be node dependent. The second energy metric is the amount of energy required by the virtual inertia sources to provide the inertial response. Equation (4.2) equates the inertial response energy with $P_{M}$ denoting the vector containing the power output of the virtual inertia generators. The diagonal matrix $R_{M}$ contains positive weights for each virtual inertia power output.

$$
E_{M}=\int_{0}^{\tau} P_{M}^{T} R_{M} P_{M} d t
$$

Given a stable system, the $H_{2}$-norm is a measure of the output energy for a specific disturbance input. The system's sensitivity and amplification can thus, be obtained for a specific input disturbance. The smaller the system's amplification to a particular disturbance, the better the system can reject that specific disturbance input and thus, the system is more stable. The optimisation goal is thus, to find the distribution of virtual inertia for a given power system, that will minimise the $\mathrm{H}_{2}$-norm.

\subsection{Power system single-line diagram model}

The Eskom Western Transmission (TX) network single-line diagram model (see figure 4.2) in DigSilent PowerFactory was used for the virtual inertia placement optimisation and results simulation. The single-line diagram in PowerFactory provides a graphical interface, however, for the optimisation a mathematical model is needed. Figure 4.2 is to indicate the format of the graphical model before it was reconstructed in mathematical form, and not to present detail as this is sensitive information of Eskom. Refer to appendix B for further detail in regard to the modeling of the power system components.

With the use of graph theory, the swing equation (3.5) and linearised power-flow equations, the single-line diagram model was reconstructed in matrix and vector form. This made it suitable for state-space domain modeling, control, stability analysis and optimisation.

A python script was created to interface with the simulation software, and read the singleline graphical model together with the information of all the relevant network elements. A Matlab script was then written to collect the data from the python script and interpret the data to construct a state-space model representation, derive a $\mathrm{H}_{2}$-norm cost-function, and using the Matlab optimisation tool-box to find the optimal distribution for the virtual inertia considering a trip at the Koeberg power plant. The LaPlacian model of the Western 


\subsection{Linearising the power-flow equation}

TX was verified by running a load-flow simulation and comparing the voltage angles at each node.

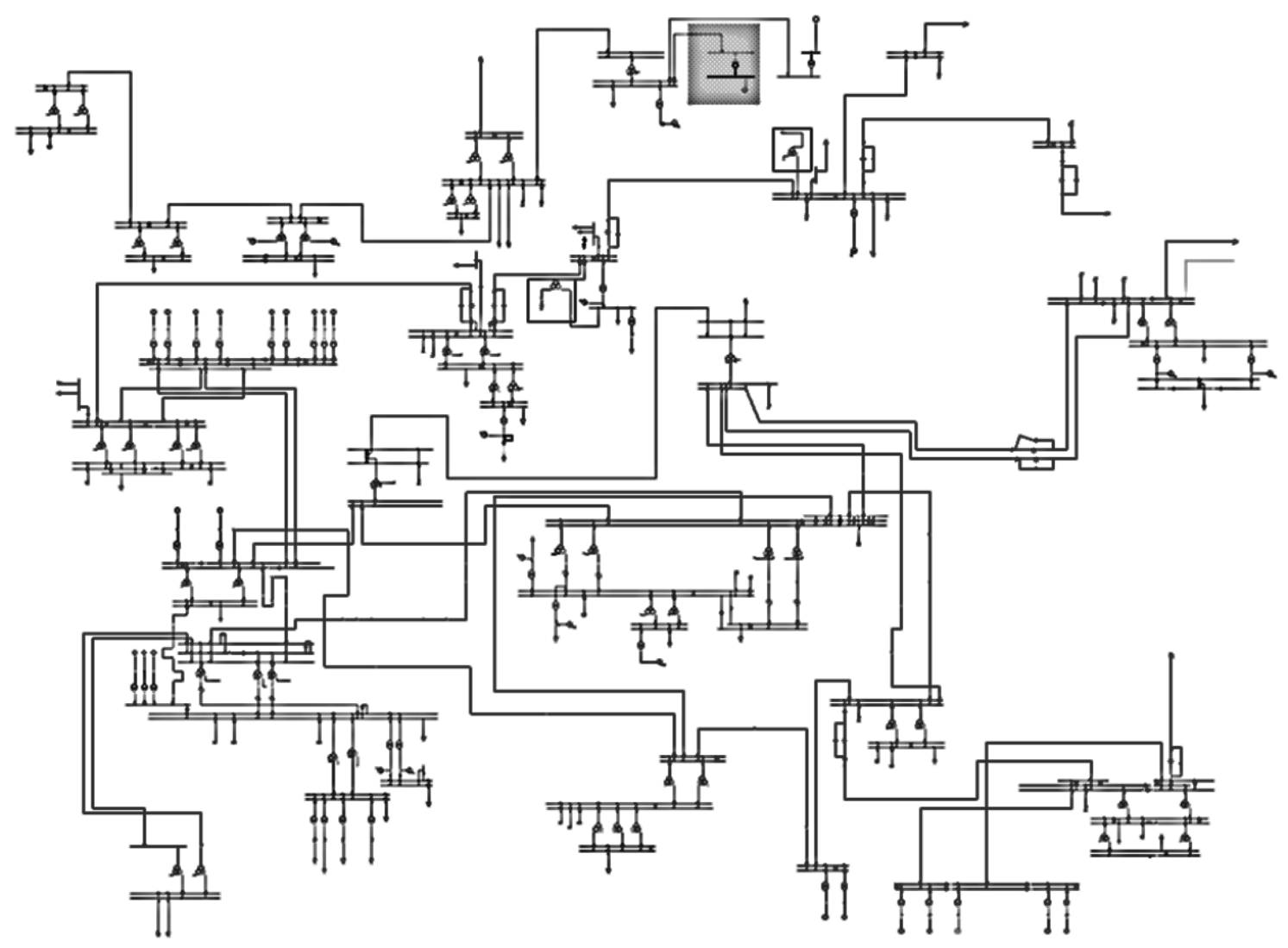

Figure 4.2: Single-line diagram model of the Eskom Western TX system.

\subsection{Linearising the power-flow equation}

The power-flow equation (4.3) is used to model the active power flow in the network, and to connect the swing equations at each bus together:

$$
P_{i}=\sum_{j=1}^{N}\left|V_{i}\right|\left|V_{j}\right|\left(G_{i j} \cos \left(\delta_{i}-\delta_{j}\right)+B_{i j} \sin \left(\delta_{i}-\delta_{j}\right)\right)
$$

To simplify the model, three assumptions are made [73]:

- The resistance of the transmission lines are significantly less than the reactance. With $z=r+j x$ and $y=1 / z=g+j b$, it can be shown that $g \approx 0$ and $b \approx-1 / x$.

- For typical system operation, the voltage angle differences between buses $i$ and $j$, are less than 15 degrees. The angles are therefore considered "small", which means the following approximations can be made:

$\rightarrow \cos \left(\delta_{i}-\delta_{j}\right) \approx 0$ 


\subsection{State-space model of the power system}

$\checkmark \sin \left(\delta_{i}-\delta_{j}\right) \approx \delta_{i}-\delta_{j}$.

- The values of $\left|V_{i}\right|$ and $\left|V_{j}\right|$ in the per-unit system are very close to 1 , during normal operation. Therefore, the values of the voltage magnitudes are set equal to one.

With these assumptions, the power-flow equation (4.3) is linearised and is now as follow:

$$
P_{i}=\sum_{j=1}^{N} B_{i j}\left(\delta_{i}-\delta_{j}\right)
$$

By expanding equation (4.4), the terms can be rearranged in vector form:

$$
\underline{P}=B \cdot \underline{\delta}
$$

where, $\underline{P}$ is the real power injection vector, $\underline{\delta}$ is the voltage angle difference vector, and $B$ is a square $n \times n$ matrix. The $B$-matrix is singular, due to dependencies. The dependency comes from the fact that the sum of the generation equals the demand. The singularity problem is solved by removing a row, and use the corresponding bus voltage angle as the reference angle.

\subsection{State-space model of the power system}

Graph theory is used to construct the LaPlacian ( $B$-matrix), also called admittance matrix or Kirchoff matrix, which is a matrix representation of a graph. To model the power system's frequency dynamics the swing equation (3.5) is re-written in vector form as follow:

$$
M \cdot \underline{\dot{\omega}}+D \cdot \underline{\omega}=\underline{\Delta P}-B \cdot \underline{\delta}
$$

Selecting the state-variables as follow:

- $\underline{\dot{\delta}}=\underline{\omega}$

- $\underline{\dot{\omega}}=-M^{-1} B \cdot \underline{\delta}-M^{-1} D \cdot \underline{\omega}+M^{-1} \cdot \underline{\Delta P}$

Using the swing equation in vector form together with the B-matrix, a state-space representation of the power system's frequency dynamics is obtained as follow:

$$
\left[\begin{array}{c}
\underline{\dot{\delta}} \\
\underline{\dot{\omega}}
\end{array}\right]=\left[\begin{array}{cc}
0 & I \\
-M^{-1} B & -M^{-1} D
\end{array}\right] \cdot\left[\begin{array}{l}
\underline{\delta} \\
\underline{\omega}
\end{array}\right]+\left[\begin{array}{c}
0 \\
M^{-1}
\end{array}\right] \cdot \underline{\Delta P}
$$




\subsection{State-space model of the power system}

For a system with $n$-buses, $M$ is a square-matrix with $n$ entries on the diagonal, containing the inertia present at each bus. The parameter, $D$ is also a square-matrix of size $n$ with the available damping of each bus filled on the diagonal of the matrix. The state-variables, $\delta$ and $\omega$, represents the bus voltage angles in radians [rad] and frequencies in radians per second $[\mathrm{rad} / \mathrm{s}]$, respectively. The generation/load imbalance is represented by $\underline{\Delta P}$.

As presented by [72], the governors and virtual inertia, which form feedback control loops were added to create an augmented state-space representation of the power system. The open-loop power system model is thus, in the following form:

$$
\begin{aligned}
& \underline{\dot{x}}=A \underline{x}+B \underline{u} \\
& \underline{y}=C \underline{x}+D \underline{u}
\end{aligned}
$$

Energy metrics for frequency deviation and virtual inertia effort are incorporated into the $H_{2}$-norm, by adding the matrices $Q$ and $R_{M}$ to the output (C) and input (D) matrices respectively, of the multiple-input and multiple-output (MIMO) state-space model.

The parameters to be optimised is captured in the feedback controller, $u=-K \underline{x}_{v i}$, where $K$ is a diagonal matrix, with the elements on the diagonal representing the amount of virtual inertia that are placed at the corresponding locations, and $\underline{x}_{v i}$ is the virtual inertia frequency state-variable, a sub-set of the state-variable vector of the system. The closedloop state-space model is thus, as follow:

$$
\begin{aligned}
& \underline{\dot{x}}=(A-B \cdot K) \underline{x} \\
& \underline{y}=(C-D \cdot K) \underline{x}
\end{aligned}
$$

The governor regulates the speed of the prime-mover, which drives the generator. The governor is modeled with a gain and a first-order lag time constant using the following transfer-function in the Laplace domain [74].

$$
P_{\text {governor }, i}=-K_{i} \cdot \frac{1}{1+T_{l a g} \cdot s} \cdot \omega_{i}
$$

- $P_{\text {governor }, i}$ : The change in power output due to governor action.

- $K_{i}$ : The gain is equal to $1 / \rho$, where $\rho$ is the droop parameter of governor $i$.

- $T_{l a g}$ : This is the time constant representing the delay in governor action.

- $\omega_{i}$ : The frequency deviation measured at the local bus $i$. 


\subsection{State-space model of the power system}

The state-space representation of equation (4.11) is derived as follow. With $P_{\text {governor }, i}$ as the output $Y$, and $\omega_{i}$ as the input $U$ of the transfer-function, the state-variable is represented by $X$, and equation (4.11) is re-written as:

$$
\frac{Y}{X} \cdot \frac{X}{U}=-K_{i} \cdot \frac{1}{1+T_{l a g} \cdot s}
$$

By selecting the numerator to equal $\frac{Y}{X}$, the following is obtained:

$$
Y=-K_{i} \cdot X
$$

The equation is in the form, $y=C \cdot \underline{x}$, thus the output matrix is $C_{i}=-K_{i}$.

The denominator of equation (4.12) is set equal to $\frac{X}{U}$, thus the following is obtained:

$$
U=X+T_{l a g} \cdot s \cdot X
$$

Take the inverse Laplace transform:

$$
u=x+T_{\text {delay }} \cdot \dot{x}
$$

Rearrange for the derivative:

$$
\dot{x}=-\frac{1}{T_{\text {delay }}} \cdot x+\frac{1}{T_{\text {delay }}} \cdot u
$$

Equation (4.16) is now in the form $\underline{\dot{x}}=A \underline{x}+B \underline{u}$, which means, $A_{i}=-\frac{1}{T_{\text {delay }}}$ and $B_{i}=\frac{1}{T_{\text {delay }}}$. The $A_{i}, B_{i}$, and $C_{i}$ parameters of each governor in the network are entered on the diagonal of the $(n \times n)$ matrices $A_{g}, B_{g}$, and $C_{g}$ respectively, where $n$ is the number of buses and $i$ the index.

The virtual inertia are used a negative feed-back loops that measure the frequency at the local bus and inject active power accordingly. The virtual inertia is modeled as proportional and derivative control (PD-control). The transfer-function in the Laplace domain is as follow [72]:

$$
P_{v i r t u a l, i}=\frac{m_{i} \cdot s}{\left(T_{\text {meas }} \cdot s+1\right)\left(T_{\text {lag }} \cdot s+1\right)} \cdot \omega_{i}
$$

- $P_{\text {virtual }, i}$ : The change in power output due to the virtual inertial response.

- $m_{i}$ : The gain is equal to the amount of virtual inertia $\left[\mathrm{MW} \cdot S^{2}\right]$. 


\subsection{Cost-function}

- $T_{l a g}$ : This is the time constant representing the delay in virtual inertial response.

- $T_{\text {meas }}$ : The time constant representing the sampling of the system frequency.

- $\omega_{i}$ : The frequency deviation measured at the local bus $i$.

Using the same derivation process as for the governor, the state-space model is derived from the transfer-function.

$$
\begin{gathered}
A_{i}=\left[\begin{array}{cc}
-\frac{T_{\text {meas }}+T_{\text {lag }}}{T_{\text {meas }} \cdot T_{\text {lag }}} & -\frac{1}{T_{\text {meas }} \cdot T_{\text {lag }}} \\
1 & 0
\end{array}\right] \\
B_{i}=\left[\begin{array}{c}
\frac{1}{T_{\text {meas }} \cdot T_{\text {lag }}} \\
0
\end{array}\right] \\
C_{i}=\left[\begin{array}{ll}
m_{i} & 0
\end{array}\right]
\end{gathered}
$$

Similar to the governor, the $A_{i}, B_{i}$, and $C_{i}$ parameters of each virtual inertia source in the network is entered on the diagonal of the $(n \times n)$ matrices $A_{v}, B_{v}$, and $C_{v}$ respectively, where $n$ is the number of buses and $i$ the index.

The aggregated matrices and vectors of the governors and virtual inertia sources are used to create an augmented state-space representation of the power system, with an augmented state-vector:

$$
\underline{x}=\left[\begin{array}{l}
\underline{\delta} \\
\underline{\omega} \\
\underline{x_{g}} \\
\underline{x_{v}}
\end{array}\right]
$$

\subsection{Cost-function}

The $H_{2}$-norm captures the energy amplification in a system when it is subjected to a disturbance impulse. In general, a controller aimed to minimise the energy amplification can lead to very large input signals that may saturate the actuators. It is thus, necessary to include the input signal in the cost-function for a realistic controller design. The optimal controller thus, minimises the energy consumed by the system for maximum rejection performance against a disturbance input [75].

The $H_{2}$-norm is the energy of the output of a system [76] [75]:

$$
\begin{array}{lc}
\underline{\dot{x}}= & A \underline{x}+B(\underline{u}+\underline{\nu}) \\
\underline{y}= & C \underline{x}+D \underline{u}
\end{array}
$$


in response to a vector impulse function $\nu$.

The $y_{i}(t)$-component to the impulse in $\nu_{j}$-channel is:

$$
\begin{aligned}
& y_{i j}(t)= \begin{cases}C_{i} e^{A t} B_{j}, & \mathrm{t}>0 \\
0, & \mathrm{t} \leq 0\end{cases} \\
& g(t):=\left[\begin{array}{ccc}
y_{1,1}(t) & \cdots & y_{1, m}(t) \\
\vdots & \ddots & \vdots \\
y_{p, 1}(t) & \cdots & y_{p, m}(t)
\end{array}\right]
\end{aligned}
$$

The $H_{2}$ norm of the system is the sum of the energies of $y_{i j}(t)$.

$$
\begin{aligned}
|G(\cdot)|_{2} & =\sqrt{\int_{0}^{\infty} \sum_{i=1}^{p} \sum_{j=1}^{m} y_{i j}^{2}(t) d t} \\
& =\sqrt{\int_{0}^{\infty} \operatorname{trace}\left[g^{T}(t) g(t)\right] d t}
\end{aligned}
$$

Writing equation (4.22) in vector form:

$$
\begin{aligned}
|G(\cdot)|_{2} & =\sqrt{\int_{0}^{\infty} \operatorname{trace}\left[\left(C e^{A t} B\right)^{T} C e^{A t} B\right] d t} \\
& =\sqrt{\operatorname{trace}\left[B^{T} \int_{0}^{\infty} e^{A^{T} t} C^{T} C e^{A t} d t B\right]}
\end{aligned}
$$

The observability gramian $\left(P_{o}\right)$ of a system is defined as:

$$
P_{o}=\int_{0}^{\infty} e^{A^{T} t} C^{T} C e^{A t} d t
$$

The importance of the observability gramian, $\left(P_{o}\right)$, is that it can be computed without integration, but as a solution of the Lyapunov equation:

$$
P_{o} A+A^{T} P_{o}+C^{T} C=0
$$

By solving equation (4.26) for $P_{o}$, the $H_{2}$ norm, used for optimisation, is then finally computed as follow:

$$
|G(\cdot)|_{2}=\sqrt{\operatorname{trace}\left[B^{T} P_{o} B\right]}
$$

For details about the Lyapunov equation, Lyapunov stability theory and the observability gramian, the reader is referred to appendix D. 


\subsection{5-bus network simulation test}

A 5-bus network, as depicted in figure 4.3, was used for the initial test of the optimisation scheme. This section will explain the procedure from single-line diagram to cost-function, and finally the results.

\subsubsection{Single-line diagram model}

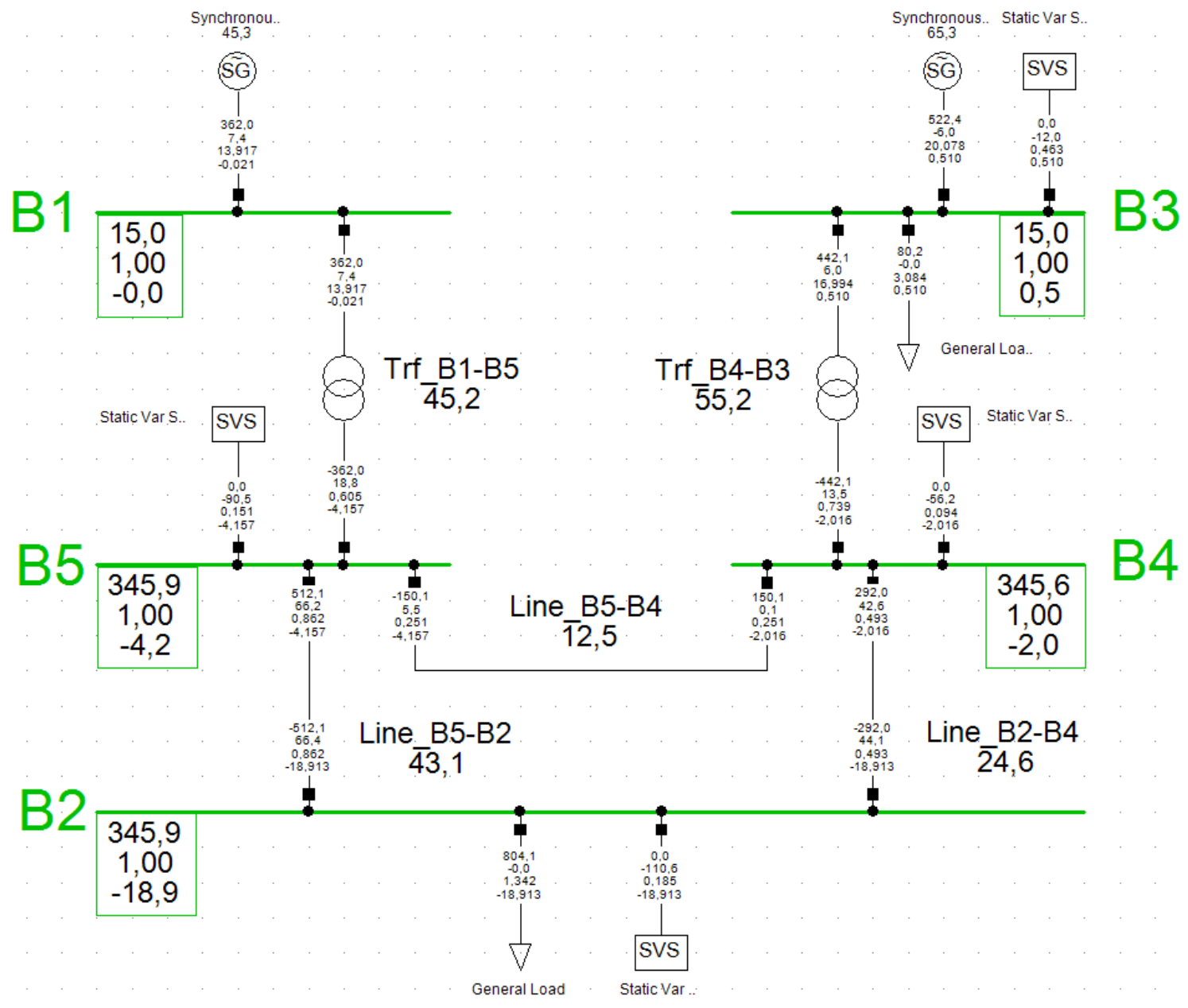

Figure 4.3: 5-bus network.

The 5-bus network has two 800 MVA synchronous generators. The generator connected to bus B1, which is also the reference machine, outputs $362 \mathrm{MW}$ and has an inertia constant $\mathrm{H}=6.63$ seconds. The second synchronous generator is connected to bus B3, outputs 522 MW and has an inertia constant of 8.37 seconds. Using equation (3.9), the aggregated inertia is $\mathrm{H}=7.5$ seconds. The network contains two loads. The load at bus B3 sinks $80 \mathrm{MW}$ and zero reactive power, since only real power is of interest. The second load is located at bus B2 and consumes $804 \mathrm{MW}$ and zero Mvar. Two transformers, one between $\mathrm{B} 1$ and B5, and one between B3 and B4, transform the $15 \mathrm{kV}$ to $345 \mathrm{kV}$. Static var 


\subsection{5-bus network simulation test}

systems (SVS) are used to keep the voltage at each bus at 1 per-unit value, since this is part of the assumption to simplify the model. Three $345 \mathrm{kV}$ transmission lines complete the 5-bus network model.

\subsubsection{Graph theory and model construction}

Algebraic graph theory has a significant role in the study of electrical networks. These networks range from small integrated circuits to large-scale continental-size power systems. Early electrical circuit analysts developed and studied many fundamental results of electrical networks and the theory of graphs. Algebraic graph theory and electrical networks share a long history of joint development. Gustav Kirchhoff pioneered and formed the foundations of electrical circuit modeling and analysis. The development of algebraic graph concepts and theory was motivated by the work of Kirchhoff and the published work of Leonhard Euler with the title "Solutio problematic as geometriam situs pertinentis", which translates to "The solution of a problem relating to the theory of position". Algebraic graph theory concepts and constructions have enabled fundamental advances in the theory of electrical networks. It is in graph-theoretical language that Kirchhoffs laws are most powerfully expressed. It is through matrix theory that the discrete nature of graphs is most powerfully analyzed. It was through the advancement of matrix theory that graphs are expressed and its discrete nature is analysed in a powerful way. The concepts and fundamental advancements in electrical network theory are due to the development and construction of algebraic graph theory. It is through graph theory that Kirchhoffs laws are powerfully expressed and used. Graph theory, matrix analysis, and electrical networks have a strong relationship and should be used in a complementary manner [77].

Graph theory is an interdisciplinary area. Everything in the world is linked, cities are linked by streets, rails, and flight networks. Web-pages on the Internet are linked by hyper-links. Components of an electric circuit are connected, Social Networks, Fraud patterns, Power consumption patterns etc. Once a problem is modeled as a graph it can be solved at more abstract levels and thus, open for optimisation techniques such as cost-function minimisation.

Using graph theory to model the power system, opens the possibility to analyze and optimise the power-flow, location of distributed renewable power plants, and auxiliary services to ensure the stability and reliable operation of the power system. Graph theory is useful for studying the integration of renewable energy in the power system in terms of placement of virtual inertia and power-flow optimisation. 


\subsection{5-bus network simulation test}

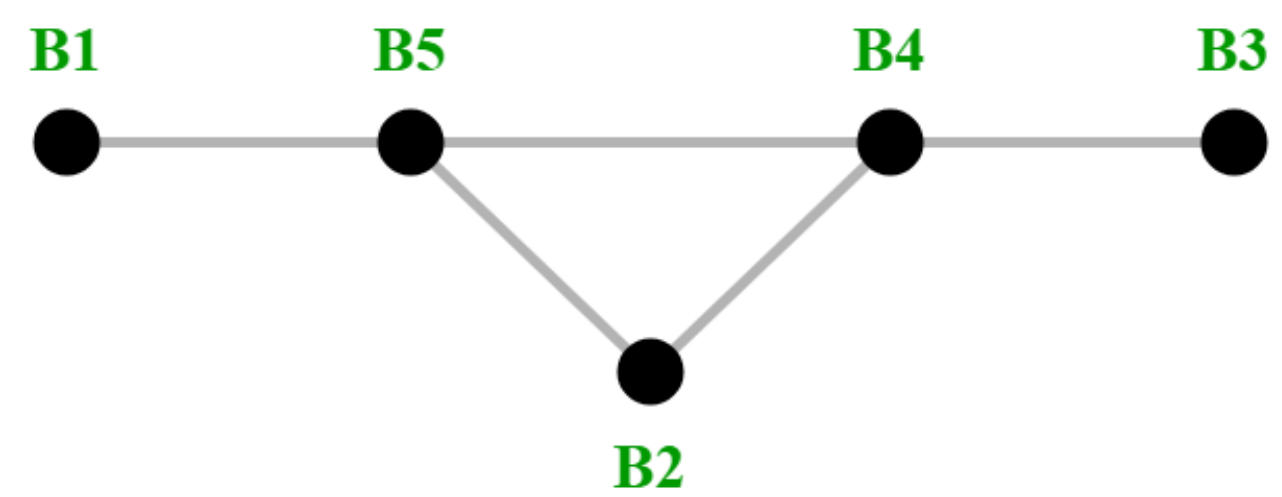

Figure 4.4: 5-bus network graph model.

The single-line diagram is first simplified to the graph, as seen in figure 4.4. The black dots are called nodes or vertices, which are the terminal of a bus or sub-station. The line connecting any two vertices is called an edge, which represents transmission lines. The number of edges connected to a vertex is known as the degree of that vertex. The rank of a graph is, $n-1$, where $\mathrm{n}$ is the number of vertices. A graph $G$ is thus an ordered pair $G=(V, E)$ where $V$ is a finite set of vertices and $E$ is a set of 2-subsets of $V$. The graph model in figure 4.4 is described as follow:

$$
\begin{gathered}
V=\{1,2,3,4,5\} \\
E=\{\{1,5\},\{5,2\},\{5,4\},\{2,4\},\{4,5\}\}
\end{gathered}
$$

By converting the single-line diagram to a graph model provides a mathematical representation of the topology of the network. This is useful for analyzing interconnectivity and power flow paths. To convert the single-line diagram in PowerFactory to a mathematical graph model, a Python script was developed to gather all the network components from the single-line diagram. The gathered data was then categorised according to the type of element, and then labeled numerically as shown in tables 4.1, 4.2, and 4.3.

\begin{tabular}{|c|c|c|c|c|}
\hline Bus (name) & Bus number & $\begin{array}{c}\text { Voltage } \\
{[\mathrm{kV}]}\end{array}$ & $\begin{array}{c}\text { Voltage } \\
{[\mathrm{p} . \mathrm{u} .]}\end{array}$ & $\begin{array}{c}\text { Voltage angle } \\
{[\text { degrees }]}\end{array}$ \\
\hline B1 & 1 & 15 & 1 & 0 \\
\hline B2 & 2 & 345.9 & 1 & -18.9 \\
\hline B3 & 3 & 15 & 1 & 0.5 \\
\hline B4 & 4 & 345.6 & 1 & -2.0 \\
\hline B5 & 5 & 345.9 & 1 & -4.2 \\
\hline
\end{tabular}

Table 4.1: 5-bus network buses (nodes). 


\subsection{5-bus network simulation test}

\begin{tabular}{|l|c|c|c|c|}
\hline Line (name) & Bus 1 & Bus 2 & $\begin{array}{c}\text { Reactance } \\
{[\text { Ohm] }}\end{array}$ & $\begin{array}{c}\text { Apparent power } \\
\text { rating [MVA] }\end{array}$ \\
\hline Line_B2-B4 & 2 & 4 & 119 & 345 \\
\hline Line_B5-B2 & 5 & 2 & 59.5 & 345 \\
\hline Line_B5-B4 & 5 & 4 & 29.75 & 345 \\
\hline
\end{tabular}

Table 4.2: 5-bus network transmission lines.

\begin{tabular}{|c|c|c|c|c|}
\hline $\begin{array}{c}\text { Transformer } \\
\text { (name) }\end{array}$ & Bus 1 & Bus 2 & $\begin{array}{c}\text { Reactance } \\
\text { [p.u.] }\end{array}$ & $\begin{array}{c}\text { Apparent power } \\
\text { rating [MVA] }\end{array}$ \\
\hline Trf_B1-B5 & 1 & 5 & 0.16 & 800 \\
\hline Trf_B4-B3 & 4 & 3 & 0.08 & 800 \\
\hline
\end{tabular}

Table 4.3: 5-bus network transformers.

The reactance of the transformers in table 4.3 are given in per-unit (p.u.) according to the apparent power rating of the specific transformer. To calculate the actual reactance of the transformer in regard with the network, base values for the network was chosen as follow:

- $S_{\text {base }(\text { network })}=800 \mathrm{MVA}$

- $V_{\text {base }(\text { line-to-line })}=345 \mathrm{kV}$

- $Z_{\text {base }(\text { network })}=V_{\text {base(line-to-line })}^{2} / S_{\text {base(network })}$

With the base values and using the values in table 4.3 the per-unit reactance of the transformers in regard to the network are calculated as follow:

$$
x_{\text {trf }(\text { network })[p . u .]}=x_{[p . u .]} \cdot\left(S_{\text {base }(\text { network })} / S_{\text {base }(\text { transformer })}\right)
$$

The actual value of the transformer reactance is calculated using the new per-unit value and the base impedance of the network:

$$
x_{t r f}=x_{t r f(\text { network })[p . u .]} \cdot Z_{b a s e(\text { network })}
$$

With the transmission line and new transformer reactance, the B-matrix can be constructed, as derived in section 4.2. As mentioned before in section 4.2, the entry of the 


\subsection{5-bus network simulation test}

reference bus must be removed to avoid singularity in the B-matrix. In this case bus B1 is the reference bus, since it is connected to the reference machine and the voltage angle at $\mathrm{B} 1$ is zero degrees. After the edges (E) between the vertices (V) of the graph $G(V, E)$ has been established, Kirchhoff's current law (KCL) method was utilised for the active power flow, to find the vertices where real power is sourced (generation buses) and where real power is sinked (load buses), and thus a power injection vector was created with the following result:

\begin{tabular}{|c|c|}
\hline $\begin{array}{c}\text { Bus } \\
\text { (Vertex) }\end{array}$ & $\begin{array}{c}\text { Power } \\
{[\mathrm{MW}]}\end{array}$ \\
\hline 1 & 360 \\
\hline 2 & -800 \\
\hline 3 & 440 \\
\hline 4 & 0 \\
\hline 5 & 0 \\
\hline
\end{tabular}

Table 4.4: Real power injection vector.

\subsubsection{Verify graph model}

Using the B-matrix, the real power injection vector as presented in table 4.4, and rearranging equation (4.5) the voltage angles at each bus/vertex can be calculated and compared to the original single-line diagram model to verify the reconstructed mathematical model. The voltage angle results are summarised in table 4.5.

$$
\underline{\delta}=B^{-1} \cdot \underline{P}
$$

\begin{tabular}{|c|c|c|}
\hline $\begin{array}{c}\text { Bus } \\
\text { (Vertex) }\end{array}$ & $\begin{array}{c}\text { Single-line model } \\
\text { voltage angle (degrees) }\end{array}$ & $\begin{array}{c}\text { Graph model } \\
\text { voltage angle (degrees) }\end{array}$ \\
\hline 1 & 0 & 0 \\
\hline 2 & -18.9 & -18.692 \\
\hline 3 & 0.5 & 0.523 \\
\hline 4 & -2.0 & -1.998 \\
\hline 5 & -4.2 & -4.125 \\
\hline
\end{tabular}

Table 4.5: Compare single-line with graph model using node voltage angles.

Analyzing the results from table 4.5, it can be seen that the graph model (linearised power-flow calculation) and the single-line model (non-linear power-flow calculation) are very close in comparison, with the largest deviation 0.2 degrees. For a linear power-flow 


\subsection{5-bus network simulation test}

calculation on the single-line diagram model, the comparison improves, with the voltage angles agreeing with at least two decimal points.

\subsubsection{Optimal virtual inertia allocation}

After the model was verified the cost-function was setup as described in section 4.4. The optimisation script uses all the vertices (5-buses) as possible locations for the placement of virtual inertia, thus allowing complete location freedom. The cost-function is setup to expect a disturbance at all five buses and thus, have equal weights in the Q-matrix of equation (4.1). The inertial response effort matrix, $R_{M}$, from equation (4.2) also distributes the weight uniformly. The total virtual inertia budget is $M_{\text {total }}=50 \mathrm{MW} \cdot \mathrm{s}^{2}$.

The interior-point-method and the genetic algorithm was utilised to minimise the $\mathrm{H}_{2}$ norm cost-function. The genetic algorithm found the lowest point in the cost-function and the allocation result is as follow:

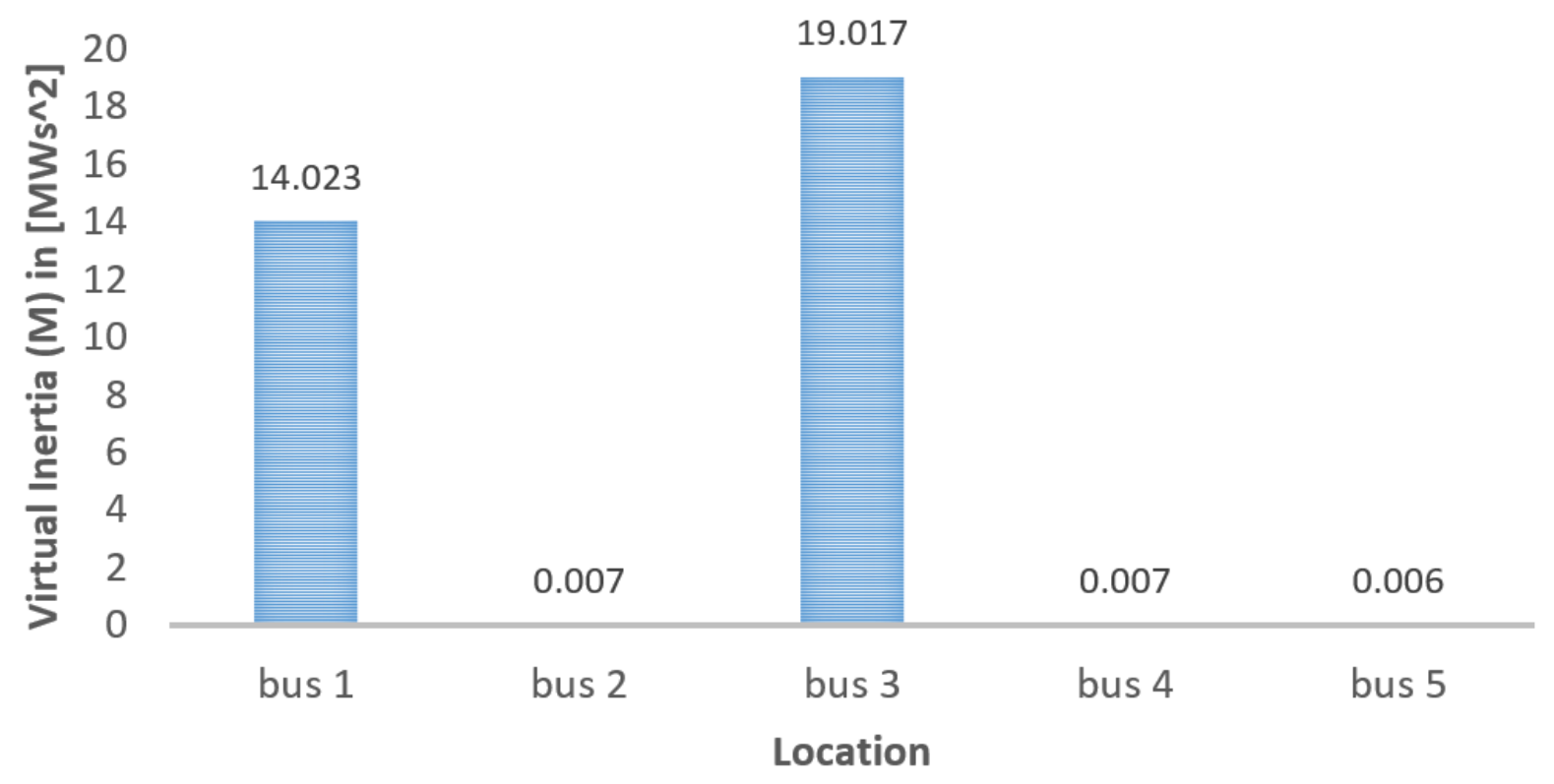

Figure 4.5: Optimal allocation of virtual inertia for the 5-bus network.

From figure 4.5 it is seen that virtual inertia are mainly allocated to buses $1 \& 3$. Bus 3 is allocated the most virtual inertia $\left(19.017 \mathrm{MW} \cdot \mathrm{s}^{2}\right)$, and bus 1 takes the second largest share $\left(14.023 \mathrm{MW} \cdot \mathrm{s}^{2}\right)$ of the allocated virtual inertia. The total allocated virtual inertia $\left(M_{\text {total }}\right)$ is $33.06 \mathrm{MW} \cdot \mathrm{s}^{2}$, thus $16.94 \mathrm{MW} \cdot \mathrm{s}^{2}$ remains from the given budget of $50 \mathrm{MW} \cdot \mathrm{s}^{2}$.

The optimal allocation result was then implemented on the 5-bus network. A load step-up (10\%) disturbance was executed on bus 2 (80.4 MW increase) to trigger a generation/load imbalance, which simulates a low-frequency event and thus, activate an inertial response 


\subsection{5-bus network simulation test}

from the power system. The results for a sub-optimal and an optimal virtual inertia allocation were obtained and are compared in the following section.

\subsubsection{Power system simulation results}

The DigSilent PowerFactory simulation of the single-line diagram model with the allocated virtual inertia was performed and the results for two allocation scenarios are shown and compared in table 4.6. The first allocation scenario does not make use of the optimal results, but rather a random distribution of virtual inertia. The second allocation makes use of the virtual inertia distribution that minimises the $\mathrm{H}_{2}$-norm cost-function. The result metrics used for comparison are as follow:

- $H_{2}$-norm: The value of the cost-function to minimise.

- $M_{\text {total }}$ : The total virtual inertia used for the allocation $\left[\mathrm{MW} \cdot \mathrm{s}^{2}\right]$.

- Frequency nadir: The lowest point of the frequency deviation [Hz].

- $R o C o F_{\text {max }}$ : The maximum RoCoF during the frequency excursion $[\mathrm{Hz} / \mathrm{s}]$.

- $R o C o F_{a v g}$ : The average RoCoF till the point of frequency nadir $[\mathrm{Hz} / \mathrm{s}]$.

- $P_{\text {inertia }}$ : The maximum power injection from the virtual inertia [MW].

- $E_{\text {inertia }}$ : The energy used in the inertial response [MJ].

\begin{tabular}{|l|c|c|}
\hline & Allocation 1 (sub-optimal) & Allocation 2 (Optimised) \\
\hline$H_{2}$-norm & $2.71 \times 10^{7}$ & $2.052 \times 10^{6}$ \\
\hline$M_{\text {total }}$ & $50 \mathrm{MW} \cdot s^{2}$ & $33.06 \mathrm{MW} \cdot s^{2}$ \\
\hline Frequency nadir & $49.906 \mathrm{~Hz}$ & $49.93 \mathrm{~Hz}$ \\
\hline$R_{0} C o F_{\max }$ & $-4.127 \mathrm{~Hz} / \mathrm{s}$ & $-1.373 \mathrm{~Hz} / \mathrm{s}$ \\
\hline$R_{0} C o F_{\text {avg }}$ & $-0.058 \mathrm{~Hz} / \mathrm{s}$ & $-0.048 \mathrm{~Hz} / \mathrm{s}$ \\
\hline$P_{\text {inertia }}$ & $127.4 \mathrm{MW}$ & $26.5 \mathrm{MW}$ \\
\hline$E_{\text {inertia }}$ & $59.81 \mathrm{MJ}$ & $2.33 \mathrm{MJ}$ \\
\hline
\end{tabular}

Table 4.6: Optimal allocation of virtual inertia for 5-bus network simulation results.

Comparing the results of the two scenarios, it is seen that the optimal allocation does not use the full budget of virtual inertia and still delivers a more desirable response. The optimisation results in a higher frequency nadir compared to the sub-optimal allocation. The maximum RoCoF is reduced from $-4.127 \mathrm{~Hz} / \mathrm{s}$ to $-1.373 \mathrm{~Hz} / \mathrm{s}$, which is a significant improvement in frequency stability. The average RoCoF from the point of disturbance to frequency nadir improved from $-0.058 \mathrm{~Hz} / \mathrm{s}$ in allocation 1 to a lower $-0.048 \mathrm{~Hz} / \mathrm{s}$ in 


\subsection{Western TX case study}

allocation 2. Comparing the power injection from the virtual inertia sources for the inertial response, the first allocation reached a maximum output of $127.4 \mathrm{MW}$, where allocation 2 reached a peak of $26.5 \mathrm{MW}$, which is substantially less real power. The energy required for the virtual inertia reduced from 59.81 MJ to 2.33 MJ which is a significant result for maintaining and improving system stability.

\subsection{Western TX case study}

A case study was done on the Eskom western transmission network. This network does not possess any large generation plants except for Koeberg nuclear power station, which consists of two 1072 MVA generators, each with an inertia constant $H=5.61$ seconds. The optimisation and test were performed considering the trip of Koeberg nuclear power plant. The optimal allocation result are presented in figure 4.7. Table 4.7 summarises the results for three scenarios.

\subsubsection{Building the power system model and optimisation script}

Three python scripts were developed to interact with the simulation software, DigSilent PowerFactory 2017. The first script, extraction.py, was developed to walk through the contents of the single-line diagram model and extract the following elements from the model, see figure E.2 in appendix E for the script flow-diagram:

- Buses: These are the terminals of the substations, which will form the nodes or vertices of the graph model. The attributes collected from a bus included the name of the bus (e.g. Palmiet 400 BB2) and the voltage angle (e.g. $-7.59^{\circ}$ ) at the bus.

- Transformers: These connect buses of different voltages in a sub-station. The attributes gathered were the name (e.g. Acacia 132/33 T5), the names of the two connecting buses (e.g. Acacia 132 BB1 \& Acacia 33 BB1), the apparent power rating [MVA], and the per-unit reactance [p.u.].

- Branches: This is the transmission lines connecting sub-stations together through the buses. The information collected form the branches were, the name of the branch (e.g. Droerivier-Hydra 400_2), the reactance [Ohm], voltage $[\mathrm{kV}]$, and the active power-flow $[\mathrm{MW}]$ in the branch.

- Generators: These inject power into the network, and since they are synchronous machines they are also the source of inertia for frequency stability. The information obtained includes, the name of the generator (e.g. Koeberg Gen1), apparent power rating $[\mathrm{MVA}]$, voltage $[\mathrm{kV}]$, and active power dispatched [MW]. 


\subsection{Western TX case study}

The next four scripts were developed in Matlab. These scripts are graph.m, state-space.m, H2_construction.m and GArev1.m. The purpose of these three scripts is to develop the graph model, build a state-space representation of the power system network, construct the $H_{2}$-norm cost-function, and lastly setup the optimisation function to minimise the cost-function.

The script graph.m imports the data extracted from the python script, extraction.py. The script graph.m reduces the list of buses, by aggregating parallel buses which have similar names and voltage angles, as indicated in figure 4.6. See figure E.3 in appendix E for the graph.m script flow-diagram.

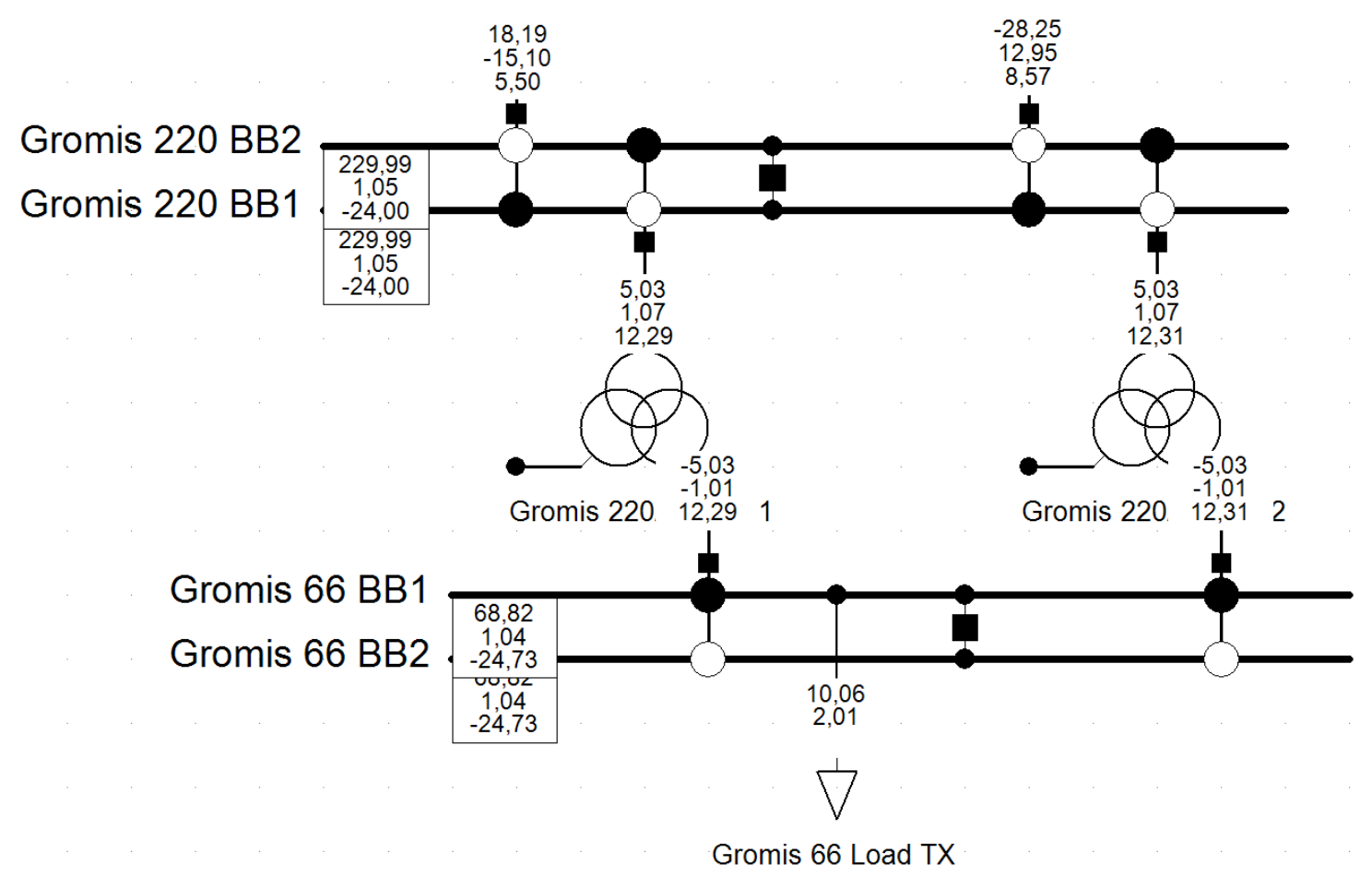

Figure 4.6: Parallel buses in Gromis sub-station.

From figure 4.6, where Gromis sub-station is used as an example, it can be seen that there are two sets of parallel buses \{Gromis 220 BB1, Gromis 220 BB1\} and \{Gromis 66 BB1, Gromis 66 BB2\}, these parallel buses does in fact form one bus through a breaker switch. Thus, for simplifying the model these parallel buses are aggregated to form one single-bus. After the list of buses were reduced, each bus were assigned a number, which represents the specific bus. The bus vector is presented in appendix $\mathrm{C}$. The bus-vector size is $56 \times 1$.

After the bus vector is created, the second step is to create a list of transformers in the network. The names of the two connecting buses of each transformer are replaced with the corresponding number of each bus. In terms of the graph $G(V, E)$, the transformers 


\subsection{Western TX case study}

form the edges (E) connecting buses or vertices (V). The transformer's per-unit reactance where converted to an equivalent reactance, sharing a common system base and the appropriate voltage base values, through the use of equations (4.31 \& 4.30). As in the case of the parallel identical buses, there exists also transformers operating in parallel as seen in figure 4.6. The transformers operating in parallel are aggregated to form a single connection or edge between the two vertices of interest. To form an aggregated transformer, the parallel transformers susceptance (in this case it is the negative of the inverse of the reactance) were added, the apparent power ratings were summed, and the active power was summed to create the aggregated transformer. The vertices of interest are thus, only connected with one edge.

To build the branch vector required to analyse the name of the branch. The name of a branch comes from the buses that the branch connects, thus the name Acacia-Koeberg 132_2 means that the branch connects the $132 \mathrm{kV}$ buses of Acacia and Koeberg together. The names of the connecting buses are then replaced with the corresponding vertex numbers, thus forming the edges between the vertices of interest. Like the buses and transformers, the parallel branches are aggregated to a single branch to reduce the number of edges between two specific vertices to one edge.

To finish the graph model the admittance matrix (B-matrix) and the power injection vector are created. The admittance matrix puts weights on the edges of the of the graph $G(V, E)$. These weights are required to calculate the power-flow between two vertices, as shown in equation (4.4). The admittance matrix is an $n \times n$ matrix and is calculated using the branch and transformer reactance as follow to create a single admittance matrix.

The off-diagonal elements $(k \neq j)$ :

$$
B_{k j}=-\frac{1}{x_{k j}}
$$

The diagonal elements $(k=j)$ :

$$
B_{k k}=-\frac{1}{x_{k}}+\sum_{j=1, j \neq k}^{N}\left(-\frac{1}{x_{j k}}\right)
$$

After the edges (E) between the vertices (V) of the graph $G(V, E)$ has been established, Kirchhoff's current law (KCL) method was utilised for the active power flow, to find the vertices where real power is sourced (generation buses) and where real power is sinked (load buses). In an AC system, active power flows from the bus with the higher voltage angle to the bus with a lower voltage angle, thus the voltage angle of the two buses of 


\subsection{Western TX case study}

interest were compared to find the direction of the power flow between the two buses.

The second Matlab script, state_space.m builds the swing equation in vector form, thus the frequency dynamics at each bus is captured. Equation (3.8), which describes the relationship between the inertia constants $H$ and $M$, was used to calculate the inertia $M$ for the vertices representing a synchronous generation bus. The inertia, $M$, and damping, $D$, of each generator is stored respectively on the diagonal of two $n \times n$ matrices. The state-space model is then constructed as derived and explained in section 4.3. The similarity transform is operated on the state-space matrices (A, B, and $\mathrm{C}$ ) to diagonalise the Jacobian matrix, thus the new matrices are $A_{S}, B_{S}$, and $C_{S}$. The governor and virtual inertia state-space matrices and vectors, as derived in section 4.3, are added to the power system state-space model to create one an augmented model, see figure E.4 in appendix E for the script flow-diagram.

The next Matlab script, H2_construction.m, takes the augmented state-space model and the energy metrics (4.1) and (4.2) to construct the $H_{2}$-norm cost-function. To evaluate the system's energy amplification due to a disturbance input, a term $F \underline{\nu}$, is added to the state-variable dynamics.

$$
\underline{\dot{x}}=A \underline{x}+B \underline{u}+F \underline{\nu}
$$

Where $\mathrm{G}$ is a matrix encoding the location of the disturbance and applies a gain to the disturbance vector $\nu$. The location of the selected disturbance, was at bus 33, which represents Koeberg power plant as shown in appendix C. The feed-back gains of the virtual inertia models are placed in the system's feed-back matrix, $K$, according to the augmented state-variable vector.

Equations (4.1) and (4.2) were used to build the performance output, $y_{p m}$, which will be included in the $\mathrm{H}_{2}$-norm cost-function metric. The performance metric is as follow:

$$
\int_{0}^{\infty} y_{p m}^{T} \cdot y_{p m} d t=\int_{0}^{\infty} \omega^{T} \cdot Q \cdot \omega+p_{\text {virtual }}^{T} \cdot R_{m} \cdot p_{\text {virtual }} d t
$$

Where

$$
\underline{y_{p m}}=\left[\begin{array}{cccc}
0 & 0 & 0 & 0 \\
Q^{\frac{1}{2}} C_{S} & 0 & 0 & 0 \\
0 & 0 & 0 & 0 \\
0 & 0 & 0 & 0
\end{array}\right]\left[\begin{array}{c}
\underline{\delta} \\
\underline{\omega} \\
\underline{x_{g}} \\
\underline{x_{v}}
\end{array}\right]+\left[\begin{array}{c}
0 \\
0 \\
0 \\
R^{\frac{1}{2}}
\end{array}\right] \underline{u}
$$




\subsection{Western TX case study}

With $\underline{y_{p m}}$ in the form $\underline{y}=C \underline{x}+D \underline{u}$. The closed-loop system is thus,

$$
\begin{gathered}
\underline{\dot{x}}=(A-B \cdot K) \underline{x}+F \underline{\nu} \\
\underline{y_{p m}}=(C-D \cdot K) \underline{x}
\end{gathered}
$$

The cost-function as derived before in section 4.4, and using the closed-loop state matrices, the cost-function is written as:

$$
H_{2}=|G(\cdot)|_{2}=\sqrt{\operatorname{trace}\left[F^{T} P_{o} F\right]}
$$

Refer to figure E.5 in appendix E for the H2_construction.m script flow-diagram.

The last Matlab script is GArev1.m. This script configures the optimisation tool by setting the constraints and creating the format for the result output. The virtual inertia allocation lower bound was set to zero $\mathrm{MW} \cdot \mathrm{s}^{2}$. The upper bound was set to $25 \mathrm{MW} \cdot S^{2}$, thus providing sufficient freedom to concentrate the placement of virtual inertia if that minimises the cost-function. The total virtual inertia budget was set to $80 \mathrm{MW} \cdot \mathrm{s}^{2}$, which is the same amount provided by Koeberg power plant.

Refer to figure E.6 in appendix E for the GArev1.m script flow-diagram.

The genetic algorithm was deployed to minimise equation (4.40). The virtual inertia distribution which resulted in the best obtained minimisation of equation (4.40), is shown in figure 4.7 .

\section{VIRTUAL INERTIA ALLOCATION}

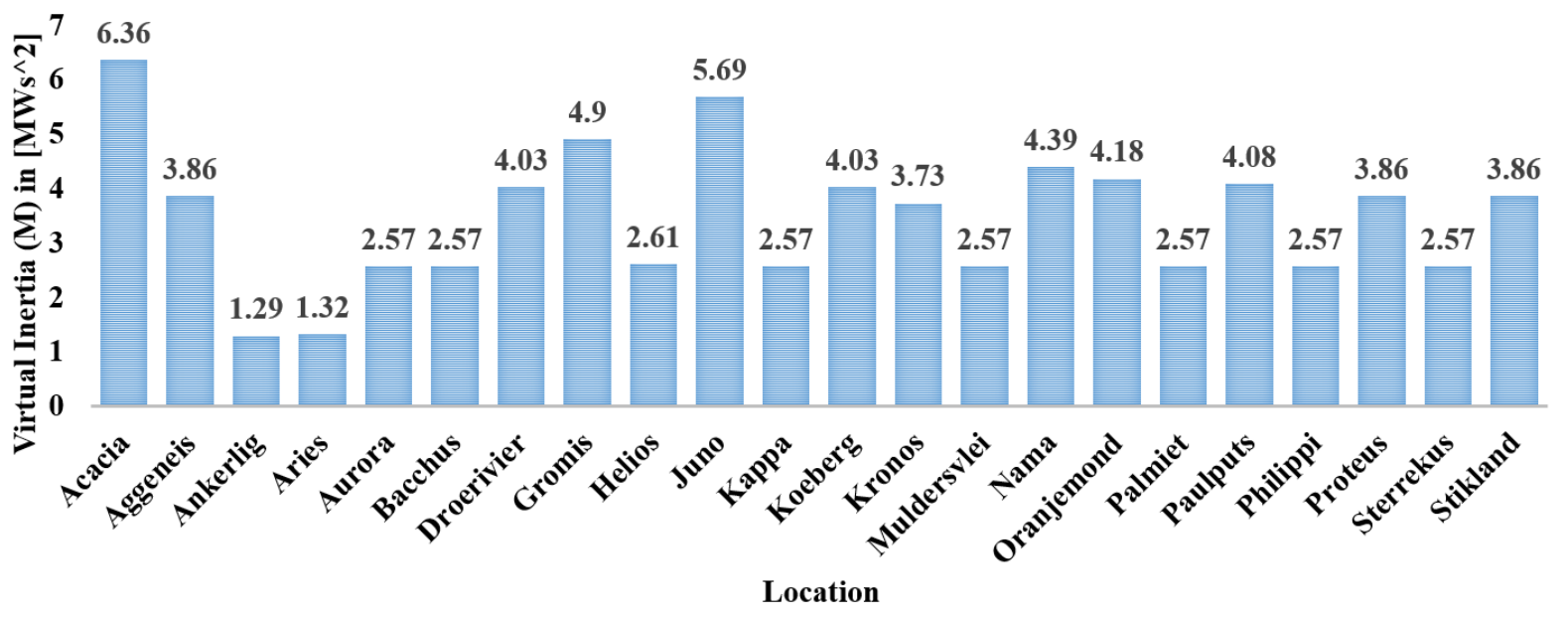

Figure 4.7: Optimal allocation of virtual inertia for the South African western TX. 


\subsection{Western TX case study}

The next two python scripts are, calc_inertia_setting.py and Apply_VI_settings.py. The script calc_inertia_setting.py retrieves the result from the optimisation output and divides the virtual inertia allocated to a particular bus to specific control-loop parameters, for the individual units in the RPP, refer to figure E.7 in appendix E for the script flow-diagram.

The last script, Apply_VI_settings.py, interfaces with DigSilent PowerFactor simulation software and configure the individual RPPs and their units according to the virtual inertia control parameters as calculated by calc_inertia_setting.py. Figure E.8 in appendix E presents the flow-diagram for the script Apply_VI_settings.py.

\subsubsection{Case study sumulation results}

The single-line diagram with the configured parameters and the disturbance, at Koeberg power plant, were simulated for three scenarios. The first scenario is for a high penetration of inverter-based generation, but with no virtual inertia implementation. The second scenario includes virtual inertia implementation, but the allocation of the virtual inertia is not according to the optimisation result. The third scenario uses the optimisation result. The results of the three scenarios are summarised and compared in table 4.7

Table 4.7: Simulation test results

\begin{tabular}{|c|c|c|c|}
\hline & $\begin{array}{c}\text { No virtual } \\
\text { inertia }\end{array}$ & $\begin{array}{c}\text { Sub-optimal } \\
\text { allocation }\end{array}$ & $\begin{array}{c}\text { Optimal } \\
\text { allocation }\end{array}$ \\
\hline $\begin{array}{c}\text { Average } \\
\text { RoCoF [Hz/s] }\end{array}$ & -0.111 & -0.102 & -0.068 \\
\hline $\begin{array}{c}\text { Control } \\
\text { effort [MJ] }\end{array}$ & N/A & 392.814 & 366.978 \\
\hline $\begin{array}{c}\text { Frequency } \\
\text { nadir [Hz] }\end{array}$ & 48.968 & 49.012 & 49.064 \\
\hline $\begin{array}{c}\text { Time to } \\
\text { nadir [s] }\end{array}$ & 10.372 & 10.686 & 14.843 \\
\hline
\end{tabular}

From a control system perspective the optimisation strives to make the power system critically damped. The significance of a critically damped system is it allows the system to converge to equilibrium the fastest and without oscillations [78]. Critical dampening is important to prevent large power and frequency oscillations, as well as reducing the amount of time the system can't respond to new disturbances. 


\subsection{Western TX case study}

The results presented in table 4.7 indicates that the optimal virtual inertia allocation reduces the RoCoF from $-0.102 \mathrm{~Hz}$ per second to $-0.068 \mathrm{~Hz}$ per second, while using 25.836 MJ less energy than the sub-optimal allocation. The results also show that the inertia does not improve the frequency nadir very much, but delays the time when the nadir is reached. Comparing the time to nadir for the sub-optimal versus the optimal allocation, it is seen that the two nadirs are close in value, however, the optimal allocation reaches its nadir 4.157 seconds later than the sub-optimal allocation's frequency nadir. Another interesting note about the results is that, comparing the case with no virtual inertia to the sub-optimal case, it is noted that the virtual inertia did not improve system stability significantly if the placement of virtual inertia is inefficient and not according to the optimal distribution. 


\section{Chapter 5}

\section{Summary and Conclusions}

\subsection{Conclusions.}

Investigating the impact of future high RES penetration, it was noted that inverter-based generation is the fastest growing generation source. It is thus, inevitable that inverterbased RES generation will contribute a significant or even a majority share towards the generation mix of the future power systems. With high share of inverter-based RES in the generation mix comes increased variability and thus, a greater need for flexibility is required since balancing the generation with variable load demand becomes a greater challenge. From a transient stability perspective, increased inverter-based RES deteriorates the system's frequency stability, as a result from the decline in system inertia. This leads to fast transient response dynamics and increases the difficulty for frequency control. The SAGCC only makes provision for RES to participate in primary/droop control during over-frequency events, however, RES plants are not required to assist in inertial response, during low-frequency events.

Power system stability was reviewed considering the three pillars, rotor angle, voltage and frequency stability. For high penetration of inverter feed-in, the responsibility of rotor angle (which becomes voltage angle for inverters) and frequency stability shifts to the technology replacing the synchronous generator. The decline in system inertia means that the power system becomes more sensitive to disturbances. A disturbance on the system influences the system states (voltage angle and frequency) to deviate from the desired equilibrium point.

It was seen in chapter 3 that due to conventional power plants being dispatched based on the residual load, which is more variable then the actual system load, the number of online synchronous generators varies over time. The impact of varying amount of online synchronous generators directly influences the system inertia. The variability in system 


\subsection{Conclusions.}

inertia translate to variability in system stability, leading to an unpredictable and unreliable power system.

For a system with a low quantity of inertia the focus shifts to the distribution of inertia within a multi-area network to maximise the performance of the frequency response in order to maintain adequate stability margin. To mitigate the decline in inertia and to control the distribution of inertia in a network, virtual inertia was investigated and simulated for wind and solar PV plants. The results for both cases shows an improvement in the system's frequency response to a generation/load imbalance disturbance input.

The swing equation shows the interaction between voltage angle, frequency, power-flow, damping and inertia. The equation indicates that higher quantity of inertia increases the stability of the frequency. This is true for one synchronous generator, however in a network of multiple synchronous generators, which oscillate against each other, the location of inertia becomes important. The significance of inertia distribution was seen during different simulations using the same amount of total system inertia, but with different distributions, which leads to different frequency responses.

Since the performance of the frequency response depends on the location of the inertia and not solely on the inertia quantity, the total system inertia was discarded as a stability metric. Energy metrics where used to construct a cost-function to evaluate the system stability. The $\mathrm{H}_{2}$-norm cost-function was constructed with the use of graph theory to represent the system in the state-space domain. The genetic algorithm was used to find the distribution of virtual inertia that minimises the cost-function.

A small 5-bus network was used to test the optimisation. The simulation of the 5-bus network with optimal virtual inertia allocation showed promising results, which lead to the testing of larger networks and ultimately to the Western TX network of Eskom. The Western TX optimisation results indicates a significant improvement in RoCoF. The time to reach the same frequency nadir is extended with 4.16 seconds for the optimal allocation. The energy used for the inertial response is $25 \mathrm{MJ}$ less for the optimal distribution. The average power used for the sub-optimal scenario is $36.76 \mathrm{MW}$, where the optimal allocation used on average 24.72 MW, i.e. 12.04 MW less power.

The final conclusions on the virtual inertia allocation simulations and the stability analysis is that the amount of inertia alone is not a satisfactory metric for frequency stability, since similar amounts of inertia result in different performances for different allocations. Inertia emulation at every node can be decremental to stability performance, thus location of inertia matters with respect to the disturbance input location, network topology, 


\subsection{Recommended Future Work}

location of generators and loads, and power-flow paths.

To summarise, inverter-based RES generation integration introduces increased variability, uncertainty and uncontrollability into the power system. This leads to increased difficulty in balancing generation with load, which results in decreased frequency stability. The replacement of synchronous generators with inverter-based generation reduces the system inertia, making the power system behavior more "nervous" during a disturbance on the system. Further drawbacks include increased ramp-rates and cycling of conventional dispatchable power plants, which reduces the life-span of the power plant and increases the maintenance costs. To combat these issues the power system needs high flexibility. This requires balancing reserve and fast acting operational reserves. This is where RES can contribute to the system's flexibility through curtailment and providing virtual inertia to restore the system's declining inertia. It is difficult to define a hard limit for RES penetration, since increased VRE has an aggregation effect. The benefits of VRE aggregation increases with increased wide-spread distributed RES plants. Aggregation reduces variability, uncertainty and to a less extend uncontrollability. This makes balancing easier, decreases maximum ramp-rates and the amount of cycling of power plants. Thus, utilises less of the power system's flexibility, and requires less operating reserve.

\subsection{Recommended Future Work}

Plenty of research is done on generating renewable energy, however, these sources must eventually be integrated into the power system. For safe and reliable operation of the power system with high share of inverter-based VRE in the total generation mix, more research is required and solutions for integrating these sources. In terms of frequency stability, further research on virtual inertia or similar fast power response mitigation techniques are required to compensate for the variability of RES and limit the influence of disturbances on the system. Research on activation schemes for virtual inertia is necessary to insure no false triggers, yet fast response is obtained.

Further research is needed on the aggregation of VRE generation, especially for wind, since the aggregation of variable sources operate differently than individual generation units or plants and reduces variability. This should be complemented with a research on favorable locations for RES development and integration. This research would greatly complement the work done on optimal allocation of virtual inertia.

Additional work can be done on probabilistic models for disturbance event forecasting, which can be used in the optimisation of virtual inertia allocation, to configure the power 


\subsection{Recommended Future Work}

system, using the virtual inertia, for the most anticipated disturbance event and its location.

Modeling the power system using graph theory and state-space modeling allows for more abstract simulations and optimisation, which is network specific. For a large power system the model can become large with many inputs and outputs across the network. To reduce the network model, while maintaining system information, Kron-reduction can be implemented to reduce the number of nodes used. Kron-reduction is the basis for the well-known star $(\mathrm{Y})$ to delta $(\Delta)$ transformation, which reduces four nodes to three nodes while maintaining information about the system. This reduction decreases the amount of computations and thus, results in shorter simulation time and faster optimisation.

Further work should be done using graph theory on power system networks. With the network being described mathematically in matrix form, the propagation of a disturbance in the network can be analyzed and studied, to implement mitigations effectively. 


\section{References}

[1] Rajay Das, Prof Durlav Hazarika and Prof Shakuntala Laskar, "Issues of power system economics and operational planning," 2016. [Online]. Available: http://shodhganga.inflibnet.ac.in/bitstream/10603/110819/6/06_chapter1.pdf 1, 2

[2] E. Kyriakides, M. Polycarpou (Eds.), Intelligent Monitoring, Control, and Security of Critical Infrastructure Systems. Springer-Verlag, 2015. [Online]. Available: http://www.springer.com/cda/content/document/cda_downloaddocument/ 9783662441596-c2.pdf?SGWID=0-0-45-1477627-p176840025 1, 2, 38

[3] Kai Heussen, Morten Lind, "Decomposing objectives and functions in power system operation and control," 2009 IEEE PES/IAS Conference on Sustainable Alternative Energy (SAE), 2009. [Online]. Available: https://ieeexplore.ieee.org/document/ 55348731

[4] Prabha Kundur, Power System System Stability and Control, 1st ed. McGraw-Hill, 1994. 1, 2, 10, 11, 13, 21

[5] A. E. Fitzgerald, C. Kingsley and S. D. Umans, Electric Machinery, 6th ed. McGrawHill, 2009. 1, 2, 21

[6] Jennifer Leisch, Jaquelin Cochran, "Integrating variable renewable energy into the grid: key issues," 2015. [Online]. Available: https://www.nrel.gov/docs/fy15osti/ 63033.pdf 2, 3

[7] National Renewable Energy Laboratory (NREL): David Palchak, Jaquelin Cochran, Ali Ehlen, Brendan McBennett, Michael Milligan, Ilya Chernyakhovskiy. Lawrence Berkeley National Laboratory (Berkeley Lab): Ranjit Deshmukh, Nikit Abhyankar. Power System Operation Corporation Limited (POSOCO): Sushil Kumar Soonee, S.R. Narasimhan, Mohit Joshi. U.S. Agency for International Development (USAID): Priya Sreedharan, "GREENING THE GRID: Pathways to Integrate 175 Gigawatts of Renewable Energy into India's Electric Grid," 2017. [Online]. Available: https://www.nrel.gov/docs/fy17osti/68530.pdf 2 
[8] Pieter Tielens, Dirk Van Hertem, "The relevance of inertia in power systems," Renewable and Sustainable Energy Reviews, vol. 55, pp. 999-1009, 2016. [Online]. Available: https://www.sciencedirect.com/science/article/pii/S136403211501268X 2, 3, 46

[9] European Commission, "Renewable energy progress report," Report from the commision to the european parliament, the council, the european economic and social committee and the committee of the regions. [Online]. Available: https://ec.europa.eu/transparency/regdoc/rep/1/2017/EN/ COM-2017-57-F1-EN-MAIN-PART-1.PDF 2, 3, 9

[10] International Renewable Energy Agency (IRENA), International Energy Agency (IEA), "Renewable Energy Integration in Power Grids (Technology Brief)," 2015. [Online]. Available: http://www.irena.org/publications/2015/Oct/ Renewable-energy-integration-in-power-grids 2

[11] Francisco Daz-Gonzlez, Melanie Hau, Andreas Sumper, OriolGomis-Bellmunt, "Participation of wind power plants in system frequency control: Review of grid code requirements and control methods," Renewable and Sustainable Energy Reviews, vol. 34, pp. 551-564, 2014. [Online]. Available: https: //www.sciencedirect.com/science/article/pii/S13640321140020192, 3

[12] Johan Morren, Jan Pierik, Sjoerd W.H. de Haan, "Inertial response of variable speed wind turbines," Electric Power Systems Research, vol. 76, pp. 980 - 987, 2006. [Online]. Available: https://www.sciencedirect.com/science/article/abs/pii/ S0378779605002713 2, 3

[13] Mohammad Dreidy, H. Mokhlis, Saad Mekhilef, "Inertia response and frequency control techniques for renewable energy sources: A review," Renewable and Sustainable Energy Reviews, vol. 69, pp. 144-155, 2017. [Online]. Available: https://www.sciencedirect.com/science/article/pii/S1364032116309212 2, 3

[14] A. Ulbig, T.S. Borsche, G. Andersson, "Impact of low rotational inertia on power system stability and operation," IFAC Proceedings Volumes, vol. 47, no. 3, pp. 7290-7297, 3 2014. [Online]. Available: https://arxiv.org/pdf/1312.6435.pdf 3, 22, $38,42,43,44$

[15] Jacob Aho, Andrew Buckspan, Jason Laks, Yunho Jeong, Fiona Dunne and Lucy Pao (NREL), "Tutorial of wind turbine control for supporting grid frequency through active power control," 2012 American Control Conference Montreal, Canada, no. 1, pp. 1-14, 6 2012. [Online]. Available: http://www.nrel.gov/docs/fy12osti/54605.pdf $3,21,27$ 


\section{REFERENCES}

[16] Grid Connection Code for RPPs in South Africa, "Grid connection code for renewable power plants (RPPs) connected to the electricity transmission system (TS) or the distribution system (DS) in South Africa," July 2016. 3, 23, 24, 45, 55, 59

[17] Sarah, "How Summer Dog Sled Tours Help Us As A Competitive Racing Kennel," May 2015. [Online]. Available: https://turningheadskennel.com/ running-hard-how-summer-dog-sled-tours-help-us-as-a-competitive-racing-kennel/ 3

[18] Sebastian March, "Posts Tagged With: sled dog positions," February 2013. [Online]. Available: https://iditarodoutsider.wordpress.com/tag/sled-dog-positions/ 4

[19] Eskom Transmission, Thava Govender, "The eskom transmission development plan 2018 to 2027 (tdp 2017)," Public forum, 10 2017. [Online]. Available: http://www.eskom.co.za/Whatweredoing/TransmissionDevelopmentPlan/ Documents/2018-2027TDP_PubForumPresentationOct2017rev3.pdf 5, 14, 15, 16

[20] (Fraunhofer IWES) K. Knorr, B. Zimmermann, Dr. S. Bofinger, AK. Gerlach; (CSIR Energy Centre) Dr. T Bischof-Niemz, C. Mushwana, "Wind and solar pv resource aggregation study for south africa," Final Report, 11 2016. [Online]. Available: https://www.csir.co.za/sites/default/files/Documents/ WindandSolarPVResourceAggregationStudyforSouthAfrica_Finalreport.pdf 5, 17

[21] E. Bayer, "Report on the German power system," Agora Energiewende. [Online]. Available: https://www.agora-energiewende.de/en/publications/ 9

[22] P. Kundur, J. Paserba, V. Ajjarapu, G. Andersson, A. Bose, C. Canizares, N. Hatziargyriou, D. Hill, A. Stankovic, C. Taylor, T. Van Cutsem, V. Vittal, "Definition and classification of power system stability ieee/cigre joint task force on stability terms and definitions," IEEE Transactions on Power Systems, vol. 19, pp. 1387 1401, 2004. [Online]. Available: https://ieeexplore.ieee.org/document/1318675 10

[23] M. Eremia, Handbook of Electrical Power System Dynamics. John Wiley \& Sons, Incorporated, 2013. [Online]. Available: https://ebookcentral.proquest.com/ lib/sun/detail.action?docID=1129732 10, 11, 12

[24] Saikat Chakrabarti, "Notes on power system voltage stability," 2011. [Online]. Available: http://home.iitk.ac.in/ saikatc/EE632_files/VS_SC.pdf 12

[25] J. Calitz, C. Mushwana, Dr. T. Bischof-Niemz, "Statistics of utility-scale solar pv, wind and csp in south africa in 2016," CSIR Energy Centre Report, 4 2017. [Online]. Available: hhttps://www.csir.co.za/sites/default/files/Documents/ StatisticsofREinSAin2017-CSIR-FINAL.pdf 17 
[26] J.G. Wright, T. Bischof-Niemz, J.R. Calitza, C. Mushwana, R. van Heerdena, "Future wind deployment scenarios for south africa," WindAc Africa, 2017. [Online]. Available: https://researchspace.csir.co.za/dspace/handle/10204/10070 17

[27] Deutsche Gesellschaft fur Internationale Zusammenarbeit (GIZ) GmbH, “Assessing the impact of increasing shares of variable generation on system operations in south africa," Flexibility study report prepared for Eskom and Department of Energy, 9 2017. 18, 20, 21

[28] Paul Denholm, T. R. Jyothsna, Matthew O'Connell, Gregory Brinkman, and Jennie Jorgenson, "Overgeneration from solar energy in california: A field guide to the duck chart," National Renewable Energy Laboratory, November 2015. [Online]. Available: https://www.nrel.gov/docs/fy16osti/65023.pdf 19, 20

[29] Akarin Suwannarat, Birgitte Bak-Jensen, Zhe Chen, "Power system stability with large-scale wind power penetration," Power and Energy Systems, AsiaPES 200\%, no. 3, 4 2007. [Online]. Available: http://citeseerx.ist.psu.edu/viewdoc/download? doi $=10 \cdot 1 \cdot 1.517 .7729 \&$ rep $=$ rep $1 \&$ type $=$ pdf 21

[30] Pieter Tielens, Dirk Van Hertem, "Grid inertia and frequency control in power systems with high penetration of renewables," Google Scholar and KU Leuven published, 4 2012. [Online]. Available: https://pdfs.semanticscholar.org/1cd1/ 9e3ae4b3ff6919570cf6faa693a13d21652a.pdf 21, 46

[31] Australian Energy Market Operator (AEMO), "Black system south australia 28 september 2016," March 2017. [Online]. Available: https://www.aemo.com.au/-/media/Files/Electricity/ NEM/Market_Notices_and_Events/Power_System_Incident_Reports/2017/ Integrated-Final-Report-SA-Black-System-28-September-2016.pdf 25, 26

[32] Anderson Hoke, Dragan Maksimovi, "Active power control of photovoltaic power systems," 2013 1st IEEE Conference on Technologies for Sustainability (SusTech), 2013. [Online]. Available: https://ieeexplore.ieee.org/document/6617300/authors\# authors 28

[33] Istvan Vajda, Zalan Kohari, Laszlo Benko, Victor Meerovich, and Wolfgang Gawalek, "Investigation of joint operation of a superconducting kinetic energy storage (flywheel) and solar cells," IEEE TRANSACTIONS ON APPLIED SUPERCONDUCTIVITY, vol. 13, June 2003. [Online]. Available: https: //ieeexplore.ieee.org/stamp/stamp.jsp?arnumber=1212049 29 
[34] Matthew L. Lazarewicz, Alex Rojas, "Grid frequency regulation by recycling electrical energy in flywheels," IEEE Power Engineering Society General Meeting, 2004, January 2005. [Online]. Available: https://ieeexplore.ieee.org/stamp/stamp. jsp?tp=\&arnumber $=1373235 \& \operatorname{tag}=129$

[35] J.M. Carrasco, L.G. Franquelo, J.T. Bialasiewicz, E. Galvan, R.C. PortilloGuisado, M.A.M. Prats, J.I. Leon, N. Moreno-Alfonso, "Power-electronic systems for the grid integration of renewable energy sources: A survey," IEEE Transactions on Industrial Electronics, vol. 53, pp. 1002-1016, June 2006. [Online]. Available: https://ieeexplore.ieee.org/document/1667898/ 29, 30, 32, 33, 34

[36] "Beacon Power," 2018. [Online]. Available: http://beaconpower.com/ stephentown-new-york/ 29, 30

[37] Laura Geggel, "Why is hydrogen the most common element in the universe?" Live Science, April 2017. [Online]. Available: https://www.livescience.com/ 58498-why-is-hydrogen-the-most-common-element.html 30

[38] Office of Energy Efficiency \& Renewable Energy, "Hydrogen production: Electrolysis," Energy.Gov, U.S. Department of Energy, 2018. [Online]. Available: https://www.energy.gov/eere/fuelcells/hydrogen-production-electrolysis 30

[39] Trevor M. Letcher, Richard Law, David Reay, Storing energy: with special reference to renewable energy sources, 1st ed. Amsterdam, Netherlands : Elsevier, 2016. 30

[40] Haisheng Chen, Thang Ngoc Cong, Wei Yang, Chunqing Tan, Yongliang Li, Yulong Ding, "Progress in electrical energy storage system: A critical review," Progress in Natural Science, vol. 19, pp. 291-312, March 2009. [Online]. Available: http://www.sciencedirect.com/science/article/pii/S100200710800381X 30, 32, 33, 36

[41] Andreas Zttel, "Materials for hydrogen storage," Materialstoday, vol. 6, pp. 2423, September 2003. [Online]. Available: https://doi.org/10.1016/S1369-7021(03) 00922-2 30

[42] J. Kurtz, C. Ainscough, L. Simpson, M. Caton, "Hydrogen storage needs for early motive fuel cell markets," National Renewable Energy Laboratory (NREL) Technical Report, November 2012. [Online]. Available: https://www.nrel.gov/docs/fy13osti/ 52783.pdf 30

[43] Steven G. Chalk, James F. Miller, "Key challenges and recent progress in batteries, fuel cells, and hydrogen storage for clean energy systems," Journal of Power Sources, vol. 159, pp. 73-80, September 2006. [Online]. Available: https://www.sciencedirect.com/science/article/pii/S0378775306006240 30 
[44] J. K. Kaldellis, D. Zafirakis, "Optimum energy storage techniques for the improvement of renewable energy sources-based electricity generation economic efficiency," Energy, vol. 32, pp. 2295-2305, December 2007. [Online]. Available: https://www.sciencedirect.com/science/article/pii/S0360544207001302 30, 36

[45] "Utsira Wind Power and Hydrogen Plant," 2004. [Online]. Available: http: //www.newenergysystems.no/files/H2_Utsira.pdf 30, 31

[46] Morel Oprisan, "Introduction of Hydrogen Technologies to Ramea Island ," 2007. [Online]. Available: http://www.globalislands.net/userfiles/_canada_ Newfoundland2.pdf 31

[47] Richard Luke, "Compressed air storage for electricity generation in South Africa," 1996. [Online]. Available: https://open.uct.ac.za/bitstream/handle/11427/9629/ thesis_ebe_1996_luke_r.pdf?sequence=1 31, 33

[48] Sabine Donadei, Dr. Gregor-Snke Schneider, "Long-term energy storage with compressed air storages," July 2014. [Online]. Available: https://www.ees-magazine. com/long-term-energy-storage-with-compressed-air-storages/ 31, 32

[49] J. Jewitt, "Impact of caes on wind in tx, ok and nm," Annual peer review meeting of DOE energy storage systems research, San Francisco, USA, pp. 1-16, October 2005. [Online]. Available: https://www.sandia.gov/ess-ssl/docs/ pr_conferences/2005/Jewitt_CAES.pdf 32

[50] Fritz Crotogino, Klaus-Uwe Mohmeyer, Dr. Roland Scharf, "Huntorf caes: More than 20 years of successful operation," Spring 2001 Meeting Orlando, Florida, USA, April 2001. [Online]. Available: http://www.fze.uni-saarland.de/AKE_Archiv/AKE2003H/AKE2003H_Vortraege/ AKE2003H03c_Crotogino_ea_HuntorfCAES_CompressedAirEnergyStorage.pdf 32

[51] PowerSouth Energy Cooperative, "Compressed air energy storage mc intosh power plant," Brochure 2027 East Three Notch Street Andalusia, AL 36421, September 2018. [Online]. Available: http://www.powersouth.com/wp-content/uploads/2017/ 07/CAES-Brochure-FINAL.pdf 33

[52] Dr. Michael Nakhamkin, Madhukar Chiruvolu, Chan Daniel, "Available compressed air energy storage (caes) plant concepts," PowerGen, 2007. [Online]. Available: http://www.espcinc.com/library/PowerGen_2007_paper.pdf 33

[53] "South Africa Energy Storage Technology and Market Assessment," March 2017. [Online]. Available: https://www.idc.co.za/images/2017/eskom/USTDA_Public\% 20Version.pdf 33 
[54] Mairaj ud din Mufti, Shameem Ahmad Lone, Shiekh Javed Iqbal, Muzzafar Ahmad, Mudasir Ismail, "Super-capacitor based energy storage system for improved load frequency control," Electric Power Systems Research, vol. 79, pp. 226-233, January 2009. [Online]. Available: https://www.sciencedirect.com/science/article/ pii/S0378779608001739 33

[55] Felix A. Farret, M. Godoy Simoes, Integration of alternative sources of energy, 1st ed. Piscataway: IEEE Press, 2006. 33

[56] A.G. Ter-Gazarian, M. Godoy Simoes, Energy storage for power systems, 2nd ed. Stevenage : IET, 2011. [Online]. Available: http://digital-library.theiet.org.ez.sun. ac.za/content/books/po/pbpo063e 34

[57] Sherisse Pham, "Tesla has built the world's biggest battery in Australia," 2017. [Online]. Available: https://money.cnn.com/2017/11/23/technology/ tesla-south-australia-battery-wind-farm/index.html 34

[58] Rob Verger, "Tesla actually built the world's biggest battery. Heres how it works." 2017. [Online]. Available: https://www.popsci.com/ tesla-building-worlds-biggest-battery-how-it-will-work 34, 35

[59] Tesla Team, "Tesla Powerpack to Enable Large Scale Sustainable Energy to South Australia," 2017. [Online]. Available: https://www.tesla.com/blog/ tesla-powerpack-enable-large-scale-sustainable-energy-south-australia 34

[60] EPRI, "Electricity energy storage technology options," A White Paper Primer on Applications, Costs, and Benefits, December 2010. [Online]. Available: https://www.epri.com/\#/pages/product/000000000001020676/?lang=en 36

[61] H. Ibrahim, A. Ilinca, J. Perron, "Energy storage systems characteristics and comparisons," Renewable and Sustainable Energy Reviews, vol. 12, pp. 1221-1250, June 2008. [Online]. Available: https://www.sciencedirect.com/science/article/pii/ S1364032107000238 36

[62] R.C. Hibbeler, Kai Beng Yap, Mechanics for Engineers Dynamics, 13th ed. Pearson Education South Asia Pte Ltd, 2012. 38

[63] Duncan J. Glover, Mulukutla S. Sarma, Thomas J. Overbye, Power System Analysis \& Design, 5th ed. Cengage Learning, 2012. 38, 102, 111, 112

[64] U. Tamrakar, D. Shrestha, M. Maharjan, B. Bhattarai,T. Hansen and R. Tonkoski, "Virtual inertia: Current trends and future directions," Applied Sciences, vol. 7, no. 7 , p. $654,2017.47$ 


\section{REFERENCES}

[65] Thomas Ackermann, Wind Power in Power Systems, 2nd ed. John Wiley \& Sons Ltd, 2012. 47

[66] Gilbert M. Masters, Renewable and Efficient Electric Power Systems, 2nd ed. John Wiley \& Sons, Inc., 2013. 50, 116, 117

[67] I. Erlich, M. Wilch, "Primary frequency control by wind turbines," IEEE Power and Energy Society General Meeting, 2010. 51

[68] X. Wang, M. Yue, and E. Muljadi, "Pv generation enhancement with a virtual inertia emulator to provide inertial response to the grid," IEEE Energy Conversion Congress and Exposition (ECCE), 2014. 56

[69] K. H. Youssef, M. A. Wahba, H. A. Yousef, and O. A. Sebakhy, "A new method for voltage and frequency control of stand-alone self-excited induction generator using pwm converter with variable dc link voltage," American Control Conference, 2008. 56,57

[70] H. Bevrani, T. Ise, and Y. Miura, "Virtual synchronous generators: A survey and new perspectives," International Journal of Electrical Power $\& 6$ Energy Systems, vol. Volume 54, 2013. 57

[71] T. Jouini, C. Arghir, F. Dorfler, "Grid-forming control for power converters based on matching of synchronous machines," 2017. [Online]. Available: http://control.ee.ethz.ch/floriand/docs/Articles/Jouini-Arghir-Dorfler-2017.pdf 57

[72] Groß, D. and Bolognani, S. and Poolla, B. K. and Drfler, F., "Increasing the resilience of low-inertia power systems by virtual inertia and damping," Bulk Power Systems Dynamics and Control Symposium (IREP), 2017. [Online]. Available: http://people.ee.ethz.ch/ floriand/docs/Articles/Gross_IREP_2017.pdf 66, 70, 71

[73] Kenneth Van den Bergh, Erik Delarue and William D'haeseleer, "Dc power flow in unit commitment models," TME Working Paper - Energy and Environment, vol. WP EN2014-12, 2014. 68

[74] J. Machowski, J. Bialek, and J. Bumby, Power System Dynamics - Stability and Control, 2nd ed. John Wiley \& Sons, 2008. [Online]. Available: https://app.knovel.com/ hotlink/pdf/id:kt006JLFE2/power-system-dynamics/governing-system-steam 70

[75] Kemin Zhou, Essentials of robust control. Prentice Hall, 1999. [Online]. Available: https://ebookcentral.proquest.com/lib/sun/detail.action?docID=1129732 72

[76] Leonid Freidovich, Pedro La Hera, "Lecture 3: How to Compute H2 and Hinf Norms," 2010. [Online]. Available: http://www.control.tfe.umu.se/Courses/ Optimal_Control_for_Linear_Systems_2010/lectures/Lecture_03_OCLS.pdf 72 
[77] Florian Drfler, John W. Simpson-Porco, Francesco Bullo, "Electrical networks and algebraic graph theory: Models, properties, and applications," Proceedings of the IEEE, vol. 106, pp. 977-1005, May 2018. [Online]. Available: https: //ieeexplore.ieee.org/document/8347206/authors\#authors 75

[78] Massachusetts Institute of Technology, "Under, Over and Critical Damping," 2011. [Online]. Available: https: //ocw.mit.edu/courses/mathematics/18-03sc-differential-equations-fall-2011/ unit-ii-second-order-constant-coefficient-linear-equations/ damped-harmonic-oscillators/MIT18_03SCF11_s13_2text.pdf 86

[79] Surajit Chattopadhyay, "Electric power quality in power system," Department of Applied Physics, 2009. [Online]. Available: http://shodhganga.inflibnet.ac.in/ bitstream/10603/155290/13/13_chapter\%206.pdf 106

[80] F. Tahri, A. Tahri, Eid A. AlRadadi, A. Draou, "Analysis and control of advanced static var compensator based on the theory of the instantaneous reactive power," 2007 International Aegean Conference on Electrical Machines and Power Electronics, 2007. [Online]. Available: https://ieeexplore.ieee.org/document/4510559 106

[81] DIgSILENT PowerFactory 2017, "Synchronous Machine," 2016. 107

[82] Mitsubishi Electric Corporation, "Mitsubishi electric power system stabilizer (pss)," September 2010. [Online]. Available: $\quad$ http://www.meppi.com/Products/GeneratorExcitationProducts/Static\% 20Excitation\%20System/Power\%20System\%20Stabilizer.pdf 109

[83] DIgSILENT PowerFactory 2017, "Overhead Line Models," 2016. 110

[84] DIgSILENT PowerFactory, "Two-Winding Transformer (3-Phase)," 2017. 110, 112

[85] Teshmont Consultants LP, Karim Shaarbafi, "Transformer modelling guide," July 2014. [Online]. Available: https://www.aeso.ca/assets/linkfiles/4040. 002-Rev02-Transformer-Modelling-Guide.pdf 111

[86] DIgSILENT PowerFactory 2017, "General Load," 2017. 112

[87] Ali Mohammadi, Sajjad Farajianpour, Saeed Tavakoli, Masoud Barakati, "Fluctuations mitigation of variable speed wind turbine through optimized centralized controller," TELKOMNIKA Indonesian Journal of Electrical Engineering, December 2012. [Online]. Available: https://www.researchgate.net/publication/270159023_Fluctuations_Mitigation_ of_Variable_Speed_Wind_Turbine_through_Optimized_Centralized_Controller 114 
[88] Vivek Tamrakar, S.C. Gupta and Yashwant Sawle, "Single-diode pv cell modeling and study of characteristics of single and two-diode equivalent circuit," Electrical and Electronics Engineering: An International Journal (ELELIJ), vol. 4, August 2015. [Online]. Available: https://wireilla.com/engg/eeeij/papers/4315elelij02.pdf 115, 116

[89] T. T. Yetayew, T. R. Jyothsna, "Improved single-diode modeling approach for photovoltaic modules using data sheet," Annual IEEE India Conference (INDICON), December 2013. [Online]. Available: https://ieeexplore.ieee.org/document/6726092/ authors\#authors 115

[90] D. A. Neamen, Microelectronics - Circuit Analysis and Design (International edition), 4th ed. McGraw-Hill, 2010. 116

[91] Snehamoy Dhar, R. Sridhar and Varun Avasthy, "Modeling and simulation of photovoltaic arrays," SRM University. [Online]. Available: http://www.iitk.ac.in/ npsc/Papers/NPSC2012/papers/12118.pdf 116, 117

[92] DIgSILENT PowerFactory 2017, "PV System," 2016. 117

[93] Maya Ramakrishnan, "A gentle introduction to lyapunov functions," August 2003. 125

[94] H.W. Steyn, "Lecture: Nonlinear systems analysis," 2016. 126

[95] Stephen Boyd, "Lecture 12 basic lyapunov theory," 2008. [Online]. Available: http://stanford.edu/class/ee363/lectures/lyap.pdf 126

[96] Mohammed Dahleh, Munther A. Dahleh, George Verghese, "Lectures on dynamic systems and control," 2011. [Online]. Available: https://ocw.mit.edu/courses/electrical-engineering-and-computer-science/ 6-241j-dynamic-systems-and-control-spring-2011/readings/MIT6_241JS11_chap24. pdf 126 


\section{Appendix A}

\section{The Swing Equation}

Reference [63] derives the swing equation.

Using Newton's second law of motion, the synchronous machine's rotor motion is described by:

$$
J \alpha_{m}(t)=T_{m}(t)-T_{e}(t)
$$

where,

$J$ : moment of inertia of the rotor $\left[\mathrm{kg} \cdot \mathrm{m}^{2}\right]$.

$\alpha_{m}$ : rotor's angular acceleration $\left[\mathrm{rad} / \mathrm{s}^{2}\right]$.

$T_{m}$ : net torque supplied by prime mover $[\mathrm{N} \cdot \mathrm{m}]$.

$T_{e}$ : net electrical torque, which accounts for the generator's electrical power output $[\mathrm{N} \cdot \mathrm{m}]$.

The angular acceleration is defined as:

$$
\alpha_{m}(t)=\frac{d \omega_{m}(t)}{d t}=\frac{d^{2} \theta_{m}(t)}{d t^{2}}
$$

with

$\omega_{m}:$ rotor angular velocity $[\mathrm{rad} / \mathrm{s}]$.

It is convenient to measure the rotor angular position with respect to a synchronously rotating reference axis instead of a stationary axis. we define

$$
\theta_{m}(t)=\omega_{m s y n} \cdot t+\delta_{m}(t)
$$


where,

$\omega_{m s y n}:$ synchronous angular velocity of the rotor, $\mathrm{rad} / \mathrm{s}$

$\delta_{m}$ : rotor angular position with respect to a synchronously rotating reference, $\mathrm{rad}$

Using equation (A.2) and (A.3), (A.1) becomes

$$
J \frac{d^{2} \theta_{m}(t)}{d t^{2}}=J \frac{d^{2} \delta_{m}(t)}{d t^{2}}=T_{m}(t)-T_{e}(t)
$$

It is also convenient to work with power rather than torque, and to work in per-unit rather than in actual units. Accordingly, we multiply (11.1.5) by $\omega_{m}(t)$ and divide by $S_{\text {rated }}$, the three-phase volt-ampere rating of the generator:

$$
\frac{J \omega_{m}(t)}{S_{\text {rated }}} \frac{d^{2} \delta_{m}(t)}{d t^{2}}=\frac{\omega_{m}(t) T_{m}(t)-\omega_{m}(t) T_{e}(t)}{S_{\text {rated }}}
$$

Finally, it is convenient to work with a normalised inertia constant, called the $H$ constant, which is defined as

$$
\begin{gathered}
H=\frac{\text { stored kinetic energy at synchronous speed }}{\text { generator volt-ampere rating }} \\
H=\frac{\frac{1}{2} J \omega_{\text {msyn }}^{2}}{S_{\text {rated }}}
\end{gathered}
$$

Solving equation (A.7) for $J$ and using equation (A.5),

$$
2 H \frac{\omega_{m}(t)}{\omega_{m s y n}^{2}} \frac{d^{2} \delta_{m}(t)}{d t^{2}}=P_{(m) p . u .}(t)-P_{(e) p . u .}(t)
$$

Defining per-unit rotor angular velocity,

$$
\omega_{p . u .}(t)=\frac{\omega_{m}(t)}{\omega_{m s y n}(t)}
$$

Equation (A.8) becomes,

$$
\frac{2 H}{\omega_{m s y n}} \omega_{p . u .}(t) \frac{d^{2} \delta_{m}(t)}{d t^{2}}=P_{(m) p . u .}(t)-P_{(e) p . u .}(t)
$$

For a synchronous generator with $P$ poles, the electrical angle relates to the mechanical angle, 
$\alpha(t)=\frac{P}{2} \alpha_{m}(t)$

$\omega(t)=\frac{P}{2} \omega_{m}(t)$

$\delta(t)=\frac{P}{2} \delta_{m}(t)$

Similarly, the synchronous electrical radian frequency is

$\omega_{\text {syn }}=\frac{P}{2} \omega_{m s y n}$

The per-unit electrical frequency is

$$
\omega_{p . u .}(t)=\frac{\omega(t)}{\omega_{\text {syn }}}=\frac{\frac{2}{P} \omega(t)}{\frac{2}{P} \omega_{\text {syn }}(t)}=\frac{\omega_{m}(t)}{\omega_{\text {msyn }}}
$$

Equation (A.10) can now be written as

$$
\frac{2 H}{\omega_{\text {syn }}} \omega_{\text {p.u. }}(t) \frac{d^{2} \delta(t)}{d t^{2}}=P_{(m) p . u .}(t)-P_{(e) p . u .}(t)
$$

Modifying equation (A.12) to include a damping torque anytime the generator deviates from its synchronous speed, with its value proportional to the speed deviation

$$
\frac{2 H}{\omega_{\text {syn }}} \omega_{\text {p.u. }}(t) \frac{d^{2} \delta(t)}{d t^{2}}=P_{(m) p . u .}(t)-P_{(e) p . u .}(t)-\frac{D}{\omega_{\text {syn }}} \frac{d \delta(t)}{d t}
$$

Equation (A.13) is a second-order differential equation that can be rewritten as two firstorder differential equations. Differentiating equation (A.3)

$$
\begin{gathered}
\frac{d \delta(t)}{d t}=\omega(t)-\omega_{\text {syn }}=\Delta \omega(t) \\
\frac{2 H}{\omega_{\text {syn }}} \omega_{\text {p.u. }}(t) \frac{d \omega(t)}{d t}=P_{(m) \text { p.u. }}(t)-P_{(e) p . u .}(t)-\frac{D}{\omega_{\text {syn }}} \frac{d \delta(t)}{d t}
\end{gathered}
$$

or

$$
\frac{2 H}{\omega_{\text {syn }}} \omega_{p . u .}(t) \frac{d \Delta \omega(t)}{d t}=P_{(m) p . u .}(t)-P_{(e) p . u .}(t)-\frac{D}{\omega_{\text {syn }}} \Delta \omega(t)
$$




\section{Appendix B}

\section{Power System Modeling}

This chapter gives an overview of the modeling of the power system components and explains how the simulation software, DigSilent PowerFactory 2017, was used to model and simulate the power system. The system component models included in this chapter are: synchronous machine, transmission line, transformer, load, Wind turbine generator (WTG) and Solar PV generation.

\section{B.1 Synchronous machine}

There are various models with different complexities, ranging from low to high order representations, depending on the simulation objectives. Figure B.1 presents a crosssection of a simple 2-pole, 3-phase synchronous machine.

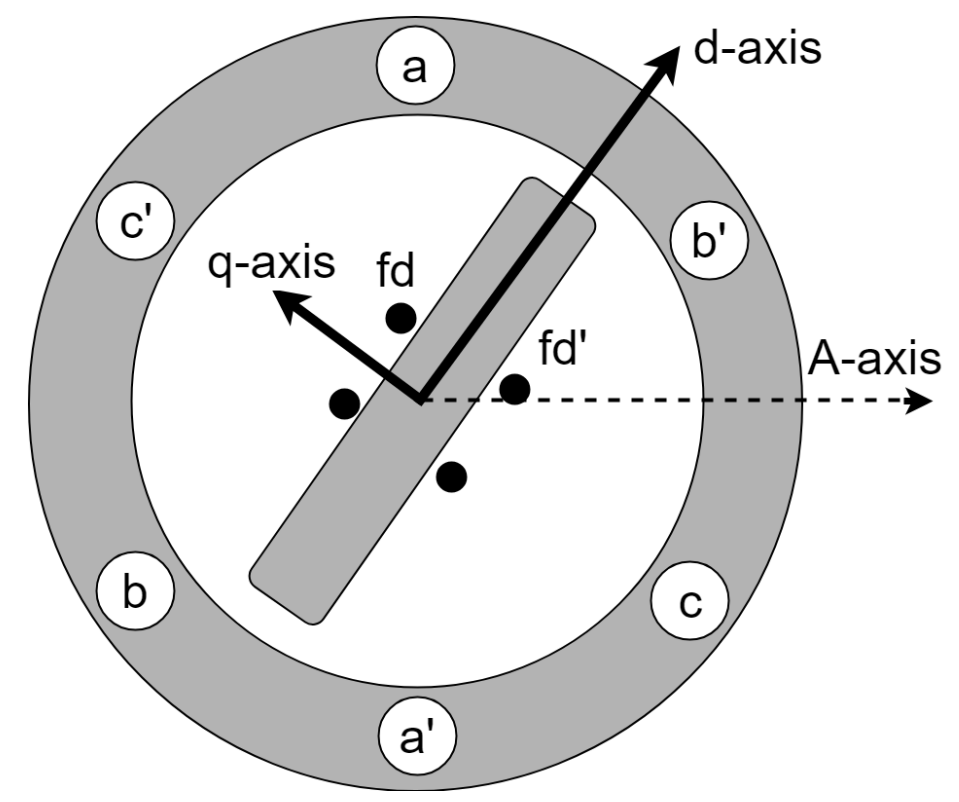

Figure B.1: Basic structure of synchronous machine. 


\section{B.1 Synchronous machine}

The following notation $\mathrm{x}$ indicates the current $[\mathrm{A}]$ direction coming out of the page and x' (with apostrophe) indicates the current direction going into the page. The structure consists of three-phases (a, b, and c). Each phase has one pole-pair which generates a magnetic field vector. Each vector is separated by an angle of $120^{\circ}$. The magnetic axis of phase $a$ is used as reference for the rotor angle. The rotor contains DC excited windings, known as the field windings, $f d$, which creates the rotor magnetic filed.

In order to simplify the control of the three-phase generator, the three-phase abc referenceframe is converted to the rotating dq0 reference frame. For balanced three-phase signals the Clarke transform is a space vector transformation of a three-phase coordinate system (abc) into a stationary two-phase reference frame $(\alpha \beta 0)$. The Clark transform is as follow [79] [80]:

$$
\left[\begin{array}{l}
f_{\alpha} \\
f_{\beta} \\
f_{0}
\end{array}\right]=\frac{2}{3}\left[\begin{array}{ccc}
1 & -\frac{1}{2} & -\frac{1}{2} \\
0 & \frac{\sqrt{3}}{2} & -\frac{\sqrt{3}}{2} \\
\frac{1}{2} & \frac{1}{2} & \frac{1}{2}
\end{array}\right] \times\left[\begin{array}{l}
f_{a} \\
f_{b} \\
f_{c}
\end{array}\right]
$$

Note that for a balanced system, the 0 -component $\left(f_{\text {zero }}\right)$ will equal zero and thus, can be neglected. The second and last transformation is the Park transform. The Park transform converts vectors from a stationary reference frame (XYZ or $\alpha \beta 0)$ to a rotating reference frame $(\mathrm{dq0})$ with an arbitrary rotating frequency. The Park transform is as follow [79] [80]:

$$
\left[\begin{array}{l}
f_{d} \\
f_{q}
\end{array}\right]\left[\begin{array}{cc}
\cos (\phi) & \sin (\phi) \\
-\sin (\phi) & \cos (\phi)
\end{array}\right] \times\left[\begin{array}{l}
f_{\alpha} \\
f_{\beta}
\end{array}\right]
$$

With $\phi$ being the instantaneous angle of the arbitrary frequency, $\omega$. The AC signals now appear as "DC" signals in the dq0 reference frame. This allows for simplified calculations and conventional PID-control techniques, before the inverse transforms are applied to obtain the three-phase AC results. With the dq-reference frame, the synchronous generator in figure B.1 is modeled in reference to the synchronous rotating dq-reference frame. The rotor should at least have one field winding, creating a magnetic field along the d-axis, which is in-line with the rotor. This is known as the model 1.0, meaning that the rotor is represented by one field winding, zero d-axis damper winding and zero q-axis damper windings. The model name convention is as follows: Model $d: q$, where $d$ is the number of $d$-axis damper windings, and $q$ is the number of $q$-axis damper windings. Model 2.2 is the most commonly used in many industrial grade transient stability simulations. 


\section{B.1 Synchronous machine}

The dq-reference frame equivalent circuits for the standard synchronous machine model used in PowerFactory is presented in figures B.2 and B.3 [81].

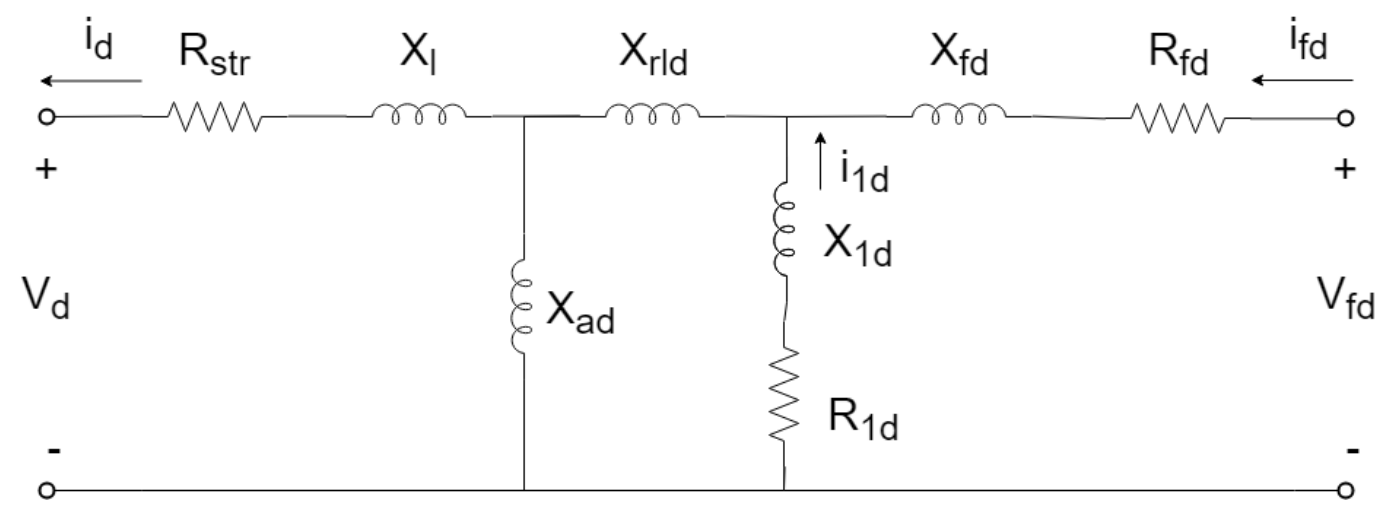

Figure B.2: d-axis equivalent circuit.

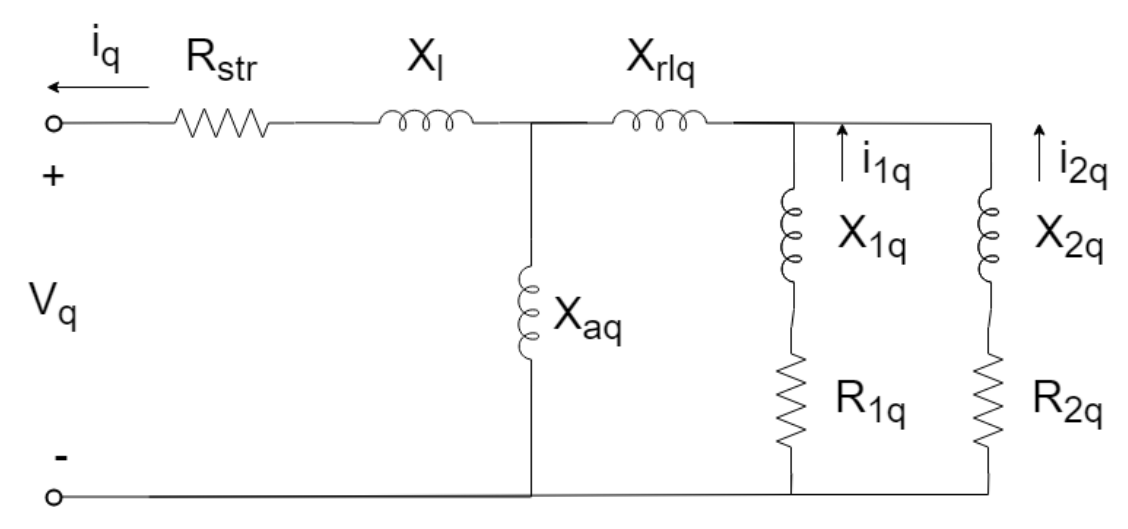

Figure B.3: q-axis equivalent circuit - round rotor.

The d-axis equivalent circuit is modeled with two rotor loops, one field (excitation) winding, and one damper winding in the d-axis. The q-axis is modeled with two damper windings in the q-axis. This model of a synchronous machine is referred to as a Model 2.2 [81]. The equivalent circuit parameters are as follows:

- $R_{\text {str }}:$ Stator resistance

- $R_{1 d}$ : Resistance of $1 \mathrm{~d}$-damper winding

- $R_{f d}$ : Resistance of excitation winding

- $X_{l}$ : Stator leakage reactance

- $X_{r l d}$ : Coupling reactance between field and damper winding

- $X_{a d}$ : Mutual (magnetising) reactance, d-axis 


\section{B.1 Synchronous machine}

- $X_{1 d}$ : Reactance of 1d-damper winding

- $X_{f d}$ : Reactance of field (excitation) winding

- $X_{r l q}$ : Coupling reactance between q-axis damper windings

- $X_{a q}$ : Mutual (magnetising) reactance, q-axis

- $X_{1 q}$ : Reactance of 1q-damper winding

- $X_{2 q}$ : Reactance of 2q-damper winding

- $R_{1 q}$ : Resistance of 1q-damper winding

- $R_{2 q}$ : Resistance of 2q-damper winding

The control diagram for the synchronous generator is presented in figure B.4. The speed of the generator is regulated by the governor, who controls the flow of steam to the turbine by actuating a flow rate valve. The governor monitors the rotation frequency and compares it to the reference frequency in order to adjust the power of the turbine. The turbine converts pressurised steam, from thermal energy, to mechanical power. The turbine functions as the prime-mover which turns the rotor shaft of the generator.

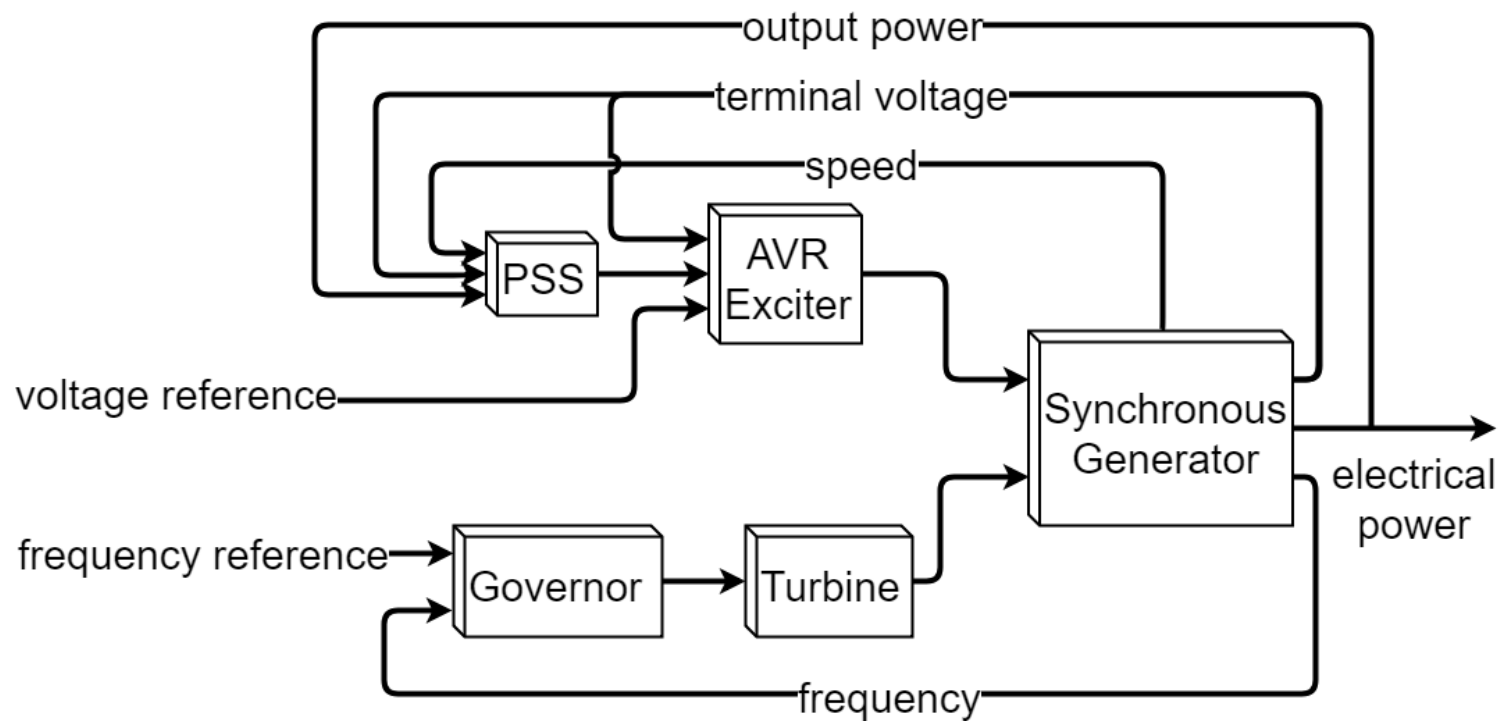

Figure B.4: Synchronous generator control diagram.

The Automatic Voltage Regulator (AVR) is a controller responsible for maintaining the output terminal voltage constant at a set value for varying load and operations. The AVR measures the output terminal voltage of the generator using a transformer and rectifier circuit. The measured signal is then compared to a reference value and adjust the exciter output accordingly. The exciter applies an DC voltage to the generator field winding, 


\section{B.1 Synchronous machine}

which is used to control the magnitude of the generator terminal voltage.

The Power System Stabiliser (PSS) improves the transient stability of the power system by controlling the exciter in such a manner to dampen the generator's rotor oscillations and power output fluctuations. There are three modes of oscillations in a power system. The first is the so called, local mode, where the local generator oscillates against the power system. the typical local mode oscillation frequency is around $1 \mathrm{~Hz}$. The second mode is the inter-area mode, which the different areas in the interconnected system oscillates against each other over long and large capacity transmission lines. The oscillating frequency rang from 0.2 to $0.5 \mathrm{~Hz}$. The last oscillation mode is the complex mode. This mode is a combination of the local and the inter-area modes [82].

Although the power output of a generator is dictated by the prime-mover (turbine), a change in excitation can introduce a transient power output change, see figure B.5a. The PSS detects the rapid change in power output and computes an excitation signal, which is added to the AVR, to combat and reduce the power fluctuation, thus dampening the rotor angle swings/oscillations [82], as shown in figure B.5b.
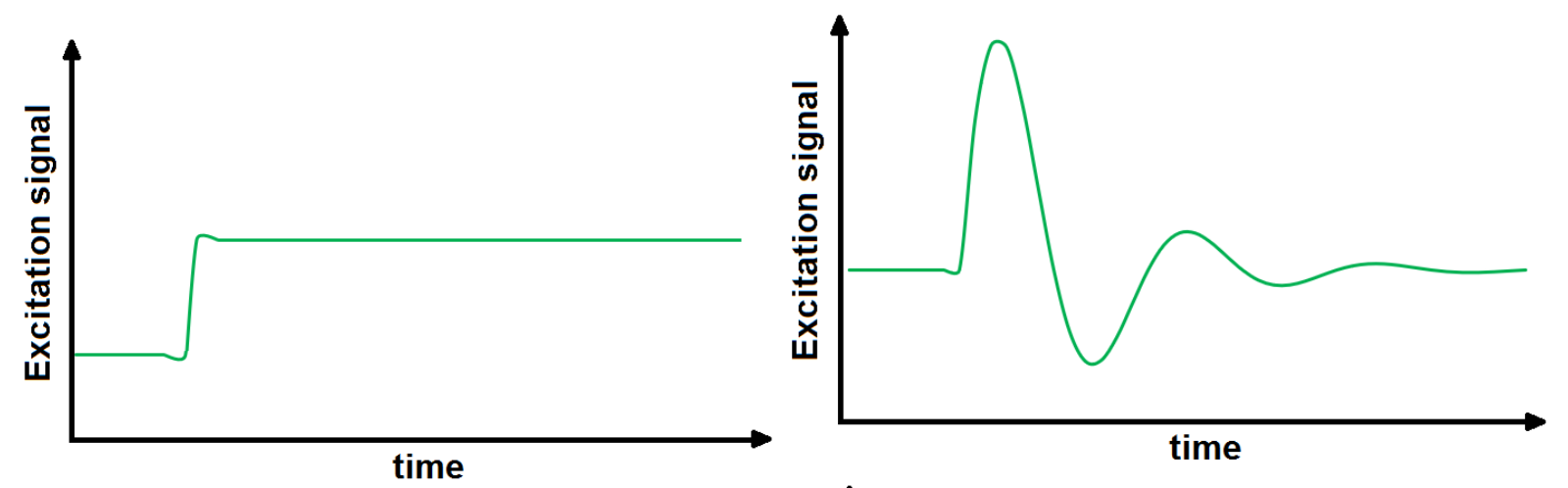

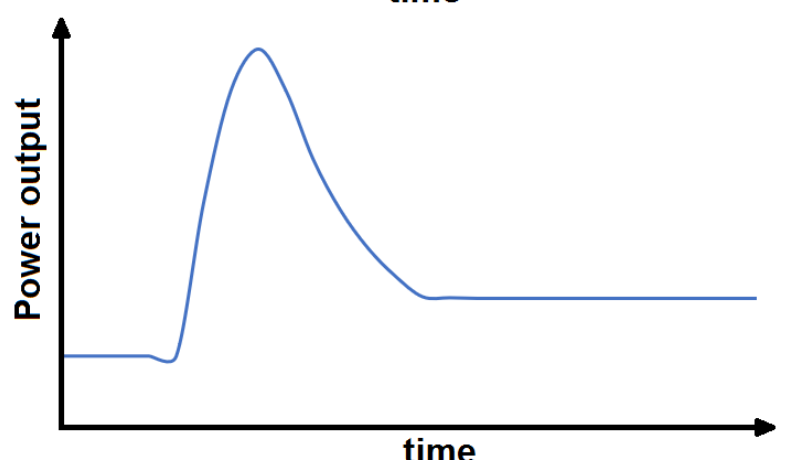

(a) Output due to field excitation step input.

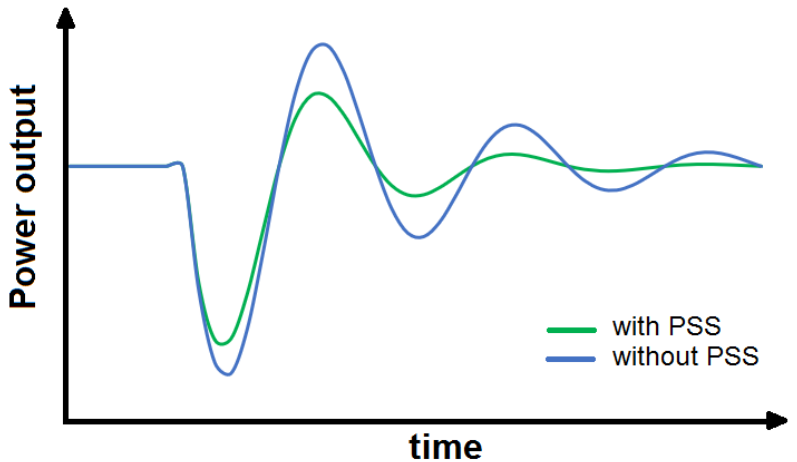

(b) PSS reduce power and rotor oscillations. 


\section{B.2 Transmission line}

\section{B.2 Transmission line}

The three-phase transmission line $\pi$ equivalent circuit model, as used by DigSilent PowerFactory 2007, is presented in figure B.6. This model is derived from the single-phase transmission line equivalent $\pi$-model. The impedance, $Z_{a b c}$, and admittance, $Z_{a b c}$, matrices is as follow [83]:

$$
\begin{aligned}
Z_{a b c}= & {\left[\begin{array}{lll}
Z_{s} & Z_{m} & Z_{m} \\
Z_{m} & Z_{s} & Z_{m} \\
Z_{m} & Z_{m} & Z_{s}
\end{array}\right] } \\
Y_{a b c}= & {\left[\begin{array}{lll}
Y_{s} & Y_{m} & Y_{m} \\
Y_{m} & Y_{s} & Y_{m} \\
Y_{m} & Y_{m} & Y_{s}
\end{array}\right] }
\end{aligned}
$$

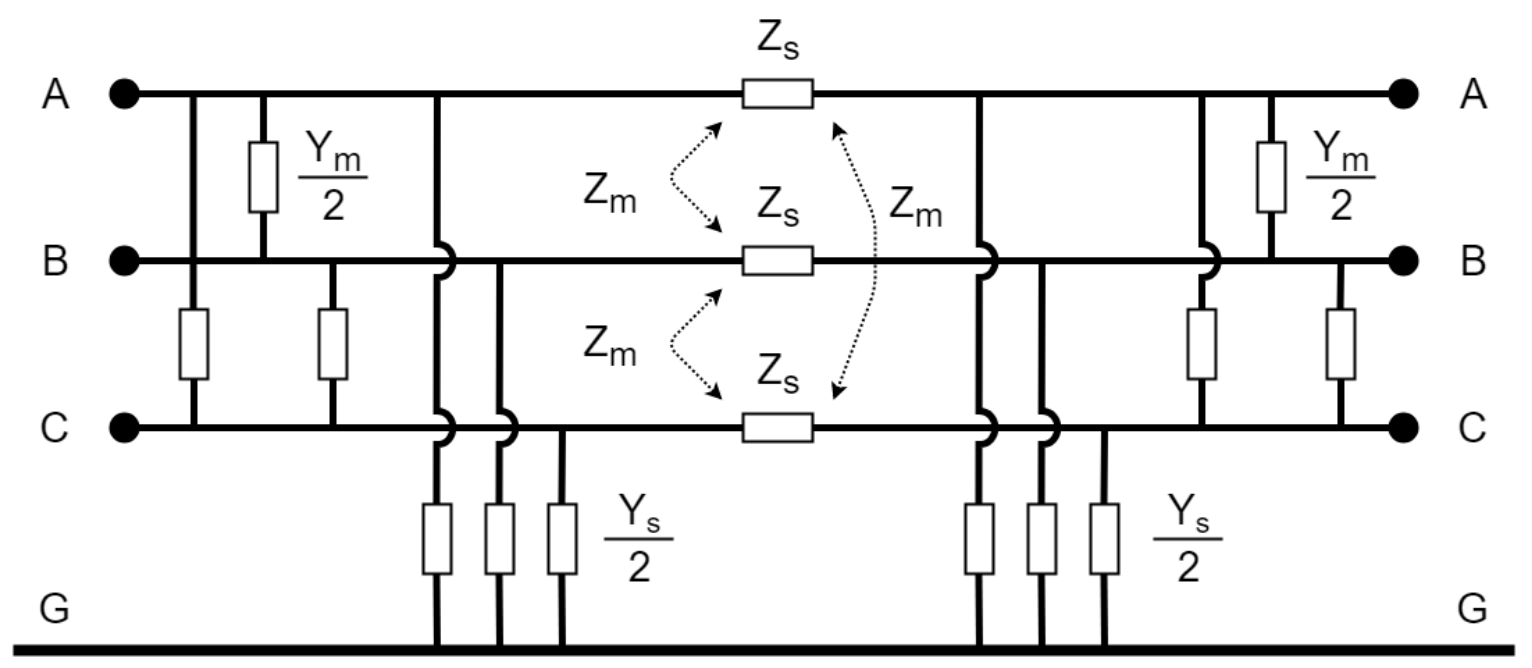

Figure B.6: Equivalent $\pi$-circuit three-phase line model.

The notation $Y_{s}$ denotes the sum of all the admittances connected to the corresponding phase. The notation $Y_{m}$ represents the negative of the admittance between two phases. The self impedance is denoted by $Z_{s}$, and the mutual impedance is denoted by $Z_{m}$.

\section{B.3 Transformer}

The circuit equivalent model of a practical two-winding transformer is shown in figure B.7 [84]. The sub-script 1 indicates the primary side of the transformer, and the sub-script 2 indicates the secondary side. The number of primary side windings is denoted by $N_{1}$, and the number of secondary windings by $N_{2}$. The component $R_{1}$ represent the winding resistance and account for the $I^{2} R$ losses in the primary side winding. Since the magnetic flux is not completely confined in the core, due to finite permeability, means that not 


\section{B.3 Transformer}

all the flux produced by the primary side winding links with the secondary side winding. The leakage reactance, $X_{1}$, accounts for the leakage flux in the primary winding. In the early days of transformers, leakage reactance was considered as negative property, which should be minimised. It was later discovered that the leakage reactance, which forms part of the total impedance, is useful for limiting fault currents in a power system. Thus, high impedance transformers are utilised to prevent fault currents reaching a certain limit value [85].

The elements $R_{m}$ and $X_{m}$ in the shunt brunch are used to represent the core behavior. The resistor, $R_{m}$ accounts for the core losses due to induced eddy currents and hysteresis in the core. In a practical transformer the magnetic resistance, or magnetic reluctance is not zero. Therefore, an excitation current, called the magnetising current is needed to generate an alternating Magneto Motive Force (MMF) to induce a $n$ alternating flux in the core. The magnetising inductance is represented with the magnetising reactance, $X_{m}$ in the shunt branch [63] [85].

The elements $X_{2}$ and $R_{2}$ represents the secondary side leakage reactance and winding conductor resistance respectively. The primary voltage is denoted by $V_{1}$ and the secondary by $V_{2}$.

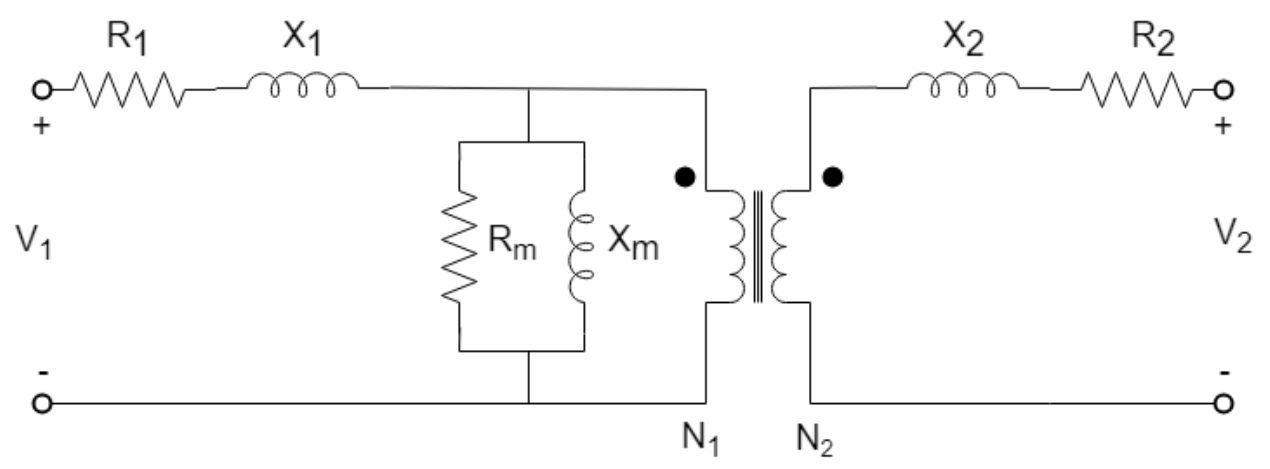

Figure B.7: Equivalent circuit of a practical single-phase 2-winding transformer.

For the analyses of circuits containing transformers, it is usually easier to work with the equivalent circuit at a single voltage. The equivalent circuit can be referred to the primary or the secondary side of the transformer. The circuit in figure B.7 is referred to the primary side, as shown in figure B.8. The parameter, $a$, used for referring the secondary side components to the primary side, is equal to the ratio between the primary side and the secondary side windings [63], thus:

$$
a=\frac{N_{1}}{N_{2}}
$$




\section{B.4 Load}

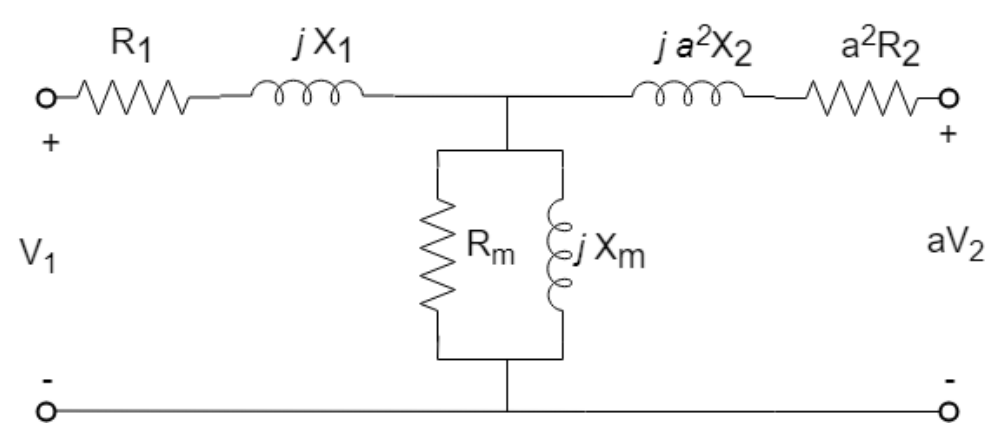

Figure B.8: Simplified transformer model referred to primary side.

In power system studies the parameters are expressed in the per-unit (p.u.) system. For a transformer the nominal voltage at the primary side is selected as the base voltage, and the nominal voltage at the secondary side is selected as the base value. Thus, the voltages at both sides of the transformer is at 1 p.u. By using the p.u. system eliminates the need for the ideal transformer winding ratio, $e^{j \phi}: 1$, which has a phase shift $\phi$ [84]. The per-unit equivalent circuit of a single-phase two-winding transformer is shown in figure B.9.

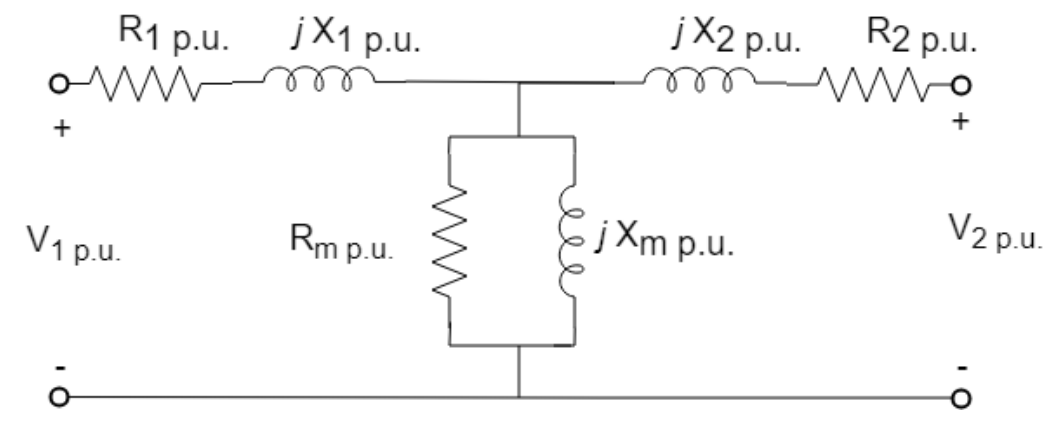

Figure B.9: Per-unit equivalent circuit of a single-phase 2-winding transformer.

For a three-phase configuration, there is no phase shift between $Y-Y$ and $\Delta-\Delta$ configured transformers, however there is always a phase shift between the primary and secondary sides of a $\mathrm{Y}-\Delta$ and $\Delta-\mathrm{Y}$ transformers. In accordance with the American standard, for the positive-sequence, the quantities on the primary side (high-voltage side) shall lead the corresponding quantities on the secondary side (low-voltage side) with $30^{\circ}$ [63].

\section{B.4 Load}

Although power system load varies relative slow over time, for transient stability studies the load is modeled as constant, since the time-scale of interest is very short relative to the time-scale of load variation. There are various types of electrical loads, such as, heating and cooling elements, lights, motors, and electronics [86]. These loads can be classified as 


\section{B.4 Load}

resistive (R), capacitive (C), inductive (L), or a combination of the previously mentioned. Restive loads consume power at unity power factor. Capacitive loads creates a leading power factor, while inductive load causes a lagging power factor. Most loads don't belong to a single category R, L, or C, but are a combination of these categories, which can have a power factor of unity, leading, or lagging depending on the combination and balance in size of the components. Figure B.10 presents a schematic of an parallel RLC load.

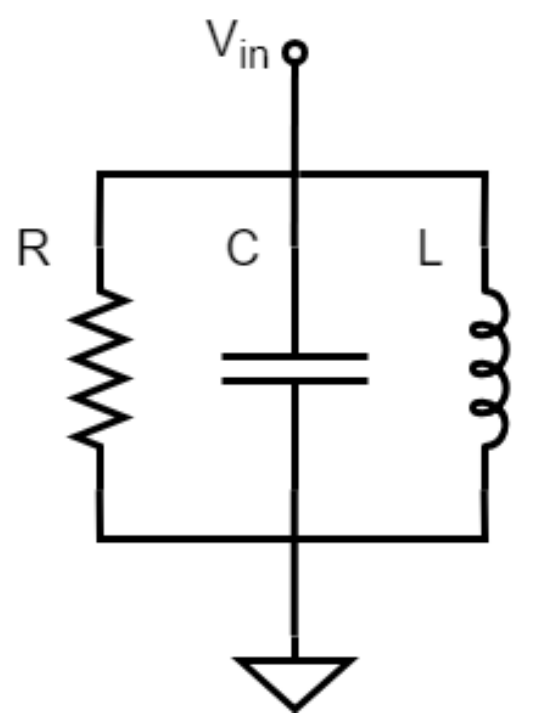

Figure B.10: RLC load.

Due to the reactive components ( $\mathrm{L}$ and/or $\mathrm{C}$ ) the load impedance becomes a function of frequency, thus, the load is frequency dependent. This means with a change in system frequency the total system load will also change. Machines such as synchronous and induction motors depends on the system frequency for their operation and are examples of frequency dependent loads. Similarly, loads can also be voltage dependent, where the power consumed is a function of the voltage magnitude.

For a three-phase system the load can be connected in star $(\mathrm{Y})$ or delta $(\Delta)$ configuration as depicted in figure B.11. In a Y-configuration a single load is connected to a phase and a common neutral point and thus, forms a three-phase load. Each load voltage is equal to the phase to neutral voltage. If the three-phase load is balanced, meaning identical and $120^{\circ}$ out of phase, then the current at the neutral conductor is zero, and can thus, be omitted. In a $\Delta$-configuration the load is connected between two phases. The load voltage is equal to the phase to phase voltage, which is higher compared to the Y-connection load voltage. The impedance relationship between the two configurations are as follow:

$$
Z_{Y}=\frac{Z_{\Delta}}{3}
$$




\section{B.5 Wind Turbine Generator}

Star-Delta starters are typically used for motors. By starting a motor using a starconnection, means lower voltage over the stator terminals and thus reduced starting current and torque. Once the motor is running the windings are switched to a $\delta$-connection, which increases the terminal voltage and ultimately higher power transfer.
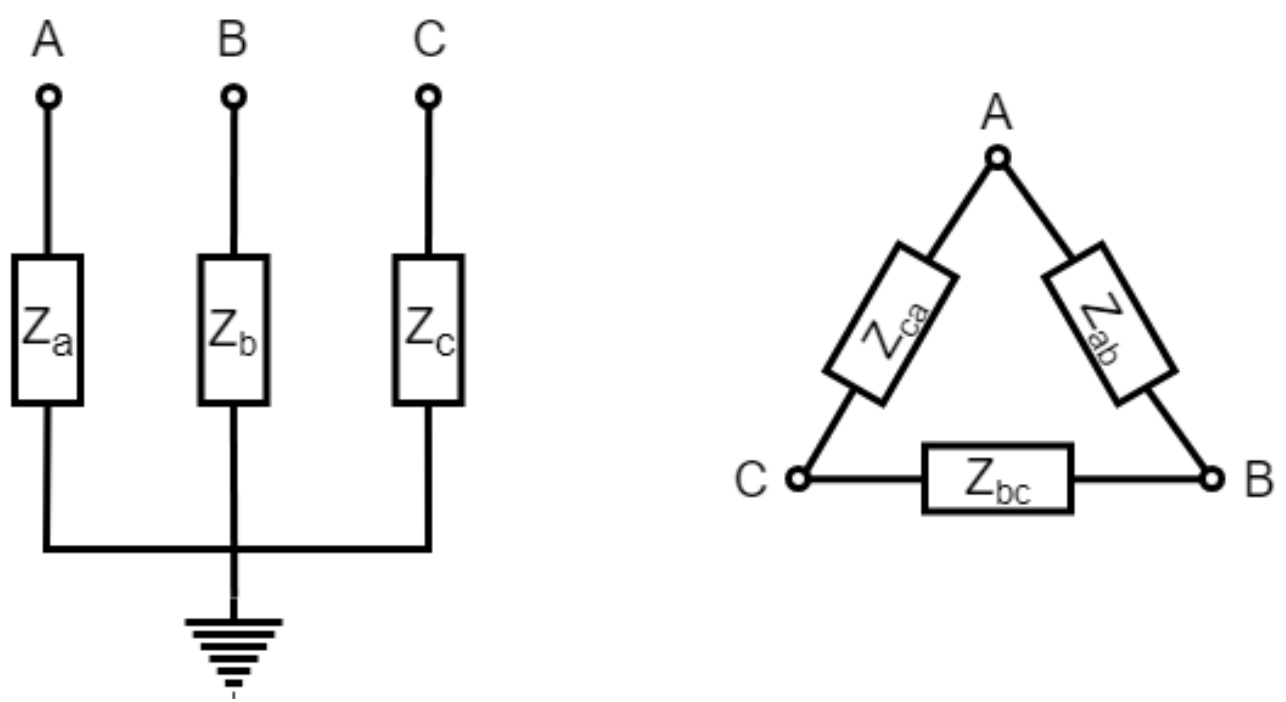

Figure B.11: 3-phase Y-connected on the left, and $\Delta$-connected on the right.

\section{B.5 Wind Turbine Generator}

Figure B.12 presents an overview of a simulation model diagram for a wind turbine generator (WTG). The WTG model interfaces with a model of the wind, which is taken as input, and outputs to a model of the power system.

The aerodynamic block simulates the wind turbine and variable blade pitch angle. The model equations convert the wind speed to a mechanical torque, which turns the generator. Due to the short-time scale of transient responses, the wind speed is assumed to be constant, $8 \mathrm{~m} / \mathrm{s}$, during this period.

The mechanical block simulates the mechanical forces on the rotor shaft, which connects the turbine to the generator. The mechanical torque from the turbine and the opposing torque from the generator is received as input. Using Newton's law of motion and a two-mass model [87], which represents the inertia of the turbine and generator rotor, the differential equation is solved by integrating over time to obtained the rotation speed.

The electrical block simulates the induction generator and the back-to-back AC-DC-AC converter that interfaces with the power system. The inverter converters the variable 


\section{B.6 Solar PV panel}

frequency from the generator to a constant frequency which is compatible for the power system.

The controllers block contains all the controllers needed for the WTG, which includes, blade pith angle control, Maximum Power Point Tracking (MPPT), and the inverter switching signals.

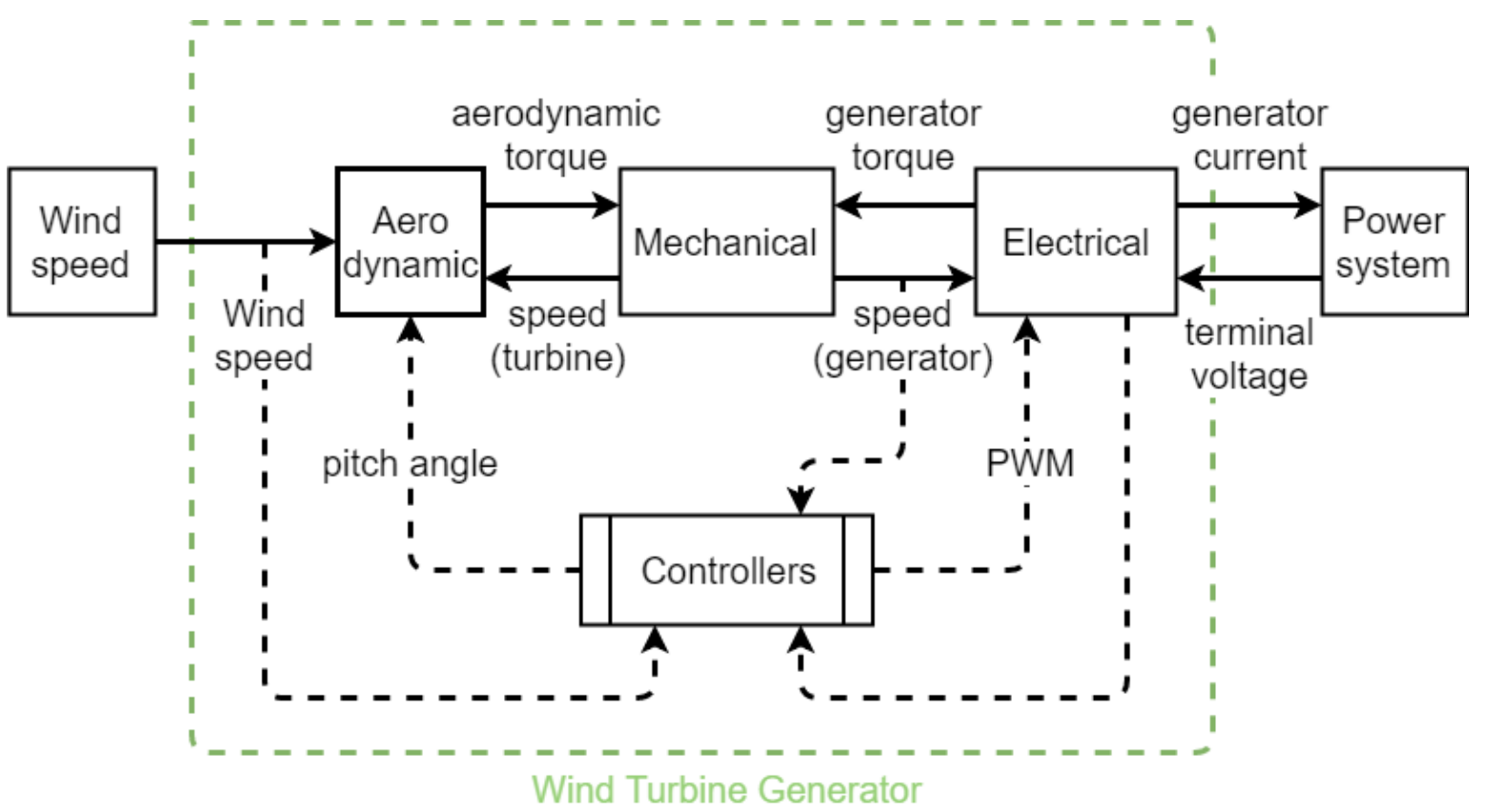

Figure B.12: Overview of the wind turbine generator (WTG) simulation model.

\section{B.6 Solar PV panel}

There are various equivalent circuit models for the solar PV cell. These models are all variants of the ideal diode model, which consists of a current source and a diode placed in parallel. The variants include, $R_{s}$-model, $R_{p}$-model (single-diode model), two-diode model and partial shaded models [88] [89]. The single-diode model, which is the most commonly used model, is a five-parameter model and an extension of the $R_{s}$, by including a shunt resistor [89]. The single-diode model circuit is shown in figure B.13. The equivalent circuit parameters are as follows [88]:

$i_{p h}$ : photo-current $[\mathrm{A}]$, and is modeled by the current source.

$i_{\text {diode }}$ : the current passing through the diode $[\mathrm{A}]$.

$i_{p v}$ : output current $[\mathrm{A}]$

$R_{\text {series }}$ : accounts for the internal resistance $(\Omega)$ and conduction losses.

$R_{\text {shunt }}$ : accounts for the leakage current (due to poor insulation) when the diode is reverse 


\section{B.6 Solar PV panel}

biased.

$R_{\text {load }}$ : represents the equivalent external resistance $(\Omega)$ as seen by the solar PV cell. $v_{p v}$ : indicates the output voltage $[\mathrm{V}]$.

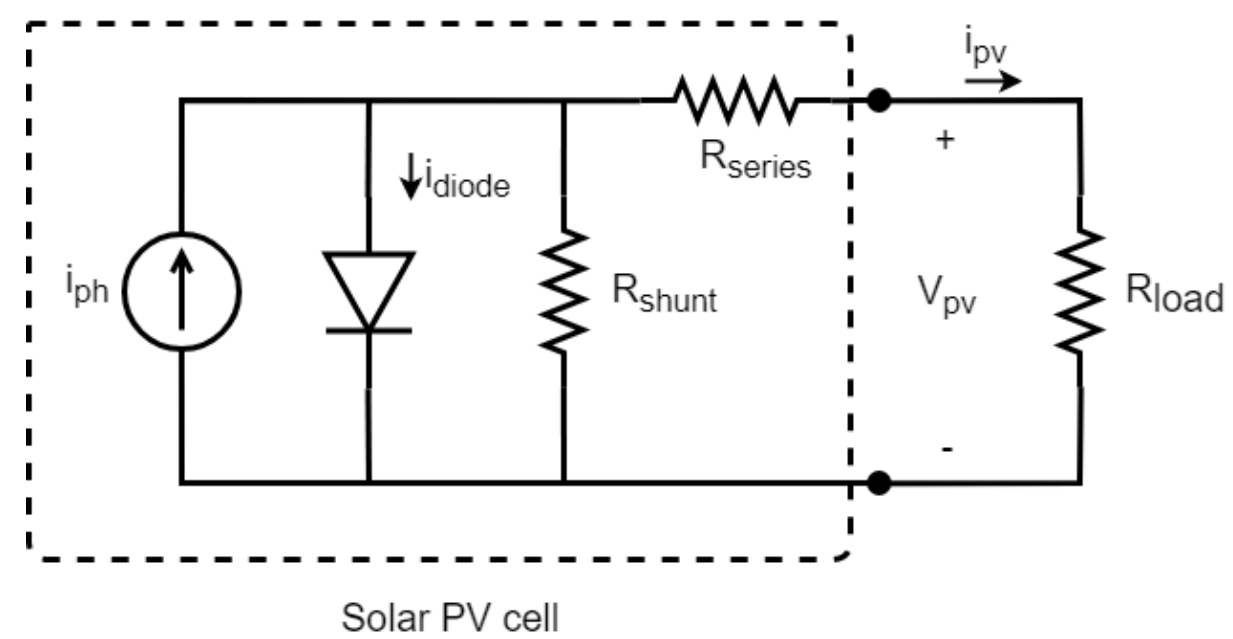

Figure B.13: Solar PV cell single diode model.

With the assumption that $R_{\text {shunt }}$ is very large and thus, the leakage current is considered negligible, the output current, $i_{p v}$, can be obtained with Kirchhoff's current law [66] [88] [90] [91]:

$$
i_{p v}=i_{p h}-i_{\text {diode }}
$$
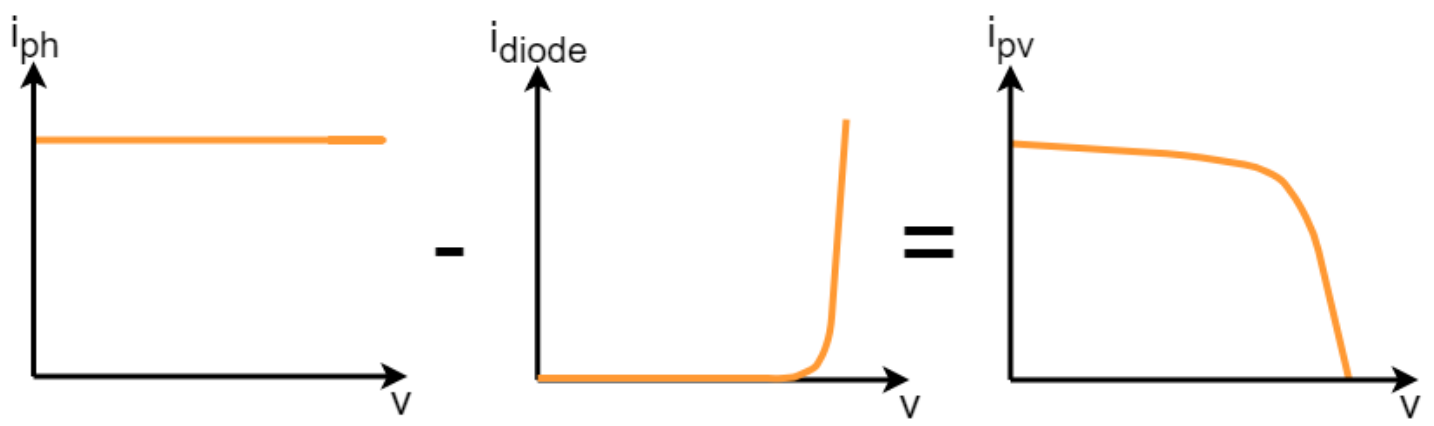

Figure B.14: Calculation of IV-curve.

$$
i_{p v}=i_{p h}-i_{0} \cdot\left[\exp \left(\frac{q}{k \cdot T}\left[V_{p v}+i_{p v} R_{\text {series }}\right]\right)-1\right]-\left(\frac{V_{p v}+i_{p v} R_{\text {series }}}{R_{\text {shunt }}}\right)
$$

$i_{0}$ : diode saturation current $[\mathrm{A}]$.

$q$ : the charge of an electron $\left(-1.6021 \times 10^{-19} \mathrm{C}\right)$.

$T$ : absolute temperature in kelvin $[\mathrm{K}]$. 


\section{B.6 Solar PV panel}

$k$ : Boltzmann constant $\left(1.38065 \times 10^{-23} \mathrm{~J} / \mathrm{K}\right)$.

The solar PV cell i-V characteristic curve is presented in figure B.15 and mathematically described by equation (B.8). The power versus voltage (P-V) curve is obtained by moving along the voltage axis and multiplying the voltage with the corresponding current value. The P-V curve is plotted over the I-V curve. From the characteristic curve, it is seen that there is a specific voltage $\left(v_{m p p}\right)$ and current $\left(i_{m p p}\right)$ which generates the maximum power, and is known as the maximum power point $\left(P_{m p p}\right)$.

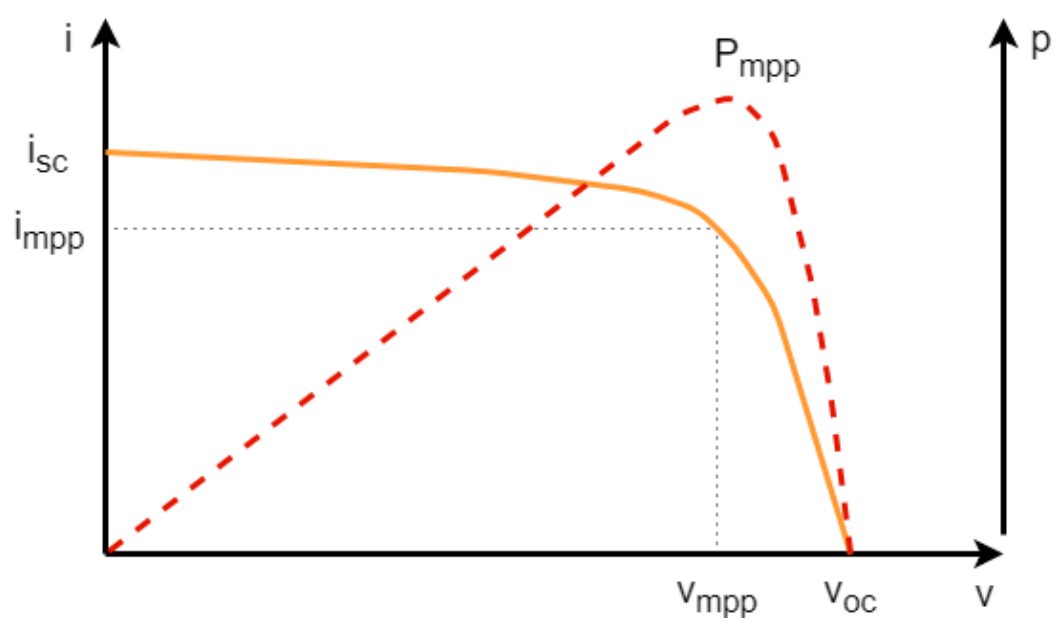

Figure B.15: I-V and P-V curve of a solar PV cell.

The solar PV cells are arranged in a module to form a solar PV panel with a certain power specification. Multiple panels are connected in series and parallel to create a string, which are connected to a MPPT controller and an inverter for feed-in to the power system [66] [91]. Figure B.16 illustrates the PV string connection to the inverter [92].

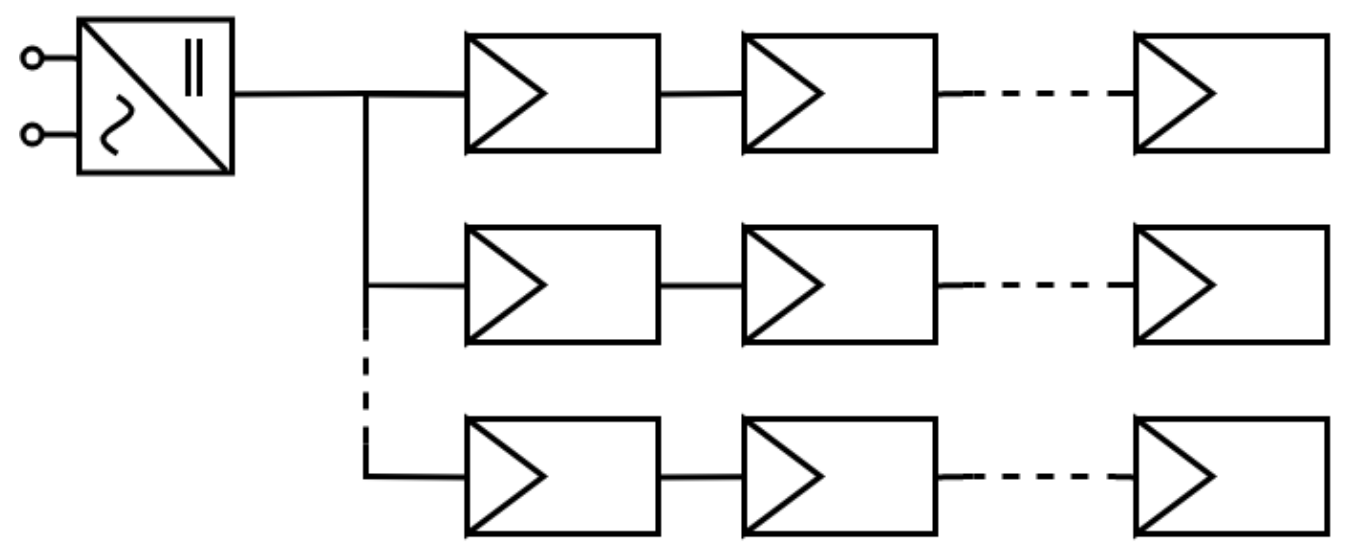

Figure B.16: Solar PV string per inverter. 


\section{B.7 DigSilent PowerFactory}

\section{B.7 DigSilent PowerFactory}

DigSilent PowerFactory is a very powerful power system simulation software program used in industry. Simulations range from simulating a single generating unit to nation-wide power system networks. The simulations time scales range from short transient response periods to large periods of time (e.g. hours, days, or months). This section describes the process followed to define the power system models as discussed in the previous sections.

\section{B.7.1 Single-line graphic}

The fist step is to setup the single-line graphical model of the power system network that will be simulated, see example in figure B.17. The single-line shows a graphical representation of the power system and indicates how the individual network components, such as the generators, transformers, lines, loads, etc., are connected to each other. The graphical model contains no modeling equations (transfer-functions) or control-loops. The implementation of the model dynamics are discussed in the following sections.

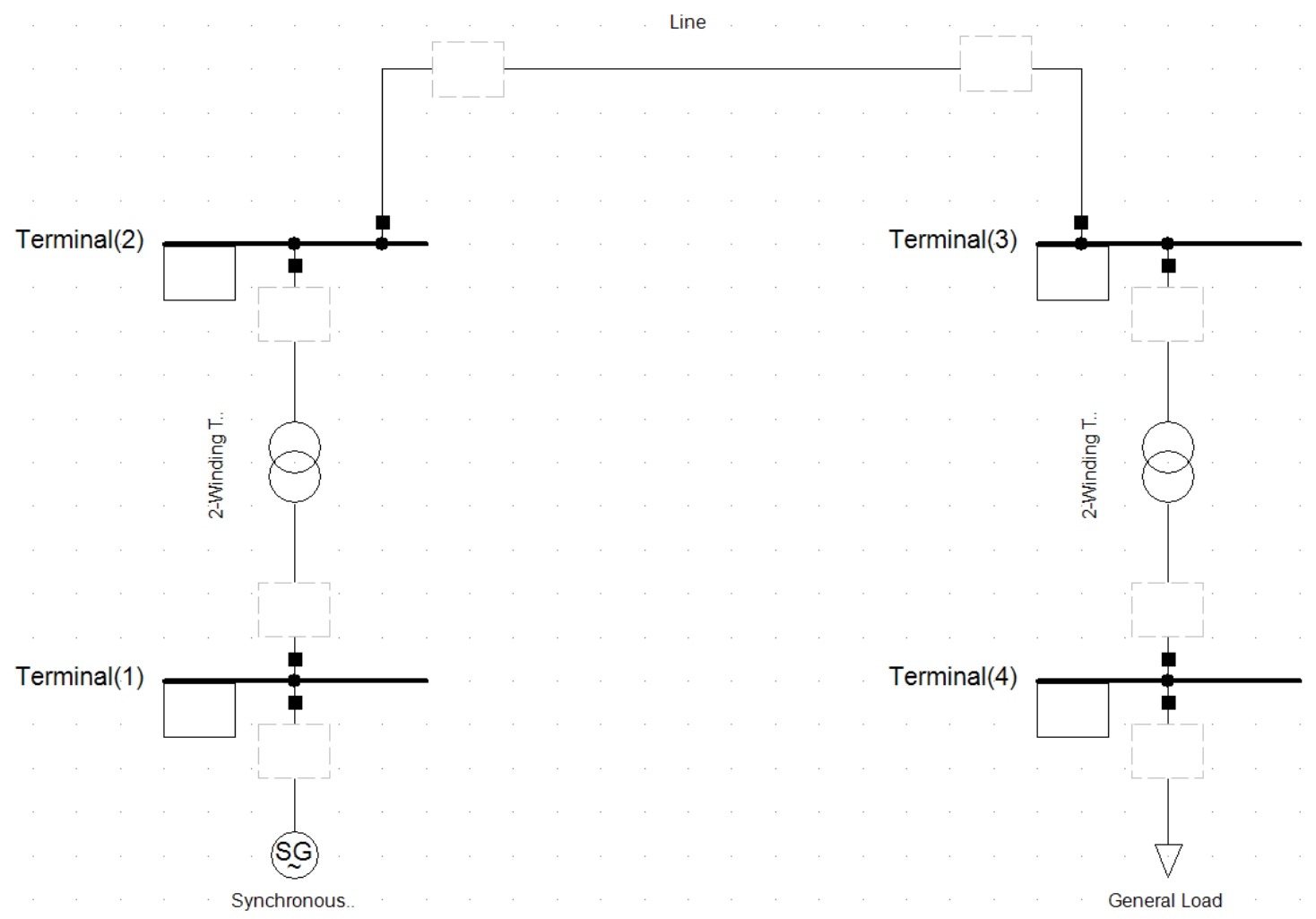

Figure B.17: Single-line graphic. 


\section{B.7 DigSilent PowerFactory}

\section{B.7.2 Composite frame}

The composite frame gives an overview of the model or control structure. It is used to the define the inputs and outputs of the models and controllers. It also defines the connection between the individual models. Figure B.18 presents the composite frame for a hydro power plant. The composite frame consists of slots and connecting signals. The slots in the hydro power plant example includes the power system stabiliser (PSS), automatic voltage regulator (AVR), governor for the water-flow valve (Hydro-GOV) and the synchronous generator $(\mathrm{SG})$. Each slot has a class name filter applied to it to ensure the proper type of element is assigned to a particular slot. There are two categories of elements that can be assigned, the first is pre-defined elements such as the synchronous machine model with the class name ElmSym. The second category is user-defined elements with the class name ElmDSL. The DSL stands for DigSilent Simulation Language (DSL), which are used to define transfer-functions, model parameters and control-loops. The elements assigned to these slots are defined in the block/frame diagram, which is discussed in the next section.

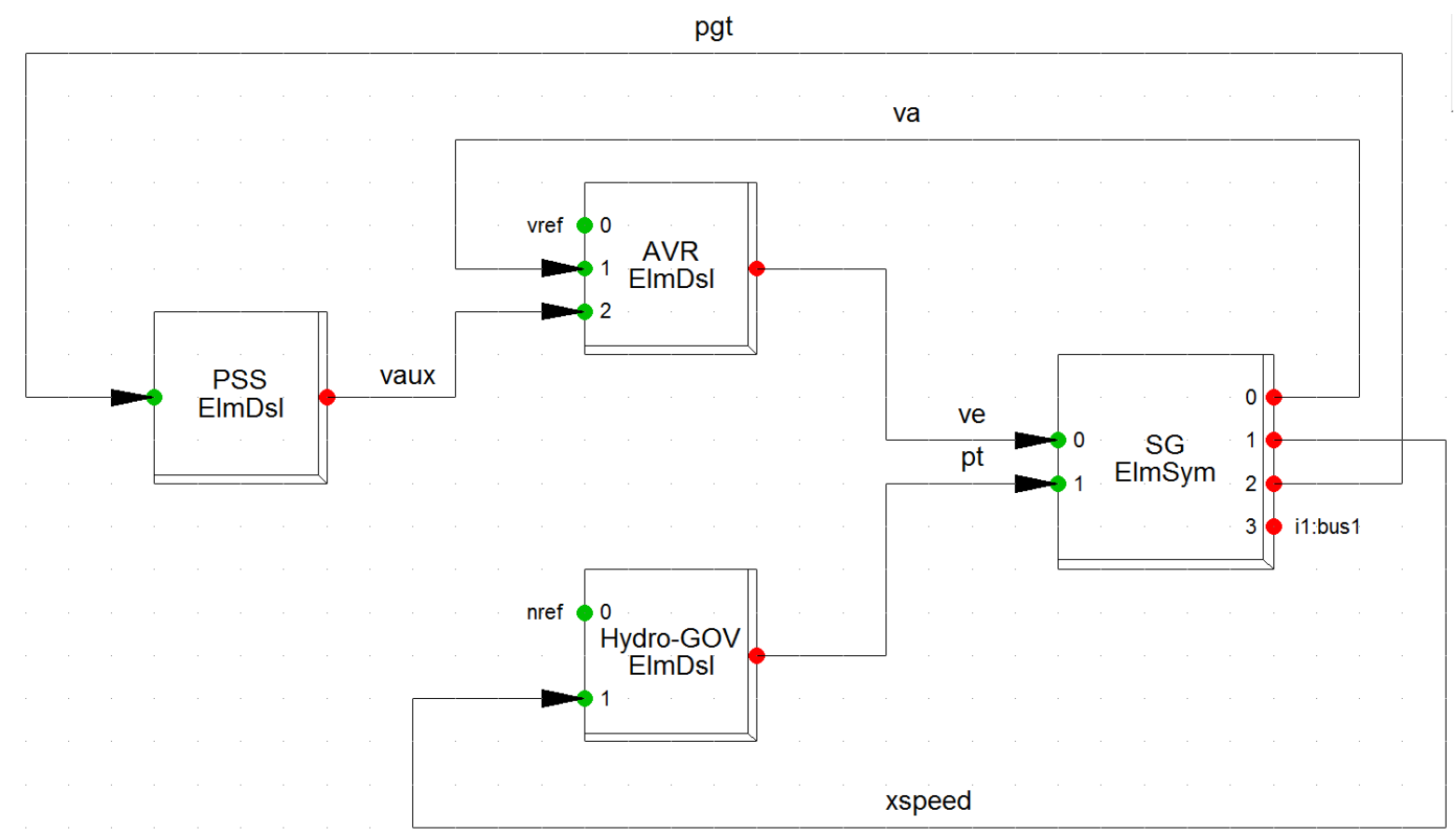

Figure B.18: Composite frame of hydro power plant.

\section{B.7.3 Block diagram}

The block diagram is the fundamental element in the design of the simulation models and controllers. The model equation such as the transfer-functions of the individual models and controllers are defined here using DSL. The state-variables, output-signals, and block parameters are also defined here. Figure B.19 presents an example of a block diagram for the PSS controller. 


\section{B.7 DigSilent PowerFactory}

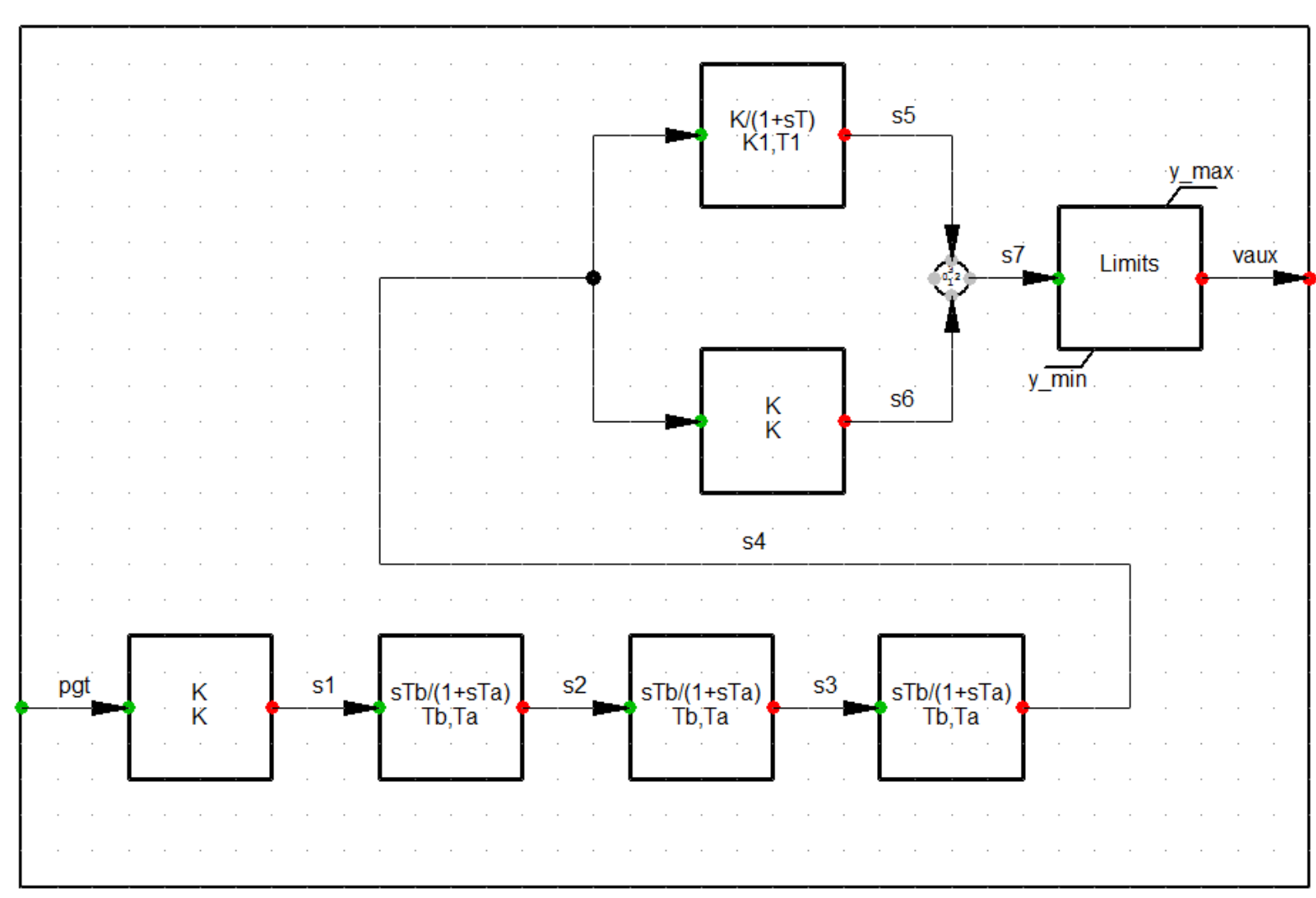

Figure B.19: Block diagram of Power System Stabiliser.

After the block definitions are complete, the block are connected with signals to define their interactions. Before the block diagram is complete, the initial conditions of the state-variables needs to be found and defined in terms of the input signals and model parameters using DSL, in order to complete the individual model or controller.

\section{B.7.4 Common model}

After the block digram is complete the common model must be created. The common model is used to enter the model parameters as shown in figure B.20. The block diagram can only be used through a common model. The common model is created from the block diagram. The block diagram parameters are defined as variables and still needs to be assigned values. The common model in figure B.20 is created for the PSS block diagram in figure B.19, thus the input vales of the common model is related to the parameters of the block diagram.

The common models are then assigned to the slots of the composite frame (figure B.18) through the use of a composite model, which is discussed in the following section. 


\section{B.7 DigSilent PowerFactory}

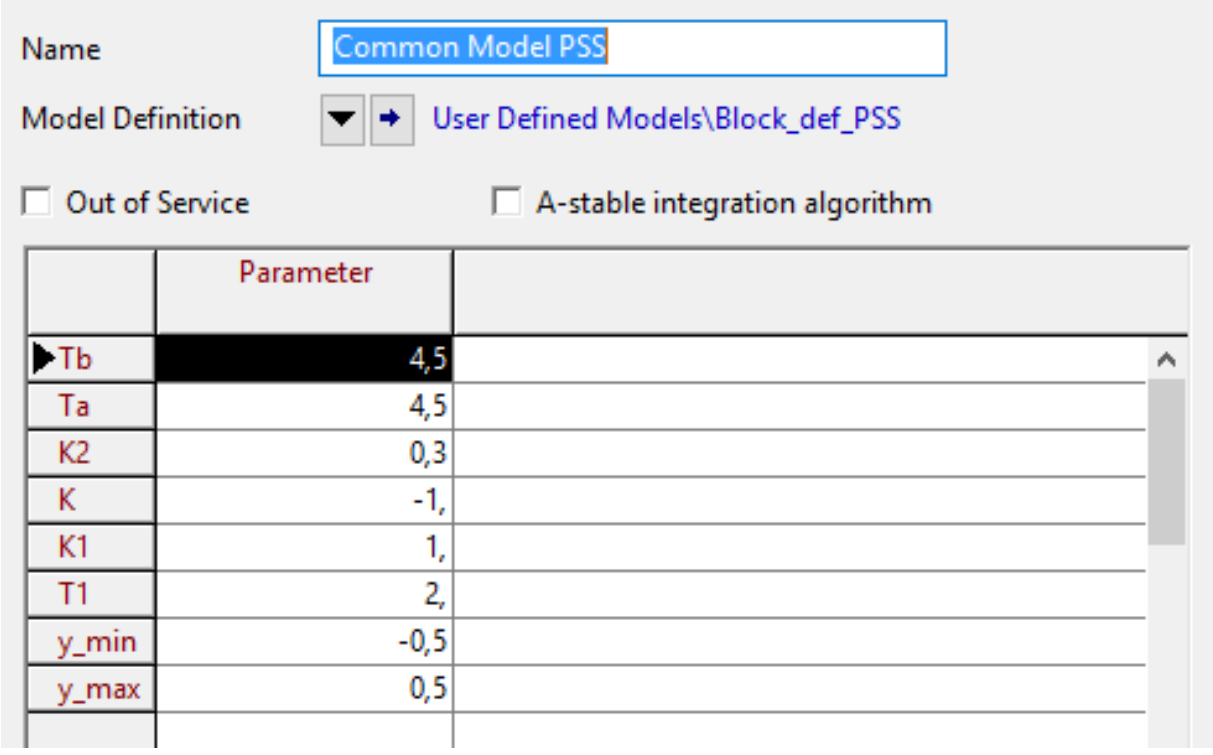

Figure B.20: Common model of the Power System Stabiliser.

\section{B.7.5 Composite model}

The composite model is the link between the composite frame with a specific power plant. The composite model links the common models with specific generators in the network as is setup in the single-line graphic. Figure B.21 presents the composite model of the hydro power plant with the relevant slots for the generator and controllers.

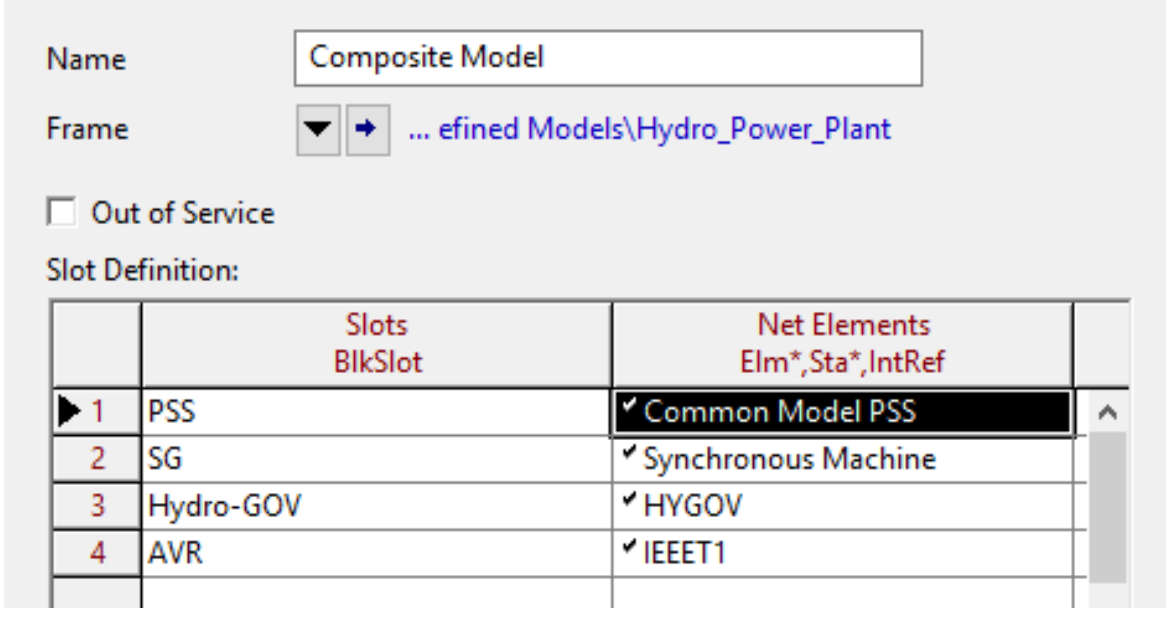

Figure B.21: Composite model of a hydro power plant.

To summarise the model definition process in PowerFactory, a hierarchy of the model definitions is shown in figure B.22. After all the necessary models and control-loops have been created the power system model is then ready to be simulated. Any of the model signals or external network signals can be selected to be analyzed in the simulation output to complete the simulation of the power system. 


\section{B.7 DigSilent PowerFactory}

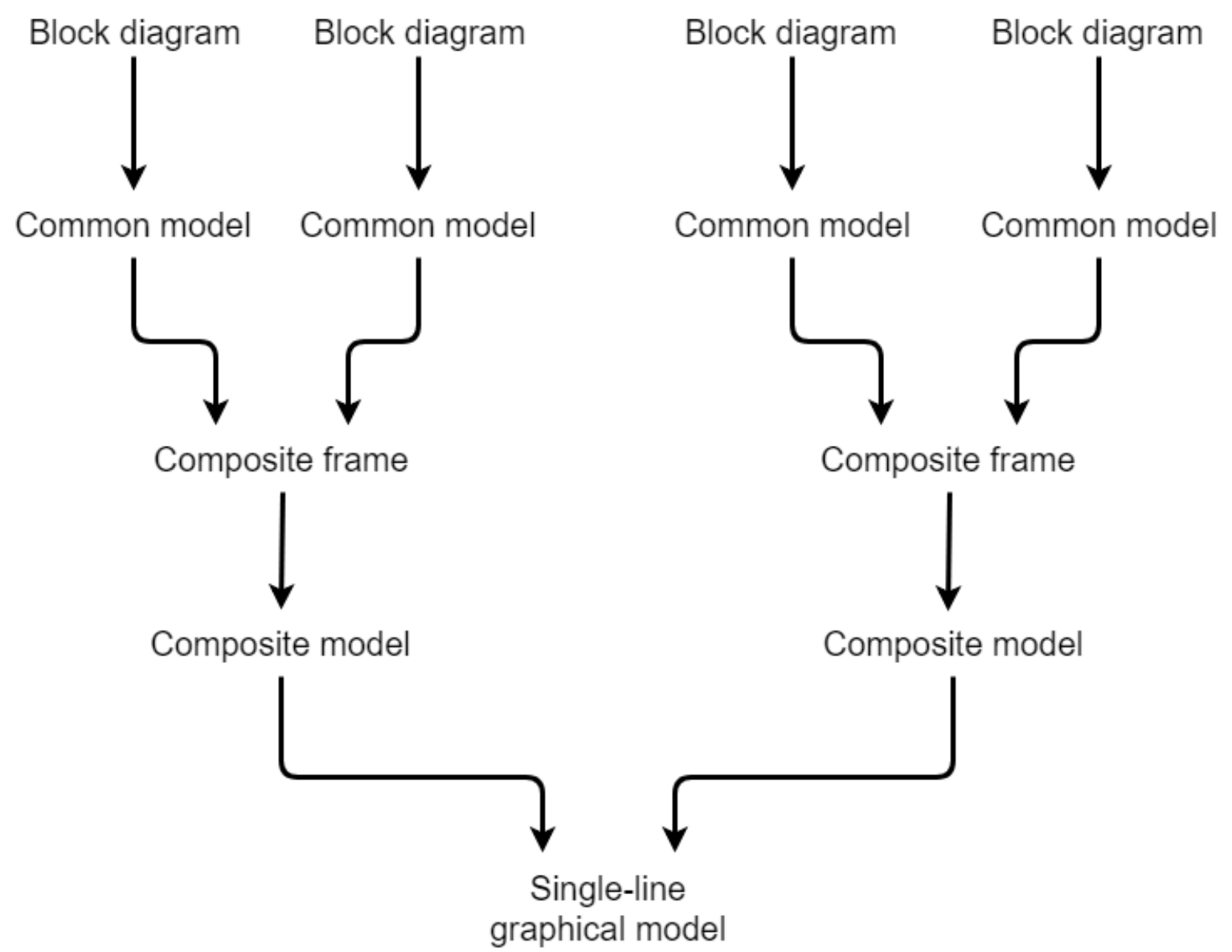

Figure B.22: PowerFactory model definition hierarchy. 


\section{Appendix C}

\section{Bus vector}

\begin{tabular}{|c|c|c|c|}
\hline $\begin{array}{c}\text { Bus } \\
\text { (Vertex) }\end{array}$ & $\begin{array}{c}\text { Bus } \\
\text { (name) }\end{array}$ & $\begin{array}{c}\text { Bus } \\
\text { (Vertex) }\end{array}$ & $\begin{array}{c}\text { Bus } \\
\text { (name) }\end{array}$ \\
\hline 1 & Acacia 132 & 15 & Aurora 400 \\
\hline 2 & Acacia 33 & 16 & Bacchus 132 \\
\hline 3 & Acacia 400 & 17 & Bacchus 400 \\
\hline 4 & Acacia 66 & 18 & Droerivier 132 \\
\hline 5 & Acacia 11 & 19 & Droerivier 22 \\
\hline 6 & Harib 220 & 20 & Droerivier 400 \\
\hline 7 & Kokerboom 400 & 21 & Gromis 220 \\
\hline 8 & Hydra 400 & 22 & Gromis 66 \\
\hline 9 & Aggeneis 220 & 23 & Helios 400 \\
\hline 10 & Aggeneis 400 & 24 & Helios 22 \\
\hline 11 & Aggeneis 66 & 25 & Juno 132 \\
\hline 12 & Ankerlig 400 & 26 & Juno 22 \\
\hline 13 & Aries 400 & 27 & Juno 400 \\
\hline 14 & Aurora 132 & 28 & Juno 66 \\
\hline
\end{tabular}




\begin{tabular}{|c|c|c|c|}
\hline $\begin{array}{c}\text { Bus } \\
\text { (Vertex) }\end{array}$ & $\begin{array}{c}\text { Bus } \\
\text { (name) }\end{array}$ & $\begin{array}{c}\text { Bus } \\
\text { (Vertex) }\end{array}$ & $\begin{array}{c}\text { Bus } \\
\text { (name) }\end{array}$ \\
\hline 29 & Kappa 400 & 43 & Palmiet Gen1 \\
\hline 30 & Kappa 765 & 44 & Paulputs 132 \\
\hline 31 & Koeberg 132 & 45 & Paulputs 220 \\
\hline 32 & Koeberg 400 & 46 & Philippi 132 \\
\hline 33 & Koeberg Gen1 & 47 & Philippi 400 \\
\hline 34 & Kronos 132 & 48 & Proteus 132 \\
\hline 35 & Kronos 400 & 49 & Proteus 400 \\
\hline 36 & Muldersvlei 132 & 50 & Proteus 66 \\
\hline 37 & Muldersvlei 400 & 51 & Sterrekus 400 \\
\hline 38 & Nama 220 & 52 & Sterrekus 765 \\
\hline 39 & Nama 66 & 53 & Stikland 132 \\
\hline 40 & Oranjemond 220 & 54 & Stikland 400 \\
\hline 41 & Oranjemond 66 & 55 & Stikland 66 \\
\hline 42 & Palmiet 400 & 56 & Xina 132 \\
\hline
\end{tabular}




\section{Appendix D}

\section{Lyapunov Stability}

For a system described with differential equations, various types of stability may be considered for the solutions of the equations. The most important and general type of stability is concerned about solutions converging near a point equilibrium [93].

Consider a non-linear time-invariant system system described as:

$$
\underline{\dot{x}}=f(\underline{x})
$$

with $n$ number of states. The equilibrium point of the states is denoted with $x_{e}$. When the system is in equilibrium then the following is true:

$$
f\left(x_{e}\right)=0
$$

The state variables are functions of time $(\mathrm{t})$ and the initial values ot the states are denoted with the following notation:

$$
x(0)=x_{0}
$$

The equilibrium point of the states, $x$, who's dynamics are described by differential equations, fall in three main categories of equilibrium stability.

- Lyapunov stable: The initial state values are close to the equilibrium point, and remain close to the equilibrium point for all time.

- Asymptotically stable: This is a stronger form of Lyapunov stability. All the states staring near $\underline{x_{e}}$ converge to $\underline{x_{e}}$ as time tends to infinity. A system can be Global 
Asymptotically Stable (G.A.S) or Local Asymptotically Stable (L.A.S).

For G.A.S, every $x(t) \rightarrow x_{e}$ as $t \rightarrow \infty$

For L.A.S there exists a region $R>0$ for the initial state values, where the the following is true:

$$
\begin{aligned}
\left|x_{0}-x_{e}\right| & \leq R \\
\lim _{t \rightarrow \infty}\left|x_{(t)}-x_{e}\right| & =0
\end{aligned}
$$

- Exponential stability: The states are guaranteed a minimum convergence rate to the equilibrium point.

A linear system, $\underline{\dot{x}}=A \underline{x}$, is G.A.S if $\Re\left\{\lambda_{i}(A)\right\}<0$ with $i=\{1, \ldots, n\}$.

For a non-linear system, it is usually very different to establish any kind of stability.

Lyapunov stability analysis is based on the concept of energy.

1. If stored energy decreases with time, then it indicates stability.

2. If stored energy increases with time, then it indicates instability.

With this conclusions about the state trajectories of a system $\underline{\dot{x}}=f(\underline{x})$ in terms of stability can be made without solving the differential equations [94].

The quadratic function $V(\underline{x})=\underline{x}^{T} P \underline{x}$ is a Lyapunov function, which can be used to verify stability. The function $V(\underline{x})$ can be thought of as a generalised energy function. The negative time derivative, $-\dot{V}(\underline{x})$ is the associated general dissipation function [95].

The definiteness of $V(\underline{x})$ is attributed to the $P$ matrix, which is real, symmetric, has to be positive definite and satisfy the Lyapunov equation [94]:

$$
A^{T} P+P A+Q=0
$$

There are various methods to determine whether a system is observable. One way is to use the observability gramian $\left(W_{o}\right)$ with the Jacobian matrix $(\mathrm{A})$ and output vector $(\mathrm{C})$. The observability grammian is positive definite and as follow [96]:

$$
W_{o}=\int_{0}^{\infty} e^{A^{T} \tau} C^{T} C e^{A \tau} d \tau
$$


Substituting the observability gramian $\left(W_{o}\right)$ into the $P$ matrix of equation (D.6) the $Q$ matrix is found:

$$
A^{T} W_{o}+W_{o} A=A^{T}\left(\int_{0}^{\infty} e^{A^{T} \tau} C^{T} C e^{A \tau} d \tau\right)+\left(\int_{0}^{\infty} e^{A^{T} \tau} C^{T} C e^{A \tau} d \tau\right) A
$$

Using the product-rule for differentiation, equation (D.8) can be contracted as follow:

$$
\begin{gathered}
A^{T} W_{o}+W_{o} A=\int_{0}^{\infty} \frac{d}{d \tau}\left(e^{A^{T} \tau} C^{\tau} C e^{T}\right) d \tau \\
A^{T} W_{o}+W_{o} A=\left.e^{A^{T} \tau} C^{T} C e^{A \tau}\right|_{0} ^{\infty} \\
A^{T} W_{o}+W_{o} A=-C^{T} C
\end{gathered}
$$




\section{Appendix E}

\section{Simulation Scripts}

\section{E.1 Overview}

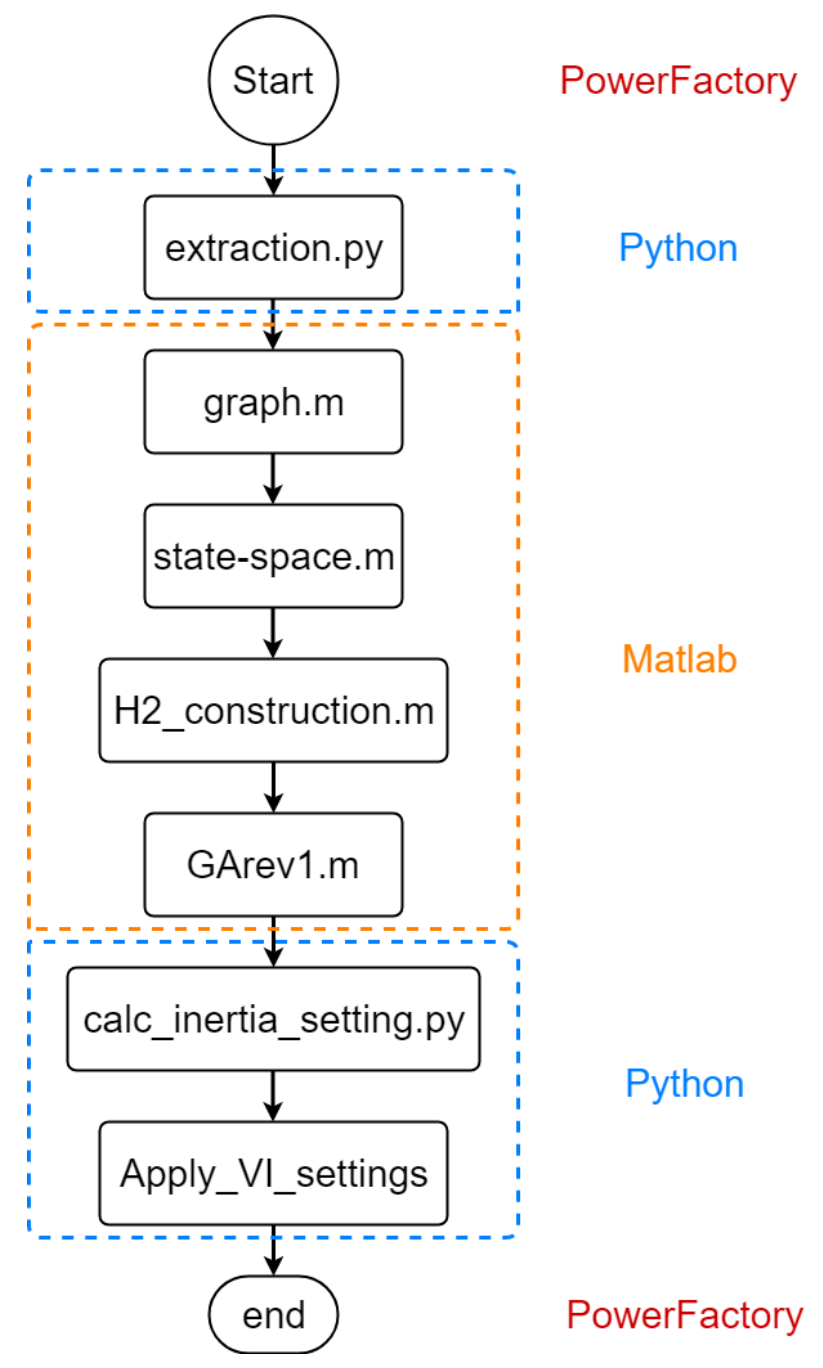

Figure E.1: Script overview. 


\section{E.2 Extraction.py}

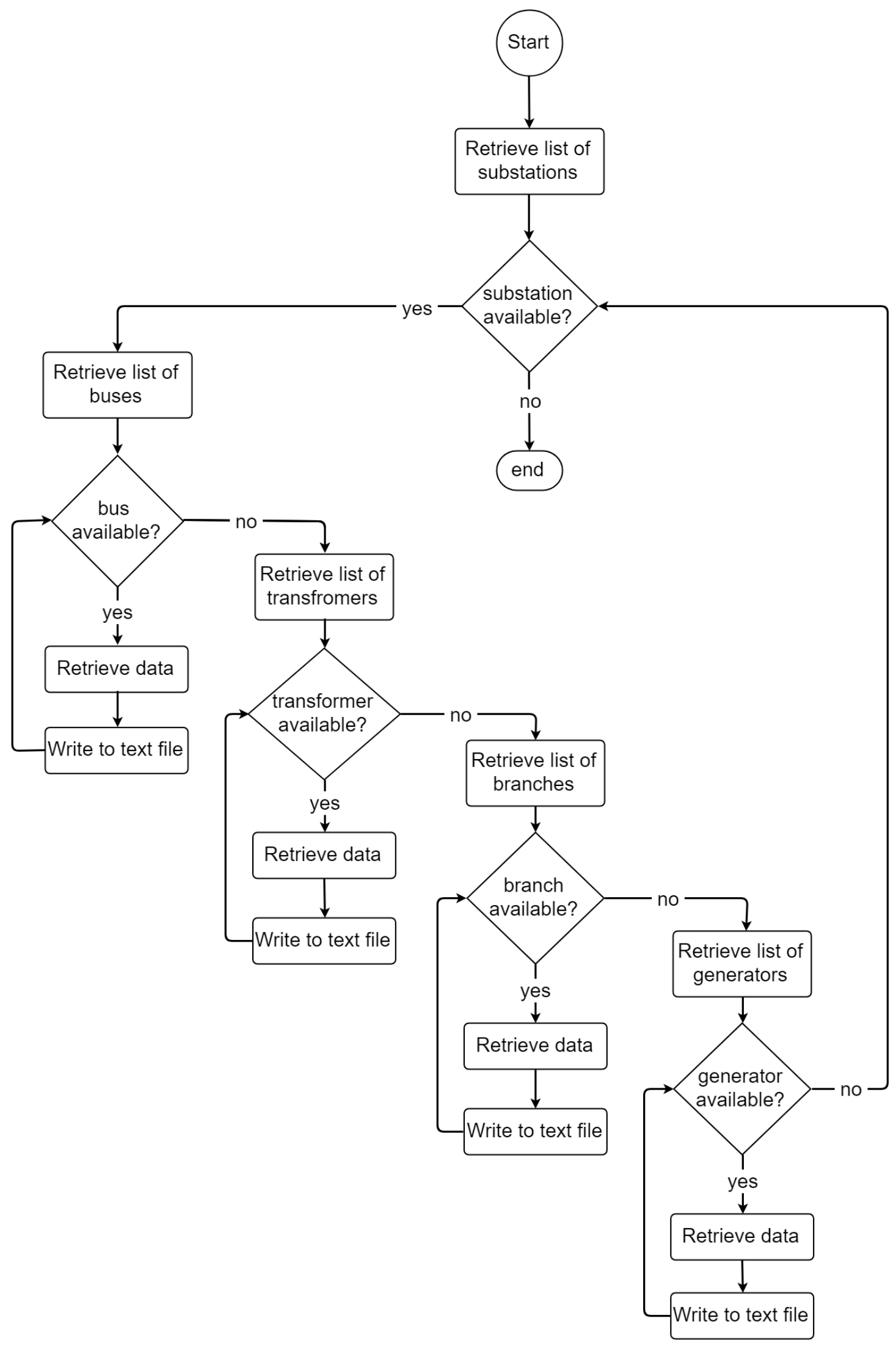

Figure E.2: extraction.py 


\section{E.3 Graph.m}

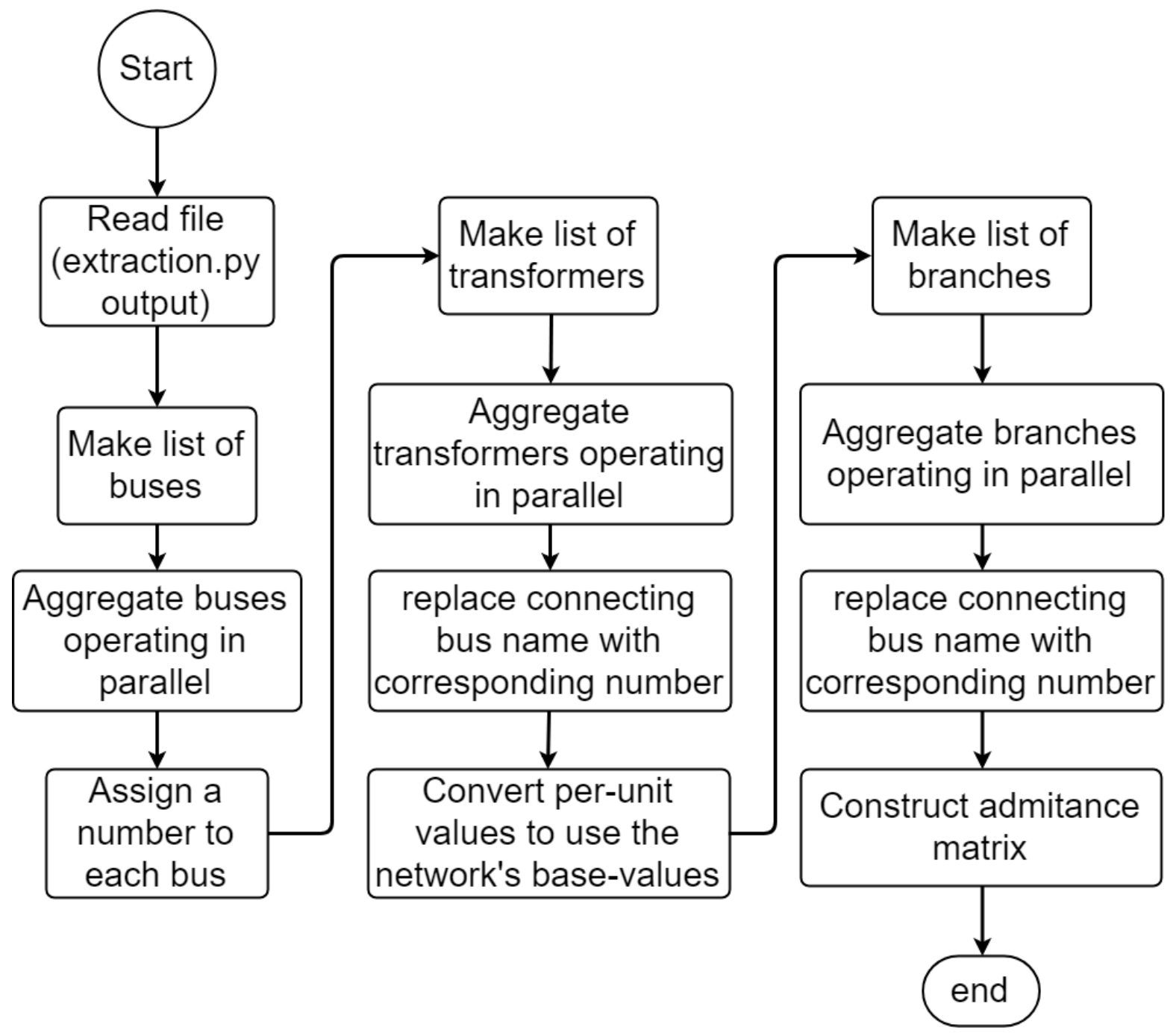

Figure E.3: Graph.m 


\section{E.4 State_space.m}

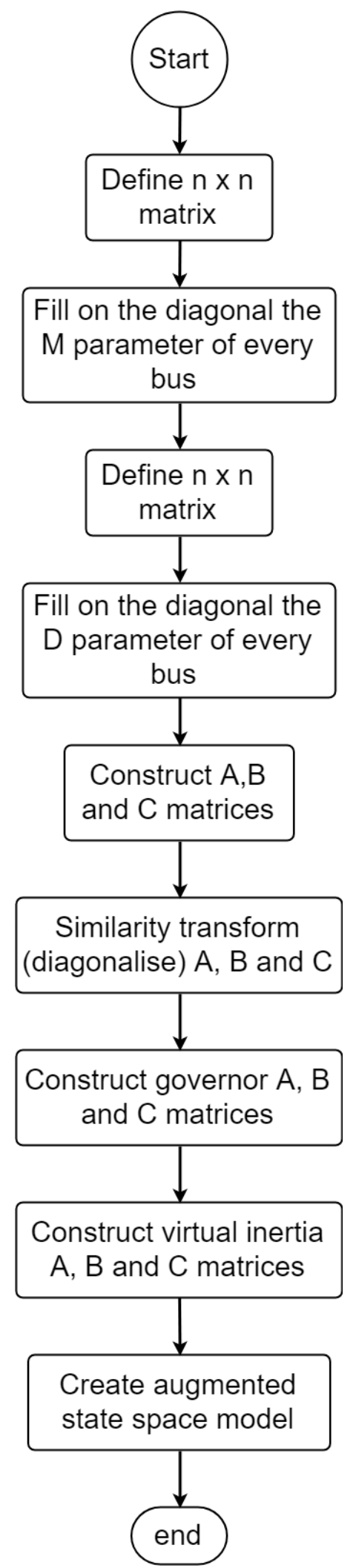

Figure E.4: State_space.m 


\section{E.5 H2_construction.m}

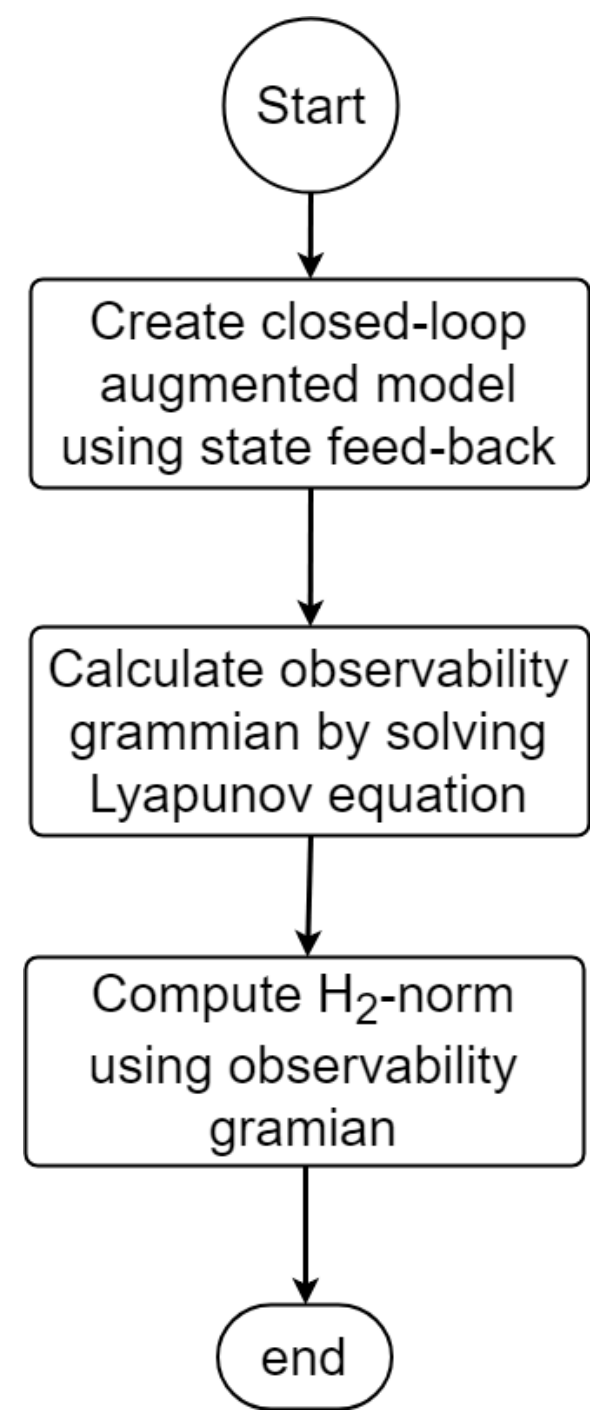

Figure E.5: H2_construction.m 
E.6 GArev1.m

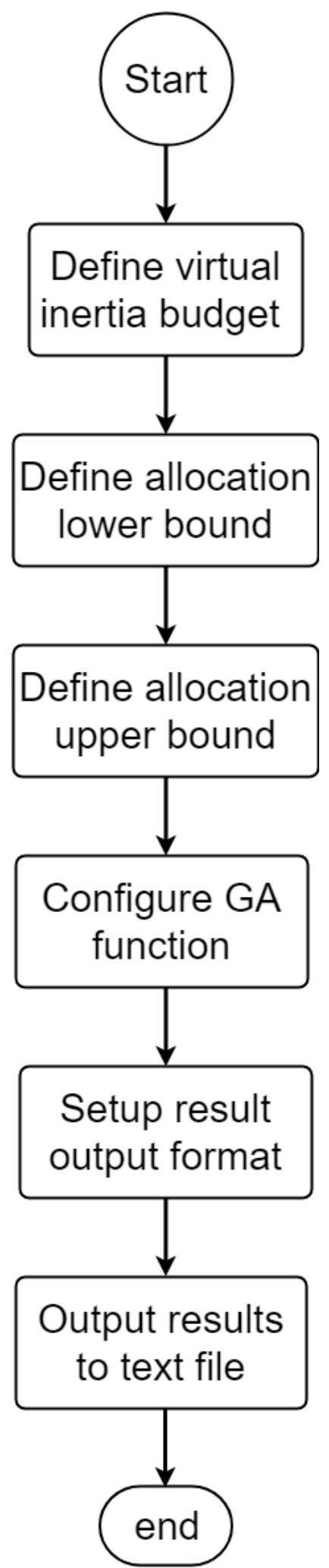

Figure E.6: GArev1.m 


\section{E.7 Calc_inertia_settings.py}

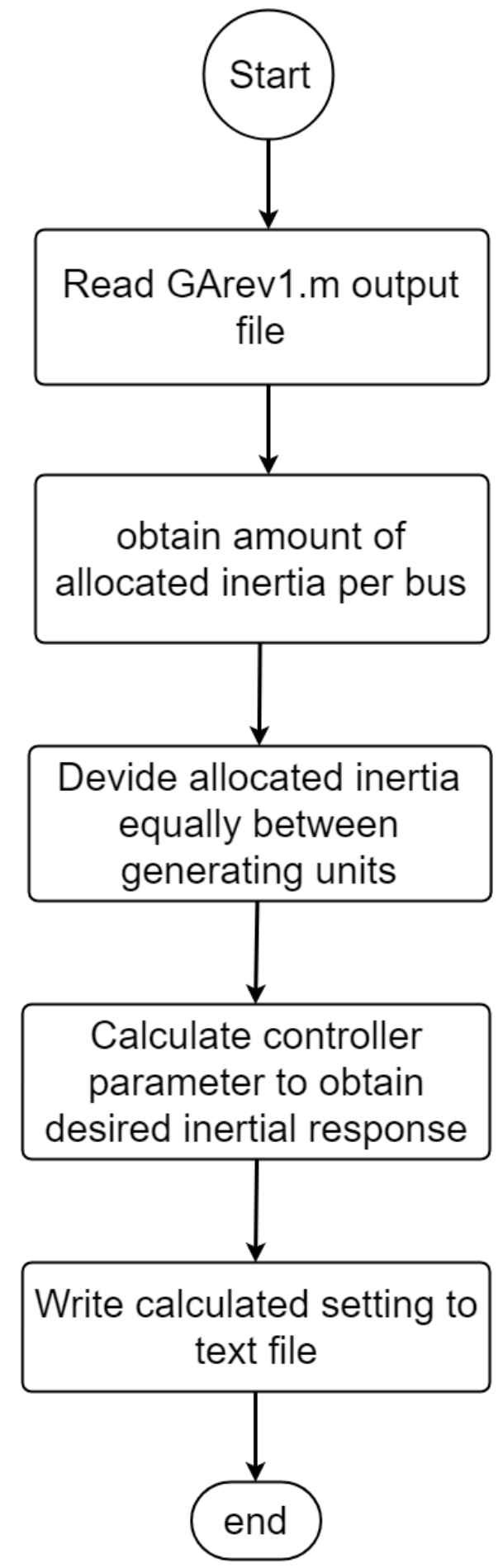

Figure E.7: Calc_inertia_settings.py 


\section{E.8 Apply_VI_settings.py}

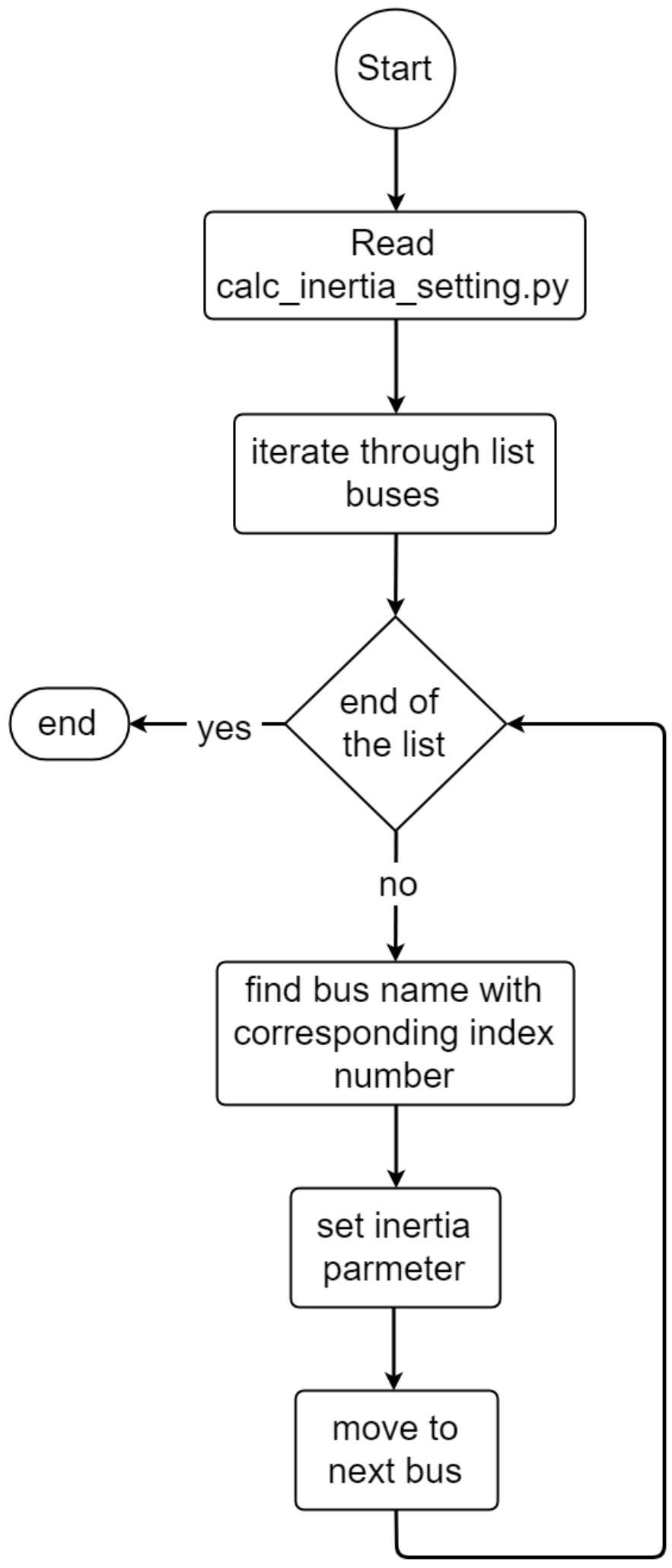

Figure E.8: Apply_VI_settings.py 